SF

507

T 93

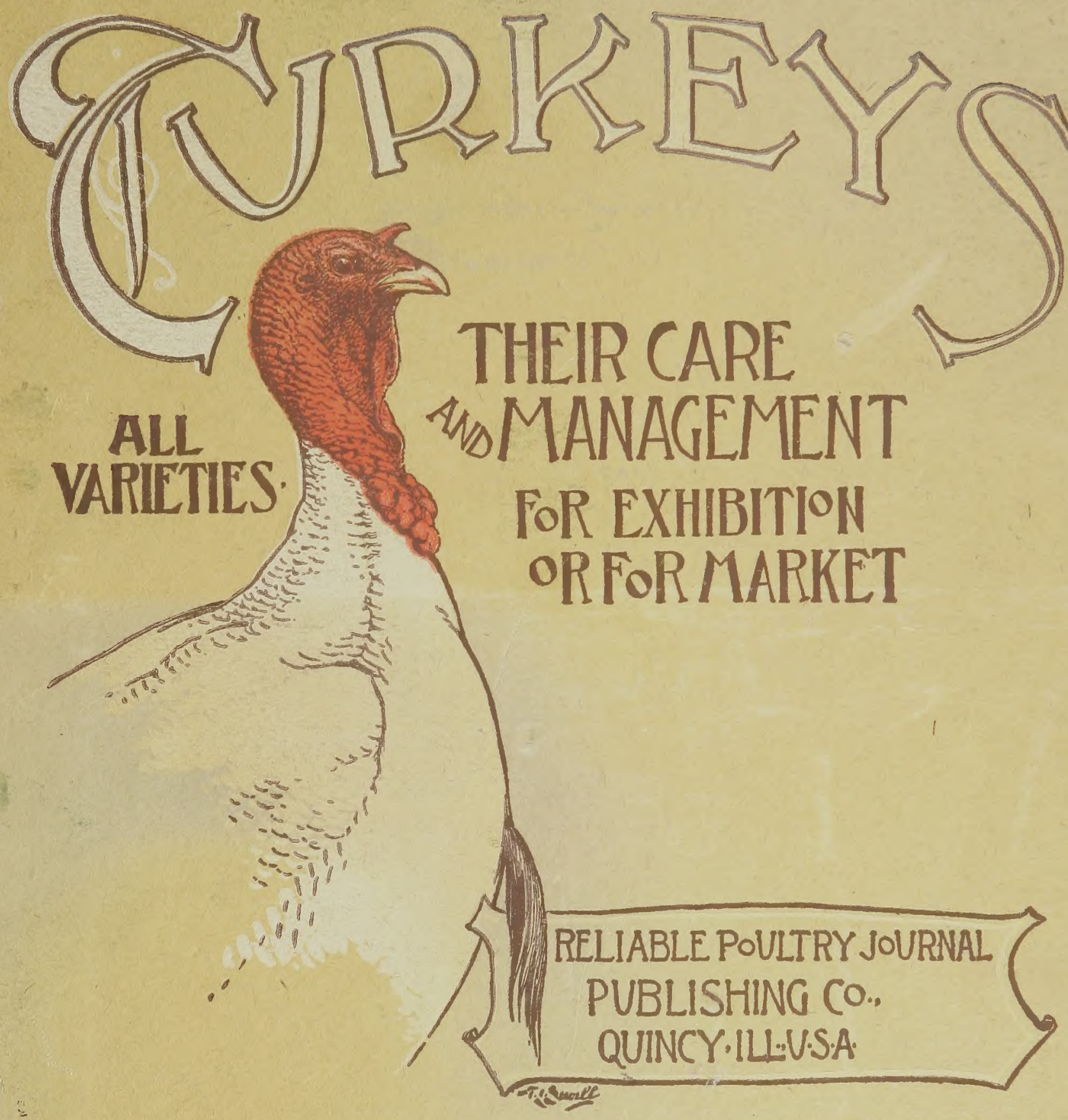

From The Library of

Dr. Olney Brown Kent 


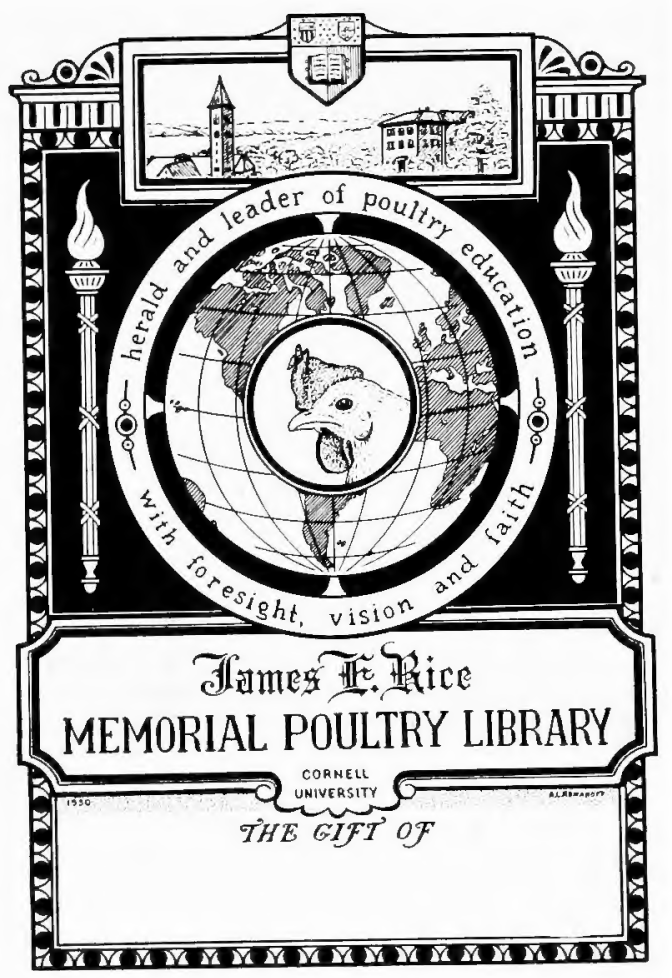

ALBERT R. MANN LIBRARY

New York State Colleges

$\mathrm{OF}$

Agriculture and Home Economics

AT

CORNELI UNIVERSITY 
Cornell University Library

SF 507.T93

Turkeys, all varieties. Their care and ma

.

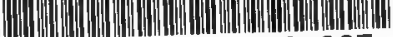

$3 \quad 1924003170267$ 


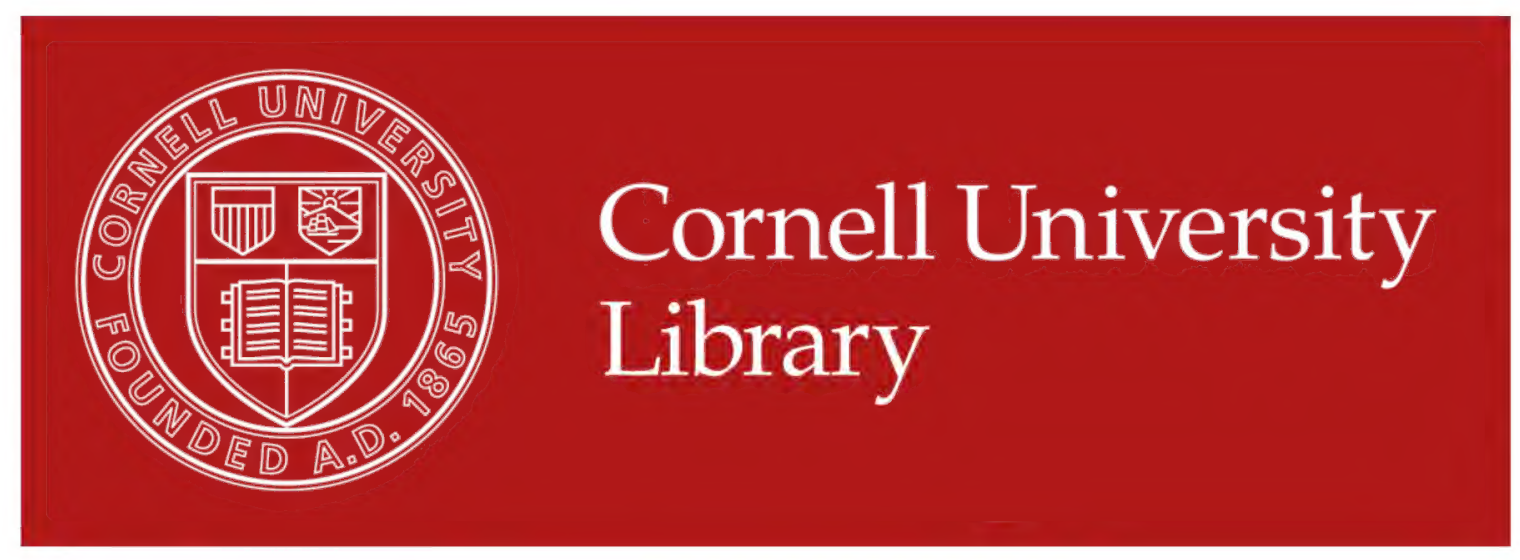

The original of this book is in the Cornell University Library.

There are no known copyright restrictions in the United States on the use of the text. 


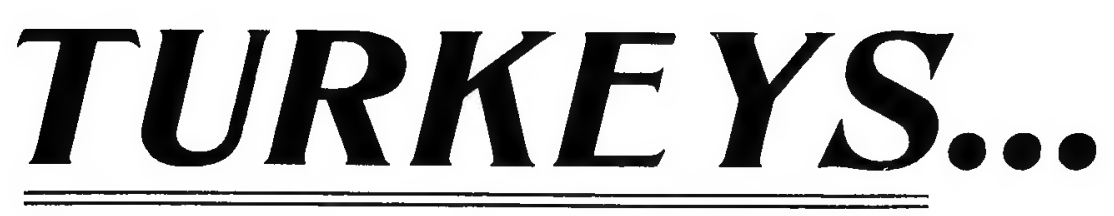

ALL VARIETIES.

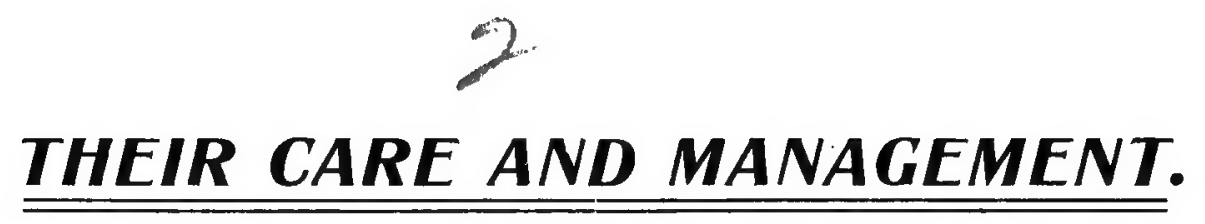

Mating, Rearing, Exhibiting and Judging Turkeys-Explanation of Score-Card Judging, with Complete Instructions.

A Collection of the Experiences of Best Known Successful Turkey Breeders, Exhibitors and Judges.

\section{FULLYILLUSTRATED.}

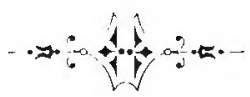




\section{$5 F$ \\ 507 \\ ti3 \\ 1749}

"A turkey bolled

Is a turkey spolled,

A turkey roast

Is a nation's boast,

But for turkey braized

The Lord be praised." 





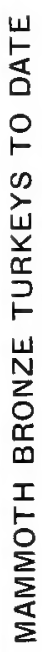

妾

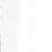

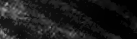

4 


\title{
TURKTYS DOMESTICATED-INTRODUCTORY.
}

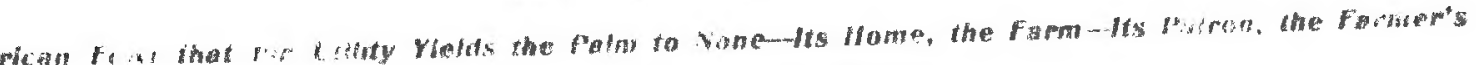 \\ Wite-lit Destiny. a Thankagiving Feast.
}

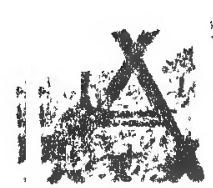

Howi native Amerian fow the turkey is

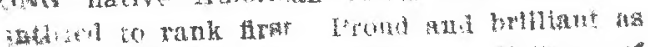

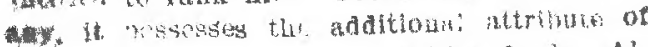

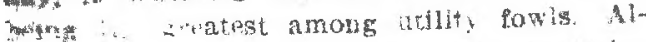

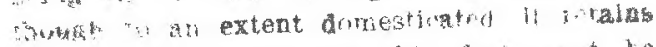

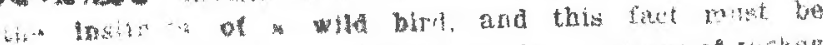

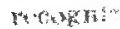

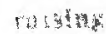

of

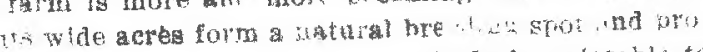

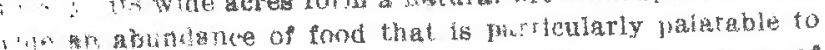
1. the of tis kis of the poutry kinglom. The nit ire of

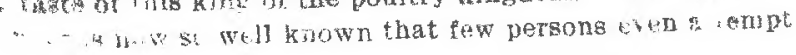
hand ir conflnemcat.

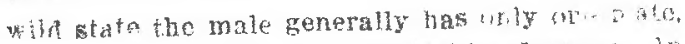

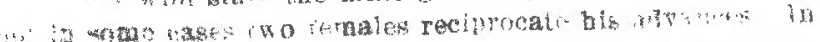

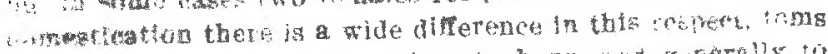

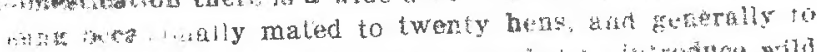

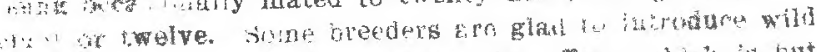

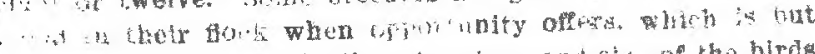
6315 .

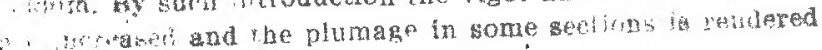
a: ate brtiat.

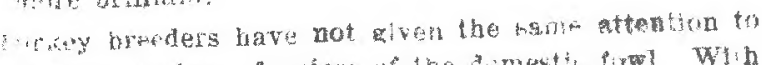

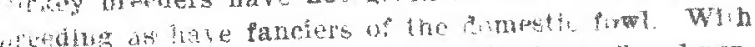

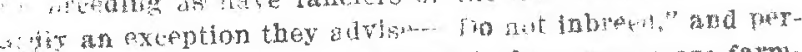

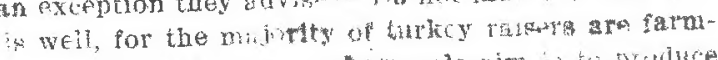

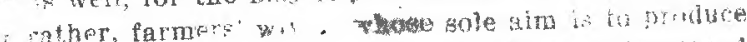

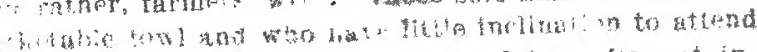

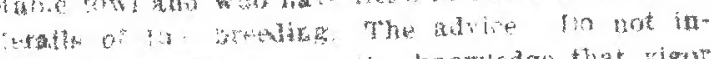

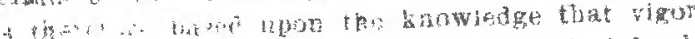

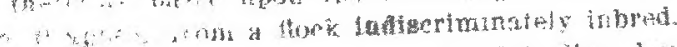

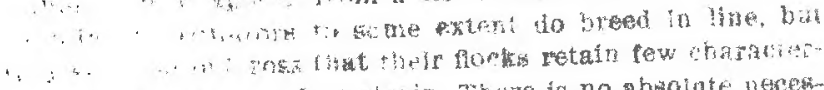

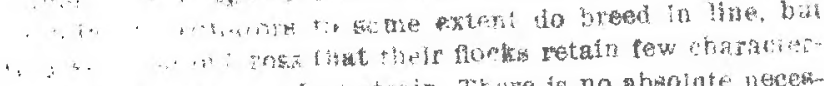

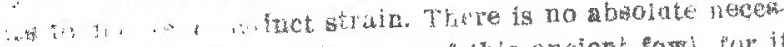

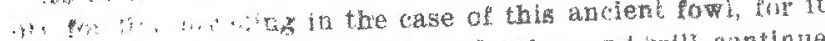

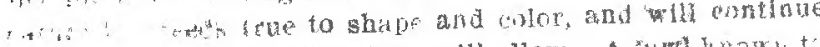

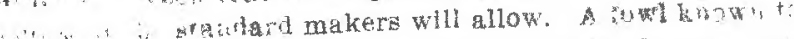

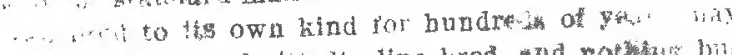

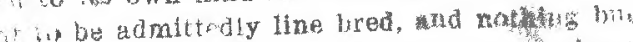

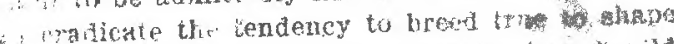

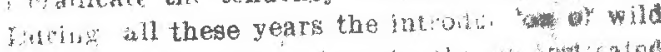

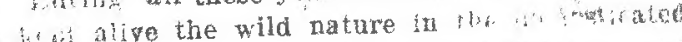

x! thi torginning of this pertod : in were

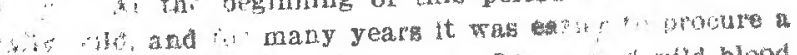

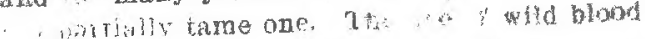

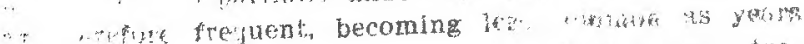

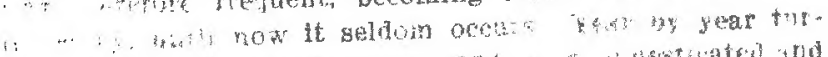

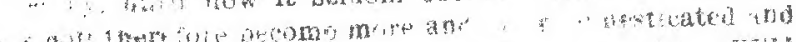

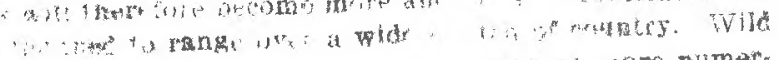

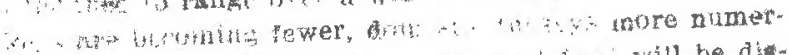

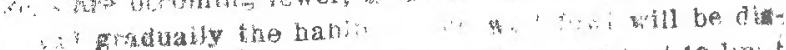

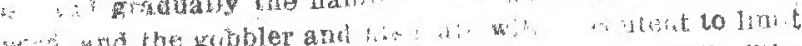

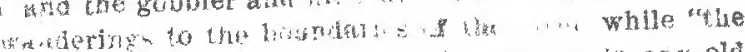

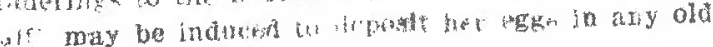

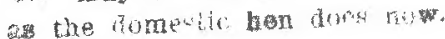

So long as the tendrucy of the turkey is to be oind, it is

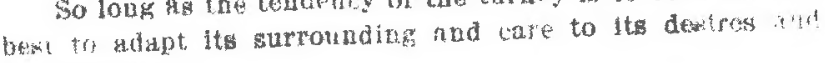
cojstiention.

The eustom is to allow tarkeys rons outshe A lintir attontion during their youthell dayg wit uniuce them $k$ cone home to rust.

In the case of young strok the general rule is to couflne theat, and to be careful hat they are not exprsed to storm, is isass, wh. This is whe but it may be overdone. One of olir ore apontunts whonf farm we have visites allow $h$ ? young stork to run witl: this mother over extensive grounds whers the orras in kept short. Thoy are healthy and bly. Timbered lands are fursid spots for young puilte if the rege forion is nut dense: and they usually thrive in stch a locatlon. "That dreadef "wul trouble" which causes the death of a large propurtion of ycing stock is less iable to ytack birds raised on the range, because they not not as likely to be overfed, and becauae llce do not mutility so rapidy at when the birds ine and.

There is a genera! impression ammg farmers that turkeys are dificul to ralse; so they are if the same nethod is s.lypted with them that holds good in ralgibe chichans on the farm, but if the habits of the wild turkey are sudied and the inck allowed to imitate them during the breeding seasovi there will be but tew obstacles to sucess. The homasile fow when it hatches its brood of chicks is uswally corned for

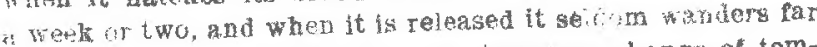
from the coop, so that in case of stoums or changs of temin rature sheiter is easily reacbet. Not so the thitky. She riay be coped for a time, but it makus little dificance it her habis, and when she is roleased it sems that the further she can get from her inte prigon the better she is plened. The boults have hitherto remained neas the corr within eall of the mo! har, they have been fed by the breot. and the change of life which the wandering spirt of the mat ne renders necessary is entirely different from thut is: have been accustomed to and calls for more robust an! s...

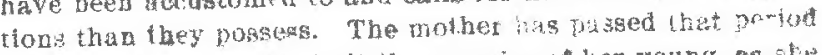
whing crutions her to limit the exercise of her young. as a bo

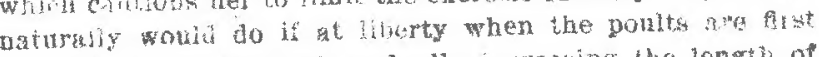
hatcher and tastear of gradually increasing the lengtin at

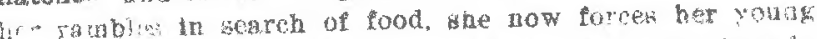

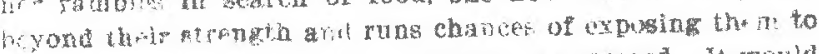
Wegthe (i) which thep have not been accustomed. It would

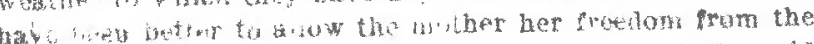

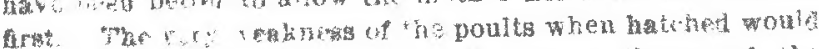
trem with. wen of shelter for a timo and the

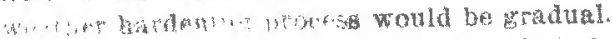

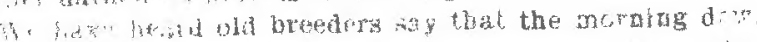

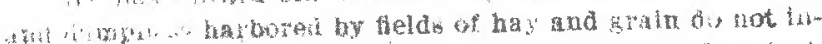

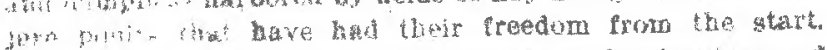

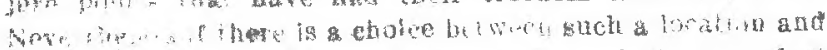

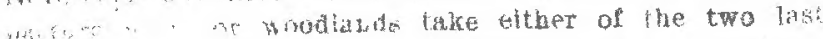

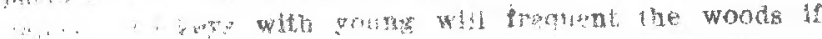

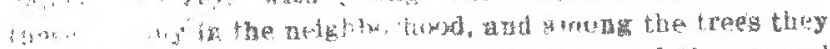

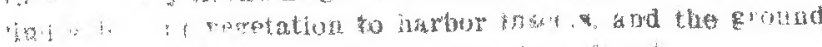

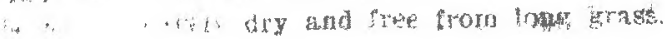





\title{
TURKEYS DOMESTICATED-INTRODUCTORY.
}

\author{
A Natlve American Fowl that for UtIlty Yields the Palm to None-Its Home, the Farm-Its Patron, the Farmer's \\ Wife-Its Destiny, a Thanksgiving Feast.
}

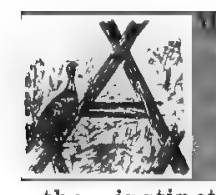

ONG native American fowls the turkey is entitled to rank first. Proud and brilliant as any, it possesses the additional attribute of being the greatest among utility fowis. Although to an extent domesticated, it retains the instincts of a wild bird, and this fact must be recognized by those who desire to make a success of turkey raising.

The farm is more and more becoming the home of the turkey; its wide acres form a natural breeding spot and provide an abundance of food that is particularly palatable to the taste of this king of the poultry kingdom. The nature of turkeys is now so wtll known that few persons even attempt to raise them in confinement.

In its wild state the male generally has only one mate, but in some cases two females reciprocate his advances. In domestication there is a wide difference in this respect, toms being occasionally mated to twenty hens, and generally to eight or twelve. Some breeders are glad to introduce wild blood in their flock when opportunity offers, which is but seldom. By such introduction the vigor and size of the birds are increased and the plumage in some sections is rendered even more brilliant.

Turkey breeders have not given the same attention to line breeding as have fanciers of the domestic fowl. With hardly an exception they advise-"Do not inbreed," and perhaps it is weil, for the majority of turkey raisers are farmers, or rather, farm'ers' wives, whose sole aim is to produce a marketable fowl and who have little inclination to attend to the details of line breeding. The advice, "Do not inbreed," is therefore based upon the knowledge that vigor would soon disappear from a flock indiscriminately inbred. Prominent exhibitors to some extent do breed in line, but they so often outcross that their flocks retain few characteristics to denote a distinct strain. There is no absolute necessity for line breeding in the case of this ancient fowl, for it naturally breeds true to shape and color, and will continue to do so if the standard makers will allow. A fowl known to have been bred to its own kind for hundreds of years may claim the right to be admittedly line bred, and nothing but crossing can eradicate the tendency to breed true to shape and color. During all these years the introduction of wild blood has kept alive the wild nature in the domesticated turkey. At the beginning of this period the birds were totally wild, and for many years it was easier to procure a wild bird than a partially tame one. The use of wild blood was therefore frequent, becoming less common as years rolled by, until now it seldom occurs. Year by year turkeys will therefore become more and more domesticated and less inclined to range over a wide stretch of country. Wild turkeys are becoming fewer, domestic turkeys more numerous; and gradually the habits of the wild fowl will be displaced, and the gobbler and his mate will be content to limit their wanderings to the boundaries of the farm, while "the better half" may be induced to deposit her eggs in any old barrel, as the domestic hen does now.
So long as the tendency of the turkey is to be wild, it is best to adapt its surrounding and care to its desires and constitution.

The custom is to allow turkeys to roost outside. A little attention during their youthful days will induce them to come home to roost.

In the case of young stock the general rule is to confine them, and to be careful that they are not exposed to storms, wet grass, etc. This is well, but it may be overdone. On $\theta$ of otir correspondents whose farm we have visited allows his young stock to run with the mother over extensive grounds where the grass is kept short. They are bealthy and big. Timbered lands are ideal spots for young poults if the vegetation is not dense and they usually thrive in such a location. That. dreaded "bowel trouble" which causes the death of a large proportion of young stock is less liable to attack birds raised on the range, because they are not as likely to be overfed, and because lice do not multiply so rapialy as when the birds are cooped.

There is a general impression among farmers that turkeys are difficult to raise; so they are if the same method is adopted with them that holds good in raising chickens on the farm, but if the habits of the wild turkey are studied and the flock allowed to imitate them during the breeding season there will be but few obstacles to success. The domestic fowl when it hatches its brood of chicks is usually cooped for a week or two, and when it is released it seldom wanders far from the coop, so that in case of storms or change of temperature shelter is easily reached. Not so the turkey. She may be cooped for a time, but it makes little difference in her habits, and when she is released it seems that the further she can get from her late prison the better she is pleased. The poults have hitherto remained near the coop within call of the mother, they have been fed by the breeder, and the change of life which the wandering spirit of their parent renders necessary is entirely different from that they have been accustomed to and calls for more robust constitutions than they possess. The mother has passed that period which cautions her to limit the exercise of her young, as she naturally would do if at liberty when the poults are first hatched, and instead of gradually increasing the length of her rambles in search of food, she now forces her young beyond their strengtin and runs chances of exposing them to weather to which they have not been accustomed. It would have been better to allow the mother her freedom from the first. The very weakness of the poults when hatched would keep them within reach of shelter for a time, and the weather hardening process would be gradual.

We have heard old breeders say that the morning dew, and dampness harbored by fields of hay and grain do not injure poults that have had their freedom from the start. Novertheless if there is a choice between such a location and pasture fields or woodlands take either of the two last named. Turkeys with young will frequent the woods if there are any in the neighborhood, and among the trees they find sufficient vegetation to harbor insects, and the ground is comparatively dry and free from long grass. 
Half the battle of raising turkeys is won if the breeders are allowed free range for some time before the breeding season, and receive only an evening meal sufficient to induce them to return home. This treatment renders them hardy, removes the surplus fat that has accumulated during the beavy winter feeding, causes the eggs to be strongly fertilized, and the poults to be on the jump from the time they are hatehed. Rearing healthy poults is a pleasure, not a hardship.

It is better to let turkeys imagine they are baving their own wild way in preparation for the laying season. There is a happy medium between the continual struggle of the attendant to make madam turkey lay in a hen's nest, and the struggle of the madam to deposit her egg on the next farm. Coax her to think she has found a secluded nest, which of course you will have arranged for her not too far from home. This will need to be done a month or so before the laying season, and is one way to avoid loss of eggs and poults.

"What is a farm without a turkey": might well be the plaint of the farmer's wife who "once had" but now "has not." In days gone by she has watched them grow day by day, looked for them to come home evening after evening with their appetites allayed, and a store of animal and vegetable food treasured up in their crops for the formation of the bone and muscle which signifies size; and it has cost her -nothing; the growing clover has been protected from injury by insect pests; grasshoppers have hopped in vain from the graceful gliding of the mother who quickly teaches her flock that these pests may be turned to account; the farmer seeing it, has been content to let them have their way, and his wife has been happy in the thought that "I shal; wear a bright new bonnet."

Imagine a little poult weighing only a few ounces, and then picture to yourself the same bird after a period tipping the scales at thirty-five or forty pounds. In this growth and in the nearly perfect beauty of a matured tom lies the attraction to the turkey raiser.

The Bronze turkey is king of all varieties. The standard places the weights high, but it should be understood that this law of weights is but a safeguard to prevent loss of size in the noble bird. Stanflard weights, are, we may say, the lowest weights that may be possessed by Bronze turkeys bred for exhibition. Certainly there are exhibited turkeys that do not come up to the requirements in weight, but the penalty in such a case is so severe that these cases are few. If a Bronze turkey in the show room is two pounds under weight its chances of winning the chief honors have gone.

Notwithstanding the importance of weight in the show room, experienced fanciers prefer that their breeding pen shall contain birds of less rather than greater weight. The eggs will be better fertilized and the young birds more vigorous than if heavy weights had been mated. As, however, the principal demand among turkey raisers is for birds of great size, the fancier is forced to breed rangy birds in order to satisfy this demand.

As a dressed fowl it is necessary that the outlines of the carcass should net be marred by any deformity, and with this in view, the American Standard requires that birds having wry tails or crooked backs shall not be allowed to compete for prizes in the show room; further, that a deformed keel shall receive a cut or penalty, which in pronounced instances may be placed at three points. This, as in the case of weight, is a wise law, intended to maintain the utility qualities of the fowl.
So far as the plumage of the Bronze variety is concerned ther'e appears to be little trouble in securing magnificent color. It seems to be a perquisite of the Bronze turkey, and enables it. to score far higher than other birds of parti-culor. This is a rule and not an exception.

To observe a matured tom strutting in the sunlight is to see one of the most beautiful utility fowls that has ween created. No farm is complete without its flock. The range they require is an obstacle to keeping them in large flocks and the very fact that they are at home upon the range is one of the reasons why they are so economically raised. They require very little food during the growing season and in the fall the farmer's wife finds that she has at comparatively no cost, a flock of birds, which sell at $\$ 1.50$ to $\$ 2$ each. This is the result of a little care and common sense, and occasionally she realizes more profit on her flock than her husband does on his farm.

The Bronze turkey is not alone in its marketable qualities; in fact, we have been told by experienced breeders that they prefer the Narragansett; it has been corroborated, too, by local dealers who find that among their customers there is more call for the medium sized Narragansett than for the larger Brouze. The standard weights for the former range from two to six pounds lighter than for the latter.

There are comparatively few Buff or Slate turkeys bred. Their standard weights are alike, ranging from twelve pounds in the pullet to twenty-seven pounds in the cock.

White Holland turkeys are second in favor to the Bronze, notwithstanding the Narragansett is creeping up in the race for the place. There has been difficulty in raising White Holland turkeys of standard weight, but by careful breeding and paying special attention to vigor we now find among experienced breeders White Hollands that tip the scale at weights above those required by the standard. White Holland turkeys are favorite table fowls, the color of their legs giving them an advantage over the Bronze, although so far as utility requirements are concerned the lines dividing leg color are not so distinctly drawn as in the case of the domestic fowl.

The Black turkey is a variety seldom seen in the show room.

It has been said that the number of turkeys bred in the east is decreasing yearly, but we believe that statement has only a local application. Speaking generally, there are far more turkeys exported now than was the case a few years ago, and we know the best of them do not all come from the west. In the fall there is annually a round-up by turkey buyers, and thousands of turkeys are killed and packed for export in many an outlying town or village. These turkeys never reach the central markets of this country and that perhaps is the reason why it has been said that they are decreasing in number. Breeders will welcome the news of such a decrease. Export of turkeys means higher prices at home, more demand, and what naturally follows-greater profits. In the export business one mistake has occasionally been made, and that is the holding back of stock for the Christmas market in Europe. Such a course is bound to calse a glut in the market, and a reduction in the profits. There is, except during the summer months, a continual demand in the old country for good stock at remunerative prices, and this demand will dispose of all the surplus that cain be raised in this country for years to come.

ROBERT H. ESSEX. 


\title{
STANDARD-BRED BRONZE TURKEYS.
}

\author{
An Illustrated, Detalled Descriptlon of What the Standard of Perfectlon Requlres in Bronze Turkeys-Male and \\ Female-With Instructions on Judging by the Score Card.
}

By Mr. Theo. Hewes, Breeder and Judge, with Speclal Charts by Mr. Sewell.

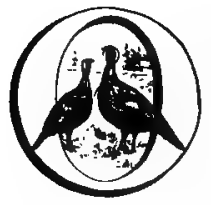

N THE breeding, care and management of turkeys, many excellent articles are written every season. Reliable information from our most prominent breeders has given the beginner a good general idea as to the fancy and commercial value of this the greatest of American fowls, but the points that go to make up a fancy show specimon have never been so fully described that an amateur may, with a reasonable degree of certainty, select the best specimens from his flock. There is alwtys a doubt in the minds of readers as to whether they understand aright from a written description, but a chart showing perfection in markings can be referred to at any time and this will give the amateur a degree of confidence he can obtain in no other way. With this idea in mind we present herewith two charts showing the correct markings and shape of Bronze turkeys, male and female. These charts hereinafter will be referred to as Figs. 1 and 3 in our description.

We shall give the reader our idea of defects, placing the same valuation on them that we would were we discounting them in the show room. In a description of this kind there is more or less repetition and the old breeders will find that we are telling that which they already knew, but we trust they will recall the time when they were beginners and bear in mind that this article is intended more for amateur than for professional breeders.

In describing and considering the Bronze Turkey we wi.l follow the same plan we have in former articles on other breeds, remembering always that the standard is the proper guide. Our aim is to give the reader a correct impression of the standard's meaning, and to call attention to any errors that in our judgment have crept in and become a part of standard law. Let us now take up the Bronze turkey male, section by section, scoring him the same as we would if we had a live specimen before us, using chart Fig. 1 as our model.

SYMMETRY OR TYPICAL CARRIAGE.

"Typical Carriage," is the wording of the present standard. We maintain now as we have from the start that the wording is wrong. "Symmetry" is proper and should be used instead of "Typical Carriage." As we understand it, "Typical Carriage" may mean any carriage that the bird is accustomed to, but "Symmetry" means the harmonious joining together of all sections so that we may have an ideal outline, strictly typioal of the breed it represents. All sections of a breed may be perfect in themselves and still be so joined together that the symmetry or typical outline will be wholly lacking. As we look at the matter, symmetry, properly understood, is the most important section in the standard and if we were purchasing a bird from a score card, and were acquainted with the judge, we would pay more attention to the cuts for lack of symmetry than to all other shape cuts combined.

Judges B. N. Pierce and F. W. Hitchcock are perhaps the best posted American judges on the section of symmetry, and if we were to see $a$ score card by either of these judges on a specimen we were intending to purchase, we state emphatically that their cut on symmetry would decide the purchase price. We are writing considerable on this section, as we wish to impress on the mind of the amateur that the proper interpretation of symmetry is of more importance than any other one section, and if you get this fact fixed in your mind you will have the shape problem solved.

Judges themselves do not give this section as close attention as they should, some judges even ignoring it altogether. This has brought the section into disrepute and quite often we hear the statement made that it should be dropped from the standard; but when as reliable a system of discounting symmetry is used uniformly as the one employed by Messrs. Pierce and Hitchcock, symmetry will become the most important section and should be retained always. Judges who are ignoring this section, or who make light of it as is done in some instances, will realize their mistake in time, for poultry associations will refuse to employ them as experts.

We now ask the reader to make a careful inspection of the chart, Fig. 1. Here we have an ideal Bronze turkey male, representing a bird over a year old or one that would be classed as a cock. In him we see the perfectly rounded outline, symmetrical and pleasing to the eye, together with the massive body that goes to make up the forty-five and forty-eight pound males, and it is just such birds as this that we must breed if we are to reach the fifty-pound weight limit, which seems to be the aim and object of a number of prominent breeders. The symmetry of a show specimen is hard to determine unless the birds are shown in large, roomy exhibition pens so the one under inspection can move about and assume natural positions without being cramped in any way. If two or more birds are cooped together, as is often the case at small shows, it is next to impossible to get them to stand as they would naturally, and the judging of symmetry under these conditions is more or less in the form of guesswork. The judges should refuse to make out a score card until all but one of the specimens are removed, so that he can get a proper idea of the outline of the one for which he is making out the card. See reproduction of score card herewith.

The only criticism we would make on symmetry of the Bronze male represented in Fig. 1 is in the body section. The outline should be a trifle deeper back of the thighs. Nearly all specimens are more or less defective in this section. While it is necessary that we have a well rounded breast, at the same time we do not want to overlook the fact thar we want something back of the legs to balance this, otherwise it will make the bird look as though it were bracing on its toes instead of standing squarely on its feet as it should.

In discounting for lack of symmetry we will call up some of the numerous defects that we find in scoring, taking one show with another. Where neck is too long or too straight, one-half out; back too narrow or too straight, falling to show the nice curve so much desired, one-half to one out; 
tail too short or too long, one-half out; if carried too high, onc-half to one out; breast too flat or too narrow, one out; breast not deep enoligh from shoulders to point of breastbone, one-half to one out; wings poorly folded so as to impair the symmetry of the specimen, one-fourth to one-half out; body too short or too narrow, one-half out; legs too short or too long, one-half to one out, as in degree.

\section{WEIGHT OF BRONZE TURKEYS.}

'This section is valued at fifteen points, and is of much importance if the breeder proposes to exhibit his birds, and equally as important if he is breeding for commercial uses and expects to compete with the breeders of heavy weights. The standard weights of Bronze turkeys are, adult cocks, thirty-six pounds; yearling cocks, thirty-three pounds; hens, twenty pounds; pullets, sixteen pounds; cockerels, twentyfive pounds. In the show room the standard instructs us to cut three points per pound for any deficit from standard weight, hence any one may readily understand that a bird that is from one to two pounds under weight has a small chance of winning prizes in keen competition. It is claimed by some that we have the Bronze turkey weights entirely too high, and that the breed would be better off if they were bred smaller. The writer is of the opinion that the present weights areplenty high enough and personally would vote to reduce rather than increase them. At the same time the committee who revised the last standard had letters from the National Turkey Club, requesting an increase in weight in bolin male and female. The trouble with an increase is that the market does not call for so large a carcass. Smaller birds are in demand and at better prices, and it is well for the breeder to look to the market side of the question. While forty-five to fifty-pound birds are handsome to look at and attract the attention of everybody, it is a
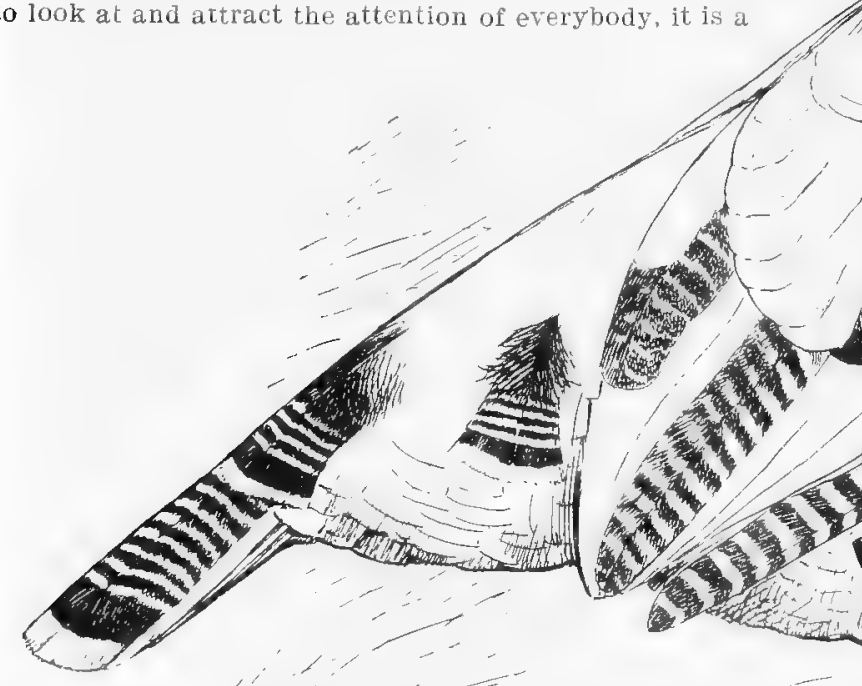

self-evident fact that few, if any of us would care to invest in one for table use, and the same rule will hold good with every family in the country. The only practical use that can be made of them is in large hotels, and there they are classed as "soupers" and as a rule sell from one to three cents per pound lower than smaller birds.

\section{CONDITION.}

This section is valued at six points, and refers not alone to the health of the specimen, but the condition of its plumage. A bird should be placed on exhibition not alone in a healthy condition, out its plumage should be carefully looked after. Exhibitors should see to it that no specimen is allowed to be entered that has broken wing or tail feathers, or is in a solled or crumpled condition, owing to the lack of proper room in which to exercise. A bird showing signs of roup or cholera should be 
debarred from competition. This is the first duty of the judge, that birds showing symptoms of either of these diseases should be removed from the show room, thus saving other birds that are liable to be infected. When a bird shows a slight cold or symptom of canker, the cut is onehalf to one; if feathers are broken or the bird is in bad shape from fighting, the cut is one-half to one and one-half. Dirty specimens which show that no care has been given them should be discounted one-half to two points.

\section{HEAD.}

Head is valued at five points, and is usually good, both as to shape and color. The standard says that in shape the head should be long and broad; in color a rich red changeable to bluish white. About the only defect that is commonly found in the shape of head is to be noted in what is called a bullet headed turkey. In other words, the head is too short. It looks more like a marble and should be discounted one-half to one and one-half, as in degree. If the beak is too long or too straight, or is damaged in any way, as is often the case in cocks that have been fighting, the cut is one-half to one, as in degree.

\section{THROAT AND WATTLES.}

This section is valued at five points, and as a rule passes without discount, especially so in color. However, the standard calls for heavy carunculations, while we sometimes find a specimen that is almost smooth. In cases of this kind the out is one-half to one.

\section{NECK.}

This section has a valuation of six points, three for shape and three for color. In shape it should be long, curving backwards; in color, a light, rich, brilliant bronze. Please note the wording, "light bronze," but it must be brilliant and show a bronze sheen. The bronze shading on the neck is not so deep as in other sections, and makes a lighter bronze by comparison with other parts of the body. The neck seldom receives a cut either for shape or color, but we sometimes find a neck that is too straight and too long, and it should be discounted one-half to three-fourths. If the color shades off to a brown on the back of the neck, as it sometimes does, the cut is one-half to one.

\section{BACK.}

This section in a turkey, as in any other variety of fowl, is of great importance, for without a well-balanced back the specimen is of little value as a breeder. This section is valued at ten points, five for shape and five for color. In shape it should curve somewhat, rising from the junction of the neck and the body, and extending in a gradual curve toward the tail. The color from neck to center of back should be a light brilliant bronze, each feather terminating in a narrow black band extending across the end. From the center of back to tail coverts the color should be black, each feather heavily edged with bronze. In describing the shape of back we think the standard should say something about proper length. As I remember the revision committee's report, on this breed it read, "medium in length." As it now reads no preference may be given to a long, a short or a medium length, so long as the general shape conforms to the general description. The committee's report (I refer to the committee that met at Fisher's Island) read about like this: "Back-Broad, of medium length," and then followed the present description. As it now stands the most important section of the bird, so far as the shape is concerned, is passed without a proper description.

We next refer to a few defects in back that should be discounted. If the back is too straight, failing to show the curve above referred to, the out is one to one and one-half points. If the curve is too prominent, giving the bird the appearance of having a hump back, the out is one to two. If the back is deformed or crooked, the specimen is disqualified. In color, if the feathers fail in the narrow black bands across the end, the out is one-half to one. There is sometimes a shading of brown on the backs of males. It is a narrow edging on the outside of the black. When this color crops out it should be discounled one to two points, as in degree. With the poor description of back, as furnished by the standard, I would suggest that the amateur study the general shape of the back on the chart (Fig. 1) and take it for his model. You will not go far wrong if you adopt this as a practically ideal bird and try to breed to it.

\section{BREAST.}

From a commercial viewpoint this section has mure real value than any other section on the bird, while from the fancy standpoint it is seldom good enough to pass without a

\section{American Poultru Assodidion Score Berd}

Name of Assoclation, .......... Highland..........

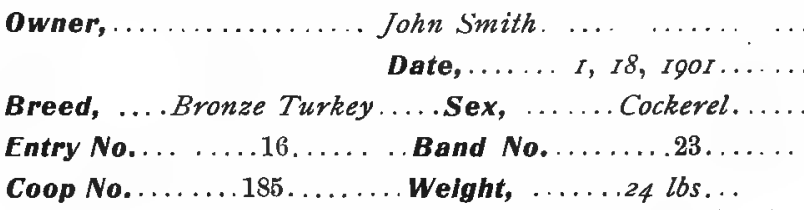

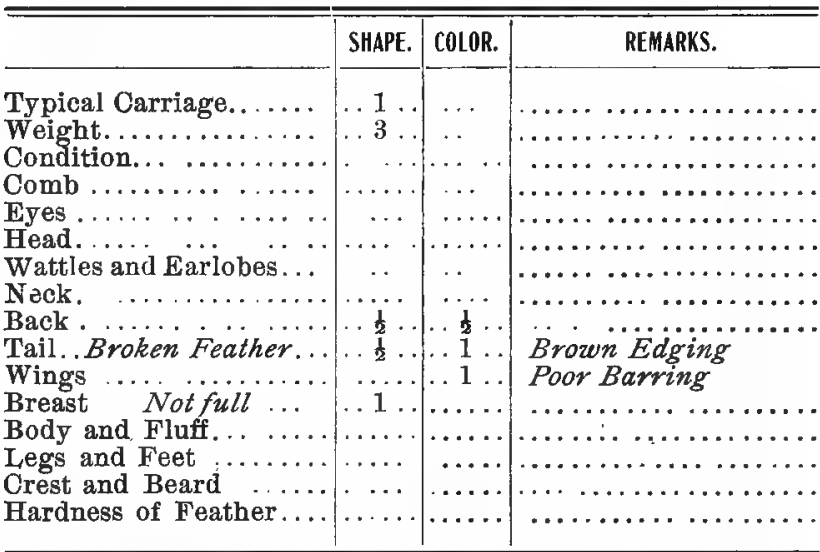
Total Outs, . .81 . .

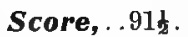

Judge, ......... Theo Hewes. ........ Sec'y,........ John Brown........

Reproduction of Score Card, Showing Sampie "Cuts" for Defects.

discount. It is valued at ten points, and like the back is subdivided, five for shape and five for color. In shape it should be broad, deep and full; in color, a light, rich, brilliant bronze. If the breast is too narrow or is flat, the out is one-half to one and one-half. If it is too shallow or not deep enough through from the shoulder to point of breastbone, the out is one-half to two, as in degree. If the color fails in the narrow edge of the black, giving the surface a dead sort of color, the out is one-half to one. If some of the feathers on the breast show an outside edging of white, the out is one-half to one and one-half, as in degree.

BODY AND FLUFF.

Like breast and back this section has a valuation of ten points and is divided equally between shape and color. In regard to shape, it has the best general description of any of the sections described by the standard. The standard says, "Body-Long, deep through the center and well rounded. In color, body black, beautifully shaded with bronze, but not so decided or so rich as that of the breast. Fluff-Black, each feather ending in a wide black and bronzy band extending 
across the feather, with a narrow edging of white or gray." The standard description of the shape of this section shows clearly that there was an error either in the committee's report on back shape, or some part of their report on back was lost before it was presented at the Boston meeting, for in body section the standard calls for a long, deep body, which would require at least a medium length of back.

In color of body and fluff the description is not so good. We find that the most brilliantly colored specimens show the tracing of white or gray on the outer edge from the thighs back; in fact, the feather as shown on the thigh of Fig. 1 should have this white edge the same as is shown on the breast of the female. See chart of female (Fig. 3).

If the body is too short or too narrow, the out is onehaif to two, as in degree. If flat, failing to show a well rounded outline, the cut is one-half to one. If too shallow through, that is, not deep enough from back to point of keel bone, the out is one-half to two, as in degree. If keel is crooked or slightly twisted, the out is one-half to cne; if badly twisted or so much out of line that the crookedness the thighs. With this exception we hesitate to criticise the chari in any way as an ideal outline.

\section{WINGS.}

So far as color is concerned this is the most important of all the sections, and it is seldom that a specimen passes without a discount. The standard valuation is four for shape and six for color. Owing to the importance of this section from the color standpoint, the revision committee tried to add more points to color, so as to subdivide the section, but it was found that six points were all that could be given without injuring some other section.

We again call attention to chart (Fig. 1) and ask the reader to study careiully the wing feathers as illustrated by Mr. Sewell. In order to help the reader to get a clear understanding of this important section, we give the standard wording, and ask the reader to follow Mr. Sewell's drawing from wing bow to the end of the flight feathers. The standard says, "Bows black, with a brilliant bronzy or greenish

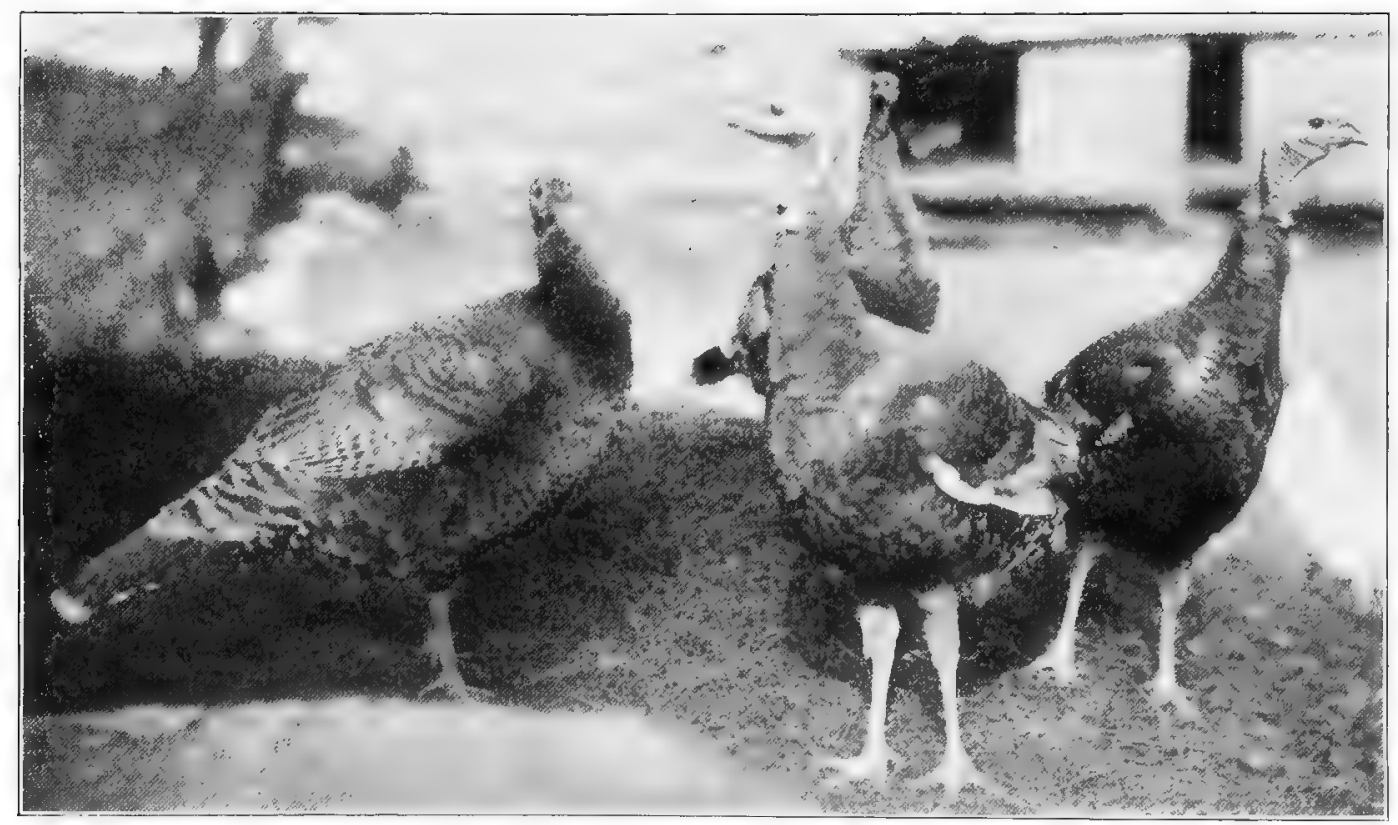

The Pride of the Farm.

can be seen when viewed from the outside, the out should be the limit allowed by the standard, namely, three points.

While on this section, permit me to call the attention of the amateur to the fact that while crooked breast bones do not disqualify and will not invariably reappear in the progeny, we would not advise their use if you can avoid it, as this as well as other defects will be bred into the young if used repeatcdly in the breeding pen.

In color the body is usually good, although the fluff is liable to run into a snuff color, bordering on a dingy brown. This defect in color should be discounted one-half to one and one-half points. If the white band fails to show up at the end of the feather, leaving the feather black, the out is one point.

If the body does not extend well out behind the legs, but cuts off short in this region, giving the bird the appearance of having too much weight in front of the legs, the out is one-half to one and one-half. In our chart (Fig. 1) we would adcl a trifle more to the length and depth of the body behind lustre. Primaries, each feather evenly and distinct:y barred across with parallel bars of black and white extending the entire length of the feather. Secondaries, black or dark brown, evenly and regularly barred, crossed with bars of white or gray, color changing to a bronzy brown as the center of the back is approached, with but little admixture of white. An edging of white or brown in the secondaries is very objectionable. Coverts, a beaıtiful rich bronze, the feathers terminating in a wide black band, forming a proad bronzy band across the wings when folded, and separated from the primaries by a glossy black, ribbon-like mark formed by the ends of the coverts."

Note carefully the tracing of the bronze on wing bow. Up near the top the feathers are solid black, but as they approach the wing-bar the bronze edging deepens, giving the wing when viewed in the sunlight the color of burnished gold. The description of wings might go farther and add that the last bar on the primaries and secondaries should end with black. This is correct, at any rate, and it will be 
well for the amateur to make a note of it. Again, it is well to remember that the tracing or barring should extend to the end of the feathers. Quite often we find a specimen that is unusually good in color, especially so in primaries and secondaries, except that near the end of the feather the barring will stop and the last two inches will be solid black. When the wing of the male is perfect in color, except this black, mate him with females that show more white than black in their flights, and should you have one that has a wing with the last bar white instead of black, she will be all the more valuable as a breeder. In scoring the wing of either male or female, when this black appears at the end of feather the out is one point.

If the barring is irregular, showing zig-zag tracings across the wing, the out is one-half to one, as in degree. If examining this fowl carefully, and the photograph, while good, does not do the bird justice. The photographer allowed the lower end of the flight feathers to be taken in a shadow, making the ends of the feathers look blurred. The photographer was at fault, not the feathers, as we know personally that the barring in this case extends to the ends of the feathers.

TAIL.

This is another important section, especially as regards color. In this respect it is next in importance to the wingin fact, a specimen with perfect wings would be debarred from the breeding pen if it failed to show fairly good color in this section. The tail has the same valuation as wings, four for shape and six for color. As a rule, this section is

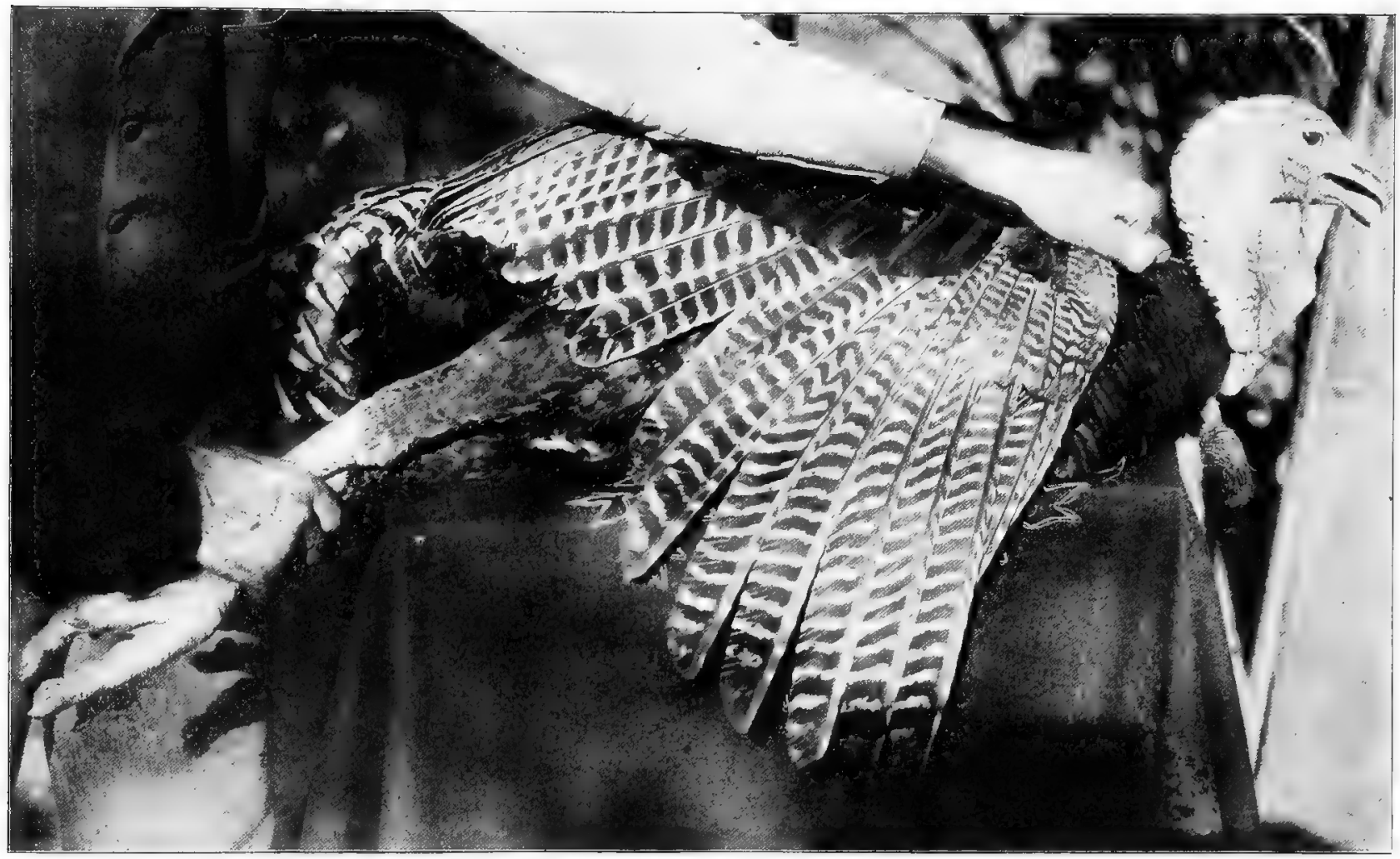

Fig. 2-Reproduced from Photograph-Showing Standard Barring on Wing of Bronze Turkey Male.

the barring appears only on one strde of the quill the other sido showing black or a mixed up muddy color, the out is onc-half to two, as in degree. If: the secondaries show a slight tracing or edging of white or brown, the out is onehalf. If this edging is prominent enough to mar the beauty of the wing, the out is oue to two. If the coverts fail in the black band at end of feather, causing what would be termed an unfinished wing, the out is one-half to one and one-half points.

In order to show breeders the remarkable progress that is being made in the breeding of this variety we refer the reader to the half-tone of wing Fig. 2, on page 24. This shows the wing of a bird owned by Mr. W. J. Bell. While this wing is not absolutely perfect, for there is a slight break in color at the lower end of the flight feathers at the same time there have been few better wings shown in this country, and Mr. Bell has a right to feel proud of this specimen, both as to color of wings and tail.

In Fig. 2 (this page) is shown the wing of a male bird owned by Mr. B. F. Hislop. He is a grand specimen, both as to color and shape. The writer has had the pleasure of better understood by the average fancier than the wing, not as regards breeding, but in regard to discounts and what really constitutes perfect color. In shape the standard says, "rather long." This is not a good description. In our opinion it should read, "rather long and well spread," as a pinched tail on a turkey spoils the beauty of the specimen, no matter how finely colored it may be, while a well spread tail carries with it the complete curve of the back and shows off to advantage the fancy color in the coverts.

We again call attention to Fig. 1 and ask that the reader study the markings as illustrated by Mr. Sewell, not alone in the tail proper, but in the tail coverts as well. The standard says, in description of the color of the tail proper, "each feather irregularly penciled with narrow band of light brown and ending in a broad black band with a wide edging of white or gray, white preferred." We do not quite like this wording, at the same time we hardly know how to make it any plainer to the amateur, except in the description of the end of the feather. The standard says, "white or gray, white preferred." I would suggest to the amateur that he make his standard read "white," as gray is not the correct color and 
should be discounted. The black band referred to near the end of the feather should be a rich metallic black and the white a pure white. On a well bred specimen the two colors are so pure and distinct as to give them the appearance of ebony and alabaster joined together on straight lines, in fact, it is doubtful if there is a fowl in existence, either tame or wild, where the two colors, white and black, show so distinctly and with so beautiful an effect as on the tail and tail coverts of well bred Bronze turkey males.

The standard says, in describing the coverts, "Coverts black or dark brown, each feather irregularly penciled with a narrow band of light brown, ending in a wide black and bronze band extending across the feather with a wide edging of white or gray, white preferred." The more distinct the color throughout the whole plumage, the better. Here again our advice to the amateur is, drop the word gray and strive to produce the pure white edging, which is the seal of beauty of the breed and which, with careful selection of the breeding stock, can be obtained in a large percentage of the offspring.

In chart (Fig. 1) you will note that the color of the coverts shows black. The end color of the tail proper is hidden by the coverts, but. the fluffy portion of the feather is black. Will say, however, that in the tail proper all of the web portion of the feather should be penciled with straight bars as shown on the chart. In scoring the specimen the judge always examines the tail color, well down near the roots of the feather, for many otherwise good specimens are found to be defective there. One of the common defects to be found at the root of the tail feathers is solid black; this defective coloring sometimes extends upward three or four inches from the base, with no sign of penciling. Such tails should bc discounted one-half to one and one-half. Another defect sometimes found at the base of the tail feathers consists of broad bands or bars of pure white. As a rule, this is caused by trying to breed too wide a band of white on the tail coverts and on the ends of the tail feathers. Too much "White blood" crops out at the base of the tail, and sometimes it will show at the base of the primaries in wings.

Here we come upon the secret of what makes the breeding of fancy poultry so deeply interesting. If 'we attempt to mix our colors too strongly, nature silently, but unfailing$l y$, steps in and blurs them up for us. If these wide white bars appear at the base of feathers, the out is one-fourth to one-half, as in degree. Where the barring is irregular on the tail

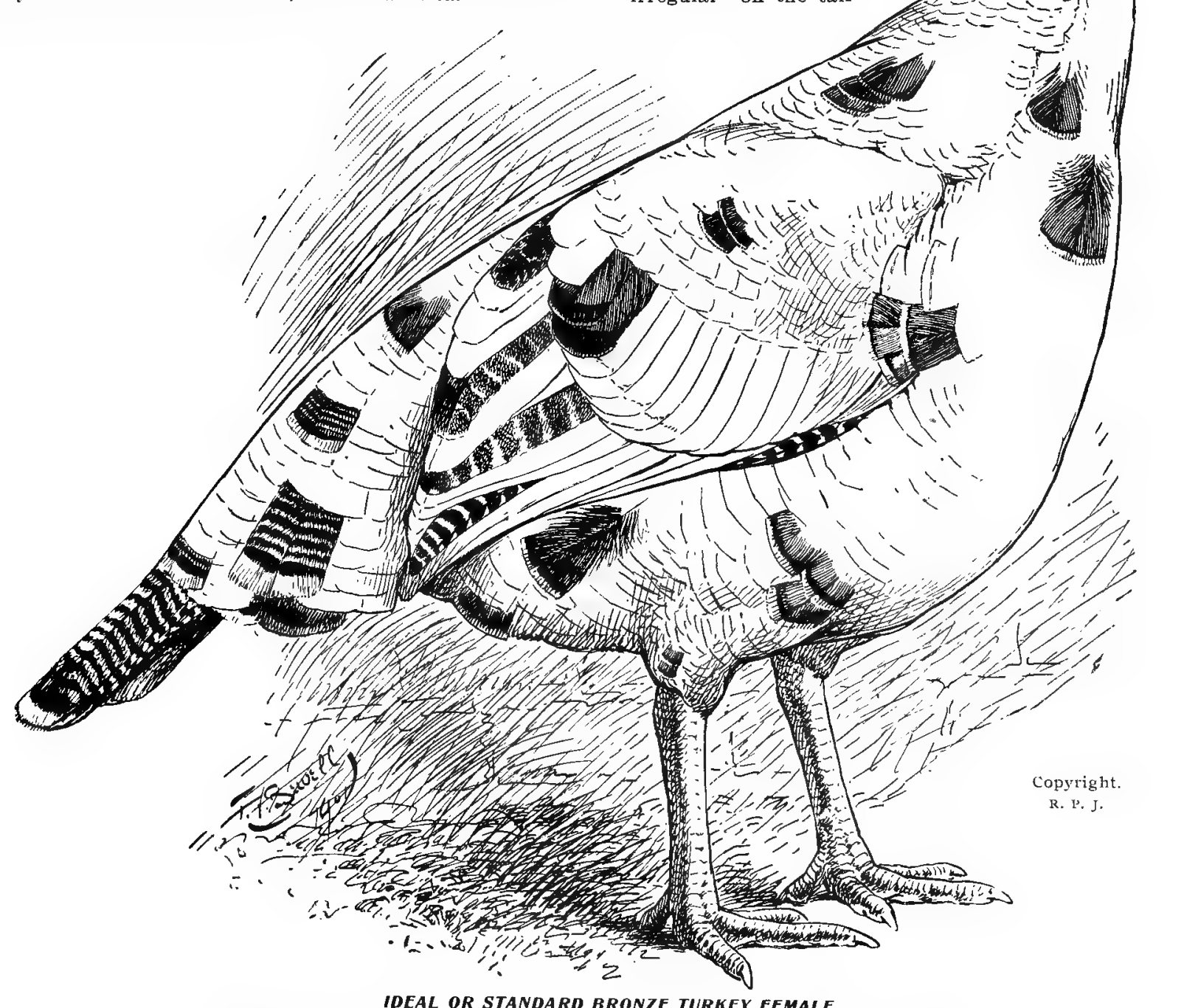

IDEAL OR STANDARD BRONZE TURKEY FEMALE. 
proper the out is one-half to one. Where the white outside lacing is mixed with gray or brown the out is one-half to one and one-half. Where the coverts fail to show a cleal edging, the out is one-half to one. If mixed with brown or a dirty gray, the out is one-half to one and a half. A tail that shows a decided edging of brown or red should be severely discounted in the show room and be discarded from the breeding pen, for it shows an outside cross with the wild turkey, and is not, in color, a pure bronze.

On page 24 in Fig. 3 is shown a half-tone made from a photograph of the tail of the same bird that is represented in Fig. 2. This illustration shows the reader what remarkably good color Mr. Bell has secured in his breeding stock. The tracing of the barring on the tail is not so distinct as that on the chart, at the same time you can trace it by a careful inspection of the photographs, and the outside edging of white is as fine as the writer has ever seen.

\section{LEGS AND TOES.}

'This section, while not valued high in the scale of points, is really of considerable importance both to the commercial and fancy breeder. The standard gives the legs and toes a valuation of five points, and describes them in shape as follows: "Thighs long and stout; shanks large, long and strong; toes straight and strong."

Once more we call your attention to Fig. 1 . Here you will find the pair of legs that the standard describes. Fig. 1 is meant to represent a full grown, up to weight cock bird, and under him are just such legs as the judge should find under all large, well-balanced specimens. In color the thighs should be the same as the lower breast, although less rich and decided. The shanks in young birds should be dark, approaching black. In adult birds they are usually of a pinkish hue or flesh color. Toes, same as shanks. However, the toes in matured specimens show less of pink as a ruie than the leg proper.

In shape the legs should stand well apart, giving the specimen a broad, massive appearance when viewed from the front. The toes should be straight and well spread. The legs should be of fair length so as to hold the specimen well up in the air, but not so"long as to make the bird look leggy; at the same time they should be a trifle longer than medium. If the legs are small in bone, giving the bird a feminine ap- pearance, the out is one-half to one. If the legs are too short or too long, the out is one-half to one and one-half. If set too close together, the out is one. If knock-kneed, the out is two. If the toes are crooked, one-half to one. If the ends of the toes are missing, the out is one-half to two. If the Iegs are in bad condition, that is, scaly or soiled, the out is one-half to one. If off in color, the out is one-half to one and one-half, as in degree.

\section{BRONZE TURKEY FEMALE.}

In Fig. 3 is shown the outline of a Bronze turkey female that for shape and markings in all sections has never been surpassed by any drawing that we have had the pleasure of seeing. Mr. Sewell has done himself great credit in the execution of this chart. It is one of his masterpieces as the world's foremost delineator of fowls.

It is not necessary for us to go into extensive detail in describing the different sections of the female Bronze turkey, as the shape of the male and female is alike, except that the cock has a more masculine look throughout.

What we have said in regard to color, markings and shape of the male will apply equally as well to the female, the only exception being on back and breast. In these sections instead of a rich, bronzy surface we should find on the outside of feathers a narrow edging of dull white or gray. A common defect in females is a brown or snuff color that sometimes traces on outer edge to the white lacing on the feathers of the back and breast. When this off-color appears it should be discounted one-half to two, as in degree. Another section that is more liable to show the brown or snuffcolored edging on females than on males is the back of the neck. Quite often they will show a stripe of brown and this defect should be discounted one-half to two, as in degree.

It is not to be expected that we shall obtain as brilliant color on the wings and tails of females as we do on males, but our aim is to mate together each year the very best of the flock until such time as we find on them the same brilliant color on wings and tail coverts as we do on our best exhibition males. I believe that if the amateur will study carefully the description of defects and our system of placing a valuation on same, together with the two charts, he will be pretty well prepared to select and also mate his best specimens.
THEO. HEWES.

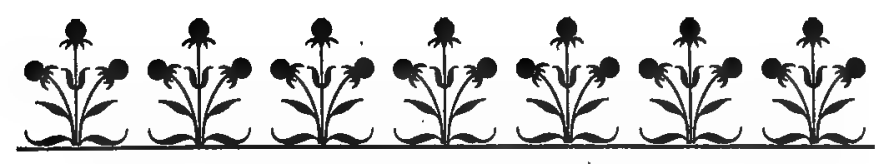




\title{
TURKEYS-THEIR CARE AND MANAGEMENT.
}

\author{
An American Wild Fowl that in Domestication has been Brought to an Advanced Standard of Excellence and Serves \\ Hlghly Practical Purposes-Standard Requirements of Different Sectlons-Mating to Produce \\ Exhibition Specimens-General Advice on Care of Flock.
}

By S. B. Johiston.

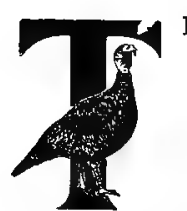

HERE are a number of turkeys bred in this part of the state, so that we are generally well acquainted with the different varieties, although our work has been confined to the Bronze variety. There are five varieties besides the Bronze in the standard, namely the Narragansett, Buff, Slate, Black and White Holland. Then there is a white sport from the Bronze that is nearly as large as that variety and that has more desirable features than the White Holland, which is the smallest variety in the standard. The White Holland is a good bird, but is too small and will not bring the marketman as profitable returns as the Bronze or Narragansett. I believe fewer people raise the Black Turkey than any other variety, as it is not liked by shippers on account of black pin feathers. Bronze, White Holland or Buff Turkeys arr easier dressed and pin feathers are not evident.

The Bl'cnze Turkey is the largest of all varieties. It matures quickly, and by the holiday season will attain its full weight It is docile and easily kept at home. It is sail by some that the Bronze Turkey is not easily kept at home, bui I have found that turkeys of any variety not having proper care will stray away. In hardiness and vigor chere is no variety that can surpass the Bronze when properly bred. The wild turkey is so near in color to the Bronze that by carefully introducing new blood by wild hens the breeder can get hardiness and vigor unequaled. Turkeys that are hacched in April, May and June will begin laying the latter part of March or the first of April the next year. I believe that all varieties of turkeys in the same latitude begin laying about the same time. In this latitude they begin about the first of April more generally than in March. There seems to be always a good demand for turkeys of all varieties. It takes the Bronze variety about three years to get its full weight-in other words, to get its heaviest weight, while most other varieties attain their full weight by the second ear. There are more Bronze Turkeys raised than all other varieties combined, which fact is proof enough that the Bronze has more good qualities than any other variety.

RANGE AND HOUSING.

Turkeys do not do well in small and crowded quarters. They can be raised to some extent on a small range, but such specimens generally are stunted in size and of poor color, just as is any other stock that is ill-kept. When the turkey was first found it ran wild in the forest, hence the love of range is about its first instinct and it will attain nearer perfection in size and color when it has freedom. Some writers advocate the housing of turkeys, but in my experience $I$ have not fond this best. I have learned that a turkey hen can take care of its young better than either a domestic hen or myself, as the turkey mother seems to understand the little poults' chirpings and knows what they need. I have tried raising turkeys in coops and pens, keeping them close to the house, but with poor success. When the season is not too severe, turkeys (an be given the run of the place, and if they have good quarters in which to roost at night, under bushes or something of that kind, and are looked after during the day for a few weeks, they will not need much food, but will do better and grow faster than those kept close to the house and fed from five to six times a day. Turkeys raised in this way are less trouble, have better plumage and are more vigorous, and in the fall when the corn is being gathered they can be toled to the house to roost. Turkeys kept close to the house and not extra well fed will stray off, hence the advantage is all with the one who raises $r_{1}$ is turkeys away from the house.

I have found that a roost built close to the ground is of great advantage to young birds that are growing fast, as it often happens that promising youngsters are injured in flying from high roosts. I believe that a shed open to the south and closed to the north, east and west is of great. advantage in severe weather in keeping turkeys dry and free from lrafts. Such a shed makes a good feeding place when there is snow or mud, and would make a good roosting place if the turkeys could be induced to roost in it. The great trouble is to keep them from roosting on top of the shed, but this can be prevented by running a two-foot wire netting around the top. I should not attempt to raise turkeys on one or two acres of ground, but with proper care a furty-acre farm will give ample forage for five hundred birds. In these days it is a large flock that contains more than one hundred turkeys. They do best when divided into flocks of about fifty.

\section{STANDARD REQUIREMENTS OF DIFFERENT SECIIONS.}

In order to mate breeding pens correctly and to do justice by his customers the breeder should understand the judging of fowls. To make this matter plain I shall take the bird, section by section, and cut for defects as would a judge when scoring in the show room.

Symmetry-Symmetry, or typical carriage, is first in the scale of points and to be perfect in this respect a fowl must have perfect shape in every section. I prefer the term symmetry to typical carriage. Symmetry means a perfect joining logether of all parts, thus making a symmetrical whole, while typical carriage may mean any pose the specimen might take regardless of symmetry. Symmetry is valued at eight points. So far as typical shape is concerned, if a bird loses one point in this section he is cne-eighth bad; two points, one-fourth; one-half point one-sixteenth. If the bird is too narrow and fails to round out in breast, back and body, with the tail too short, as is usually the case with narrow birds, the cut should be from two to three points, according to degree. The standard calls for a deep, long bódy; handsomely rounded. When the legs are too long or too short and stand too close together the cut should be from one-half to one and one-half points. The weight clause is valued at fifteen points. Standard weights are: Adult cock, 36 pounds; yearling cock, 33 pounds; cockerel 25 pounds; hen, 20 pounds; pullet, 16 pounds.

Condition-Condition is valued at eight points and all 
that goes to make a perfect, healthy specimen is considered. If $a$ bird show any signs of roup or cold it should be cut from one-half to one point; scaly legs, one-half to one; if head or wattles are torn from fighting, one-half to one point.

Head-This section is valued at five points and the standard requires it to be long, broad and carunculated. The beak must be strongly set in the head and have a graceful curve; eyes should be bright, dark hazel and clear. Wattles and throat are valued at five points. The head should be a bright red, changeable to bluish white, and the beak a horn color.

Neck-The neck is valued at six points, three for shape, three for color. It should be long and well curved back, with the plumage a light rich brilliant bronze. It is sometimes too short and too straight, and if so it should be cut from one-half to one point, according to defect.

Back-This is valued at ten points, five for shape, five for color. It should rise in a graceful curve from the neck to the center of back and then descend in a like manner to the tail. From the neck to the center of back the plumage should be a bright brilliant bronze, each feather terminating in a narrow black band; from the center of the back to the tail coverts the feathers should be dark, heavily edged with bronze. Common faults of the back are too narrow between the shoulders and too flat or straight. For these defects cut from one-half to two points. When the color appruaches clear black or brown or gray it should be cut from one to two points.

Breast-The breast is also valued at ten points, five for shape, five for color. It should be very broad and full, in color a light brilliant bronze. If too narrow, failing to round out nicely, it should be cut from one to three points. If black or brown in color, it should be cut onehalf to two points, according to defect.

Body and Fluff-The body is valued at ten points, five for shape and five for color. It should be long and handsome; in color black, shaded with bronze, but not so rich as the breast. The fluff should be black, each feather ending in a wide black and bronze band, terminating in a white or gray edging. This section is seldom found faulty. If flat or wedge-shaped it should be cut from one-half to one and onehalf points; if it approaches brown or black it should be cut from one to two points.

Wings-The wings are valued at ten points, four for shape and six for color. They should be large, well folded, the wing bows of a brilliant bronze or greenish Iustre; quill feathers evenly and distinctly barred, with parallel bars of black and white, extending the entire length of the feather. As it nears the center of the back the color changes to at bronze brown with very little white in it. White or brown on the lower edge of quill feathers is very objectionable. The bar should run clear across, and as there is not one judge in ten who cuts for lack of this, it is a common fault. If the wings are too long and lap on the back at tips the specimen should be cut from one-half to one and one-half points. The coverts should be a rich bronze and terminate in a wide black band, forming a broad bronze band across the wing when folded.

Tail-The tail is valued at ten points, four for shape and six for color. It should be black, irregularly penciled with light brown, ending in a broad black band with a wide edging of white or gray, white preferred; coverts black or dark brown, irregularly penciled with light brown, ending in a wide black and bronze band extending across the feathers with a wide edging of white or gray, white preferred. Small, short legged birds are apt to have a tail too short for good symmetry, and the tail folded too closely. This should bo cut from one to two points. Defects in color of tail are mostly found in the brown penciling. Some birds will bave splotches of brown and scarcely any penciling. Sometimes brown appears between the white edging; and the black. The white should come up to the black without any intermixing of brown. When brown is found it should be cut severely. There should not be any buff tinge in the white.

Legs and Toes-Legs and toes are valued at five points. The thighs should be long and stoutly built and the plumage a beautiful bronze. The toes should be stout and straight and of a pinkish hue; color of young birds, dark approaching black. Crooked or chalky legs and toes should be cut one to two points. If the legs are too short or too long, cut from one to two points.

Color of Females-The entire plumage of the female should be similar to that of the male, but the colors are not so brilliant nor clearly defined. On the edging of the feathers is a dull white or gray. Note-Crooked keel or breast bone should be cut from onehalf to three points.

MATING BRONZE TURKEYS FOR PRIZE WINNERS.

If I were asked the most essential point for breeders, I should say first of all vigor. then size, then fine markings of plumage. The fancier mus consider size, because nine out of every ten want size first. It is not the rule, however, that the biggest turkeys are the highest scorers, no matter how well they may be bred. To improve size, weight and markings, select the finest marked tom of good big bone, with typical carriage, strong and vigorous, and mate him with the largest hens possible, no matter if they are not so well marked. Then the next season reverse the order and if you are so fortunate as to get well marked birds of both sexes, mate them in the following manner: For the females, select tall, rangy birds, with long, deep bodies, broad backs, and full rounded breasts, with as big bones, feet and legs as possible. In color, the head and wattles should be a rich red, but under different circumstances the head is changeable to bluish white. The plumage of the neck and breast should be a rich, lus. trous bronze, the breast and back in front of wings showing a narrow lacing or edging of gray. The back is somewhat darker in color, as it shows a narrow black band across the feathers as they ncar the lesser tail coverts, these ending in a white or gray edging. The primaries and secondaries of the wing feathers must be as near standard as possible.

I take it for granted that every breeder has the standard, for it is the book of authority, and sets forth clearly the disqualifications. I would say, however, that the white or gray bars should be about three-sixteenths of an inch in width with the black or brown bars about three-eighths of an inch. They should be even and straight across the feathers. The tail should be long and black, with pencilings of light brown across the feathers, the feathers ending in a broad, black band with an edging of dull white coming right up to the black. The feet and legs should be dark, apprcaching black. This is of lnss importance in the females than in the wale.

The toin has more influence on shape and color of offspring than has the female. He should be as near perfection 
in carriage and color of plumage as it is possible to get. $\mathrm{He}$ should be of medium size and of good vigor. In my opinion, the standard makes a mistake in calling for larger birds, as this detracts from their profit as egg-producers. A good, vigorous tom will mate with eighteen or twenty hens. As to the best age for breeding fowls, I use a two-year-old male and female one year old, or vice versa. Yearling turkey hens will lay more eggs than an older hen, but the two-yearold hen's eggs will hatch stronger poults. Hens are profitable as a general thing until they are four years old. I have kept some good layers until they were six years old. As a rule turkeys are not profitable after they are four years old. Three to four-year-old tom turkeys usually become cross and irritable and are dangerous to have about where there are children.

I have the best success with pullets from sixteen to twenty pounds, and old hens from eighteen to twenty-three pounds. They lay more fertile eggs than larger hens, are more active and healthy and make better mothers. Turkey hens do not all commence laying at once, and generally by the time the first layers want to sit the last ones to lay are ready to begin. Turkey hens should be carefully fed at the laying season if fed at all, as they will pick up on the range nearly all the food they need. If allowed to get too fat they will not lay until late. It is a good plan to feed meat two or three times during the month before you want them to lay, as it will have a tendency to make the eggs more fertile. Turkey eggs as a general thing are sure to hatch. I have had hens lay as many as four clutches of eggs in a season. Turkey eggs will hatch in twenty-eight days, but with medium sized turkeys it usually requires twenty-nine days, and eggs from very large hens frequently run over to thirty days. I have an eighit-foot fence around about two acres on my home place that I use for the laying turkeys in the spring. I use boxes and barrels turned on the side for nests.

\section{AT HATCHING TIME.}

One should be very careful in setting turkey hens, as they are of a wild nature. It is best to try a hen, if one has valuable eggs, by giving her a few nest eggs for a day or so, then at night taking the nest eggs out and putting the good eggs in. Be careful to have the bottom of the nest firm and solid, so that the eggs will not roll about. Have the nest so formed that it fits the shape of the hen. In this way tho eggs will all be the same distance from the hen's body and receive the same amount of heat. Sprinkle the eggs at sitting time and two or three times curing hatching time with Lambert's Death to Lice, or some other good insecticide. If your hen is gentle you might take the poults out of the nest as they hatch. This leaves more room for those that are to hatch. If the hen is inclined to be irritable, it is best to leave her alone, as she may get excited and trample on the poults. I have successfully used incubators for hatching turkey eggs, but when it comes to putting the poults in the brooders it is another matter. It is all right to hatch them in an incubator if one has hens to which he can give the young poults to be raised. I never feed my young turkeys until they are twenty-four to thirty-six hours old. They are first given grit, then some oatmeal or groats. I use very little soft food. When giving soft food it is best to mix it with sweet milk and give only what they will eat up at one meal, as turkeys should never have sour food. Give table scraps and any green food you may have. Cottage cheese is a good food for poults and is particularly good with cut onion tops, salted and peppered to taste. Oat groats are highly recommended as a dry food for poults. Give millet seed, kaffir corn. wheat and then cracked corn. Feed these grains alternately.

AT MARKETING TIME.

I have found that winter feeding differs from summer feeding, as in cold weather poultry needs corn on account of its heating and fat-producing qualities. Turkeys on the range in warm weather do not require much corn. If one has a large range the turkey crop is almost clear profit. Turkeys intended for market should not be fed heavily until within about two weeks of selling time, when they should be given all the corn they will eat, with a change of food as often as possible so that they will not tire of the corn before they are fat. Make corn their main food.

The average price for turkeys on the market is eight cents per pound. When stockmen get five cents per pound for hogs and cattle they make a good profit. It does not take anything like the amount of food to produce turkey meat that it does to produce cattle or hogs, and it is very seldom that the turkey grower gets less than eight cents per pound. On the other hand, it is seldom that the cattle grower gets more than four cents per pound for his beef or pork. When turkeys are properly raised they are a benefit to the crop, instead of a waste, as they destroy numerous insects. In California turkeys are rented out to men who have vineyards, who turn the turkeys loose among the vines to destroy insects. Turkeys do not require to be fed on a grain ration until within a few weeks of marketing time, as they get their living from the gleanings of the field. In this way they get a large frame, which the grower can fatten when seliing time comes. Turkeys should be fed away from other poultry. Sandy or gravelly land is the most suitable for turkey raising. Low, swampy land is not desirable, as it creates rheumatisn, to say nothing of the filth.

s. B. JOHNSTON.

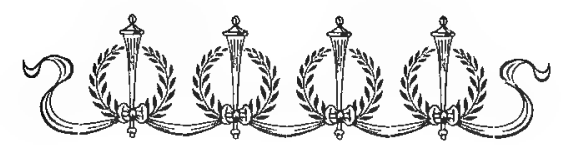




\title{
SUCCESSFUL TURKEY RAISING
}

\author{
With the Minimum of Labor-Laylng House for Turkeys-Hatching the Poults-Housing Turkeys with Poults- \\ Feeding Young Turkeys-Roosts for the Young BIrds-Shlpplng Crates for Palrs, Trlos and Pens.
}

By Mrs. M. L. Singleton.

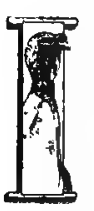

AM AWARE that no two breeders manage their turkeys exactly alike, in fact, there are no iron-clad rules in turlkey raising. Our surroundings differ so from those of others, that it is useless to formulate rules that would be impossible for them to follow, but there is one safe rule for beginners. No matter what your environments may be, start with the very best stock you are able to buy. If you have money enough to buy a good pair only, do not spend it for a trio or pen. If you can spare the money for first-class birds, of course a trio or pen is desirable. To the thoroughly equipped breeders who have years of experience behind them, my methods will appear crude, doubtless. It is not for the breeder of experience that this article is written, but for those whose advantages are not great and who must struggle perhaps for years to gain the knowledge that will make them successful turkey raisers.

I learned several years ago that I had neither the time nor strength to follow the hens around and hunt their eggs in fence corners and hedge rows, so I had a laying house built for them. It is not a very elaborate affair, but it accommodates them very comfontably. A week or two before I think it time for them to hunt nests, I have them driven every morning into this house. In this way they become accustomed to going in and usually by the time they begin to lay they will go without being driven. When the turkeys lay from twenty-five to thirty eggs, I set them under domestic hens, putting nine or ten under each hen. We find that there will be as many poults as one turkey hen ought to carry. Of course you have to use a great many domestic hens where there are many turkey eggs to hatch, but it pays, I think, as they hatch so much better for me than do the turkeys. I do not set the first turkeys that get broody, but break them up and let them lay a second clutch. By the time the first turkey eggs have been incubated two or three weeks, the last hens will probably be getting broody.

\section{SETTING THE TURKEY HEN.}

In the meantime, I arrange my turkey nests, which are empty barrels, as I consider them among the very best nests. I saw out two or three of the staves about half the length of the barrel, that is, just below the middle hoop. I stand the barrel in the colner of one of my poultry houses with the open end up, because:I think setting the eggs on the ground causes bad results. By making the nest on the closed end of the barrel the eggs do not come in direct contact with the damp ground, and they are yet near enough to obtain sufficient moisture. Tack an old piece of carpet or gunny sack on the barrel over the opening and another over the top. Put in a lot of new straw and shape it into a solid, but rather shallow nest, and it is ready for the turkey. In the evening I remove her from her old nest and putting her gently in the barrel, drop the curtain over the opening. I have previously put a few chicken eggs in the nest so if she is restless and - inclined to stand up at first, there will be no harm done. The second day I raise the curtain and put food and water near the barrel, but if she does not come off, I let her alone for a day longer, and if she still refuses to come off, I lift her out. After she has eaten, I see that she goes back on the nest. When she has become accustomed to it, I lift the curtain up so that she can come out into the poultry yard and dust and pick around, always being careful to see that she goes back on the nest. I arrange a number of these nests in the different houses to accommodate the different broods that come off. A day or two before the little ones are due to hatch, I remove the eggs from one of the chicken hens, putting them under the turkey hen. When the little poults appear she is just as proud of them as though she had done all the work of incubating. As the little poults get dry and strong, I remove them to a flannel lined basket in the house. When evening comes, if the turkey is a very gentle mother, I carry them back and let them remain with her, as the warmth from her body strengthens them, but if she is a foolish old hen, I wrap the basket warmly and keep them in the house. When they are all dry and strong enough, I remove the mother turkey and her little ones to their future home. It is this home I wish to tell you about most particulariy.

\section{HOUSING THE TURKEY AND POULTS.}

I do not remember to have read an article on turkey raising in which the writer did not suggest that a nice, shady orchard was a desirable place for turkey coops. Now I admit an orchard is all right, provided it is located where you can run out and look after the young turkeys at all tiwes, but when one has all the work of a large house on one's shoulders and cannot get any help that is worthy the name, then I say most emphatically, don't. Here at Elmhurst is a large, shady yard at the west side of a building which bas a porch almosi the full length of the dining room and kitchen. A door opens cut of each of these rooms on the porch. At the end of the porch is the pantry, which has a window in the west side, so if $I$ am in either the aining room or kitchen, I can step out on the porch and see my turkeys, but if I am in the pantry, I can lock through the window and see them, for it is in this side yard under the elm trees that sny turkey coops are placed. "Turkey coops in the yard!" J. hear some housekeeper exclaim. Yes, for my turkey coops are very neat affairs and do not detraci very much from the beauty and neatness of our yard. The coops are renewed each year, that is, I turn the last year's turkey coops over to the chickens and get new ones, because for some reason my turkeys always thrive better in new coops. These coops cost only twenty-five cents each and a little work for they are dry goods boxes sawed slanting, so that they are only about half as high at the back as they are in front. There are beards nailed on to extend over the front and rear: The lower boards are taken off the front of the coop and battens nailed on for the door, which slips back in place and is fastened with a wooden button which is just above the door. About six inches above the door another board is removed and screen wire nailed on to ventilate the coop.

\section{FEEDING AND CARING FOR POULTS.}

Now we have the turkey hen and Her brood in a nice new coop under the elm trees where just enough sunlight filters 
through to keep the ground dry, and not enough to hurt the tenderest poult. The next thing is to feed them. For the first day or two I give them nothing but light bread soaked in new milk and pressed as dry as possible, with plenty of black pepper sprinkled over it. After that I feed them almost entirely on egg corn bread soaked in sweet milk, in which is mixed raw egg. Right here I want to say, there is nothing better for young turkeys than raw eggs. I learned several years ago that they are far superior to boiled eggs. I know that curd or clabber cheese is highly recommended by a great many persons, but I have found it a very injurious food for poults. I have believed this for several years, but

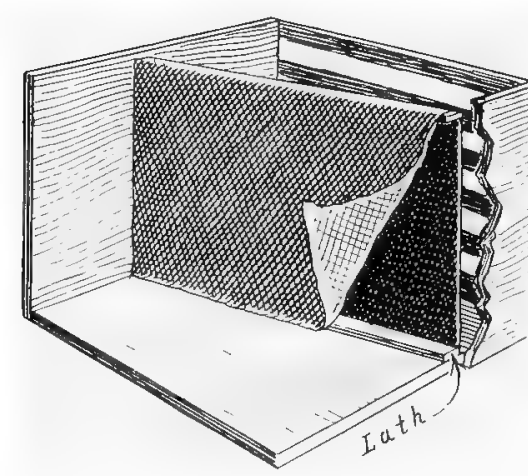

Fig. 1-Coop for two turkeys, showing lath at top, over whlch the cloth partition hangs, and the lath at bottom to which it is tacked. menced to feed sparingly last spring,and in less than two weeks I lost five or six poults, and in every case but one I found the curd packed in the entrails. The other case was enlargement of the gall bladder, caused from indigestion.

Before putting the hen and her brood in

the coop, I cover the bottom with hay or straw, otherwise there is danger of the hen injuring herself from slipping on the boards. I once had a valuable turkey almost ruin herself in this way. The young ones, however, get injured much more easily on the straw. I keep the mother and turks in the coop for a day or two, unless the weather is very mild, and then I stake them out in an open place in front of the coops. "This is done by tying a stout twine, snch as fleece or wool is tied with at shearing time, to a short stake and driving the stake even with the top of the ground. I measure the twine so that it will not be long enough to wrap around any tree or shrub. but near enough to the coop so that she can go in, but not around it. The string I tie on the leg, just above the foot. The hen will work and pull at the string for awhile, but she soon becomes accustomed to it, and when I take her out to tie her each morning she seems perfectly satisfied. This way has a great many advantages to me over the old way of putting them in a pen in the orchard. In the first place, the hen cannot kill the poults by jumping in and out. Secondly, they are right in sight, where I can give them my personal attention at all times. Third, if a rain comes np, I run out, untie the hen and put her inside the coop. The young ones rush up for the food I give them and I put as many in with each hen as I think she ought to have, because you see I have several of these families in the yard and one mother is the same as another to them. By the time the rain comes, the hens with their broods are all safely housed, for it only takes a few minutes to attend to all of them. Fourth, by the time I give them their liberty, which is not till the poults are three or four weeks old, they have become accustomed to their roosting place, and the flocks are usually running together. The hens never separate, but all come in aut, night, bringing the whole drove with them. It is very seldom that they fail to come up, but if they do, I go after them and drive them up, because if they form the habit of staying out, it is almost impossible to break them.

When they outgrow their coops and show signs of wanting to fly up to roost, I drive them into the turkey house.

which is well ventilated, where I have roosts made about two feet from the ground. I do this for fear of sudden rains in the night, for I am not strong enough to get up and carry turkeys in out of the wet. I used to do such things in the past when my coops were kept under a shady tree in the orchard, but I realized that it was only a question of time when I should be compelled to give up the business entirely, or keep the turkeys where they could have my personal attention at all times.

When they are a few weeks old. I feed them any small grain that I have, but the principal food is corn chops dampened just sufficient to cause the fine part to adhere to the coarse. As they get, older and until they are sold, they are fed almost entirely on corn. They must be well supplied with grit and oyster shells. When I first commenced to raise turkeys in such close quarters, I was told by all my neighbors that I would stunt them so that they would never recover from it, but as I raise the heaviest turkeys that have ever been raised in this part of the country, my friends have quit talking.

I have been asked what preparation I give my turkeys for the show room, and my answer is, none whatever. From the time they are four or five weeks old until they are shipped to customers, they have the range of a one-hundredand-sixty-acre farm, and as soon as they are old enough to withstand the hard rains at night, they are made to roost outside in the open air. If during the winter we have deep snows, and protracted cold spells, we drive them into the barn and allow them to roost there until the weather moderates. Managed this way, there is no danger of them contracting colds and roup when being shipped a long distance.

\section{SHIPPING CRATE FOR TURKEYS.}

Seeing the forlorn and bedraggled condition of turkeys shipped in pairs and trios to our station, made me wonder if the turkeys I shipped to customers looked the same when they arrived at their destination, and I determined to devise some means of preventing them from picking each other and breaking their feathers while on the journey. The crate I use is my own invention, as I have never seen one anything like it, and while it is a very simple affair, it answers the purpose admirably. I use narrow cloth-lined crates for shipping turkeys, making the crate for a pair just a little wider than for a single bird, and for a trio a little wider than for a pair. Any style of crate will do, but the ends should be upright pieces so as to have something to nail partitions to. In making a coop for a pair, after the frame is made and before it is lined, nail on two laths lengthwise of the crate, one the width of a lath below the to $p$, the other against the bottom. Nail them firmly to the upright piece at either end. These laths are just slanting enough to show the space at one end to be about twice the width of the other. When you have the laths firmly in place,

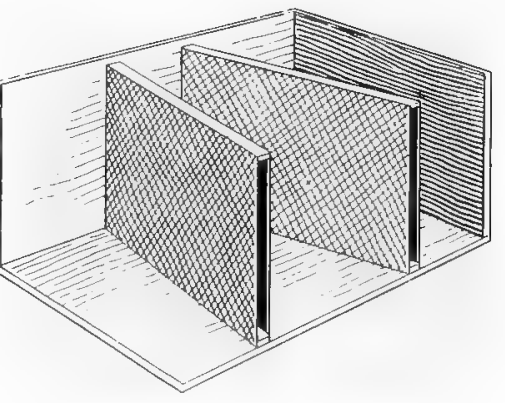

Flg. 2-Showing coop for trio, with cloth partitions in place. take a piece of your lining twice the depth of the crate, drop it over the top lath, tacking it firmly to the floor on each side of the bottom lath. Now you have a good, firm partition, one that will sway gently with the motion of the birds, but keep them apart as effectually as a stone wall. If you wish to ship a male and female, have the space on one side of the partition a little wider than the other side, 
as the male is always broader across the back. Make it just wide enough for them to rise up and sit down comfortably. When putting them in the crate, place the tom with head toward the wide space at one end and the head of the hen toward the wide space at the other end, having their heads at opposite ends. There is no danger of fighting, and the space being wider at one end and narrowing down at the other, there is no chance for them to turn around, which I have seen them do in a narrow crate that is the same width. In shipping a trio, follow the same general directions, having the wide end of the wide compartment and the narrow ends of the side compartments at one end of the coop, and at the other end, the narrow end of the center compartment and the wide ends of the side compartments. Have the middle space somewhat larger than the side spaces and place the tom in it, with a hen on either side. I believe the same plan could be followed in shipping a pen, making the crate wider and adding two more partitions. The crate must not be lined until the partitions are put in, because there is no room to nail.

No matter how you raise or ship your turkeys, be honest in your dealings with your customers. In corresponding with them, describe your birds honestly, sending a tail, wing and covert feather. If your birds are well marked, the customer can tell it by the feathers, but they have to depend on you for correct weight, shape, etc. Remember always, the golden rule and judicious advertising are the only safe rules to follow in poultry culture. If you do not sell all your birds this year or next, you will some time, and if you do, you will not be ashamed to look your customers in the face if you should meet them.

MRS. MARY SINGILETON.

\title{
UNSUCCESSFUL TURKEY BREEDING.
}

\author{
Frequent Causes of Lack of Success May be Traced to the Parent Stock-Introduction of New Blood Often DIs- \\ misses Disease from the Flock-A Device to Prevent Turkeys Flying Over a Fence.
}

From Rhode Island Experiment Station Report. portion of those who attempt to raise turkeys use small and immature birds for breeders. Many kill their earliest and best birds for the market and keep for breeding those that are too small or too late to be salable. They kili the goose that lays the golden eggs. In buying a new gobbler or a few hens to change the blood they choose late hatched, immature turkeys because they cost less. The reason sometimes given for this is that old hens are too cunning about stealing their nests and that young turkeys lay earlier. This practice is not confined to the poorest and least intelligent people, as would be expected, but is followed by those well informed and who appreciate and pay for a well-bred horse or cow. If such a course were followed with horses and cattle the best stock in existence would be ruined in a few generations. Many who know that turkeys two years old or older give the strongest and largest young, continue to kill off the young hens for market after breeding from them one season. There seems to be a dread of having something too old or unsalable left on their hands. To breed from immature or poor specimens is to violate one of the first laws of breeding. Selection of the best for generations has given us the improved and most profitable breeds of stock. The hereditary influence of such selection is of great value. The most inferior bird out of a flock of such blood may 'throw back' and breed very fine stock and do better than a much finer specimen from a poorly bred strain, but the repeated seleotion of inferior birds for a number of generations makes this inferiority hereditary.

"The future stock depends almost entirely on the parent birds or their ancestry. If valuable birds are used for breeding, their offspring will be like them and amply repay the extra expense. The best are none too good and are the cheapest.

"Crandall Brothers, previously mentioned as having used western gobblers furnished by Mr. Vose, raised so many more turkeys in consequence that they estimate the benefit derived the first season at $\$ 100$. It would have been econ- omy for them to have paid $\$ 50$ for the two gobblers rather than use the kind of stock they had previously bred from. This expenditure would have paid the first season, to say nothing about the improvement in their breeding stock for the future. Many breeding turkeys are over-fat in the spring-have been overfed or given too fattening food. Quite frequently they die at this time as the result of over-feeding. The progeny of over-fat birds are less vigorous. Late hatched hens that are growing all the time need more food; cannot store up a surplus and lay earlier because they are thin. Feed the old hens clover and less carbonaceous food in the latter part of winter and they will give better satisfaction. Corn is all right when turkeys can find their own green food and insect ration to go with it, but when they get little exercise and can get nothing else to eat they become abnormally fat.

"If a turkey becomes sick and is allowed to roam with the others, and eat, drink and roost in the same places, the others will probably have that trouble very soon. If a flock becomes diseased, the land which they wander over may become contaminated and infect other flocks that occupy the same ground. Therefore stamp out disease when it first appears. Let every turkey raiser be a board of health; quarantine or kill and bury deep all sick fowls and disinfect what they have contaminated. Prevention of the spread of disease is possible. Doctoring very sick turkeys is rarely practicable. If turkeys are kept where they may drink from stagnant pools in the barnyard, near the pig pen, privy vault, or from the sink drain, sudden and fatal attacks of bowel trouble should be expected among them. A running stream is of great value on a turkey farm. If brine is poured out and they drink it or they pick up pieces of salt, salt meat or salt fish, death usually follows.

"In shingling or 'boarding' turkeys a thin board or shingle, in which holes are bored, is fastened across the shoulders of the bird by soft cords, tapes or strips of cloth. When of the proper shape and the holes are in the right place, if the cords are not tied too tight, they may be worn twelve months without injury to the turkey. By this method 
they may be confined to one field as easily as sheep. This is better and surer than clipping one wing. The only objection to it is that turkeys thus hampered are almost at the mercy of dogs. When the board is first adjusted the turkeys try to free themselves, but they usually accept the situation in less

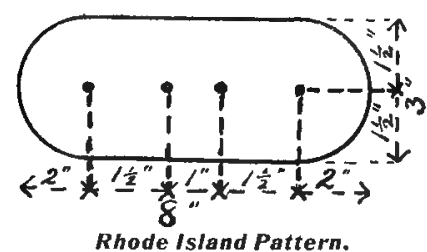

than an hour and do not seem to mind it afterward. Various shaped boards are used. The diagrams show two styles and give the dimensions.

"The strings are usually tied on the top of the board. In fastening tho western style the string is passed down through one hole in front of the wirg close to the body and around under the wing and up through the other hole and is tied on top of the boaid. Mr. Barbee uses a board ten jnches long and five inches wide and fastens the strings under the wings. An ordinary shingle is strong enough for most hens, but large gobblers require something stronger and light barrel staves are often used. In those that we have seen threeeighths-inch augur holes were usel. Some use a large gimlet for making the holes."

Mrs. B. G. Mackey, the well-known Bronze Turkey breeder, has the following to offer in regard to this subject:

"It is quite a problem training the turkeys to stay at hoine. Last year I tied a man's large straw hat on the back of my turkeys with young ones. I made a hole on each side of the rim at the crown, ran cloth strings through the holes and tied the string around each wing. It was laughable to see the hens at first. They tried to fly, they jumped up in the air, ran forward and backward, but when they found themselves securely fastened to the hats they finally accepted

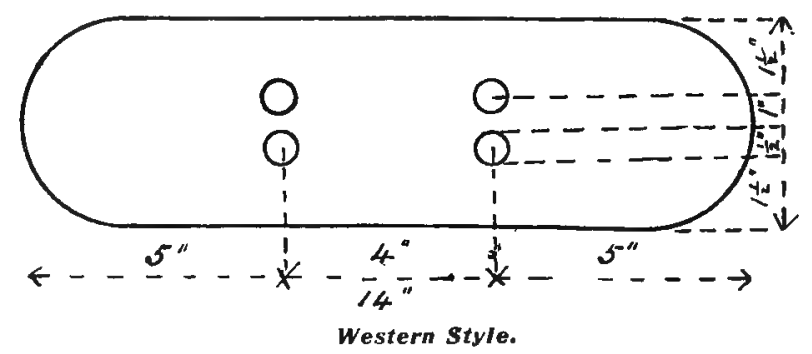

the situation. Living on the public road, I had to answer a good many times the question, "Why do you put hats on your turkeys?" The hat is much better than a board. The crown prevents the hen from going through the fence, and in a rainstorm the brim is a protection to the poults."

\section{TURKEYS ON FISHERS ISLAND.}

\section{Turkey Raising Profitable-They are Not Difflcult to Breed under Proper Conditlons-WIde Range Essentlal- Half-wild Turkeys-Selecting Breeding Stock-Hatching and Ralsing Poults-Profits.}

\section{By E, M. \& W. Ferguson.}

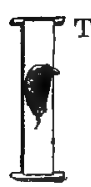

T ALWAYS gives us great pleasure to write anything pertaining to Bronze turkeys, and especially to our turkeys, for our work with them has been productive of much satisfaction, not to speak of a very considerable profit.

While we shall make this article chiefly a history of efforts in turkey breeding, rearing and exhibiting and a brief treatise upon our methods, we realize that all turkey raisers have not the same environment and will endeavor to write in such a manner as will be interesting and instructive to every breeder wherever he may be and by whatever conditions surrounded.

It seems to be an established fact that turkey raising in this country, particularly in the east, is on the decline; where years ago a flock numbering one or two hundred was a profitable adjunct on the majority of country farms, now these birds are found but rarely and then in flocks of a dozen or less, tolerated rather than fostered. The cause is hardly apparent; the thickening settlements have not yet encroached upon the solitude of many a back-lying farm where green pastures and sheltering woodlands offer ready for use, the best possible food and shelter. True, they may damage to some extent the growing crops, but they will render services much more valuable than what they destroy, in the wholesale destruction of bugs and insects which threaten the farmer on every hand and which they incessantly pursue as the prinripal article of their diet.

We are sometimes told that turkeys ale difficult to raise and lack a strong constitution, but common sense, backed by our actual experience, telis us that such is not the case. In fart if they be allowed to indulge their natural desire for a wide range and outdoor life the year round, and are properly bred, anything but strength and hardiness in their make-up would seem well-nigh impossible. But where such cases exist it seems to us that the cause must be found in the absence of one or other of these conditions.

We believe that a wice range is very essential and that although turkeys can be reared and kept in an enclosure of moderate area, a much less percentage will reach the highest reveiopment in size, shape or color. With this condition provided and a lack of vigor prevailing an inherent weakness must be present in the blood of the parent stock. This may be traceable to indiscriminate inbreeding or unwise mating. In no other domesticated fowl does deterioration so closely follow careless breeding, and for a farmer to breed the same small flock year after year with no further attention than is required to select the largest and fattest for his Thanksgiving dinner, is to invite failure by the most expeditious course.

Mistakes in adding new blood may prove equally demoralizing; in fact, we can cite cases that have come within our own observation where a breeder has sadly depreciated the value of his stock by adding a bird which, apparently strong and healthy in itself, had an inherited weakness caused by poor breeding. We speak of these matters not to discourage the prospective breeder or the disheartened farmer, but to 
emphasize the advisability of close adherence to the methods that have proved successful and the value of a careful study of the principles involved.

Some years ago we managed to secure at heavy expense a flock of genuine wild turkeys, which, although purchased for the purpose of crossing with our Bronze to make a better foraging market bird, have proved to be of inestimable value for infusing new vigor into run-down flocks, and we sell every year a large number of toms for this purpose. The half-wild make a market fowl par excellence; they are rapid growers, carrying a considerable amount of fine-grained meat, and support themseives almost entirely throughout the year by foraging. When crossed on the pure Bronze as a strengthening agent, reducing the wild blood to one-fourth, the increased stamina is the only apparent effect.

\section{SELECTING BREEDING STOCK.}

The selection of breeding stock with us begins as soon as the young turks are given their first food in the fall, say the first of October, when any bird that gives particular evidence of lusty good health and sturdy growth becomes an object of especial interest to be carefully watched as it matures and finally selected for use if it has constantly maintained its robust lealth; but it is discarded if the slightest evidence of weakness has been detected.

The final seleciion is made usually in January when the stock is at its best. We have found that one male to every twelve females is about the right proportion, and we advise that at least two males be allowed to run in the same flock in view of the fact that occasionally a hen will refuse to mate with a certain tom, but can readily agree with aunther, and also to gafeguard against loss should one of the males be, or at any time become, wholiy or partially impotent. When one recollects that the female is served by the male only once in a season, the wisdom of this plan is obvious. But care must be taken to use toms that have been accustomed to each otjer's society and that agree, else it will be necessary to confine one each day while the other runs with the inens, changing them every night.

We endeavor to get our breeders in a condition of medium flesh, as a fat bird never gives satisfactory results. For this purpose we consider oats to be the best food, and it is fed exclusively so long as food is required during the breeding season.

When we began with turkeys we did all manner of things supposed to contribute to their welfare, but we have gradually given up trying to do what they are better able to do themselves, until now we leave them pretty much to their own devices and find the results far more gratifying.

\section{THE TURKEY AND HER POULTS.}

Occasionally it happens that two or three hens are found laying in the same nest, a proceeding which is usually discovered by the slightly different color of the eggs. In this event we remove all $\mathrm{eggs}$ as laid, substituting a couple of china eggs or duck eggs to guard against a change of nest. When one hen begins to sit we give her a full quota (fifteen to eighteen eggs) and confine the other hens for a few days after which they will begin laying again in another nest. If, however, the discovery is made after incubation has vegun, we prefer to let them sit together unless we can ascertain unobserved that there is but one sitting of eggs. And we will here state that we always try to make our visits at a time when the hen is absent, otherwise she may become worried and give up her nest. When the hatch is complete, we provide a little nourishment for the young turks in the form of stale bread moistened in milk; this will assist them to gain strength until they are well on their feet, after which time they get their food from the earth and air. Occasionally we find one weaker than the others, by reason of slowness in hatching, which is unable to leave the nest with its maies; such a one we care for until it is strong enough to go with the hen. After they are all able to hustle about, we put poults and hen out in the low bush with which the Island is plentifully supplied, and pay no further attention to them until well into the autumn, when we begin to get them together for the fall feeding.

As they grow and develop through the late summer and early fall they gradually form into several large flocks which wander about together under the guidance of the old toms, each flock having its own roosting place, generally at least a mile from that of any other. In October they are found to be in excellent condition and require but little feeding to fit them for the Thanksgiving market. At this time they are very suspicious of any one who tries to approach them, but soon become reconciled to the presence of the feeder and will surge around him with such force as to endanger his footing. Corn is the only food given at this season and as killing time approaches we feed them all they will eat.

The greater part of the market stock is devoted to the Thanksgiving trade and is shipped to private families all over the country; but there is always a certain number that are not fit at that time and which are reserved for the Christmas season. By furnishing each year a very fancy grade we find ready sale for all we have to dispose of for table use at a considerable advance upon the highest market quotation. These are carefully picked and drawn, the heads, shanks and last joint of wing being removed, and are then packed in clean boxes, in which they are shipped direct to the residence of the consumer.

December usually ushers in the advance orders for breeding and exhibition birds, in which we always do a large and satisfactory business. Having so large a number to select from (all of which are selected specimens from the hundreds that we raise), we find little difficulty in filling the most exacting order, and it is seldom that we receive a complaint.

Although our business in turkey eggs for hatching was very satisfactory, we decided to discontinue their sale three years ago and have had no cause to regret our decision. $\mathrm{W}_{\theta}$ find it far more profitable to set every egg ourselves and sell the stock instead. In shipping the birds we know that the purchaser will get full value for his money, while in selling eggs too much depends upon various conditions.

\section{PREPARING FOR EXHIBITION.}

Our method of preparing turkeys for the show room is simple indeed. It consists wholly in taming the bird and getting it accustomed to being handled. Our turkeys coming from a range of over five thousand acres are as fit as only a free, wild life can make them, full of rich, red blood, which sustains their vigor and spirits through the longest trip and the tedious, weakening confinment of the exhibition hall. They have a hard, smooth and wonderfully brilliant plumage together with that robust development and noble carriage that is never found in a turkey raised in confinement.

We select the birds that we are going to show about two weeks in advance of the time when they are to be exhibited, and always take up more than we expect to show to insure having our full entry in case one or more of the birds becomes damaged in plumage or otherwise. These are handled with the utmost care, as it is very easy for a struggling bird to break a number of wing flights or to strip feathers from its thigh, where a careless handler is almost sure to get his grip. 
PROFITS.

To any one who has read the foregoing paragraphs it must be evident that turkey raising as it is managed hereand we know of no reason why our methods and success can not be duplicated in almost any locality-is much more profitable than any other farm crop that the farm can produce. Any one who is apt at figures can easily figure out the possible profit to be derived in his own locality which will be governed by the cost of food, the area of the range available, and the price that can be obtained for the product.

We would say in concluding that as many questions will doubtless arise in the mind of the reader which have not been clearly answered in this article, we shall be glad to see them at our farm, where we shall always be pleased to explain every cletail of the business and where we can give far better instruction verbally with the birds and their inome to iliustrate our words.

E. M. \& W. FERGUSON.

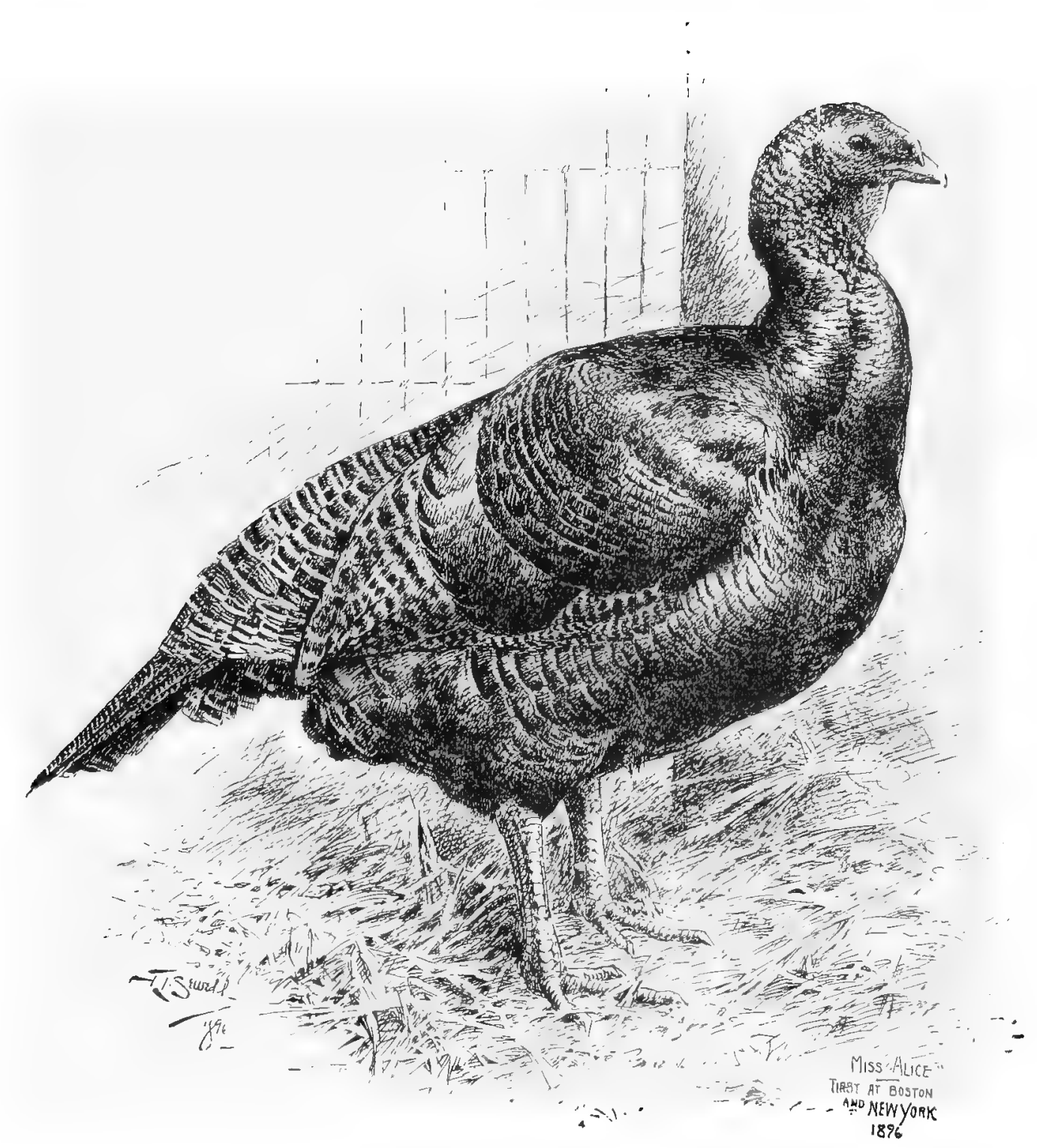

"Miss Alice," a Bromze Turkey Men, that Traveled Two Thousand Miles to Shows, and Never Was Defeated. Owned by E. M. \& W. Ferguson. 


\title{
TURKEYS AND PIN-MONEY.
}

\author{
Raising Common Turkeys for Market Brings a Supply of Pln-Money to Many a Farmer's WIfe-Breeding Thorough- \\ bred BIrds Means an Increased Supply-Methods Employed by a Successful \\ Woman Fancler of Bronze Turkeys.
}

By Mrs. F, A. Hargrave.

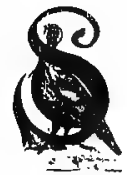

OME SIX years ago, much to my disappontment, we moved to the farm, and a friend presented me with a trio of Bronze turkeys of just ordinary breeding. This trio of birds, with some Barred Rocks, became a great consolation to me in my loneliness. From early childhood I was not fond of the farm, with its many laborious tasks calling one from early morning to late at night. Perhaps in wisajom. You know one never really is wise till he becomes conscious of the fact that he knows but little. My first stepping stone to success in raising turkeys was in supplying myself with poultry journals and books pertaining to turkey raising compiled from the experience of other turkey breeders.

Last spring a neighbor became very enthusiastic about turkeys and started in the spring with nine hens and one

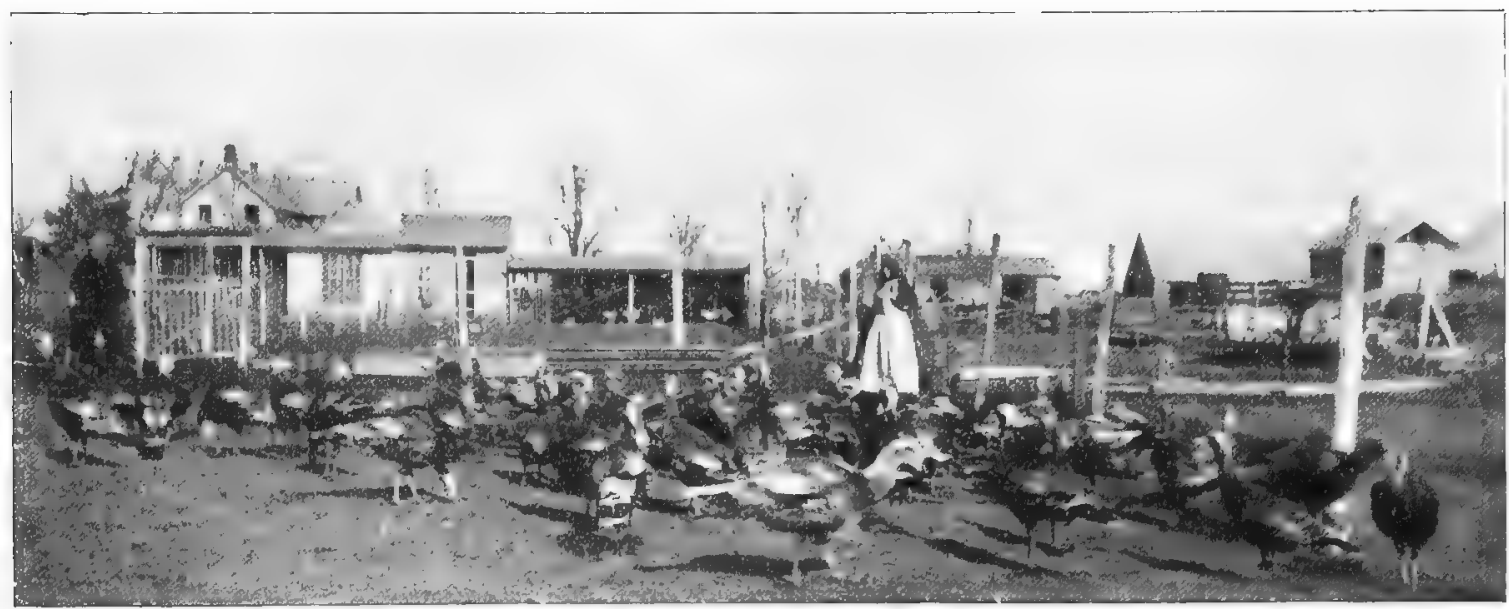

The Flock of Mrs. Hargrave.

the east one's peaceful rest is not disturbed so early and so late - I hope not. But here in the west we still display the hustling nature innerited from our forefathers of a generation ago, and time has not much decreased it. Perhaps this is the reason that in 1890 Illinois ranked first in turkey raising with 1,043,947 turkeys to her credit; Iowa, second, 940,849; Missouri, third, 928,751; Kansas, fourth, 530,397, and Texas, fifth, 535,916.

My chosen occupation, teaching, took me early in life to my coveted place of abode-the city. There I taught for a number of years previous to taking up housekeeping and poultry raising.

All women will understand from intuition why I took up poultry raising, and especially the raising of turkeys. But for fear the men may not guess aright, I will say it was to replenish my empty pocketbook. I greatly missed my regular monthly income and took this method of overcoming my loss. Pardon this personal reference, but I feel my case does not differ materially from that of a thousand other women who may read this book and my experience will perhaps be of help to them in solving their problems.

\section{MAKING THE START.}

I lost two of that first trio, one hen and the tom, and I raised nine out of the eleven that hatched-seven pullets and two toms. During the raising of these $I$ was gaining tom, boasting that she would raise as many turkeys as her neighbor. The season passed and "turkey gathering" time came. A flock of twenty-three turkeys was the result of her season's efforts, besides which she lost part of her breeding stock.

Conversing with her one day, I said: "What was the trouble?"”

' $\mathrm{O}$, I don't know, but when hatched, I put them in a pen and the mother in a coop and tried to keep them there till four or five weeks old, and they just kept dropping off till they were nearly all gone."

"What did you feed?"

"Anything and everything they would eat-the same I fed my chickens."

"Did you keep grit for them?"

"Grit? No, what do they need grit for? I never give my chickens any."

"Do you take any poultry paper?"

"No, I am so busy I would not get time to read it and besides I had put my money into turkeys and had none to spare for a paper."

"Did you ever raise turkeys before?"

"Some little, but I never kept only two or three hens and a tom and they took care of themselves."

Dear reader, this woman failed and condemns turkey raising except for only those who are "lucky." There is 
no such thing as luck in the poultry business. It is all good common sense rightly applied, with labor, pluck and perseverance to help crown your efforts with success. The old adage, "Anything is easy if you know how," is a good one. However, you must remember there is no business that does not have its obstacles to be met.

I should advise any one who has not raised turkeys to get the cheaper grade of some thoroughbred variety you fancy, and learn with them. Then if you have losses it will noc hankrupt you, and when you have mastered the details necessary to raising these successfully you can invest in bilds of fine plumage and other fine points possessed by fancy fowls, to the extent of your much enlarged pursenever forgetting, however, that there is always something to bo learned.

For those who have had success in raising common turkeys and who wish to start with some special variety of thoroughbred turkeys, I should advise them to get a pair, trio or pen of the best your purse will afford and apply to them your knowledge of care and feeding gained while raising the common birds.

\section{BENEFIT TO GROWING CROPS.}

Turkeys by nature are prone to wander over the fields for a great share of their living, thereby gaining a healthy, robust constitution and at the same time ridding the fields and meadows of grass and weed seeds, grasshoppers and other insects that are harmful to growing crops. This certainly is converting evil into good. They will do this in the fall of the year when the corn is ripe and never disturb the ears of corn. Mine do, but I always feed my turkeys at home some.

My reason for selecting the Bronze variety was on account of their beautiful plumage, large size, hardy constitution and their ability to obtain a great share of their living by foraging.

The Bronze turkey is more generally bred than any other variety of turkey, but there are other beautiful and profitable varieties that are growing in popularity.

From those first seven pullets that I raised, mated with a tom not akin, I the next year raised 170-a number $I$ have never been able to quite reach since, because then I did not sell eggs. I closed out everything that year and bought fancy birds for the season's breeding stock. In no year have I fallen below the one hundred mark.

I have never had those heart-rending scenes of disaster, with losses and crosses in raising turkeys that some record they have had. For which success I am very, very thankful. I attribute it to a great extcnt, as $I$ said in the beginning of this chapter, to posting myself upon the raising and management as given in our poultry papers, and to one turkey book.

\section{ITEMS OF INTEREST.}

I find it no harder to raise a large flock than a small one. It means simply a little more setting of eggs, a little more feeding, all at the same time, and a little more dusting. When I raised the $170 \mathrm{I}$ had no better conveniences for raising them than a farmer's wife usually has who tries and raises hundreds of chickens, but I immediately set about having separate roosting coops, or houses, made from odds and ends that were otherwise going to waste on the farm and I succeeded wtih the assistance of a large dry goods box or two, and grandpa as carpenter. These coops I have used ever since and they are good for years of service yet.

I now keep my breeding pens of ten to fifteen females and one tom in yards inclosing from one and one-half to three acres of land, which is mostly covered with orchards. All that can be plowed of these pens is sown to rye every fall, though I am trying clover this year. I mark the breeding hens of one yard by clipping the right wing, and another yard by clipping the left wing, and the outside pen, which I train to nest in the barn, I leave unmarked on the wing. This is far preferable to the old method of allowing the stock to run at large. The turkeys do fully as well or better, more eggs are saved, besides a great deal of labor in hunting the eggs. There is one objection to clipping the wing, for me, and that is it gives the wolves a better chance at the turkeys when they are turned out of the pens. Dogs also are more liable to catch them.

\section{CARE OF SITTING HENS.}

1 set my hens in goods boxes turned side down out in the turkey pen, or bring the hen to a similar nest prepared in one of my adjoining poultry sheds, using oats straw or clover trash for nesting material, being careful that too much is not used to prevent the eggs from turning and that the nest is not too concave, causing the eggs to roll together and become broken. They have easy access to feed, water, grit, charcoal, lime and dusting box. I prefer for some reasons having each hen shut in her respective nest box and opening it regularly each day for her exit to feed, watching till she returns. If the nest boxes are always open, often two or more hens will return to one nest, breaking some eggs, perhaps, and leaving other eggs to chill. When set in the pen she needs attention, as the laying hen may disturb her and break the eggs.

My experience has taught me that my sitting and brooding hens should have some grain, especially the pullets, in order that they may develop into larger hen turkeys.

I have discarded the barrel for a sitting nest box unless it be a large barrel or a small turkey. Too many eggs are broken or shuffled out of the barrel.

CARING FOR THE YOUNG.

It would not be a turkey article if I did not say dust your mother turkey while sitting two or three times with some good insect powder, and the little poults at least every two weeks, oftener if by examination you see it is necessary. You will find the lice on the wing quills, around the vent and on the head and throat.

I feed the little ones stale light bread softened with water or sweet milk and squeezed dry, alternating with hard boiled eggs and clabber cheese after they are a few days old, and $I$ always put in fine chick grit till they are ten days or two weeks old, old enough to pick grit from the box themselves. I give a little pepper once or twice a day with the food, occasionally onion or garlic tops, and lettuce if I have it. They greatly enjoy picking the lettuce heads tied to something in their little pen or run. I feed five times per day, just what they will ciean up, gradually diminishing to three meais per day, and by the time they are three weeks old I begin giving them cracked Kaffir corn, wheat or other small grain, adding cracked corn later, and whole Kaffir corn. When old enough to go to the range for the day I feed but twice-an exclusively grain ration at night.

I do not feed what I call the "baby turkey feed" so long as I did a few years ago. I begin the grain earlier and find they develop just as rapidly and with less expense and trouble to me. Keep them growing, not fat, the first year of their lives and the weight will be all right. Heavy feeding to fatten for heavy weights when the birds are six to eight or nine months old is detrimental to having a large turkey when older. As a rule, those heavily fatted toms and pullets that were stuffed to meet the demands of the show room and the trade for thirty-two and thirty-three pound toms in early spring never develop into as large birds as those that were simply kept growing during this period. If one is raising for market then begin to feed for fattening as soon as the range runs low in september and October and keep it up till they go to market. MRS. F. A. HARGRAVE, Secretary-Treasurer of the Western Turkey Club. 


\title{
CARE AND MANAGEMENT OF TURKEYS.
}

\author{
RalsIng Bronze Turkeys in Canada-Best Soll for Turkeys-Inbreeding and LIne Breeding-Shape, Color, MarkIngs- \\ Roosting Houses Used with Success-Young Hens as Breeders-Setting the Hen-Care of \\ the Young-Diseases-Catchlng and Welghlng-Selling Stock.
}

\author{
By w. J. Bell.
}

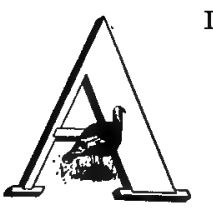

LTHOUGH I am aware that turkeys are raised successfuily on all kinds of soils and in nearly all locations, I believe that sandy land or clay with an abundance of gravel is a better place than heavy clay soil, especially if the latter is not well drained. On two of my turkey farms the goil is gravelly clay and there is running water all days of the year and from those farms have come my largest turkeys.

When I moved to my present farm in 1893, which has no sand or gravel in its composition, I noticed the poults a day or two after they were moved out on the ground from the nest commenced to look sickly. I could not imagine what was the matter, as they were free from lice and their treatment was the same as previously given on the home farm. In watching them going around I noticed they were picking at small substances. I inmediately procured some fine gravel for them, and an improvement was noticeableinabout a day's time. This shows what is gained by close observation and also that the dying of poults is causednot by the food given, which is usually the cause assigned -but through overlooking what may seem unimportant matters. I consider a fiftyacre range necessary for even a small flock.

BREEDING SHOW STOCK.

Some writers say that to mate Bronze turkeys you have only to "discard all specimens disqualified by the standard." After thirteen years spent in breeding these birds I must say I disagree with them, for I have found the selection of the Iargest specimens and inbreeding them to certain extent will increase the size instead of decreasing it, but when carried too far inbreeding will impair the vitality and produce deformities. Therefore, to properly mate these birds is, I claim, as much of a problem as mating any of the standard. breeds of fowl. I wish the reader to remember that I am referring to the production of Bronze turkeys for breeding and show purposes.

In regard to the shape of the male I like one that stands well up. By this I mean one that carries his breast high, the same to be moderately full and well rounded. I have no ise for the bird that carries his breast and body in a straight line parallel with the ground. Fig. 1 is my idea of a good shaped bird, either for the breeding yard or show room, except that the fcathers on the rear part of the back were raised a little when the photograph was taken. Select a bird with good, heavy bones, and see that the toes are straight.

\section{COLOR.}

When you examine the different birds in the show room you will find on breast and neck almost as many shades as birds. There is the green bronze, the black bronze, a dull brown bronze and a yellow bronze. The latter is my preference, and what I think is called for in the standard, although plenty of judges favor the black bronze color. The body and back will be darker, with bronze reflections. The logs should be pink.

In the wings and tail are where the faults appear. Spread the wing and look for solid black feathers in the primaries, irregular barring in both primaries and secondaries and also a white edge along the bottom of each feather in the latter. They are bad faults. Fig. 2 is a good wing. The tail, which includes tail coverts, is seldom perfect; in fact, I have never seen one. The black bars near the end of the tail coverts (I mean the row of feathers lying farthest out of the tail proper) are generally missing, and two center feathers of the tail proper always have the the brown barring more or less mixed. I have noticed the latter peculiarity in the wild partridge. Spread the tail coverts apart and look at the bottom of the tail proper and in a great many cases you will find white barring the same as on the wing. This is another serious fault. Some breeders are satisfied with a tail which is all speckled with black and brown so long as it has the black band near the tip and a white tip. Now I am satisfied that a feather regularly barred with brown and black, with the broad black band and dull white or gray tip, is the proper color. Fig. 3 is as good in color of tail as I have seen. 


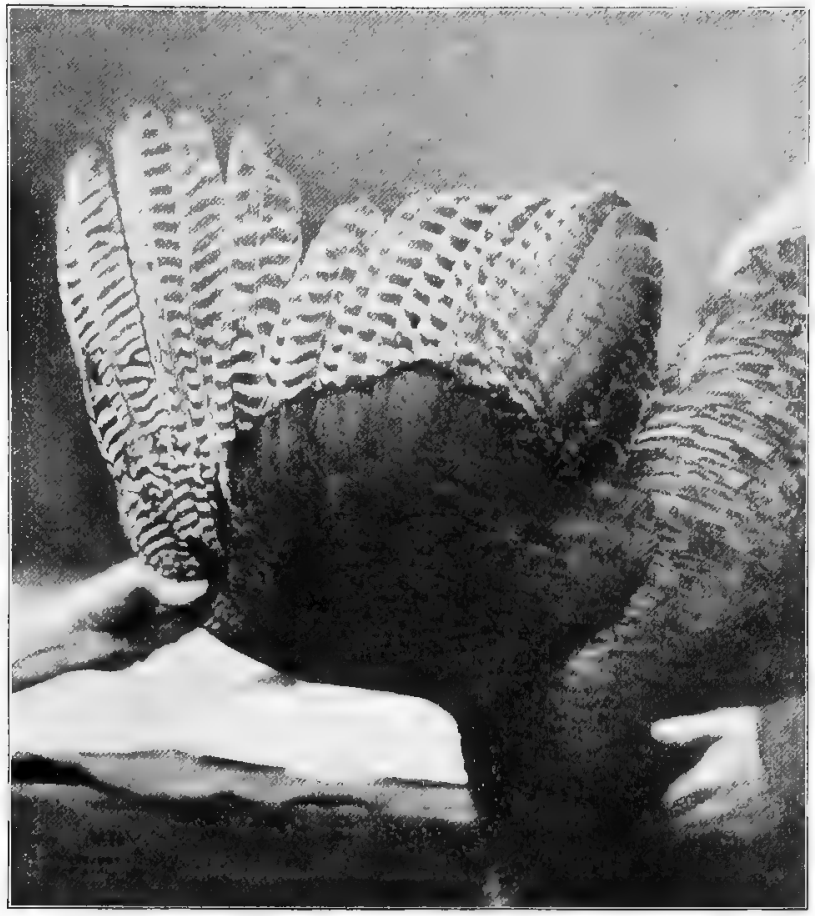

Fig. 2-A Good Wing.

Bred and Owned by Mr. W. J. Bell.

I do not refer to all the shape or color sections, but only to those which are usually faulty or in dispute. The above will give you my idea of a good male to head a pen, except or one point, and that one in my estimation is the most important, viz., you should insist on having a line-bred bird. If you use a bird produced from two strains entirely different in build and in a great many sections in color as well, what can you expect? My advice is to have a good male sired by good males of one iine of breeding.

What I have said in regard to shape of male will apply to the females also. The standard says of the female: "The entire plumage is similar to that of the male, but the colors are not so brilliant or clearly defined, and the edging of the feathers aull white or gray." Now some breeders say that hells should have a gray edge to breast and back feathers, and I must admit that the gireat majority of hens are marked that way; still the meaning I take from the "color of the female" section in the standard is that they should have the same color as the male, and I claim that the females in all our shows are scored too high. It is not impossible to produce them, for I have produced quite a $f \in W$ and find a great demand for them.

Young hens in my experience have proved the most satisfactory breeders. The old hens in a great many cases (and young hens sometimes) will lay soft shelled and misformed eggs in spite of all I can ỏo. I have starved them; have had an abundance of old mortar and lime before them; have given them free range and everything I could think of, but I cannot stop them entirely. I consider it the only fault the Bronze turkeys have. Usually I mate seven or eight hens with one male, but I think more than that number would still give satisfactory results. Any shed or building not too warm will do for a roosting place for breeding stock. They should be giver free range during the daytime in all weather. I would advise feeding the male pretty well, but the hens only lightly.

\section{SETTING THE HEN.}

At this stage it is a good plan to have nests prepared, as I have noticed hens looking up nests a month in advance of laying. Have them roomy, so the hen can turn and come off without breaking the eggs, and place them in all the corners and secluded places that you can find. By doing this early I save myself the trouble to a great extent of hunting the turkey nests. It is a good plan to watch which hen lays in a cortain nest, and mark the eggs as you gather them, placing them in bran in a cool room until the turkey wants to set. Then dust the nest well with insect powder and wive them to her-about seventeen eggs if she lays that many. Some advocate placing the first laying under domestic hens and forcing the turkey to lay a second lot, but here in northern Ontario the late Juiy hatches are seldom a success. About two days before the eggs are due to hatch dust the hen and nest well with insect powder. I consider this one of the most important things to do, as a young turkey cannot stand a dose of lice the first thing.

\section{CARE OF THE YOUNG.}

When you bring the young from the nest mark them on the web of the foot with a small poultry punch. If marked when about twenty-four hours old they seldom bleed and the hole never grows together. By doing this and keeping the hens' eggs separate you can ascertain which hen is producing the best birds. I now come to a period in which my treatment of turkeys radically differs from other successful breeder's, but I have had very few casualties under this system and so I intend to continue following it, and, further, I can raise them by this system just as easily as chickens. About twelve hours after the last poult is hatched I take them to a larger box-turkey and all. I feed them bread soaked in milk. They will not eat much at first, but by sticking a little of it around the sides of the box and working it on your hand among them, they get started. I keep them in this box from one to two days, depending on the weather, and get them taught to eat off my hand. Then I change them to an Asnaped coop with no bottom, and a lath front, and gradually I substitute shorts for the bread in their food.

I feed them their shorts entirely out of my hands until they are sold. I am very often told by my customers that they are surprised at the tameness of my turkeys. Another

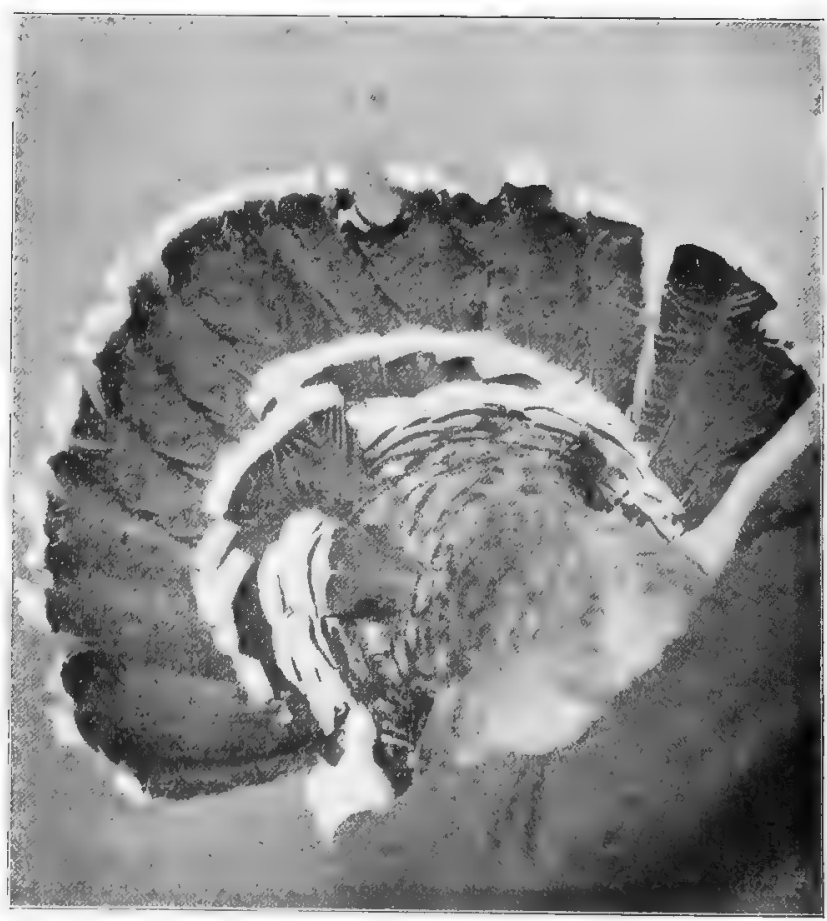

Fig. 3-A Fair Tall.

lised and Owned ly Mr. W. J. Rell. 
advantage gained by feeding out of your hand is that there is no food left on the grouna to sour-a frultful source of bowel trouble.

Up till five weeks of age I feed five times per day and cut dandelion leaves fine and mix with the shorts nearly every meal. I occasionally cut onion tops instead of the dandelions. Give plenty of milk-any kind-to drink, and keer fresh water before them all the time. Something which should never be neglected is to move the coop the breadth of itself every day. In mixing the shorts it is important to have them quite damp, but not sticky. There is one fine grade of shorts it is impossible to mix properly. I am aware some claim that feeding five times per day will kill the

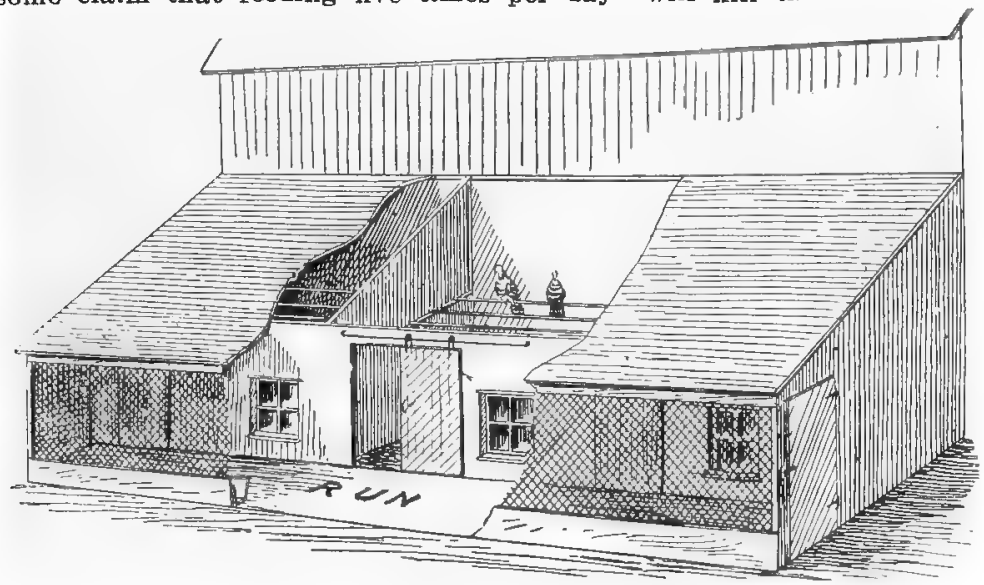

Fig. 4-W J. Bell's Turkey House.

With roof cut away to show Interior Arrangement.

poults, but they surely have not tried feeding shorts and milk. Shorts digest very fast and I believe is a preventive of bowel trouble. At any rate $I$ have found it a very slowkilling process.

At about five weeks old I give the hen her liberty and let them have free range of the farm and roost on the fences or buildings until fall. I only feed twice per day during the summer-shorts mixed with milk in the morning and clean wheat at night. If grasshoppers are plentiful they will ofttimes refuse the wheat, but with me they never refuse the shorts.

\section{HOUSING.}

When I first started I found great difficulty in getting them to roost in a shed at night during winter. I would spend over an hour keeping them from going on the fences and buildings, so $I$ thought of a plan which has worked satisfactorily ever since. I built a lean-to on the south side of my farm barn. Twelve feet from the barn and parallel thereto four posts were placed twelve feet apart and seven feet above ground. On these were placed a four by four-inch scantling. Then to the side of the barn, twelve feet from the ground, another scantling was spiked, and on these were placed the rafters. The two ends were then boarded up close and also the front, except what was required for doors and windows.

Now the rafters were not cut off close to the building, but extended over about four feet. Straight under the points of rafters I placed four short posts twelve feet apart and two feet above ground and boarded this two feet up solid. From these boards to the point of rafters was strung poultry netting. One and a half feet from the ground and against the two-foot boarding was nailed a V-shaped trough the entire length, thirty-six feet, and a door placed on the end of this "run." The inside or house proper can be divided into two or three compartments as required, with roosts, and a large sliding door and a window for each compartment. I adro- cate placing the roosts on a level and about four feet from the ground. All I have to do now is to place food in the truugh, drive the turkeys into the "run," leave the sliding doors open and they have plenty of light to see their food and are compelled to roost inside. Then, again, if the weather is warm the windows can be raised and the sliding doors left open all night, and if cold all can be closed. Figs. 4 and 5 will give an idea of this building. Of course the rafters are boarded over and shingled.

\section{DISEASES.}

I shall touch very lightly on this part of the subject. I have had very few turkeys die from disease. At one time I housed them in a building much too small, and they contracted roup. I tried doctoring, but found it was not a success, and now use all my energies in preventing disease. I firmly believe if you let your birds have free range in daytime, feed at regular intervals and keep them free from lice you will have no more trouble than in raising any other line of live stock. My greatest troubles have been soft shelled eggs and fcxes.

\section{CATCHING AND WEIGHING.}

While our Provincial show was judged by score card and all birds were weighed, I was generally asked by competitors to catch their turkeys and place them on the scales, as I could handle the birds more easily than any other. In catching a turkey, if on the ground, I stand on left side, place my right arm over its back and grab both legs. Lift by placing left hand under the breast. It may try to break loose for a second or two, but hold steady, and it will give up. If the bird is on a perch, grab by both legs from behind-right hand for right leg and left hand for left leg-and draw quickly from the purch so its breast or wings will not strike it; then hold steadily while it flaps, afterwards it will remain quiet if held by the legs. In placing on the scales hold its feet toward you with the right hand and breast with the left. Lay it on its right side and pull its right wing down towards its breast as much as possible when withdrawing your left hand. Make your movements gradual and quiet and you will have very little trouble. It is alnost impossible to get their weight while standing on their feet. In weighing as above if small counter scales are used it is advisable to place a box of the same size as the scales and about one foot high under tine scales, as the head and tail of the turkeys will droop a little on each side and having the box under the scales prevents them touching the floor.

\section{SELLING STOCK.}

It would require a whole book to treat this subject properly, as it includes advertising and making coops. I think the best advice I can

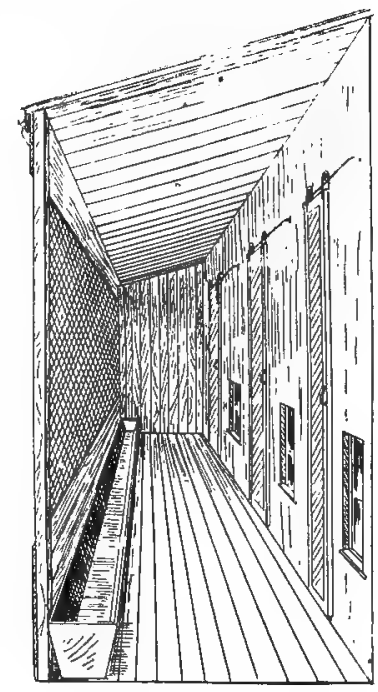

Fig. 5.

Runway in Turkey House. Showing Feeding Trough and
Wire Netting. give is to be perfectly honest and truthful. I have found more persons lie about the weights of their turkeys than about any other one thing in this world. I have bought turkeys at different times to be a certain weight and in almost 
every case have found them from five to ten pounds short. I am aware that turkeys will lose about two pounds in transit, no matter how short the distance, but seldom more. Then again you will notice prominent breeders using cuts that have been in existence for years as if said cuts were from photographs of their stock. A case of his kind which amused me and caused me not to trust a leading breeder with my order was to find a cut on his envelope and underneath labeled "S-3rd, 1st prize cockerel at C-_-, 1899," and right in front of the cut in small type was "F. L. Sewell, 1887," which showed that the cut was made before the bird it was supposed to represent was hatched.

In regard to advertising, I would say try small ads in different papers and then increase the space in those papers which give best results. Do rot try to make people believe you have the only good ones on earth, but state just what you have done in the show room and what you have to offer. Showing comes under the head of advertising, and I find it must be done or we drop out. I would say exhibit at the largest shows, as it is not the amount of money you can "clear" at the show, but the amount of reputation for good stock that you can gain. Answer all correspondence promptly and be carefui to answer all questions asked as far as it lies in your power. Upon receipt of an order acknowledge by first mail, stating what day you will ship.

For shipping coops I use dry basswood. Take four pieces one and one-half by one and one-half inches and thirty inches long for corner posts. Nail two pieces three inches wide, two feet long and one-half inch thick on each end, and two pieces three inches wide, three feet long and one-half inch thick on each side. This will give you a light square frame. Nail on a bottom of one-half-inch basswood and two pieces three inches wide, one-half-inch thick on top. Tack factory cotton all around the coop and after the cotton is on nail lath about four inches apart around the coop. This makes a light, strong coop in which to ship a pair of young turkeys.

For old birds it would have to be larger in every way, and for a single bird it could be narrower. I generally try to ship by night trains, as the birds are quieter at night and do not abuse themselves so much by breaking their feathers and bruising their flesh.

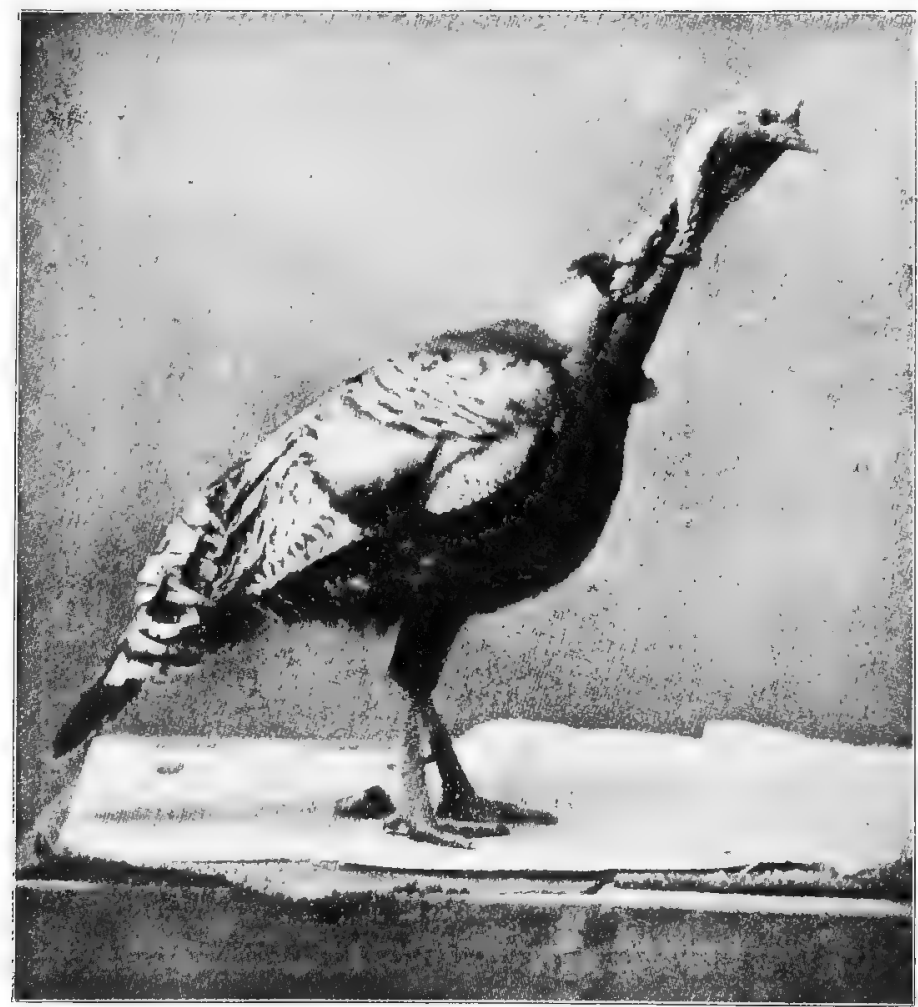

Flo. 6-Sweepstakes Bronze Turkey at Ontario Provinclal Show, Guelph, 1900. Bred and Exhlb/ted by W. J. Bell. 


\title{
POINTS ON TURKEY BREEDING.
}

\author{
Loss of Vitallty in Turkeys and Lack of Fertllity In Eggs-Injured Females-Food for the Young-Danger from Lice \\ The/r Causes-Care of the Layers and Silters-Indlgestion and Diarrhoea-Preparatlon for Market- \\ The Poults-Feeding the Breeding Stock-Advantages of Roostling Outslde.
}

\author{
By J. F. Crangle.
}

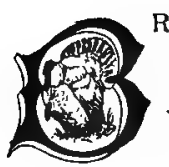

RONZE turkeys are more raised than any other variety, for several reasons. First, they are the largest; second, they are hardy and well adapted to this climate; third, they are good layers and the best of mothers; fourth, they are most satisfactory for marketing, being full-breasted and possessing the desired color of flesh. They will lay eighteen to forty eggs a season under proper care.

Generally it is considered that one male will mate with six to ten females. I have used one male for twenty-five hens, but I do not think it well to risk using only one male with your entire flock (especially if you have more than eight or ten females) for the following reason: A female usually allows the male to tread once. If from any cause the male did not effect proper connection, the eggs would not be fertile and the best part of the season would be lost because the first litter is considered the best.

The hen after connection selects a spot for her nest and a few days after it is made. This is usually done by scratching up the earth so as to make a hollow place to keep the eggs from rolling out. A great deal of the risk of males not fertilizing the eggs could be avoided in the following way: Use two toms alternately every day, but under no consideration allow both toms to run with the females at the same time. If you do you will, as a rule, have bad luck, as the males will fight and at times hurt themselves, also the females.

The lack of fertility in eggs and vigor in young poults is one of the main reasons for the decline in turkey breeding in the eastern states, and perhaps all over the United States. In many of the eastern states, where a few years ago hundreds of tons of turkeys were raised, they now have to import, mostly from western states, to meet the demand, as it seems almost impossible to raise them. I think the main cause is in-breeding. There are many farmers who in the past have not thought it necessary to obtain new blood, and who thought they could save a few dollars by borrowing a tom from a neighbor, in this way using the same blood year after year. This has been done for so many years that the vitality has been about bred out. For the past few years turkey breeders no doubt have seen their folly, because many of them are now looking months ahead for a good male. The vitality had gotten so low that it created disease, and I am sure that many of the turkey diseases with which we have to contend have been caused by lowering the vitality of the turkey. I believe there is no other variety of birds in which the vital forces decrease so rapidly by in-breeding as in the turkey.

I think it possible under proper management to raise turkeys in every state in the Union, and I believe if farmers in general will be more careful about in-breeding and will see that they have the proper kind of males to breed from, such as will introduce new, strong, hardy blood into their stock, they will be able to raise turkeys as they have in years gone by. To people who are having trouble in raising turkeys I advise using a half wild male if they have large range. It is almost impossible to get a pure wild tom in this country, although you may happen to mun on one by accident. About all the people who claim to have wild turkeys have nothing but half-breeds, yet with a half wild tom you can get enough new blood to make the offspring very much stronger, and this will be noticeable the first season.

\section{THE LAYING AND HATCHING SEASON.}

After the turkey commences to lay, in many sections of the country, the nights are cold and in many places the thermometer goes down to the freezing point. When hens are laying and you are afraid of frost, the eggs should be gathered every evening and marked with the date. Then they should be placed in a pan or basket in common wheat bran with the big end of the eggs down, as by so doing you will keep the air cell in good condition. Put them in a cellar or any cool place and turn them every day. It is not best to turn them completely over; turn them only part way over each day. It is safe to keep them ten or twelve days, but I would not advise keeping them any longer than possible, as they are liable to get stale, in which case not so many of them would hatch. When the eggs are removed from the nest a glass egg should aiways be put in. If you do not put glass or wooden eggs in the nest the hen will probably leave her nest and lay elsewhere.

A good mother will cover her eggs when she leaves her nest; usually this is done with dry grass or leaves, so that in looking for a turkey nest it is always necessary to be careful, as otherwise one might step on it. An ordinary hen will cover eighteen eggs. If she lays more than that number, take the extra ones and put them under a common hen, setting this hen and the turkey at the same time. If you have a gond hatch and get out more than eighteen, leave a few of the poults with the common hen. The turkey hen can brood eighteen poults with safety. Above all things. see that there are no lice on the hen when she hatches, as the poults are very tender when hatched and if the hen has lice the poults will have them on their bodies within a few hours. When you transfer poults from common hens to turkey hens dust them well with a good powder, as you want to be sure there are no lice on them.

It takes twenty-eight to twenty-nine days to hatch turkey eggs. If tine turkey does not leave her nest at that time do not disturb her for at least twenty-four hours, because oftentimes a few of the eggs are slow in hatching and she stays on the nest several hours after they are hatched for the poults to gain strength. It is always well to take a piece of stale bread moistened with milk and put it near the nest, near enough for the turkey hen to reach it. If the poults are hungry, they will also eat. This food is very important because if the hen is hungry she may leave her nest 
beiore she should, looking for food. We must remember she leaves her nest only three or four times in twenty-eight days. If she does not appear inclined to move to get the food, do not disturb her, as it is a very easy matter to find out whether she has hatched any young, for as a rule, broken egg shells will be seen near the nest. At the expiration of thirty days, if you see no signs of the young turkeys, it will be well to investigate the matter by raising the turikey of the nest and ascertaining whether the eggs are fertile or not. If they should prove to be infertile, shut up the female for four or five days in a coop large enough for her to get a little exercise. Give her food and water and a place to dust herself and in three or four weeks she will lay again.

One of the best places in which to let the hen turkey run with poults is a field where the grass is short. As a rule, a pasture is very good; woodland is also suitable. Keep them out of long grass and grain fields when there is a heary dew or it is rainy, until after the grain and hay are harvested, because the wet vegetation is bad for the young poults. It chills and sets them back in their growth and often is iatal. You will always find the largest and finest turkeys where they bave free range. As a rule, turkeys will wander some distance from home during the day, but will come back to their home every night. Under proper management you can place turkeys anywhere you wish on the farm, and by teaching them to roost in one particular place, they will come to regard this as their home, and will know no other; you will always find them wherever they have been laught to roost. This can be done by watching them a few nights in succession and driving them to the place where you wish them to stay. Just before dark they will go up in the trees or on a roost that has been put up for them. With the right kind of breeding stock turkeys at Thanksgiving time should weigh about as follows: Toms, sixteen to twenty pounds; hens, twelve to follteen pounds. I have dressed at six months old, turkeys weighing twenty-four pounds, bit they are rare.

\section{FEEDING THE BREEDING STOCK.}

'There are two things which have to be done in order to have success in breeding. One of them is to get the right kind of breeding stock, and the other is to feed them properly. These are the two main things. The proper way to feed breerling stock is to be careful not to overfeed them. After your breeders are selected, feed almost entirely on oats (scalded). I find they lo better on oats than on any other food. For a change, feed whole corn about twice per week, and at no time feed more than they will eat clean. Where turkeys have a barnyard to scratch in, you will have to be careful not to get them over-fat, and as a rule, it is only necessary to feed them at night. A good accompaniment to the food for turkeys is charcoal ground coarse. Put it in a box where they can find it. They also need shellsoyster shells are the best. On a farm they can ordinarily find all the grit that it is necessary for them to have. If the hen turkey has not enough lime to properly supply the egg shell, it will be porous. I have known many germs to die on this account.

\section{DISEASES AND INJURED STOCK.}

Under no consideration breed from a diseased turkey. It is much safer to kill a sick turkey than to let her among your flock of heaithy birds.

When the males mate with the females and they are extra heavy and clumsy, it is well to see that the male does not tear the female or hurt her back. A very good way to prevent this is to file down the toe nails of the male. I have seen them many times silp off of the female and rip open the hips or side. It is very easy to discover an injured female by her actions, more especially the next day, as she will be lame and her wings will droop. It is best to catch her at once and examine the wound, as generally they can be saved by sewing up the tear. This is not a very difficult matter. Let one person hold the turkey and another do the sewing. Pull all the feathers from the edges of the wound, and with warm water moisten them so they will stay back while you are putting in the stitches. Before sewing, the wound should be washed thoroughly with castile soap, using a small, soft sponge; then take a long, fine needle and with white silk thread draw the edges of the skin around the wound so that the parts meet as they were. Commence at one end of the wound and gradually draw the edges of the skin together over the wound as you stitch, until the tear is all closed up. Many times $I$ have taken as many as fifty stitches in one wound. Bathe the wound with witch hazel every day for four or five days. It is well to keep the hen in a small pen or coop for three or four days where there is quiet. and where you can catch her without running. If you gave her free range she might tear out the stitches. The period of confinement depends entirely on the size and nature of the wound, but as a rule, after three or four days she can be liberated with the rest of the flock.

\section{FOOD FOR YOUNG TURKEYS.}

As a rule, many young turkeys are killed by over-feeding. On large farms where the hen turkey and her poults have plenty of range, it is best to feed them only twice each day, once in the morning and again at night. Young turkeys can live on insects and many little grasses which they relish. You will always find that food they get in the fields will keep them in better condition than anything you can give them. During the berry season, especially when wild strawberries are ripe, it is a pleasure to watch the little turkeys pick and eat them. In seasons when there is a good supply of grasshoppers, the turkeys will live almost entirely on them.

When young turkeys have to be fed the best food I know of is stale bread, but be sure the bread is not sour. By stale breal I mean wheat bread three to ten days old. Moisten the bread with sweet milk, but do not get it too moist. I usually press out all the milk that I can with my hands. Clabbered milk is also good for young turkeys. Put it in a dish on the ground where they can get at it easily. During the warmest weather of summer it is best to keep all turkeys, young or old, on the hungry side, for if you do not, there is great danger of their having bowel trouble.

I have tuld you how to care for turkeys on a large range. If you are on a limited ragne, or for any reason you have to keep your birds confined, I mean young poults, take three boards twelve or fourteen inches wide and ten or twelve feet long and make a triangular pen. In this pen put the old turkey and her poults. Do not confine the hen. She will jump out and in over the boards and will not leave her poults. It is best to leave the poults in this pen for fifteen to eighteen days, and then let them range with their mother. Many persons think it is necessary to put the hen turkey in a coop to keep her near her young, but this is not the case, as the mother will stay with the poults; you could hardly drive her away. When the young poults are confined in a pen as above described, it is necessary while so young to feed them four times a day with stale bread moistened with milk. If the weather is rainy and wet, it is sometimes well to use red pepper enough to make the bread quite warm. If any of your poults are drooping it will tone them up. Clabbered milk is aiso good for them. Should you find that the young turkeys are drooping and do not seem to pick up, the very first thing to look for is lice. If your poult have lice or ticks they will not do well, and it is almost impos- 
sible to raise them. You will find at times a large blue tick on turkeys and turkey poults; they are on the neck and head only. If you should find any ticks on your poults, pick them off, then use clear lard on the head and neck. It will kill the nits that would hatch if you did not use some preventive. For the two other varieties of lice, use any good insect powder, but always be careful that none gets in their eyes. Hen turkeys generally keep free from lice if they can find any place to dust themselves, but some are very lazy and if these hens have poults they will be sure to be infested with lice, too. In looking for lice it is best to examine the little wings, as generally you will find them at the base of quills, also around vent. For the terrible ticks, which are almost sure death, look upon the neck, push back the feathers carefully until you reach the top of the head. You can easily see them, as they are good sized, and the older ones are dark blue in color, usually full of blood. If you keep your poults free from lice you will have overcome almost all danger of loss.

Stale bread moistened in milk should be fed to the poults for three or four weeks, then gradually get them to eat wheat and fine cracked corn. This grain should be scalded, as it will then assist digestion, but do not feed it until it has thoroughly cooled. Indigestion is very prevar lent among turkeys, both young and full grown.

If your poults should have diarrhoea from any cause, one feed of boiled rice will usually stop the trouble. Another common but sure relief is to give them red pepper, say one tablespoonful. Mix it with about two tablespoonfuls of wheat middlings, then moisten it with water, but do not wet it enough to make it sticky. Cut it up in abont four to six parts and roll the parts into pill shape, put them in an oven and bake them hard. It is well to have a few always on hand, as after baking they will keep for a long time in a dry place. If I have a turkey, either old or young, with a bad case of diarrhoea, I give one pill three times a day until the droppings are improved. Then give a tablespoonful of castor oil if the turkey is full grown, or a teaspoonful to a young poult. It is very seldom that I cannot stop a case of diarrhoea with this treatment.

\section{FALL FEEDING.}

I commence to feea all turkeys the first of October to get them rtady for Thanksgiving, as we all know there is more demand for turkeys at that time than at any other. They should be fed morning and night, but never more than they will eat within a few minutes. Most of the trouble we have in the fall is caused by overfeeding. At the time you commence to feed for fattening use common sense and feed lightly for the first ten days, gradually increasing the fond. The principal food from October to January first should be corn, not cracked, and the older the corn the better, as new corn will cause bowel trouble. I have seen large flocks of turkeys knocked out by feeding new corn. If you get their bowels out of order, it takes weeks to get them in good condition again. As a rule, most of your turkeys will be fat and in good condition to dress at Thanksgiving. There may be a few late hatched broods that will be improved if carried over to Christmas.

Many people adrocate putting turkeys in a closed pen to fatten. I have given this method a good trial many times and under all conditions and find it a failure. Let them have all the range they want. The results will be better and you will avoid the sickness they will have if you confine them. Many persons do not understand why their turkeys are not so fat as they should be, but almost invariably you will find that they have fed them in confinement and the turkeys could not stand it, especially for a period of several weeks. They get off their feed and will not eat. In the fall when the weather is cold, turkeys will not range far from the farm buildings. They will eat their morning food, then roam around after a little grit to help them digest it and then lie down in a warm place out of the wind. Drive all the turkeys you wish to kill in a barn or shed so as to confine them twenty-four hours before killing with no food of any kind. To look well when dressed, their crops must be entirely free from food.

\section{THE BEST ROOSTING PLACE FOR TURKEYS.}

Many persons who keep turkeys think they need shelter in the way of a building. That idea is entirely wrong. The best possible way of keeping turkeys in good health is to have them roost away from buildings, in trees if you have them. By roosting in trees they will not be in draughts, as they would be if allowed to roost in sheds or buildings. I have known turkeys to roost in trees with the thermometer fifteen to twenty degrees below zero, and be much healthier than turkeys that were inside a building. A turkey can stand any weather we have in the United States if they are roosting in trees that are partly sheltered from the wind. I have seen turkeys in trees during a snow and rain storm with the wind blowing sixty miles an hour, and they did not appear to mind it in the least.

A great improvement has been made in the size of turkeys, especially Brouze, in the past twenty years. The ordinary turkey of some years ago, as bred by the average farmer, would weigh about as follows: Toms, twenty pounds; hens, eight to ten pounds. To-day Bronze turkeys will weigh: Toms, thirty-five to forty-two pounds; hens, eighteen to twenty-five pounds. This shows what proper mating will do.
J. F. CRANGLE. 


\title{
IN NATURE'S WAY.
}

\author{
Selecting Breeders-Introduclng New Blood-RaisIng Breeders-Avoid CrossIng, but Judlclously Inbreed-Poults \\ In Nature's Way-Range Food-Housing-Difficult Sectlons to Breed Correctly.
}

By B. F. Ulrey, Treasurer National Bronze Turkey Club.

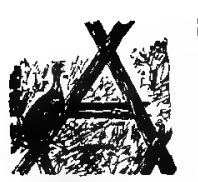

S I BREED only the Bronze variety of turkeys, and a limited number of them for exhibition and breeding purposes, and as I have had no experience with any other variety and never sell on the market, except the culls of my llock, I cannot give you much information on raising turkeys for market. However, if I were to breed turkeys for market purposes, I should employ the same methods as I do in breeding exhibition fowls, except that I should not discard a good bird if it were faulty in color. Most farmers, I notice, sell all of the early hatched turkeys on the market because tliey will bring more money and they retain the late hatched and immature poults for breeding purposes. The consequence is, they do not raise many next season, because the breeding stock has no vigor and the poults no strength when hatched.

I have bred Bronze turkeys for ten years and my method of raising them is entirely diflerent from that employed ly anyone with whom I have talked, or from the methods of poultry writers which I find printed in the poultry journals from time to time. In the first place, I keep about fifteen females in each tock, seven hens and eight pullets, headed by an adult tom, assisted by a cockerel, and I always have fertile eggs.

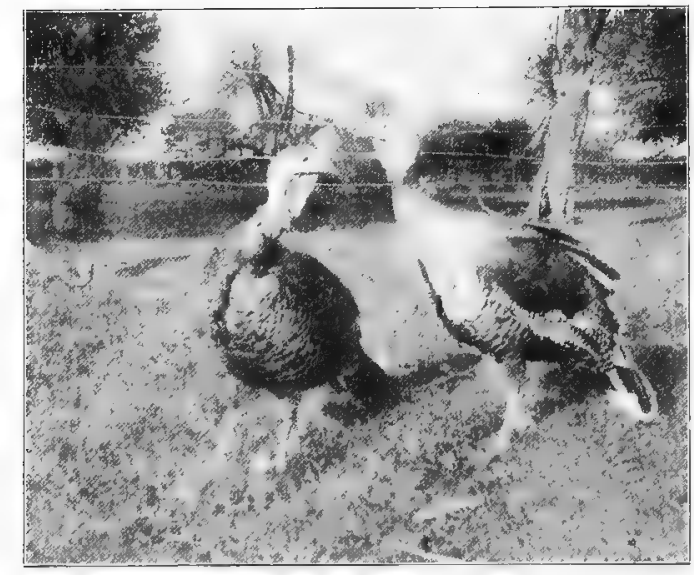

Two Winning Hens, the Property of B. F. Ulrey.

Indiana Queen (at 1eft), score 97\%; Pride of Shawnee (at right), weight at ten months old, $23 \frac{1}{2}$ pounds.

flock. Save her eggs and mark her poults, and if they prove good, you can use them successfully. On the other hand, if you buy a tom of another strain (the male counts more than half of the flock) to mate with your hens, and such mating results in poor birds, you have lost the season. I often see advertisements in poultry journals in which breeders offer stock for sale produced from twenty-seven to thirty-one-pound hens and forty to forty-seven-pound toms. Such claims are intended to catch amateurs, for any breeder of experience knows that a hen that weighs twenty-seven pounds never lays fertile eggs, and a tom that weighs forty-seven pounds never fertliizes an egg.

\section{HATCHING AND RAISING POULTS.}

I allow the hens to have their own way about their nests, although I place barrels on their sides along hedges and in secluded places in the orchard and fence corners, in each putting a small quantity of straw. The hens generally nest in the barrels and I remove the eggs every day until the hen is ready to set. I then give her seventeen eggs and at the same time put ten eggs under a domestic hen to hatch. All the poults are given to the turkey hen to raise, as $I$ find that a turkey knows more about taking care of poults than I do. I give her a good feed of corn and a drink of water The Bronze turkey commences about ten months old and she

to lay when she is will lay from twenty offers to set, tien if confined for about a week or ten days she will commence to lay again and will lay from twelve to sixteen more eggs before she becomes broodiy. Most hens lay two clutches in a season, though I have known some hens to lay all summer, and $I$ have one hen that laid ninety-seven eggs from April first to September tenth. In selecting my breeding stock I take frmales as near standard weight and color as possible, having large frames and bones and such as are not too fat. These are mated with toms that are a little above standard weight, thr cockerel weighing from twenty-eight to thirty pounds at ten months old, the yearling cocks from thirtyfive to thirty-seven pounds, the adult from thirtyeight to forty-two pounds. I am particular to have males of the best color and shape that I can get. I find that the female gives us size, while the male governs the plumage. In changing males and breeding for exhibition purposes, I always try to get a tom that is extra fine in the sections in whick my p'males are defective. The best way to introduce new blood is to rurchase a female from some successful breeder and mate her with the tom that heads your own and then let her go where she likes. If there is a meacow or pasture within three-quarters of a mile, that is where she will go. I have one hen that hatched sixteen poults and I gave her nine more hatched by a domestic hen and she raised tweniy-two of them. I have never seen a fence that will confine turkeys unless one wing is clipped, then a four-foot netting with a barbed wire above will keep them confined, but I do not wish to confine my turkeys except occasionally for a short time. Once in a while I have a hon that wanders too far from home to build her nest. I have an orchard covering about two acres which is in('losed with netting and barbed wire and in which I keep my silver Lared Wyandottes during the breeding season. I bring the wandering turkey home, clip her wing and put her in the pen described until she lays out her clutch. If a hen and her brood get to running away and going to the neighbors', I put them in the chicken yard for about ten days, after which I have no further trouble with them. I look after the hens with poults on bad days when I cannot work in the fields. If 1 find any weak poults I examine them for lice, and if I find any lice I give the poults a good dusting with insect powder. If the weather is dry, the poults find enough dust in which to wallow to keep down the lice, but 
If it is wet weather you must look out for lice. I am satisfied that nine-tenths of the poults that die are fed to death or are killed by lice.

\section{RANGE-FOOD-HOUSING.}

I give my turkeys unlimited range and feed nothing until July 15th, then I drive them home every night and give tbem a little corn. In about a week they will come home at night for food and to roost and I have no further trouble with them until I am ready to sell or show. Some writers claim that wet weather and heavy dews are fatal to poults. If such were the case I should not have a poult to-day, as the past season was the wettest we have had in several years. Still I have more poults now than I ever raised before range, as they must have exercise and a variety of food, which they cannot obtain except on an extensive range. If you will examine the crop of a poult after september first that has had plenty of range, you will find grasshoppers, bugs and worms, together with several varieties of weed and grass seeds, but very little grain. Some persons claim that a turkey will eat more than a hog. I had a chance to test the matter iast winter when I had sixty-five turkeys on hand and there came a severe snow storm which prevented the flock from getting anything to eat except what I fed them. The sixty-five did not eat a half bushel of corn a day during the week I fed them.

Never discard a good bird because it is getting old. I have known hens to be first-class breeders when seven years

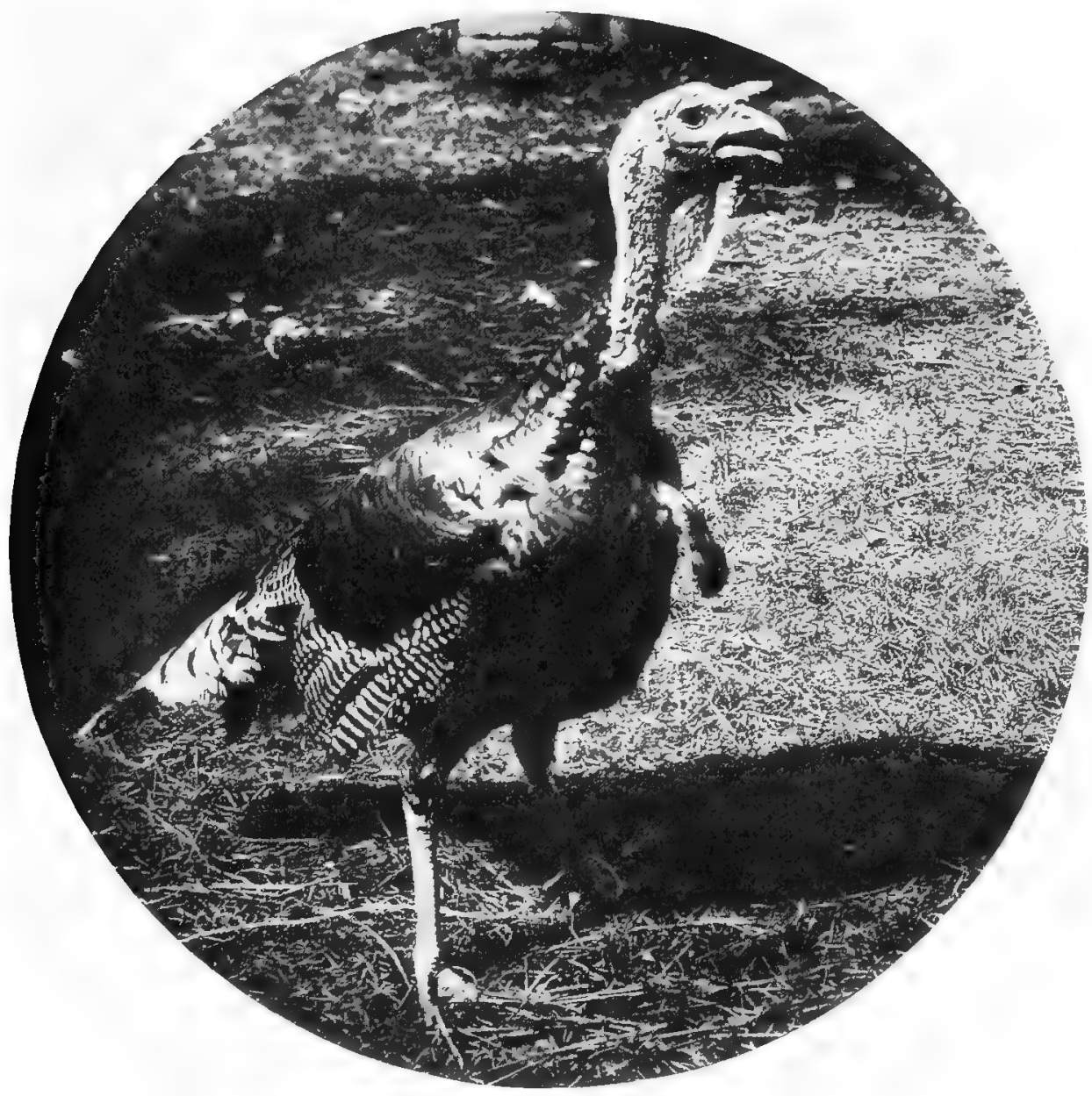

Champlon Jr. One of B. F. Ulrey's Chicago Cup Winners. Score 97 Polnts by B. N. Pierce.

in one season. I have never had but two sick turkeys during the years I have been in the business. One of these was crop-bound. I poured about a pint of warm milk down her throat and kneaded her crop with my fingers for about ten niinutes, then gave her a tablespoonfu] of castor oil and she was all right the net day. The other was a three-year-old tom which dropped off the roost dead. I commence feeding my turkeys all they will eat about November first and continue feeding until about February first, then I let them hustle for their living and they will be in good breeding condition.

I never house turkeys, as the trees and fences are the natural roosting piaces for turkeys and I think that the nearer they are raised as nature does the better the results. Turkeys cannot be raised sucessfully without plenty of old. The best tom I ever owned, both as a breeder and an exhibition bird, I sold when he was three years old because I thought he was getting too old for a breeder. The person to whom I sold him used him two seasons and he proved a successful breeder. Then this man sold him, thinking he was too old for breeding or showing, but his new master thought differently and showed him at Madison Square Garden, New York, last winter when he was five years old, and won the blue ribbon. Old "Champion" has a record of eighteen first prizes. He weighed thirty-five pounds as a yearling, forty pounds as a two-year-old and forty-three pounds when four years old. He was the sire of the first prize cock and second prize hen at Chicago, January, 1900, and to my knowledge, was the sire of eleven turkeys that scored 97 points or better. 


\section{STARTING THE BUSINESS.}

If $I$ were to start in the business of raising turkeys, having the experience I now have, I should purchase three or four of the best females I could find that were near standard weight and as nearly perfect in color as I could find. I should also buy their sire if he had proved to be a good one and should mate them to him. If I could not get the sire, I should get a cockerel from the same mating that the females were from and should mate him to the females. Then I should save the eggs from the best hen, mark her poults and save a tom from her to mate with my flock the next season. The pullets I should take to another farm and mate to a tom from the home flock. In that way I could linebreed and not in-breed too closely. When I saw there was need of new blood, I should purchase a female from the breeder of whom I purchased my original stock, and in that way I would keep the same strain, but my birds would not be near enough related to affect their health and vigor. As surely as you introduce a new strain in your flock, you will lose both shape and color and it will take at least three years of careful mating to get back where you were when you made the cross.
I find that the breast and back are the most difficult sections to breed correctly in regard to shape. As a rule, the back is too narrow and too short. We want our birds broad across the shoulders with a long back and full round breast, rather Iong legs and large feet. In color we have the most difficulty with the wings, tail and back. The standard says in regard to color of wings: "Primaries-Each feather evenly and distinctly barred across, with parallel bars of black and white extending the entire length of the feather." or the color of the tail it says: "Black-each feather irregularly penciled with a narrow band of light brown and ending in a broad black band with a wide edging of white or graywhite preferred." Now I find if we get a clear white barring in the wings we are sure to get white barring in the main tail feathers, which is a serious defect. In fact, I should not keep a bird for a breeder that had white barring in its tail. I also find that if we get a clear white edging on the tail and tail coverts we do not get a rich bronze on the back and tail coverts, and if we get a good bronze where the standard demands it, we are sure to get smutty white on the end of the tail and smoky white on the tail coverts.

B. F. ULREY.

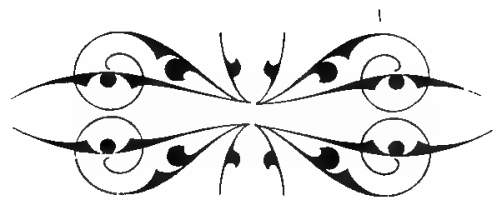




\title{
TURKEYS RAISED WITHOUT HOUSING.
}

\author{
Confining and Housing Turkeys-Turkey Eggs-Care of Poults-Feeding Corn-Diseases-How to Begin.
}

By B. F. Hislop.

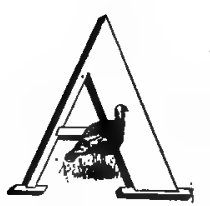

FEW years ago when we finally concluded to try turkey raising, we had already decided that the Bronze was the variety which suited us best, and we bought a trio in the fall in order to be ready for business the following spring. We had no experience, so we began to read up on the subject and to question our neighbors about their methods of caring for the young. We found that most of the neighbors allowed the turkey hens to do all the work, and when winter came, if there was a large flock of turkeys the farmer's wife clained all the credit, but if the turkey hens failed to raise large families, they had all the blame. At first we raised the poults with domestic hensand later decided to try the turkeys, but found the old ones so unruly that we again gave the poults to the domestic hens. We worked according to rules, kept the coops well scrubbed, etc., and we succeeded fairly well, raising as large a percentage of poults as we have ever raised since, but the work we did that vear, if applied to some other calling, would have obtained us far more money, and we concluded if raising turkeys required so much work we had better quit the business. The time we wasted doctoring colds that season would have discouraged most amateurs. We were afraid these colds might develop into roup, and so labored most patiently. We wish to say that we do not believe turkeys ever have roup as chickens do. We think the birds become debilitated from injudicious treatment from the time they are hatched, and when autumn comes the birds take cold, which develops into chronic catarrh. We do not believe it is contagious, but a flock will be more or less affected, as all the birds are exposed to the same causes. It is hard to cure such colds, for if a man does not know how to prevent his flock from taking cold he is hardly likely to know how to cure them. There may be flocks that have the roup, but we have never seen any, though we have seen birds whose owners thought they had roup, but which we believed to be suffering from a severe cold.

This year not one of our turkeys has a cold, although this is the season for it, and we think we understand why they have escaped. In the first place, we changed the blood, as we believe inbreeding produces weak stock, although one does not need to make too great a change. We do not think that turkeys are as liable to be off in color as chickens are, and so we have no hesitancy in putting a fine tom at the head of our flock without tracing his pedigree. A tom will do a large part in elevating a flock, but he cannot do it all, because much depends on the females. The male, so our experience teaches us, has much to do with the size, with the length of the bones, markings of the tail and wings, and also the shape of the body, but if the females are too small and poorly marked, one cannot expect anything first-class from such a mating. A large percentage of judges are very particular about the markings of the tails and wings of turkeys, so one has to look after these sections. Some judges are very particular about having a good bronze, although shape, size, etc., will help one out, but the best judges want a bronze, not a black or brown. Many breeders cannot see bronze in any but their own birds, but when the birds are all together in a show room, a person, if he has an eye for beauty, can select the bronze birds, and so can the judge-which is one good point for comparison judging.

CONFINING AND HOUSING TURKEYS.

We do not think turkeys can be raised in large flocks without a large range, although we have never tried raising them in confinement. A turkey is naturally a forager and in roaming about procures its proper food. Even if a person has solved the food problem (we do not think we have) and confines his turkeys, intending to feed them, he would prevent them from taking the proper exercise which they require as much as they do food, if they are to attain the greatest possible size and vigor. We find that the lack of size and vigor is to be seen in poults raised by domestic hens. We have been asked if it is best to house turkeys. We have never housed them ourselves. They have always roosted at night in the trees and lived around the buildings during the day, but we intend to try housing them somelime because from what we have learned we think it would be a good plan. We shall use sheds open to the south, with trees for protection on the open side. We have a grove that is a great protection to our flock, but we think they need more. When a bird stands around on a cold, bleak day, all drawn up and then goes to sleep on a naked limb, with the wind blowing a blizzard around him all night, we cannot see that it is of any benefit to him. He has the same sort of body that other stock has and if he has no shelter to keep him warm, his food has to do it. Plenty of fresh air does not mean that birds must be out of shelter. We do not think that over seventy-five turkeys in one flock will do well and we prefer fifty or less. It does not matter how early turikeys are hatched. The hens in this climate will not commence to lay much before the first of April, and the later hatehed will lay about as soon as the early ones, unless very late hatched. 
IN REGARD TO TURKEYS.

We do not keep the young birds for breeders because they are not matured enough. Breeders should be at least ten or eleven months old, the older and more mature the fow is, the better the breeder. We may not get so many eggs from the females, but we get better ones. The one drawback to two-year-old turkeys and older is that we let them get too fat in this corn country during the winter. Wo have never been able to secure such large clutches of eggs as some claim. We get an average of twelve in the first clutch and about ten in the second. Some hens will lay more, and some will lay three clutches, but they are iess in number and we never count much on them, for the hens usually hide theil: nests and we seldom bother about them. Occasionally a hen willl lay a large number of eggs, in fact, will lay all summer, but su'l eggs are seldom fertile. We have mated fifteen females with one tom with good results, and we do not believe there was any larger percentage of infertile eggs than when we mated a tom with two females. Turkey eggs are usually fertile if the hens are not too fat. We put our hens on "starvation rations," as we call it, when nearing the breeding season. At that time we feed mostly oats, meat and vegetables. Turkey eggs incubate in twentyeight days, and when the weather is rery warm a day or so less time is required, but we do not remember ever having one sit over twenty-eight days. Turkey hens seldom hide their nests for the first clutch. In the second they make the aitempt, but we wateh them and if they want to go too far away we drive them nearer home and thus get them to commence laying in a nest more convenient to us. We gather the eggs and keep them in a cool place, placing them on the small end, and if we should keep them long, we turn them, but as a rule, we do not keep them long enough to take that tronble, for if we do not set them ourselves, our customers are waiting for them. W have generally had better success in putling eggs under domestic hens, but we do not let them raise 1 he poults. We always have a turkey hell waiting to take them. If a turkey has been sitting two weeks, or even less, she will take the young if they are put under hor when a few hours old. We have tried putting pipped eggs under the turkey, but too many of them get mashed, so this year we waited until the poults were a few hours old. If a turkey chooses to sit in the proper place, we put eggs under $\mathrm{L} \in \mathrm{r}$ and set a domestic hen at the same time, but give all the poults to the turkey.

\section{CARE OF POULTS.}

We used to keep the poults and the mother hen penned up for about ten days or two weeks, feeding the young turkeys three or four times a day on boiled eggs, dandelions, curd and bread soaked with milk. They did very well, but we think now it was a mistaken kindness, for we lost a larger per cent of the young in the fall. We think that with all our care we invariably overfed, but they did not show the effects until fall. Now we make a practice of keeping the hen and poults penned up four or five days, feeding very sparingly on boiled eggs, dandelions or any green plant, such as onions or lettuce, and a little bread. We have discarded curds altogether as we think it is too much work for the benefit, in fact, we have almost concluded that it is a detriment to the turkeys, for when we fed it we were bothered by the fowls having worms more than we are now. This season we went to very little trouble to feed them after the hen was set at liberty. If it were convenient we fed them twice or three times a day, but if not, we looked after them at evening to see where they roosted, and fed them, giving them some kind of cooked food, oatmeal, and bran, and later a mash composed of equal parts of corn meal, middlings and bran, with a little meat meal, bone and venes!lan red. The food we gave them was so little that we did not consider it necessary, and as they grew older they tid not have use for it, but we still fed them in order to keep them tame and teach them that they had a home. Nevertheless, we frequently had to drive them home. A turkey on a farm range will take care of her flock and raise them strong and vigorous with very little food from the house.

There is much ado about young poults being killed by damp weather and by being out in the dew. By the time a turkey hatches in this climate it is not likely to be very coll, and unless the ground is so low that the land is flooded, there is little danger from rains. This has been a vel'y wet summer in our locality, and we had hens out in heavy rains when the poults were but a few days old and we did not lose a poult nor did the young get wet. We have a large orchard and grove that furnishes a great cieal of protection, but often the hen sat out as far from the trees as she could get, not to entirely leave the orchard, still there were no poults drowned. We think during such wet spells that the poults need to be fed more regularly, as they cannot hunt for their food. We have lost more young by having the old hen go into a coop with a part of the flock, the other part being left out and drowning, than we ever did when the hen. was out with the flock. After the frosts lill the bugs, grasshoppers, etc., the turkeys require more food, and we feed them morning and night a small ration, increasing it as the food in the meadows and pastures decreases. In the morning we feed a mash with the same ingredients that we fed to the poults while young, with the addition of charcoal and oil meal in small quantilies. We also give them cracked bone and grit, all they will eat of the latter, and at night coarse cracked corn and soaked oats. Now if the voung poults are not fed to death, so to speak, there will be liktle, if any, indigestion, and if a case now and then appears lessen the food, and in individual cases give the fowl a full tablespoonful of castor oil with from five to ten drops of turpentine in it. If one dose is not enough, give two or three, or even more, one dose a day, and search for lice. We have invariably moticed that the debilitated fowl always becumes lousy and generally has worms, as these pests invarialjy follow indigestion.

\section{FEFDING CORN.}

Do not begin too soon to feed corn. Last year we fed our chickens considerable cracked corn in the outside scratching pens. Our turkeys soon learned this and were on hand by three or four o'clock, if they had not hung around all day waiting for evening, and they got a large share of the corn. As a consequence. we lost a lot of fine birds from indigestion. We could not cure it, as we did not remove the cause. We wanted fat chickens and we paid for them with our best turkeys, but we learned our lesson. Keep your turkeys going out on the range as long as possible. Drive them away in the morning if they will not go. When the weather becomes cold and the proper time for fattening comes, then feed corn and heavy grain. We would never fatten the birds intended for breeders if the purchasers did not remand heavy weights, as fat is a detriment to the birds. We cannot blame the purchasers, as this is about the only way they can be sure of getting a large fowl and so they call for actual weights; but the tall, rangy, wellshaped, long, coarse-legged turkey, even if he does look slim in the fall, is the one that will be a large bird. Our first turkeys purchased were low, blocky birds, and they were almost as heavy in the late fall as they ever got. We thought them fine at first, but it did not take us long to change our minds, so that the next autumn we purchased a trio of birds from a well-known breeder. When they came the fowls were but a pound or two heavier than our old stock, but they were long legged, awkward, green looking birds, and we were pleased with them, for we could see into 
whar they would develop and we were not disappuinted. Since then we have known better what to purchase. Turkey raising is like a great many other things. One can read a great deal about it, but the actual experience is necessary. More than that, it can never all be learned, nor does one person possess more knowledge than all other turkey raisers combined. The longer one is in the business the less conceited he becomes if he bas any success.

\section{MARKETING TURKEYS.}

In catching poults or old turkeys, one must catch them by the legs, holding them just below the hocks with the legs together, laying the birds across the arm if you wish to curry them, or on something else if you do not. The cost of feeding a turkey on a farm does not amount to more than 50 cents per head, even with all the extras a breeder needs, and the farmer's wife who lets.the turkey do the raising is out so little one cannot estimate it. We purchase food for all our poultry together, using as we need it, and consequently when the time to balance comes we simply count up our expenses and income from all our flocks and look for the gain or income. When turkeys are raised for market, the heavy ones will pay the most profit fattened and sold for Thanksgiving and Christmas, but the younger and lighter weights that are not in as good condition as they will be later, can be marketed any time during the winter, as the turkey market does rot fluctuate so very much for good stock. We have had dressers of poultry tell us that the Bronze turkeys were the finest they handied, but we do not believe they command a higher price than other varieties, all conditions being equal. Good dressed turkeys bring from eleven to twelve and one-half cents a pound in Chicago. Every breeder should dress his own fowls, as it will pay him in all instances. Have the fowls fat and to the worls nicely and you are sure of the top price.

\section{LICE ON TURKEYS.}

We have not touched the lice question in regard to young poults. We are not much in favor of greasing, except in using a little lard on the old hen when first taken from the nest and on the tops of the poults' heads as a preventive of head lice. We dust the old hen two or three times while she is sitting, and thoroughly when we give her the poults, then watch the young and as soon as we see lice on them, dust them with good insect powder, avoiding the white, as it makes them look shabby. We do consıderable dusting, once a week for a few months, but oftener if the lice compel us 10. Dust the old hen, too, for when the lice are destroyed in this way at the beginning your trouble is over. We catch the young by having a box trap. Feed them in a bunch and when they commence to eat set the trap over them, the top of the box being laths with a little trap door in it so we can take the poults out one by one, dust them and let them go. In this way none are missed. It is not so easy to catch the old bird. Occasionally she escapes a dusting, but we manage to get her often enough to prevent trouble. We seldom have a sick poult, so we never experienced pulling wing feathers. Our trouble heretofore has been, as we said, in the fall, and we think we can steer clear of that better than we have.

\section{DISEASES OF TURKEYS AND RANGE.}

In our experience the diseases of turkeys are brought about by impaired digestion. If one can build up the constitution and remove the causes of the trouble one can cure. many of them, but when the constitution has become thoroughly broken down you might as well use the ax and stop the misery. Do not be too hasty, however, as many oi them may be cured and marketed. Colds are not necessarily fatal, nor is rheumatism, although the latter is worse, but when a turkey gets the black head he is often dead before one gets a chance to doctor him, so the best way is to begin right and avoid such trouble. A large flock is more difficult to handle than a small one. We do not aim to raise over seventy-five ill our home flock, as the range is not good on the prairies and the pastures are too small. We all know that a large cattle pasture is an ideal range, lut they are not to be found in a locality like ours, where land is high and it is all under culcivation, besides one's neighbors do not like to see another man's turkeys in their oat fields or corn fields in the fall, although it is a well established fact that turkeys eat more injurious insects than they do grain and they are a benefit rather than a detriment, but you canno' make many farmers believe it, and it is useless to try. We are trying to console our neighbors by compensating them in some way for the imagined damage, but with all that the yellow cur puts in his appearance occasionally and chews up a fine bird. It is not all clear sailing in the turkey business, and as we are located, if it were not for the pleasure we take in seeing a fine flock of the mammoth beauties, we shouli quit the business.

We do not think swampy ground would be a good place for turkeys, especially during a wet season.

\section{FOR THE AMATEUR.}

Were we to start in the turkey business, knowing what we do now, we should buy the best breeders we could find that were for sale at a price we could stand and would not be afraid of a few dollars if we could afford it. We should build a shed for them, and if we did not have some kind of a grove we think we could ill afford not to build. We should start with the Bronze, for considering all we know of other breeds, we still like them best, and think that we can make the most money out of them. The market man prefers them for their size and the fancier for their beanty. Judging from the numbers shown in our exhibitions, they are the most popular variety.

A word to purchasers-when you wish to buy, first select a reliable breeder and if you want breeding birds you can easily purchase them at a reasonable figure, but if you want show birds ior breeders (which are the best) do not expect them at common breeding stock prices, for no man's winle flock is composed of show birds, even if many of his old breeding stock were once show birds. If the breeder tells you that his hirds were never beaten in the show, immediately learn where the birds were exhibited, whether in a local show or in a show like Chicago, New York or Boston. No person has made a clean sweep at many large shows unless the competition was very small indeed.

B. F. HISLOP. 


\title{
THE FARMER'S BEST FRIEND.
}

\author{
The Mammoth Bronze Turkey So Proclaimed by One who Formerly Would Not Allow a Turkey on His Farm- \\ Turkeys as Pest Destroyers-Selection of Breeders-Hatching and Ralsing Poults.
}

By Mrs. J. M. Randolph.

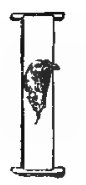

CONSIDER the most important thing in turkey raising is good, healthy breeding stock. In selecting a tom I look for good markings on wings and tail, a long body, large legs and feet, and as the standard requires heavy weight, as large a bird as I can get that meets these requirements, although in my own judgment a thirty-two pound tom is large enough. I think most old turkey breeders will agree with me that there was a great mistake made in demanding such heavy weight toms. As I believe the poults get size from the hens and markings from the tom, I select the hens with regard to size first, but with markings as good as I can get on large hens.

About the middle of February or when the hens begin to call-a sound familiar to all turkey breeders-and show signs of mating, I remove them to a young orchard enclosed with poultry netting, and clip the right wing of each sen, but I never clip the tom's wing, as be will not give trouble by trying to fly out as a hen will do if her wing is not clipped.

In this yard they have plenty of range, blue grass and clover and I never jet them out until the breeding season is over. I believe every breeder should have an enclosed yard or park for turkeys. Much as I should dislike to give up raising turkeys, I wrould do so befcre I would go back to the old way of letting them have the run of the farm. I caunot forget long, wear $;$, oftimes fruitiess searches I have had trying to find their nests, only, perhaps, to have them move again in a few days.

We have a great many osage orange hedges in this part of the country and these hedges seem to be a favorite place for curkeys to hide their nests. I have had them follow the hedge more than a mile and then make their nests. Being in an enclosure not only ensures your getting all their eggs, but they can be gathered often and thus avoid having them chill during the early spring months.

\section{TURKEY NESTS.}

Turkeys in this locality usually begin to lay the latter part of March. After confining them to the park I take some evergreen boughs and lean them against the poultry netting which adjoins a hedge fence on one side of the park, thus making a scheduled place for them to nest. I do not leave a very large opening, jut let them creep in, and they think they are hiding their nests. Usually I keep about twenty-two bens and most of them will lay their first clutch of eggs in two of these nests, but later on when the grass grows knee high they will steal their rests and sometimes elude me for several days or a week, but by that time it is warm encugil so that the eggs will not chill.

HATCHING THE POULTS.

Although turkey hens seem to be expressly designed to take care of their offspring and know how to do this part of their work to perfection, I have not found them to be as good sitters as domestic hens. For several years I have not waited until I had a turkey want to sit, but as soon as I have enough eggs for several sittings I place them under domestic hen. About two weeks before they are due to hatch I put some hen eggs under a broody turkey hen and when the turkey eggs begin to hatch I placed one or two eggrs under the turkey and she would own them without any trouble.

Last spring I kept breaking my turkey hens from sitting in order to keep them laying and so at one time some turkeys wers to hatch in a few days and there was no turkey inother for them. About that time I had another turkey want to sit, so I gave her, without moving her from the nest, two or three small Barred Rock chickens to see if she would own them, placing them under her just at dusk. Next morning she was hovering them and was very proud of her suddenly acquired family, so the next night $I$ moved her to a building and gave her eighteen little turkeys, of which she seemed just as proud as if she had sat four weeks. This was a new idea to me, but I thought why not use that plan altogether and thus keep the turkey hens laying. I did so the balance of the season with eight or nine turkeys, giving them broods when they had sat only a few days and in some instances only over night. Just one hen out of this number refised to own and care for her brood, the others acted as if they had sat the allotted time. I shall try it again this season and $I$ feel confident it will work all right.

The best success $I$ ever had in raising poults was in a small lot with very short grass and a very large coop or smajl building in which they could roost. They were kept shut in on rainy ciays and in the morrings until the dew dried off, until they were four to five weeks old. Then they were turned out to range, being driven back to their coops at night. For the first few weeks I find clabber cheese and green onion tops, pirihead oatmeal and millet seed to be good food for them. A little bone meal and small sharp grit also is put in their food once a day. I find sand and old plaster is good for them and a load of sand is hauled and placed where they can run to it. No one has any idea what a lot of sand young poults will eat until he undertakes to cairy it to them as I did one spring.

At this season we always have plenty of milk and so I give them new milk every day, first boiling it to prevent bowel trouble. When the little poults are just one week old I pull out all the flight feathers in their wings. By the time they grow out again the little birds have more strength to stand the strain of growing them. Since following this plan I have had much better success in raising them.

I also go over them once a week and treat them for lice, rubbing a very little lard on top of the head, in the quill feathers on the wing and just below the vent. I lost a great many turkeys before I kuew that when lice and mites were around the last named place they were most fatal. Remember I said a very little lard, for smearing the body with greaso is sure death, as I learned by sad experience. Occasionally I use Lambert's Death to Lice instead of lard.

After they shoot the red and can be driven to the pastures and meadows it is surprising to see how they will thrive and grow with only a little food to induce them to come home at night. A more beautiful sight in poultrydom thall a large drove of Mammoth Bronze turkeys with their bronze plumage glistening in the sunlight, I cannot imagine, 


\section{TURKEYS AS PEST DESTROYERS.}

Years ago I used to raise the old fashioned mixed turkeys, but my husband grumbled so about what they destroyed that I gave up raising them when he said if I would do so he would give me his note to pay me as much each fall as a drove ot turkeys would bring. So I did not try to raise any for several years. 'Then a neighbor wanted to exchange some turkey eggs for some pure-bred Buff Cochin eggs and I made the exchange to accommodate her, besides I wished to raise a few to have for Thanksgiving and Christmas. I raised five very nice ones and killed two of them, but decided I could not manage any longer without turkeys and so kept a tom and two pullets to raise from the next year. The next fall I sold them all and bought six pure-bred turkey hens and a fine tom and went at it in good earnest so that the next year I had a fine drove.

Near the house we had forty acres in clover and the grasshoppers were so plentiful that the turkeys seldom went more than half way across the field until they had all they wanted. The result was that when the clover was cut for seed it was found that only the part where the turkeys had ranged was of any account. The grasshoppers had ruined the other part. That convinced my husband that turkeys were a good thing to have around, in grasshopper season at least. It was wonderful how those turkeys grew.

This season we had our clover for seed on another part of the farm a mile or more from the house, and I had a drove of over one hundred turkeys. The grasshoppers ate up all the clover seed. Every day my husband would say, "I do wish those turkeys could get to that clover field, for the grasshoppers are ruining it, and I shall have to buy my clover seed." And so he did and he had to pay a good price for it. He said that after this experience he would try to havo bis clover for seed near the house. A prominent turkey breeder told me afterwards that I could have trained the turkeys to go to the field if I had begun to do it when they were first turned out to range. In a case of this kind again, I am going to try it.

I hope this article may help some farmer's wife, whose husband, like mine did, does not think turkeys pay, and who, like myself, has need of some loose change. Perhaps the husband, like mine, will become convinced that turkeys are the farmer's best friend.

\section{MRS. J. M. RANDOLPH.}

\title{
SOME PRACTICAL HINTS.
}

\author{
By O. E. Skinner.
}

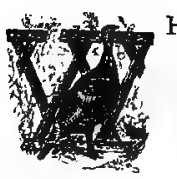

HILE I have not had as much experience in raising turkeys as a good many others, I have had continued experience with them for over thirty years, but my remalks on the turkey will be from a practical standpoint and I shall leave the fancier's portion to seme expert juage.

In the first place, everybody knows that turkey eggs, as a rule, hatch well, but the rock that wrecks all hopes is the art of raising them after they are hatched. One of the most successful turkey raisers I ever knew handled her young turkeys about as follows: She never let them out while there was the least particle of danger of getting their plumage damp, even if she had to confine them a whole day. I was there once after a heavy rain and she had them closely contined in a smail box. I made the remark, "You will surely kill every one of them confining them in such a place." But upon visiting her a few months later she still had every turkey that had hatched. I believe this is the great secret in turkey raising-keep them absolutely dry and free from lice and nature will do the rest.

Another neighbor who is just about as successful handles his the same way, only he uses turkey hens for mothers. He follows the same plan about keeping them from setting their plumage damp when young. He has domestic hens sitting on the eggs, but he keeps giving them at night to the turkey hens until they have some twenty-five or thirty each.

The cry nowadays is for as large turkeys as possible. This is all right provided you retain the full breast and good shape generally. If you will observe the daily market reports, you will notice that the quotations say that scrawny turkeys (poor shape) are either not wanted or will be taken only at a big discount. So after all it is the shape that sells the turkey rather than the overgrown size. I have always made it a point to breed for full breast and good shape more than for oversize. The cockerel shown in connection with this article is five and a half months old. As an indication of his size when grown, notice his throat wattles. This, if large, is always a good indication for size when the bird is matured.

As to feed, I do not believe it cuts much figure if the other sanitary conditions, noted above, are closely followed. Plenty of sharp grit I believe necessary for best results, however. O. E. SKINNER.

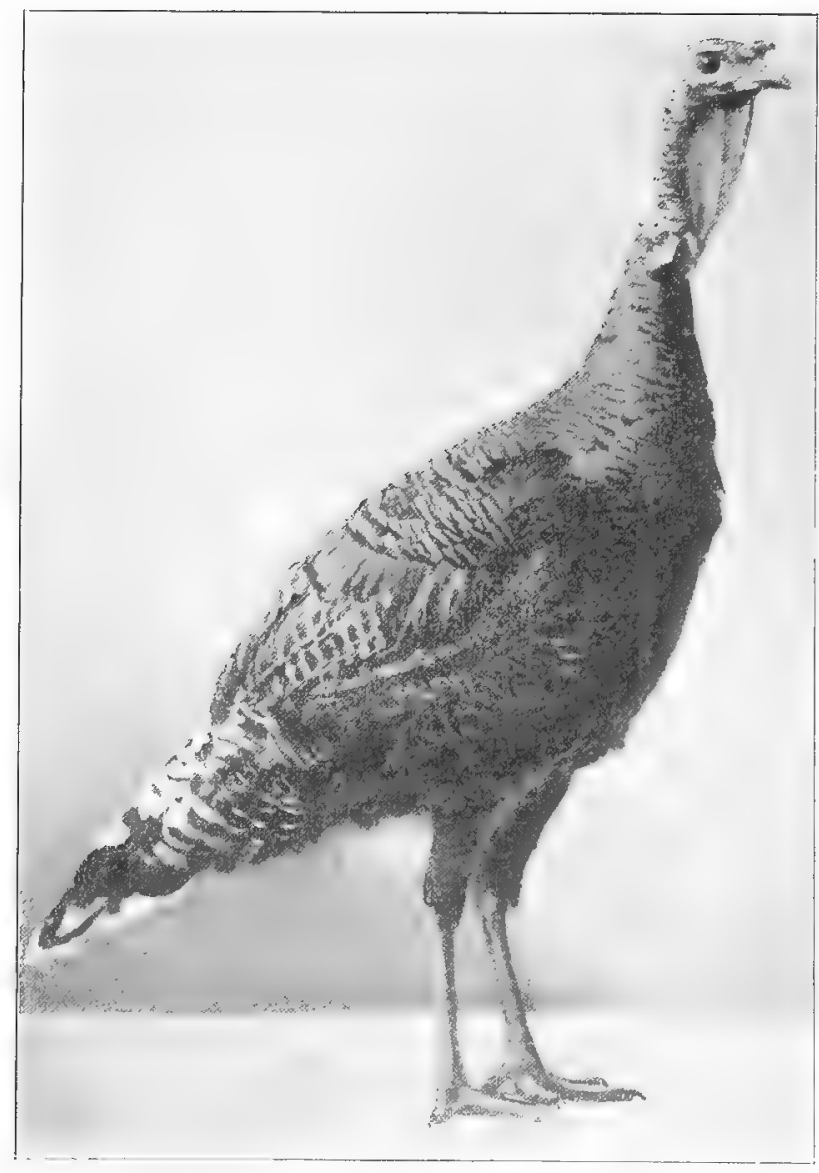

Bred and Owned by O. E. Skinner. 


\title{
EASY TURKEY RAISING.
}

\author{
Perhaps the Soll and Climate of Some Localities Make it Posslble to Leave Turkeys to Mother Nature's Kindness \\ While in Other Parts of Our Country They Need Much Fostering Care.
}

\author{
By W. A. Moon.
}

\lceil

BELIEVE there is no branch of the poultry business more profitable than the raising of turkeys; and for the true turkey fancier I think there is no branch of the business from which we derive more pleasure. I take more delight in my beautiful flock of Bronze turkeys than in any other poultry I ever raised. But I am writing this article to give my experience in order to help others if possible who are about to start, so I will begin to talk business.

I think the best way to start is to buy stock. It is better than buying eggs unless the person who buys the eggs has some kind of turkeys to hatch and raise the young poults. I will state right here that $I$ never was successful in raising young turkeys with domestic hens. In buying stock buy the best you can get. Do not make the mistake of buying in-

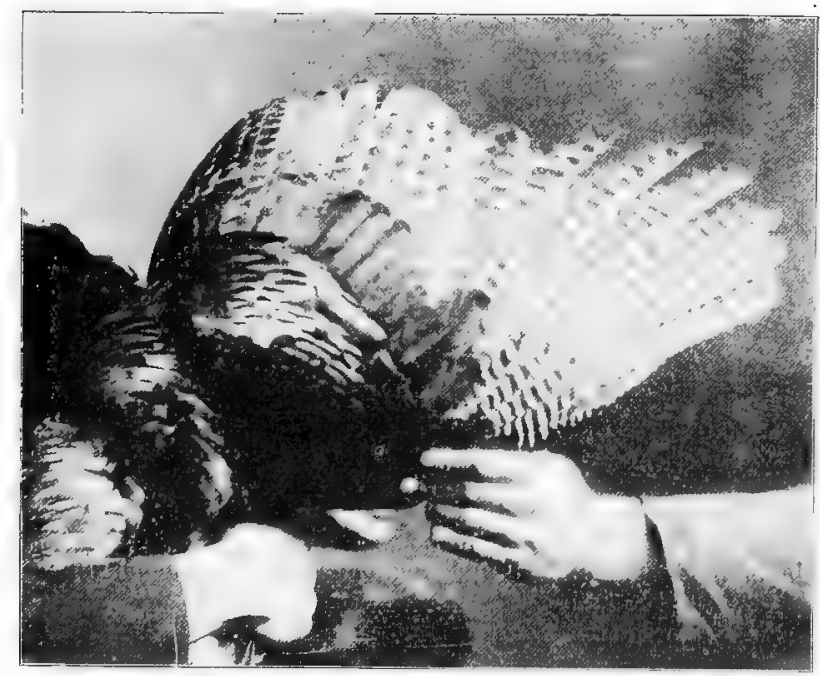

A Superior Wing, as Grown on a 48-pound Winner, Bred by Ed. Is/ey.

ferior stock because it is cheap. I know the prices of any leading fancier seem pretty high to a beginner, but his birds are almost always worth all he asks for them, which is also true of the cheap birds offered on the market. They are worth about what is asked for them and no more. If you start with inferior stock it will take you several years to reach the point at which you might have started by the payment of a few more dollars.

\section{HATCHING OF THE POULTS.}

In this latitude turkey hens usually begin to lay about the first of April. One can usually tell when they are seeking a nest by their peculiar call. I always have barrels laid down around the yard fence and in the corners, with straw placed in them for nests. Turkeys like a secluded place in which to lay. Boxes laid down close to the fence so they can creep in between the box and the fence to enter the box, make excellent nests. The turkey hen will usually lay twelve to fifteen eggs before she offers to sit. I gather the eggis every day and keep hen or china eggs in the nests for nest. eggs.

Along toward the last of the clutch the turkey hen will begin staying on the nest at night, but don't trust her with a sitting of eggs yet. She will frequently do that two or three nights and then be off all day and perhaps all night. She is just beginning to get broody. Let her get thoroughly brcody and then give her the eggs. I generally set them in the same place where they get broody with this exception, I always set them on the ground. If they have been laying in a barrel, I remove the barrel, hollow out an oblong place in the ground about two inches deep, line it nicely with the nest out of the barrel, make it seciuded by covering with boards in some manner, and she is ready to go it alone. I frequently set a domestic hen on she is ready to go it alone. I frequently set a chicken hen on turkey eggs at the same time and then give all the poults to the turkey ben, which plan usually gives her twenty or more poults, wh̆uch is enough. She should not have more than this, for after they grow a few weeks it is difficult for her to cover them. I have found that as a general rule, the greater the number of poults with one hen the greater is the percentage of loss.

I used to put the turkey hen in a coop or pen and keep her up for about two weeks. This last year I tried a new plan. I just let them come ofi the nest with their little ones and go, and I believe that is the better plan. I keep watch on them that they do not stray clear away and let them range in the fields all the time. Do not be alarmed every time it rains a little for fear your turkeys will all drown. A turkey hen hardly ever allows a iittle turkey to drown, unless she has too many. She selects a suitable place and hovers in such a manner that it is impossible for them to drown.

Last spring I bought nine eggs from a leading fancier. From them I hatched five fine poults. A small hole was. punciled in the web of the foot and they were given to a turkey hen with some others hatched the same time and she was allowed to go with them. I did not know them any more from my own turkeys until this fall when I caught all my turkeys to put on leg bands and take a record of them, and I found four with a hole in the web of the foot. I only lost one of them. I pair \$.; for the eggs, but those four turkeys are easily worth $\$ 20$. So it sometimes pays to buy eggs.

Young turkeys roost on the ground until about the time the red begins to show in the head. They then fly into a tree or on a fence somewhere. Then if you will see to it that they roost about the home you will not likely have any trouble with them straying away.

They will get their entire living in the fields until about September, when I generally begin to throw out some corn to them morning and night. It is a pleasure to feed them from this time on. They will meet you in the morning with such a chorus of "Gobble, Gobble," and they grow so fast that by Christmas the young toms weigh from twenty-five to twenty-eight pounds and the pullels from fifteen to eighteen. pounds. 


\title{
TWELVE YEARS WITH BRONZE TURKEYS.
}

\author{
A Successful Breeder EntertainIngly Writes About His Experlence In Ralsing Bronze Turkeys-For the Benefit of \\ Beginners He Tells How to Start In the Business, and How to Raise and Show Turkeys.
}

By Ed, Isley.

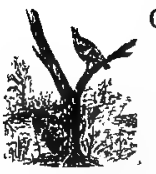

OU ASK for my experience in raising Bronze turkeys, how I started in the business, and so on. I have no inclination to air my opinions in print, nor do I wish to get into any controversy or argument with those who differ with me. They are entitled to their opinions, and I to mine. But for the benefit of those who may like to know, I will give my experience with the bird in question.

I began twelve years ago by purchasing eggs from a reliable breeder, at what then seemed a fabulous price. I risked so much and was rewarded with a poor hatch at the end of four weeks. The few that did hatch made fine market fowls only, and they were sold at market prices. So a whole year was gone and I had no turkeys for my labor.

Were I now to make a start in the business, having my present knowledge to guide me, I should purchase a fine pair or trio or breeding pen, as this would be much the quicker way of getting into business. Do not understand by this that I am opposed to buying eggs, for I am not. The choice between eggs and stock must be governed entirely by one's means. If the capital is very limited buying eggs offers the cheapest way of entering the business, although I believe the purchasing of stock to be the better plan and more satisfactory to both buyer and seller. The buyer is able to know positively just what he is breeding and his satisfaction derived from this knowledge is greater than if he buys eggs even though the poults hatched from the eggs prove to be the equal of those bred from the stock. If one feels able to do so he might invest in a sitting or two of eggs also. Then when the poultry show stason comes in the fall and winter he wonld have both old and young stock to show.

\section{IHF BREEDING STOCK.}

In selecting breeding stock give the preference to shape and color, rather than size. My experience has proven to me that abnormally large birds are unprofitable and disappointing except as show birds. A young tom weighing from twenty-five to thirty pounds and adult tom weighing from thirty-six to forty pounds are as large birds as can be used without injury to the hens. Young hens weighing from fifteen to eighieen pounds and adult hens weighing from eighteen to twenty pounds are more prolific and better mothers than those which attain a great size.

One tom and ten females make a nice flock, but if it is desirable to keep more hens in one flock two toms may be used by keeping each in a small yard on alternate days, allowing the hens to have their liberty, as they need the range and variety of food which they obtain in that way. Were the same food offered them while confined in a yard, they would not eat it. Turkeys require range. They are restless and will not eat nor lay well if deprived of their liberty.

I find that very early laying in this Iatitude is not desirable, because many of the eggs are liable to be chilled and the poults cannot be hatched to advantage before the latter part of April or the first of May. Sometimes we have a cold, rainy spring that lasts even later, and little turkeys seldom live through a storn. The hens are less likely to lay early if the quantity of food is lessened as the severity of the winter decreases. Another objection to early laying is that it entails late laying, and a hen sometimes will leave her brood when half grown to raise a second brood-which is fatal to both because the first poults need a leader and protector until nearly full grown, and the poults of the second brood are too small to stand the cold weather. It is natural for the turkey hen not to lay until spring weather is certain, and she never will desert her progeny. With our cultivation and civilization we sometimes get too far from Mother Nature.

\section{RAISINC YOUNG TLRKEYS.}

There is a great diversity of opinion in regard to the best way to raise young turkeys. After twelve years' experience

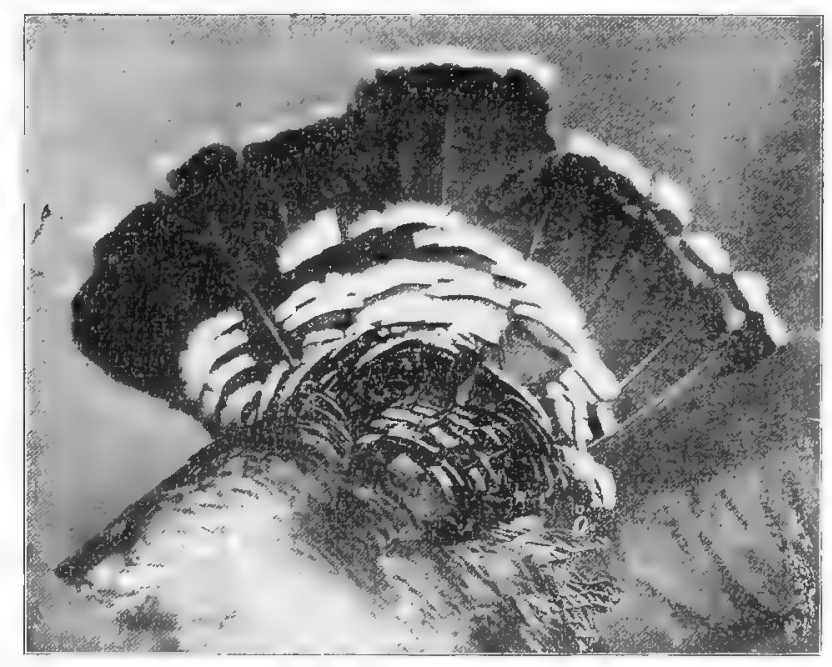

A Tall that is Above the Average-It Belongs to a 96-point Young Tom Shown by Ed. Isley.

I am decidedly in favor of the turkey hen as a mother. I use the hens for hatching, setting a domestic hen at the same time, and give all the poults to the turkey because she makes the best mother. If the hens are to act as brooders, never clip their wings, because they will need them for protection of their young from dew and storm.

Great care shou!d be taken not to feed the young poults too much at one time. This is the rock, if I may be permitted to use this figure of speech, on which the frail barks of thousands of poults have struck and gone down, together with the plans and hopes of their zealons but misguided owners. The natural habit of turkeys is to hunt for their food and they do it slowly and deliberately all the long day. Thus the process of eating and digesting are simultaneous; but when they are fed with a lavish hand they gorge themselves and in a few weeks fall victims of their own greed. 


\section{THE SHOW ROOM.}

Preparisg Bronze turkeys for the show room is a very simple matter if the birds have had good care during the summer and fall. I do not mean by this that they should be fattened, but they should be kept in a thrifty condition-just such condition as you would like to have them in if you were buying instead of selling. Washing their feet if they are dirty, and putting a numbered leg band on the leg, is all the preparation that is necessary. On no account attempt to wash the plumage, as the brilliancy will be greatly injured hy soap and water. A turiki takes perfect care of his own feathers.
ED ISLEY,

Proprietor Cherry Grove Poultry Farm.

\title{
THE WATCHWORD OF SUCCESS.
}

\author{
Experlence, Watchfulness and Common-sense Are Necessary to Ralse Prize-winning Bronze Turkeys-Something \\ About Coops for the Mother and Her Poults-Do Not Overfeed.
}

By Mrs. Nellie Bullock.

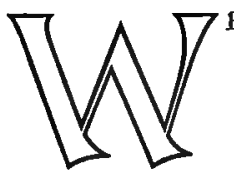

ERE I to begin the breeding of fancy turkeys and could have the benefit of my present knowledge, I think I should buy stock, the very best my purse would allow, even if I had to limit my flock to a pair. We bought eggs at different times from three noted fanciers, but something went wrong each time, either the eggs were infertile, or not strong enough to hatch, or the poults would manage to die. So I think the quicker way to secure a good flock would be to purchase birds. Turkeys are hardy after they are half grown, and most persons would sell cheaper then than after they are grown. It would not be a bad idea to invest in half-grown birds.

Raising the poults is the hard task for most beginners, and some of the more experienced ones have their hands full when they try to raise a large per cent. Practical experience, watcbfulness and plenty of common sense applied to the varying circumstances, are necessary to success. Our plan is somewhat as follows: First, we require a roomy coop with a dry floor, covered with timothy or clover chaff. Confine the mother, either a chicken or a turkey hen, on rainy days. On riry, sunshiny days, tether her to an apple tree limb, having the coop near. Clean the floor twice a week at least. If the earth is dry, it will serve very rell as a floor, otherwise, a raised board floor would be bet.c.. Dust both the mother and the poults thoroughly twice a week with Persian insect powder. For dusting the poults, I keep a two gallon, flaring earthenware crock. We put a handful of powder in the crock, then hold the poult by the feet over the crock and dust it until it looks yellow all over. I do not have so much trouble with lice as I did when I put the powder on in spots. Keep the water dishes clean and full.

We try not to overfeed, and neither do we starve them, for one is as bad as the other. We console ourselves if occasionally a poult dies, or several of them die at one time, with the thought that our neighbors, too, lose poults and that very few, no matter how much knowledge they have on this subject, can raise all that hatch.

\section{TURKEYS AS HATCHERS.}

There was an interesting item in the Reliable Poultry Journal some years ago over the initials C. H. A., which we reproduce:

"A great deal is being said lately about 'using iurkeys for hatching hen eggs, so I will give my experience. It has been really comical to see the look of doubt on the laces of people when told that we had turkeys which had never laid any eggs, sitting. Too polite to dispute the statement, their looks plainly said, 'Does he expect me to believe that story?'

"When I first read in an English poultry book of the
French method of using turkeys to hatch and care for chickens, I had no incubator and concluded to try the plan. Late in the fall I sent out in the colintry and bought a late hatchied hen turkey for very little money. In February we prepared a box (with plenty of chaff over a layer of horse manure) that could be shut up to exclude the light. Did not give either wine or whisky, but in two or three weeks she was sitting quietly on the china eggs and when taken off the nest to be fed, would voluntarily return. I then filled the nest with hens' eggs, removing them as soon as they began to pip to keep the turkey from wanting to leave the nest and putting in other eggs. After sitting three months sine was put in a yard with chickens for the rest of the summer. We put chickens of different ages with her and she received them all with equal kindness.

"This year we have two turkeys, besides an incubator, and after halching three sittings of eggs we thought best to

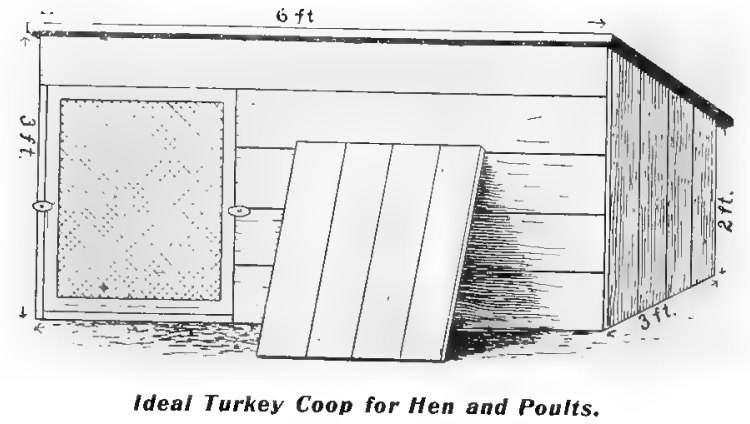

take them off the nest, but one watched her chance and went back on the nest till I filled it with eggs again, so I let her stay. The other is laying and will be ready for work later if needed.

"They make careful, patient mothers, are equal in that respect to any hen, and it is a wonder that farmers do not make more use of them than they do."

We have a coop for turkeys and poults which we find almost ideal. It is two feet high in the back and three feet in front; six feet long and three feet wide. The door is large enough to allow a turkey hen to walk in and out without inconvenience and the coop is large enough to allow a turkey hen and twenty poults to walk around when they are confined during a rainy day. We use two doors, one made of lumber for stormy times, the other of inch mesh wire nettiing for warm nights. Thus plenty of fresh air is admitted and small rats or larger animais are kept out.

MRS. NELLIE BULLOCK, Woody Rill Poultry Farm. 


\title{
TURKEYS IN NEW ENGLAND.
}

\author{
Dressing and Shlpplng Turkeys for Market-Difficulty of Raising Poults-A New England Turkey Farm-Ceneral \\ Information on Turkey Culture in the East.
}

\author{
By Geo. H. Pollard.
}

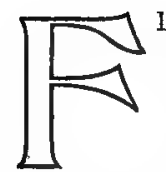

IFTY years ago turkeys were common enough or New England farms. The cock birds gobbled and strutted and told love stories under the shade of the hay stacks, while the fields and woods were traversed alike by young and old. About the only foes they had were the wily fox and the poorly trained dog. Sickness and disease were practically unknown. The flocks were made up of healthy, hardy birds, without any great pretentious to aristocratic forebears, but with the sturdy grit and get there which were characteristic of all New England life at that period, whether horses, poultry or people.

Most flocks traced their lineage back to some brave brood hatched in the freedom of the primeval forests. Doubtless much of their hardiness and self-sufficiency were inherited from this source. Certain it is that barring the moving accidents of field and flood, together with the perils from the depredations of mink, fox and such like vermin, a broo'd of young turkeys hatched meant sure good cheer for the Thanksgiving board and Christmas gathering.

Unfortunately these conditions are now greatly changed. The New England turkey growers of the present day find troubles, not only such as are due to depredations of wild or unruly animal life, but also suffer greatly from the various diseases and sicknesses which seem to be part and parcel of turkey raising under present conditions. Instead of wholly producing her own supply and exporting large numbers to other parts of the world, she is now dependent upon an imported crop of alien birds, a crop which comes from nearly all parts and sections of this country, while many are brought even from Canada. All, however, is not lost, and we are still able to produce in southern Rhode Island, eastern and southern Connecticut and in Vermont and New Hampsinire, such turkeys as delight the appetite and senses of the most fastidious of epicures. Their reputation is not confined to New England, but covers the whole country and reaches to foreign lands.

Nowhere else in the whole world are produced turkeys of such flavor and quality as go out from Rhode Island and Connecticut under the common name of Rhode Island turkeys. So well known are these hirds, and so highly esteemed are they, that not only the president's table at Washington, but the tables of many of the leading diplomats and officials who congregate in that city of high living and epicurean appetites are supplied at holiday and other times with choice specimens of the turkeys raised in this section. The Boston markets handle a large share of the stock produced in these states. Considerable numbers are also sent abroad to serve as central dishes at holiday and other elaborate banquets. Some of the leading men of Rhode Island have for years made it a custom to send to friends in England and on the continent as perfect specimens of the native Rhode Island turkey as can be procured. The fame which has come to these Rhode Island flocks may thus be seen to easily lead that of any other section or state. It is hard to say what gives the perfect flavor and delicious cooking qualities. Epi- cures disagree as to the cause, while all agree that the qualities do exist..

Hard pressing the Rhode Island and Connecticut turkeys come the Vermont birds. Ranging generally from two to three cents per pound lower in price, they are yet fit feasting for the very gods of poultry. These Vermont birds mature quickly, and when dressed show plump, yellow skin and breasts wihch appeal to the eye no less than to the taste.

\section{DIFFICULTY OF RAISING POULYS.}

The causes which have lead to the decay in production, aside from the old-time troubles from dogs, foxes and similar vermin, are not well understood. For one reason or another it has become very hard to raise the young birds. The breeding birds are hardy, strong and in every way vigorous. The females are good layers. The eggs are perfect in shell and shape. There is no trouble from lack of fertility and there seems to be abundant vitality in the germs which leads to good hatches. Notwithstanding this apparent vigor aud strength, the young poults do not live and thrive as they should. Every precaution has been taken to assure good resulta. Wild and half wild males have been brought from the south and west and mated with the native females for the infusion of fresh blood and stamina. Whole flocks of western birds have been brought here and tried. So far the results have not been satisfactory. Although the leading breeders and poultrymen have studied the matter at close range, and the state colleges, assisted by the United States government, have helped in the work, the problem is as yet unsolved. While the roving proclivities of the birds make them rather undesirable in the more thickly settled parts of the country, there are hundreds of farms which might be made to produce an immense number of turkeys at very profitable prices, if only the art of growing the young could be re-discovered, or successfully practiced. There is a demand for this product which cannot possibly be filled. Prices are high and are growing constantly higher for the best grades of birds raised here in New England. Until some decided change comes there is no probability of any drop in prices or of any very great addition to the amount of stock which will be marketed. In addition to the demand for the holiday trade and the usual sizes, there is a constantly growing call for small, early-hatched turkeys to be used as broilers. The price for these birds at two pounds to two and one-half pounds each ranges from $\$ 3$ to $\$ 4$ and sometimes $\$ 5$ per pair. These are prices which are extremely proftable, and could the young birds be hatched and supplied in sufficient numbers, it would be a very profitable undertaking for the producer. Nothing stands in the way of realizing this success save the difficulty in rearing the young birds.

Nearly all the turkeys raised in New England are Bronze, or the one time popular Narragansett. Some White Hollands are bred, but the great bulk of the breeding flocks is made up of Bronze, either pure or grade. Of course there are all sorts of mixtures made up of these breeds. In this 
respect they in a measure resemble the ordinary barn yard flock of hens. The best producer's and breeders, however, stick protty closely to the pure breeds and in this woy are able to carry the type and quality of the birds to a more sa:isfactory result in market poultry than could otherwise be attained. There is no question that in all branches purebred poultry though not necessarily bred to the feather, will produce market birds more even in size, shape and table qualities than any mixtule which comes from the indiscriminate breeding together of various kinds, types and sizes.

\section{DRESSING AND SHIPPING MARKET TURKEYS.}

Where do they come from? Every state where turkeys grow contributes to the array. Many used to be brought in from Canada. These came both alive and dressed. They used to be shipped in alive by the carload and were fattened and killed for the market. Sometimes they were not held for fattening, but were killed immediately upon arrival, Unier the present tariff this importation has practically ceased. About the only poultry now brought across the line from Canada are geese, and they do not count in this story. The Boston market is unquestionably the most fastidious poultry market in the country. While, of course, much poor stock does come to this market, there is nothing like so large a proportion of poor poultry shipped to Boston as is used in other large eastern markets. The best turkeys, aside from those raised in Rhode Island, Connecticut, Vermont and New Hampshire, come from the west. The best western turkeys come from Wisconsin and Michigan. These birds are all good sized, are perfectly dressed and the carcasses are fal and meaty. A very good quality comes from Iowa. Ohio, Indiana, Illinois and Nebraska also ship immense numbers. Missuuri sends quite a good many turkeys, but her principal shipments are geese, ducks and fowl and chickens. From the Virginias come large numbers, while Kentucky is sending birds of the very best quality. The southern birds cannol be shippes to good advantage except in the coldest months.

The present methods of shipping are a very great advance over those in common use only a few years ago. Then all poultry from a distance had to be shipped by the regular passenger expresses, or come through on the slow freights. Shipping by freight was possible only in the coldest months, and the numerous delays and the consequent inability to tell when the grods would be received, made this method of sizipping very unsatisfactory. Since the advent of the ireight express with refrigerator cars and other conveniences for keeping the temperature at a low degree, it has become possible to ship all kinds of poultry long distances on schedule time thus assuring prompt receipts in good condition. MIuch of the far-away poultry comes through in the warm months packed in ice. That is, an ordinary sugar barrel is used; a layer of ice is put in the bottom of the barrel, this is covered by a layer of turkeys, followed by another layer of ice, and so on till the barrel is full. Then it is covered by burlap and shipped by freight express direct to the eastern market. If by chance the shipment is delayed, the carrying company re-ices the bar'els, and in this manner prevents serious loss of quality. There is little doubt that poultry thus iced loses some of the flavor which it would otherwise have. The conscant soaking for perhaps days at a time, while it keeps the birds sweet and free from taint, nevertheless takes something from thejr fine table qualities.

The shape of the package has changed as much as the quality of its coutents and the method of shipping. 'Ten years ago most of the turkeys came through in boxes of all sizes, shapes and ronditions. No attention was paid to unifolmity, and secoul-hand shoe, hat, coffee and canned goods and such, other boxes as were avallable were used, together with barrels of varying sizes and conditions, from the little western apple barri up to the coffee and sugar barrels. The result of this method of packing was not altogether inviting to he eye of the buyer. Gradually more attention was given to the niatter and a steady improvement has been made until at the present time boxes are made especially for the purpose. Barrels to some extent are also used at the present time, but not nearly so commonly as in years past. The size of the packages has also changed. The rule used to be to get as large a box as possible, cramming in as many turkeys as it would hold without splitting. In some ways this mate business good for the wholesale and jobbing houses, as there were many amall dealers who were unable to handle full packages, who had to pay an extra profit for the privilege of selecting such birds as they needed. It is a question, however, if on the whole there was much gain to the wholesale handlers, as there were generally enough odds and ends left to seriously detract from the profits as a whole. The demand for smaller packages came to be felt by shippers as well as wholesalers and commission men and steps were taken to supply the want. At the present time the boxes rarely weigh more thar 150 to 200 pounds each, and great numbers are packed in boxes holding from ten to fifteen selected birds, while a less number hold from eight to twelve. This makes it possible for the small marketmen and provision dealers to buy a full package without any extra cost for breakage or seicction, and at the same time does away with a great deal of work and with much of the waste which was prevalent in the old method of packing and shipping.

The common method of packing birds is to make one layer of tom turkeys in the bottom of the boxes, while the upper layer is made up of females. This gives a selection of siz $\supset$, and is better for the retailer than where they run pretty nearly one size throughout. The best shippers are known by their private shipping marks and it is understood just how the birds may be expected to turn out. Generally the case is marked so many hens, so many toms, and if any old hens or old cock birds are in the package, they are specified on the outside so that the buyer may know just exactly what he is getting. In the long run honesty in packing nakes returns in dollars and cents and there is no other one thing which tells better for a shipper than a reputation for honst methods of boxing.

The way of dressing has changed from time to time. Yars ago a good many turkeys were shipped from the west undrawn and with ineads on. They did not altogether suit the fancy of the trade. Unless unnsual care was taken, tbey were pretty apt to arrive in a blood stained condition, due to the blool which oozed from the heads, and where the heads were wrapped in paper before shipping, the whole presenited a mussed and unfiuished appearance to the eye of the dealer. Of late years the cusiom has settled into a pretty general method of drawing and heading the birds before shipping. They are thoroughly bled out, the carcasses are kept until the animal ineat is altogether dispelled. The heads are removed and the skin drawn down over the end of the neck bones and is neatly tied, making it impossible for the birds to get at all stained or bloody in transit. Great care must be taken that all the blood is drained from the neck before tying else it will accumulate in the cavity at the end of the bone aill next to the string which ties the skin, and will coagulate and turn the color of the neck to a dismal purple which will rapidly change to green, giving a decidedly bad look, and if left any time, a worse flavor to the whole carcass.

In the good old days the nearby turkeys, those from Rhnde Islaud, Connecticut, Vermont, New Hampshire and such as were raised in Massachusetts, were brought to market nearly altogeticr by teams over the country roads. Many 
of the producers marketed their own birds. They used to leave thetr homes from one to three days before the hollday season and drive overland to Boston, Providence, and the larger New England cilies. The whole family assisted in dressing the turkeys, and the wings were generally left on. In fact, at the present time, a good many Rhode Island turkeys come to market with the flight feathers left in the tip of the wing. They are in great demand by old-time housewives to be used as brushes, and are famous for some spectal the commlssion huuses and either from stands erected by themselves, or from wagons and push carts, make such sales as are possible to the more gullible of the city's population. Their greatest trade comes, as a rule, from the lower classes of Italians and other imported peoples. The board of health furnishes an inspector whose duty it is to look up all cases of unft poultry and other market products. It often spems that, in the case of poultry at least, this inspection must be made with not more than one eye and without any

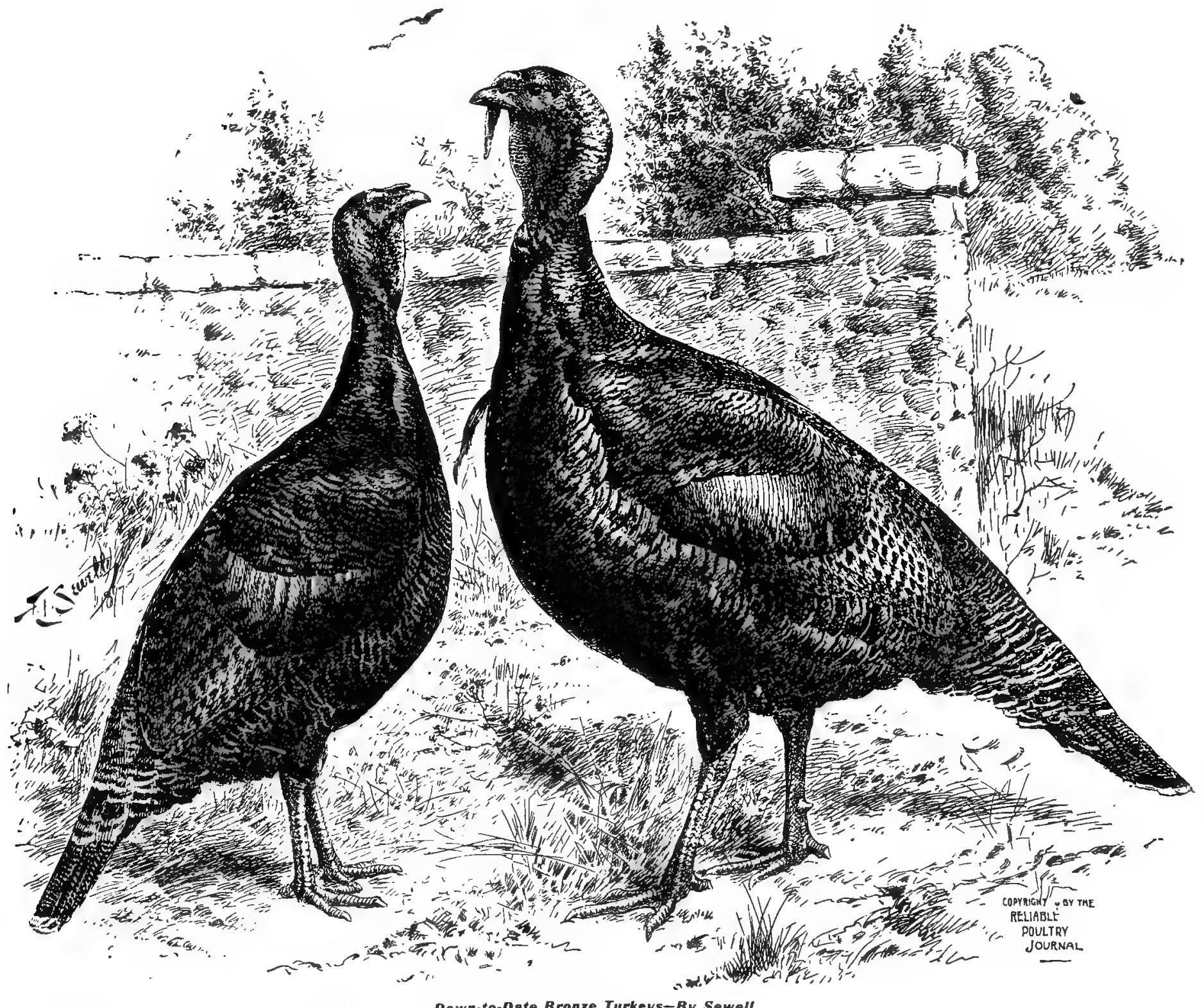

Down-to-Date Bronze Turkeys-By Sewell.

kitchen uses. In some of the best markets there is a continuous demand for turkey wings to be used for this purpose. At the present time, as in the past, any farmer or poultry dedler may, by naking application to the superintendent of markets in Boston, procure the right to certain stands where his wagon may be drawn up without interference from others, and such stock as he has may be retailed direct to the consumers. Not only the farmers and regular dealers take advantage of this permission, but many cheap dealers also avail themselves of the opportunity, and ring in under the pretense of being growers of pnultry and other produce. These men buy the cheapest grades of poultry which come to sense of smell. However, from the apparent health and animal thrift of the buyers it is evident that no great harm is done through the consumption of this ill treated and over ripe sort of poultry.

Another factor which has influenced the poultry market in New England. is the entrance of the western beef dealers into the business of killing and dressing turkeys and other poultry, ani shipping direct to their branches in the larger eastern towns and cities. Whereas, only a few years ago, the small middlemen and dealers were to be found in every such place, now the trade is largely given over to these branch houses, who combine the poultry sales with their beef 
business, and through their abilily and inclination to extend credit to the small dealers, have crowded out the men who formerly made the handling of poultry a special business. Lilke changes have come in the larger city markets. Time was when the poultry dealer in the large markets handled only poultry and game, beef dealers handled beef products, while mutton, pork, fish and other food products were handled by dealers in each line as a specialty. Of late years the lines have not been so closely drawn, and at the holiday season it is no unusual thing to find turkeys for sale in all kinds of places, ana by dealers in all sorts of goods. It is sometimes said that there is only one more step to be taken and without doubt within the next few years the Thanksgiving and Christmas seasons will find turkeys and a miscellaneous assortment of poultry for sale in the large dry goods and notion stores and that poultry', shoes, patent medicines and corsets will vie with each' other as to which meets with readiest sale. At the holiday seasons many old toms are shipped to market with their plumage intact. They are hung by the heels at doors and windows and used as signs by retail and wholesale places alike. Occasionally, in the more reckless sections, they serve to invite the attention of the passers by to some raffle or game of chance which is being carried on within. This custom used to be more common than it is at the present day.

There has been a choice lot of turkeys grown on Block Island, which is some thirty miles off the coast of Rhode Island. So many fish are shipped from this place that the term "Block Island turkey" is more generally understood to apply to cod fish than to the feathered biped to which it belongs. In most parts of Rhode Island at least a man calling for a Block Island turkey would find that a salt cod fish would be promptly weighed out and charged to his account. This concrete application of the joke has dimmed the general knowledge of the value of the genuine turkey crop of the island.

\section{A NEW ENGLAND TURKEY FARM.}

Probably more good turkeys are shipped from Westerly than from any other point in New England. While the numbers which are now sent out from this place do not by any means equal the quantities shipped in past years, yet they far exceed those from any other single point of Rhode Island or Connecticut, and probably of New England as well. In this little section of southwestern Rhode Island and extending across the line into southeastern Connecticut, which is hilly and rocky and looks altogether like a sample of New Hampshire dropped into the lap of Rhode Island, the turkeys seem to be unusually thrifty and to develop the best flesh and flavor to be found anywhere in this country. Why this should be so is a puzzle for the wise men of the poultry business to solve. Whether it is the climate, the quantity and abundance of the insect life or something pertaining to the quality of the soil is unknown to the producer. Perhaps, instead of speaking in a general way of the customs and methods in use in this section it will be better to take an example from the custom of one of the best known breeders, allowing it to stand as a fair illustration of the way the business is conducted by practically all. Of courge different producers vary in detail, as do producers of other varieties of poultry, but in the main, each locality follows pretty much the same neighborhood routine with about the same results.

For purposes of discovery we visited the plant of $\mathrm{Mr}$. $\mathrm{H}$. D. Miner. Mr. Miner is one of the oldest turkey dealers and raisers in this turkey country, and is known far and wide for his success in producing, not only market birds, but show birds as well. The house and other buildings of this place are situated near the center of the 300 acres which go to make up this farm. Situated in a hollow surrounded by hills c1 all sides except the south, and with a live stream fed by springs back in the hills and flowing freely at all seasons of the year, the conditions and situation are the most ideal for all kinds of poultry raising of any plant we have ever seen. The Bronze turkeys are kept exclusively with the exception of some wild birds, which are imported to breed with the native turkeys, thus giving an infusion of new blood and adding stamina to the flocks. White Holland turkeys and Narragansetts are also kept in the neighborhood, but Bronze, either pure or grade, is thought to be on the whole best sulted to the conditions and to produce better poultry than other breeds. Turkeys have been bred continuously on this farm for over fifty years, and very little trouble has beer had from sickness or disease. An occasional fox comes down from the hills and works havoc among the young, but otherwise little trouble is experienced, although the birds have free range of the whole 300 acres, and besides some hundreds more acres are available as extra play grounds if' desired by the birds.

'The females generally lay from fifteen to twenty eggs in a litter and commonly lay two litters in a season, though occasionally a bird goes one better and lays three litters, with a less number of eggs in each successive litter. The birds arc mated, as a rule, with one male to ten or twelve females. Mr. Miner thought that females in excess of these numbers were too many, and that where only one male was mated with eighteen or twenty females, low vitality was apt to crop out in the young from such mating.

The breeding birds have free range at all seasons of the year, and have no house shelter whatever, roosting on poles or tree branches, even in the worst blizzards and the severest cold nights. No pains are ever taken to shelter them in the least from the inclemency of the seasons, and their roosting place is the same whether in July or January, in heat or cold. They naturally take no hurt from the storms and cold except in rare instances a heavy sleet storm may come up and sleet gathering and freezing on the plumage of the birds makes them very heavy and awkward, and in case the wind is very high at such times, there is a possibility of their being blown from their roosting places and suffering injury from the fall which they get. When we remember that the males weigh from twenty-five to forty-five pounds it is easy to see that this weight encumbered by an added weight of sleet and ice would come to the ground with one of the dull and sickening thuds with descriptions of which story writers are wont to grace their pages. It is not strange that such falls frequently result in the death of the bird.

The breeding birds are fed through the winter considerabie quantities of corn. This is a measure necessary from the fact that young and old run together until the surplus birds are marketed and all have free range and are fed alike. Aftcr the market birds are culled out and only the breeders are left, the rations are changed more to oats and wheat and less corn is fed. Too much corn leads to over-fatness in the breeding birds, and this tends to unfavorably affect the brecding. Roughly speaking, about four quarts of feed would be given to twenty birds at both the morning and night feeds. Considerable cabbage is fed in the winter time. This is all the green food which is used and it is very much relished by the birds at seasons of the year when it is impossible for them to pick up grass in their ranging.

\section{DISEASES.}

The old birds are seldom sick. Whenever there is any trouble in this direction it is generally from colds, or roup, or black head. Black head is the common name for the complaint which carries off more turkeys than all other causes combined. It is most prevalent among young poults. Its cause is not well understood. Much attention has been 
given to 1uvestigation and research, but the trouble continues. The Rhode Isiand College has devoted considerable time to the subject, and has had the help of the United States Bureau of Animal Industry. The circular bulletin No. 2 was issued on the subject. After extensive examinaticns and investigations Dr. Snith found that "the hitherto undetermined disease of turkeys was due to a micro-organism belonging to the protozoa, which places the malady among the infectious diseases, so that the idea that it is tuberculosis, or due simply to improper feeding, must be given up." This very lucid explanation of the cause of the disease would doubtless be of considerable interest to the various producers if they only knew what it meant. It certainly has upset the whole business of turkey production in this part of the country, and until some way of averting the trouble is found the business will not flourish as it otherwise would.

\section{SEITING THE EGGS-RAISING THE POULTS.}

The hens generally begin to lay from the middle of March to the first of April, although sometimes one may begin to lay earlier, the severity of the weather and early or late coming spring having much to do with this. The wild turkeys do not lay as early in the season as the domesticated birds. The hens lay in all sorts of out-of-the-way places, oftentimes under a leaning rock or in some slight cavern in the hillside, and are allowed to sit in the same kinds of places. They do better when handled in this way, than where too much care is taken to give them the more complete surroundings which are generaliy considered necessary to successful hatching by ordinary every day fowl. The eggs are all set unüer turkeys, from seventeen to twenty making the average size sitting. Where the stock is properly mated nearly every egg hatches, and the young poults come out strong and sprightly and show a natural genius as grasshopper chasers and all-round bug catchers. For the first two or three days aîter hatching they are shut in a coop with the mother turkey to give them time to get their ranging legs on, and to make sure that the mother does not take them on too long rambies before they are fully up to the task. This, howrever, will not do with the all wild turkeys, as the confinement is very much against their liking and they will dash about so wildly that they are very apt to injure the young birds.

The poults are fed finely sifted, cracked corn which has been soaked for several hours in milk. Great care is taken that the mixture shall not be sour when fed, although sour milk in itself is not a bad food. When, however, the mixture has been kept so long that the corn becomes soured, it is unfit for food and is never used. The poults are fed three or four times a day all they will eat within a reasonable time. After the period of confinement is past, the hen and poults roam at pleasure and have no confinement either night or day. This constant ranging and roaming gives them fresh ground, and every opportunity to gain the strength and stamina which is jo necessary to carry any pouitry successfully along to the best results, either in a market or breeding sense. Fresh water in clean vessels is always to be had from the time of hatching. The vessels are cleaned at every watering time, and fresh water given not less than three times daily. After the roving period is reached on $\mathrm{Mr}$. Miner's farm they liave free access to the running brook and to this pure water supply Mr. Miner attributes much of his success in raising turkeys as well as other poultry. $\mathrm{He}$ thinks much of the disease and sickness which seems to follow the poultry business may be found to originate in stagnant water and unclean drinking fountains or vessels. Mr. Miner is in the habit of from time to time putting a teaspoonful of fine table salt in the watering vessel in the pro- portion of one spoonful to about eight quarts of water. This is a practice which he has followed for years, and which he thinks is highly belleficial to the poultry.

\section{SIZE OF TURKEYS DIFFERENT SEASONS DEMAND.}

The early hatched birds reach a salable size, and are ready for the Thanksgiving rarket, while the later hatches come along successfully and are marketed according to the senson and ruling prices. There is an increasing demand for the broiler turkeys and this is in a measure met by shipments which come through from the west packed in ice. The birds are killed by sticking and bleeding from the mouth. A rope is hung from a pole or beam in the picking house, a noose is made in the lower end and this is slipped over the feet of the turineys. The cut is made and they are allowed to bleed thoroughly before the feathers are pulled. Too little bleeding leaves the carcass less clear and inviting in appearance, and the keeping qualities are not so good as when properly bled out. They are generally picked clean except that sometimes upon the request of the buyers the flight feathers are left in the wing tips, and these are presented to the various customers. The skin does not tear easily in picking and the feathers are pulled as quickly as possible after bleeding. The carcass is hung up to cool and usually is not put into water, nor wiped off with a wet cloth, but is allowed to hang perfectly dry. They are drawn while warm and the carcdss is generally left hanging for about twenty-four hours, when they are packed with heads off or on, according to the market to which they are to be shipped. The wild turkeys bred in this section are conceded to have the finest flavor and the juiciest, tenderest flesh. Wild males crossed on the Bronze females give a very superior quality. The birds have large size and a very fine flavor. The wild males seldom weigh over twenty pounds, and the hens from eight to ten pounds, the Bronze males weight from twenty to forty pounds, the hens from fourteen to twenty pounds, this of course for oid breeding birds, the young birds being proportionately lighter. The best market sizes are from eight to twelve pounds. Nine out of ten customers, when asked what size turkey they want, will answer, "about ten pounds." Anyone having ability to turn out ten-pound turkeys at will would have the biggest kind of a mint, which would turn them out a fortune in short order. At Thanksgiving time the old toms and old hens are, as far as possible, worked off and what are not gotten rid of at this season generally find their finish at Christmas time. It is only at the holiday seasons that extra large birds sell at all readily, and when marketed at other times the sale has to be forced and the prices very much reduced. There is a limited demand for young turkeys weighing from fourteen to eighteen pounds, but where there is one call for a fifteen pound turkey there are rery many for such as weigh from ten to twelve pounds, and later in the season, as the spring months approach, there is an increasing demand for birds weighing from seven to nine pounds. This want is met by storing away in the freezers in times of plenty birds of this size. They are held in cold storage until the later demand comes, when they are withdrawn, and in this way the supply is made to approximate the demand.

Were it not for the cold storage facilities which bave grown up within recent years, the poultry business in its present proportions would be impossible. Before this system came into generai use such shipments as met with slight delay in selling, or had to be held for any cause beyond a few days' time, rapidly lost value because of the inability to keep the poultry sweet and free from taint. This was especially true of the spring months. The proportionate loss during March and April oftentimes took up the profits which 
were made on the sale of goods. It also confined shipping from the west to the coldest months of the year. Under the present conditions, however, birds may be shipped in refrigerator cars, or packed in ice, and upon arrival, if the market is dull and sales slow, or if the price falls below the shippers' figures, the entire shipment may be placed in cold storage and held inclefinitely without deterioration in sweetness, though after thawing they will not keep so long nor so well if they have been kept frozen for any great length of time. We know of one lot of chickens which were recently taken out of the fieezer which have been so stored for three years. They were perfectly sweet when taken out and the appearance was good. They lacked keeping qualities, and had to he very quickly disposed of after thawing. As is well known, poultry in these freezers is kept solidly frozen, and the carcasses are covered with white frost. If, after removal, they are to be quickly thawed, the common custom is to throw them into a tub, barrel or tank of cold water, where they are allowed to stay until ihe water has taken the frost completely' out of the carcass. It is not uncommon to find little lumps of ice foating in the water which have been formed by the frost which is drawn from the poultry. Most consumers of the well-to-do classes profess antipathy to all frozen poultry. The facts are that, when the poultry is fresh killed and in berfect condition, cold storage does not seem to make much difference in its flavor or appearance. Where it has been kept until in danger of spoiling, or is imperfectly dressed, it does not appeal to the fastidious taste after having been frozen for an indefinite period and then thawed. The flesh lacks juidiness and Havor, and to many it is altogether unpalatable as food. Rhode Island turkeys seldom or never reach the freezer, but are generally sold within a few hours of their arrivai in the market. With western turkeys it is very different. Many whole shipments go into the freezers rather than to sell at market quotations and a great mary are bought on the low market and held by the various dealers to be used through the summer months. Roast turkey is as common in July and August at many of the summer resorts as any other kind of poultry, and this is only possible berause of the modern storage facilities.

Several experiments have been made in shipping western live turkeys to New England, where they have been kept and fecl and, wr.en in suitable condition, killed and marketed as Rliode Island turkeys. This, however, has rarely proved to be a paying venture. The birds come through in very thin and poor condition and whether from the change of climate or because of unfamiliar surroundings, they are slow to take on nesh, and a great many are lost from one complaint or another. Tilose winich do reach the killing period by the ordinary stages lo not turn out as good poultry, nor compare at all favorably with the native stock of this section. The turkey is naturally timid in disposition and it is doubtful if they ever can be handled and changed about from one place to another in large numbers without deterioration in market qualities.

The future surcess of turkey production in New England depends upon the ability to cope successfully with black heal and kindred complaints, which now weigh so heavily on the industry, and perhaps in the majority of cases dishearten the growers, and eventually cause them to give up the attempt. If, therefore, through experiment, study and help of the colleges und aifferent stations, this trouble may be overcome, it will result in a decided boom in New England turkey culture, and will add decidedly to the money making possibilities of the more remote and far away farms. Of course, in the wore thickly settled farming regions the extensive production of turkeys will probably never prevail. The bird is it natural rover and does best when allowerl to ramble and loam witnout let or hindrance. Where the farms are near trgether and ccnsist largely of garden plots and cultivated grounds, a roving band of turkeys may, and will, make disastrous work over a considerable tract. To avoid too much trespassing and consequent ill feeling, some keepei's, in the old ciays, used to resort to a contrivance which was called a yoke, and which consisted of a thin board through which holes were made and which fastened by strips of clath across the turkey's back, the strings passing under the wings, fastening the board to the back, thus preventing the birds. fiying, and they colild be kept in any desired enclosure. The custom seems to have gone out of use. It is douhtful if any mechanical arrangement which makes unnatural conditions for the birds will ever prove altogether suecessful. Probably the only way to profitably produce large numbers would be free range, great attention to breeding stock, extreme care of mating, and the introduction of new, strong blood and the numerous little details which come to the knowledge of all poultry breeders. It is doubtful, in fact, if production in large numbers is altogether practicable. The greatest. success and the largest proportions of profit are made with small flocks of from ten to twenty breeding birds. These require vely little attention, no extra facilities, and the product counts largely as profit, and if these flocks could be scattered broadcast over New England farms it would result in the addition of many thousands of dollars in extra revenue witb very little increase in cost. GEORGE H. POLLARD. 


\title{
SUCCESS WITH TURKEYS.
}

\author{
TIme and Method of Maklng a Start-Housing and Feedlng Breeders-Nests and Food of SIttIng Turkeys-Care of \\ Poults-Lice-Fattening Stock for Market-Preparing for the Show Room-Dlseases of Turkeys.
}

By Mrs. Bettie Glover Mackey.

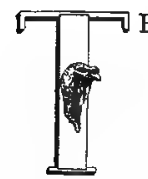

RILI there is more interest taken to-day in poultry culture than ever before in the history of the American people. There seems to be an awakening to tine fact, long proclaimed by a few, that there is money in poultry. The question is seldom asked now, "Does poultry pay'" The form has thanged and the question now is, "How can I manage my poultry to get the best returns?"

It seems to me that the poultry business, and especially turkey culture, is one belt $\pi$ hich reaches around the globe. America is sending fine turkeys to foreign countries, and the west is furnishiug the east with her best turkeys. I have shipped turkeys and eggs from ocean to ocean, from Canada to Mexico. The turkey is one American bird that will thrive in any land, will grow on any soil, or in any climate, and is considered a luxury by all, from the king on his throne to tive humblest laborer in his hut.

There are more specialty fanciers than ever before, and in no department of poultry culture is there more interest taken thall in the iurkey department. Of the many varjeties, the Bronze is the leading one now bred. It is hardy, ensy to breed to standard, has fine style and is a beauty in cclor. It is of quick growth and will attain immense weight if fed for flesh. Tine objection is urged that the Bronze is more roving in disposition than other breeds. This disposition to roam is not confined to the Bronze alone, and the roaming turkey is more healthy than the one which hangs around the back donr. Whether any other one will ever supercede the Bronze in popularity remains to be seen. Of one thing I feel assured, and that is that no breed now in existence will ever rival them. What may be produced by a cross we do not know.

While there is general admiration for the turkey, and a desire to raise them, there seems to be, among those who have never handleã them, an impression that turkeys are very hard to raise, very expensive to keep, and difficult to manage as to disposition, that is, that they are such a roving and wild nature it is almost impossible to keep them at home or tame them. This last impression has grown out of the first. For years it was the custom, when turkeys hatched on the farm, to take them as far from the house as possible and put them in a place of security from vermin, and the only person who went near them were those taking them food. This was said to be the only way in which they could be raised, for if they were kept ncar the house they would be sure to become unhealthy and die. I well remember when I thought this true. Of course, turkeys thus raised became timid and ran from every thing or person they saw. They were generally fed until six or eight weeks old and then allowed to make their own living. Naturally of a roving nature, they did not seek quarters near the house, and $I$ have seen them fly to the highest trees whenever they were approached. They would tear down shocks of corn, for how else were they to get their living? No one thought of fueding them.

\section{WILD TURKEYS IN VIRGINIA}

I do not agree with persons who think turkeys are bard to raise and keep healthy. But they cannot be raised in a haphazard manner. Follow nature as nearly as possible and the poults will do better.

Wild turkeys abound in warm, woodland countries. In the pinelands of Virginia (my rative state) wild turkeys grow in large flocks. This is a mountainous region, rocky, abounding in springs of crystal water. The pine trees are in all forests, and it is said that there is more or less of the properties of turpentine in the water. Tven in rainy seasons the rocky hills are not very wet and there are such large, sheltering twees tine hen turkey call protect her young in the hardest storms. The seasons are mild and the pine trees are said to be a preventive of vermin. As turpentine is sure death to lice. I think it reasonable that the pine will prevent them. There are abundant seeds and wild food for the fowls, with plenty of iusects and grit.

Following this lesson in nature (where the wild turkey thrives and iarge droves of tame ones are raised) I draw the conclusion that a hilly, rocky slope is a good locality; that turkeys must be kept dry, have plenty of pure water and fresh air, and at the same time not be allowed to become chilled. Either they must have a place where there is plenty of grit or it must be supplied to them. I do not favor -iving poults or chicks hot feed. It is not the natural way and we cannot improve on nature. I have succeeded in raising strong, vigorous, gentle turkeys. That it is their nature to roam cannot be denied, but this may be greatly overcome by the treatment they receive.

\section{BEGINNING WITH EGGS.}

Frequently I am asked which is cheaper to begin with, eggs or stock. This question can be truthfully answeredEggs and stock. Circumstances and surroundings largely decide which is cheaper. If you have the money buy a trio of turkeys; if not enough for a trio, then a pair; but if you have not money enough to buy the turkeys, buy a sitting of eggs. I have made some very profitable investments in eggs.

I have been asked if turkey eggs will hatch after being shipped? I reply that where eggs are rightly packed and fairly handled there is nothing in the shipping to prevent a hatch. But there is a great deal in the hen under which they are set. From exactly the same lot of eggs set at the same time one hen will hatch several hours before the other and will hatch every egg, while the other hatch will be very poor. If you break the eggs decide whether it is the fault of the egg-an infertile egg will not rot, but will be as clear at the end of the hatch as when set. Turkey eggs are usually better fertilized than chicken eggs.

Follow these directions when sitting shipped eggs: Al- 
low them to rest twenty-four hours after receiving them; longer will not hurt if kept in a cool, dry place; put them under a quiet hen in a quiet place and disturb her as little as possible. If the weather is dry sprinkle the eggs with warm (not hot) water a few days before they are due to hatch; be sure they are clean. If an egg should be broken the others must be washed with a clean cloth in clear rain water; be sure there is no grease about it, as grease will prevent the eggs frcm hatching.

\section{BEGINNING WITH STOCK.}

I should advise the beginner not to buy more than id trio. The mistake of almost all beginners is that they want to start with too many.

When writing for breeding stock state just what line of business you are in. Do you wish to sell your stock on the market or as breeders? Do you wish to raise exluibition birds or simply good pure birds? Much of the unpleasantness between customers and advertisers would be obviated if each inquirer wuld make his wants clear.

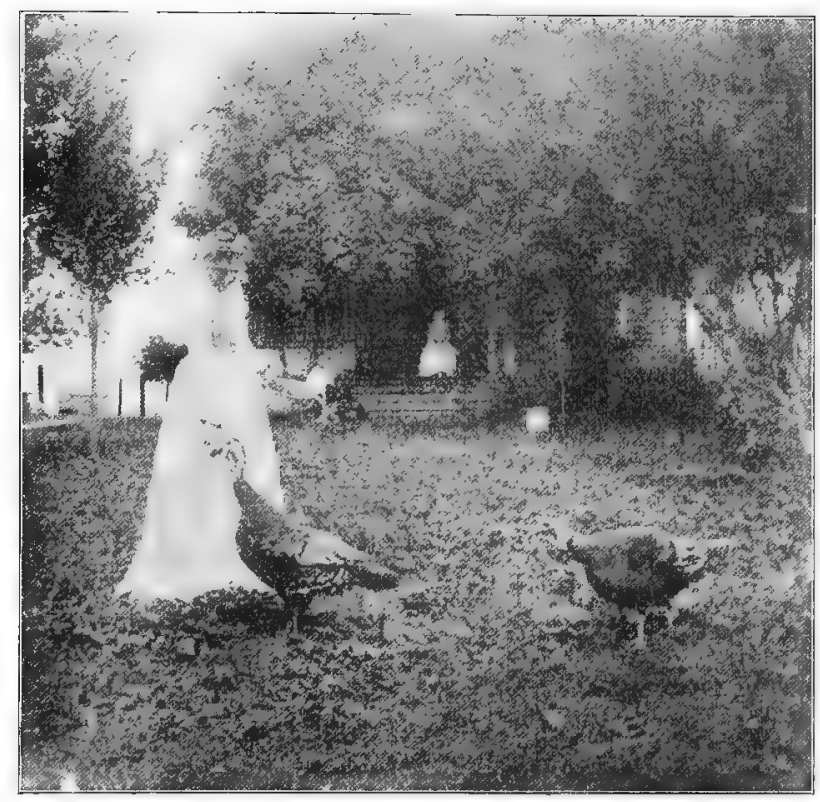

\section{Mrs. Mackey and Her Turkeys at Home}

I think from the 25th of November to the first of February the best time to buy breeding stock. The sooner it is purchased after the first of December, the better, for at that time fanciers have plenty of good birds, while later you may have to take what you can get. Turkeys always pay, and while it may seem expensive to pay for a tom to change blood, it will pay in the vigor of the young turkeys next year.

Do not hunt for the cheapest, but try for the best. This is not always the heaviest in weight, but the best bodied and the best in quality. Look out for healthy, vigorous stock. Do not wait until the weather is too cold to have the birds shipped without getting the roup. You may think this strange advice when I tell you my turkeys roost in trees all winter, but I have noticed that if you take a turkey that has been used to the cold and put it into a warm place and then expose it to the cold it is liable to take cold. This is what is done when turkeys are shipped in bitter cold weather. They are put into warm cars and exposed to the cold after being taken out and changed into a new home. Buy your breeding stock early and turn it out and let it get acclimated and used to the new home by breeding season.

The most important part of turkey culture is to start with strong breeding stock. I will not breed from a fowl of any kind that is delicate. If I have weakly chicks or poults hatched I am always glad when they die. Yet it is true that a chicken or turkey may take cold and have a sore eye or head for a short time and not be materially injured as a breeder. But when the disease becomes very bad or chronic, better kill the bird, for the progeny from a bird with a chronic disease will never be of any account.

\section{INBREEDING AND LINE BREEDING.}

In selecting or buying breeding stock, do not buy inbred turkeys. If you do you will lose by it. Possibly you may get better markings, but can you afford to sacrifice the vigor of your flock for these?

I have been asked if I think it will do to breed from the same tom two years. The question, I presume, has reference to using a tom with his pullets. There may be circumstances where this could be done to advantage. In order to secure certain points it might be done, yet I think not without loss in the number of turkeys raised. Demand, when ordering a trio of turkeys, that the breeder send male and female not related.

I advocate line breeding and practice it. But this may be done very easily without close inbreeding. I do it by mating on different farms every year. By looking up every sale and the yard from which the stock was taken, I avoid selling related stock. If a pen or trio is ordered, the tom is taken from one yard and the hens from another. These are booked, and if the same customer orders again he gets new blood. To introduce new blood, I buy eggs and use the toms in cne yard, the pullets in another, thus keeping my own line, but introducing new blood. If necessary, I import a tom at the breeding season.

One who has common turkeys would like to know whether it would be best to grade them up or start with thoroughbreds. I think this is simply a matter of what you wish to do with them. If only for market, the cross with a full Bronze tom will increase the size and beauty as well as the vigor of your flock. But why not get the best and sell your toms as breeders to your neighbors? If you have the full blood and are the first in your neighborhood to get them, you can more than replace the cost in the excess of the price over market turkeys.

Another asks, "How can I get larger turkeys? I have the Bronze, but they do not get as large as some I see advertised."

Very often those advertised are never seen except in the advertisement. But it is a fact that the size of turkeys may be increased by breeding from not only good individual birds, but from birds of good stock. The greatest reason for production of smaller turkeys is in the breeding. To save the price of a tom, a breeder decides to use one from his own flock, year after year. I do not know that using the same tom two years would cause the turkeys to degenerate in size, but the habit of inbreeding is injurious.

Again and again comes the question, "Do you prefer an old tom or a young tom "?" I can truly say, yes and no. It all depends on the conditions. I let the purchasers have their choice, but I always give to customers preferring young toms those which were bred from either yearling toms or yeariing hens, and often both. Where young toms are bred with yearling hens or pullets of large bone and large ancestors, I see no difference in the size of the young. Still in my own breeding yards I use the old toms, for people want eggs from the largest stock to be found.

\section{VIGOR, SIZE AND FANCY POINTS.}

Several have written asking which $I$ think is the most important point to consider in breeding stock. My reply is, first vigor, then size, and then fancy points. The reason I consider strong, vigorous birds the first point to be looked 
after is patent. If the parent stock is not strong, the young will not be so. Mind, I do not say weight, but size. Turkeys that are not large 1ramed birds may weigh very heavy, especially young stock, but after they are fully matured the little boned birds will not weigh so well.

Why do I say I consider size first? Simply because the standard requires weight and cuts harder for lack of weight than for auything else, and if we have to be governed by the standard we must come to consider size in breeding stock. If you were to ask my personal preference, I might give a different reply. The fancier must consider size in order to win in the show room, and then the turkeys are "cut all to pieces' on weight which they lose in shipping. Again, the fancier mist consider size because ten customers require laino turkeys where one requires fancy points. But the fancier must combine the size and fancy points and this takes study in mating. It is not the rule that the largest turkeys in the flock score tlie highest. be they ever so well bred.

1 will never believe that the demand for immense weights required by the standard and turkey raisers is wise. I have lost the heaviest turkeys I ever owned simply from being over lat, and I do not feed very much for flesh, either. It is not unusual for me to lose sales because I cannot quote as heavy weights as are demanded, yet I have as large turkeys as any fancier. I know over-fat stock is not good for breeding purposes, and so does every one who has given the subject any carcful attention, yet a turkey must weigh so many pounds regardless of consequences. If the would-be pul'chaser would be satisfied with standard weights then there would be some reason in the demands, but $I$ have often received inquiries in November for young toms weighing from thirty pounds up to sixty, "sixty preferred." Now everybody with common sense knows, or should be taught, that in this climate it is almost impossible to make a young tom weigh thirty pounds in November. or even December, and that to do so is an injury to breeding qualities. From January to March young toms may weigh from twenty-eight to thirty-two pounds without any special effort at fattening them. I prefer a pullet from sixteen to eighteen pounds rather than one heavier, and I know that I voice the sentiments of some of the best fanciers in the United States. The over large hen does not lay so many eggs, nor are those she does lay so fertile.

It will not be many years before this demand for excessive weights will be greatly. modified. Market poultrymen say our Bronze turkeys are too large for their trade, and the market pouitrymen must control the turkey trade. If we continue to increase the size of the Bronze, some other breed will take its place, and when this happens the Bronze turkey fancier who has tried to excel all others by breeding the heaviest weights will see this error.

I hope $l$ will not be considered as advocating small turkeys. for I am not, and I could call hundreds to testify that I stand for large boned turkeys. The weights of mine as adults have not been excelled in the west, but what I do plead against is the demand for the pound of flesh, which is far easier to put on the short legged, small boned turkey, than on the tall, majestic fellow, that will, as a yearling, weigh from thirty-five to forty pounds. The extremely heavy weights are fit only for the show room and the fan cier's yard, while the medium sized bird is the better turkey for all purposes. I do not like to breed from excossively large turkeys, neither does any other fancier, and yet the fancier has created the demand for these birds by advertising excessive weights to catch trade, and the farmer has caught the spirit, and without really knowing what is best, demands what he sees advertised.

If I were a farmer raising market poultry I would want turkey pullets weighing from fifteen to seventeen pounds, good large-boned birds, not fat, and young toms weighing from twenty-four to twenty-eight pounds, or yearlings from thirty to thiriy-five. I would hatch my turkeys early and in the fall they would be as gool market turkeys as anybody would want. I would keep the pure Bronze turkeys, for nothing has ever equalled them. I would not do as some have done--inbreed until I decreased both vigor and size of my birds, nor woula I save the late small, runty turkeys to breed from. I would save nice pullets and yearling hens and buy a tom from some fancier every year; or if I were short of money I might keep one two years, though I prefer changing stock every year. One tom is sufficient for twelve hens, and more may be used with perfect safety. I would keep more hens than most farmers' wives do, and instead of breaking them up from sitting, I would let them sit on their own eggs, or if preferred, I would set the eggs pari under the domestic hen, giving all the young to the turkey hen, and if I did not care to keep over so many hens 1 would sell the surplus after they had laid the early eggs. I raise la.te turkeys, but if I were not a poultry fancier, and were raising market poultry, I should not raise late turkeys; early ones are much more profitable, they are much hardier during the summer, and are not so apt to be affected with the disease which takes off hundreds of young turkeys in the fall.

The farmer should learn that he needs good, strong large-boned, vigorous breeding stock, such as will take on flesh when he wishes to market them. Nobody wants a poor turkey to eat and if the ten-pound one is fat and brings more by the pound than the twenty pound one it still pays to have the twenty-pound one, but when the marketman says he can scarcely use the forty-pound ones at any price because only hotels and large restaurants want them, the farmer has no need for forty-pound young turkeys, as some demand.

\section{BREEDING FANCY TURKEYS.}

As to shape of tom and hens to breed from-I select large head and feet, long body, long neck, held well up, and a broad back and breast, with long shanks̀. A short turkey wiil fatten carlier and look larger when not fully matured than the rangy one, but the latter will make the weight at maturity much heavier, and will produce larger turkeys. I select hens the same way, yet if they are specially well marked and good in weight I would not discard them if not quite as tall as I like them to be when pullets. I am sometimes disappointed in pullets, but cannot remember that I ever have been in a tom-pullets sometimes are no larger at two than at one year old. They often stop growing at one year, while a tom never does. Other pullets grow until they are two and three years old.

My method of mating is simply this: Select the very best tom possible, and in females do not discard a very fine marked one because it is not quite as large as desired. By this I do not mean that I breed from small boned females. There are some larger than others in all flocks of the same age, and I should not advise the use in the breeding pen of an undersized female, ur a runt. Nor should I discard from my breeding yard an extra large female because she is not quite up in fancy points for the reason that the tom will overcome to some extent the defects. The well marked female will produce large stock from the mating with a large tom, and the one not so well marked will produce evenly marked young from the mating with a well marked tom. Yet these must be exceptional cases, for it will not do for a fancier to have many females in his breeding yard that are not well marked and not very large. By undersized, we mean yullets, for if at two years old a hen is not of average size I should discard her unless there were some special point I wanted to 
impress on my flock. I think young turkeys get size from the maternal side, even more than from the paternal. Never should a fancier use a iate, small-boned tom, or a poorly marked one. As a rule toms get very thin in summer if mated with hens, and they do not eat a great deal until cold weather. I have known a tom to weigh twenty-six pounds in November and thirty-five by January. Turkeys will gain two pounds a week in cold weather, unless there is snow on the ground, then they will stay on the roost and will not eat.

I once had a red legged turkey pullet. She was not large when young, but her legs were almost too deeply colored to be called pink. I bred from her as long as she lived, or, I should say, until she was stolen. I could tell the turkeys from her eggs. They were a good size and invariably had pink legs when young, though not as deeply colored as were hers. From this hen I got that line of breeding which gives in some of my yards pink legs in young stock. I can tell it wherever I find it. But this is the only female I ever kept that was undersize after she was a pullet. The rule is that the shanks are dark when young. Some of the best hens in size have dark shanks always, while others get very bright pink-I prefer the pink legs, other things being equal. But I am candid when I say that I make size and not weight the first consideration in breeding stock.

Never breed from a turkey with a natural deformity. I once bought a sitting of eggs from one of the foremost fanciers I know. The only pullet raised had a crooked toe, but she was so fine I felt. I could breed from her. Every year there would be a lot of turkeys with crooked toes, and these were the very best otherwise. It took several years to get entirely rid of crooked toes.

While there are fewer culls among turkeys than there are among chickens, it is also true that under the present standard some of the very best breeding birds are not firstclass exhibition turkeys. For instance, all turkey raisers know that there is a tendency to brown edging on tail coverts in some specimens, and it is a notable fact that these specimens are usually very strong in wing barring and that they are decidedly larger boned than those which possess the standard gray and white edging. Now such a bird cannot be sold for exhibition, but if one is raising turkeys for market and selling toms to other market breeders, what better breeder would he want than this same brown tailed turkey, for as the market poultryman pays for pounds, it is the tom with size that one raising for market must get. Again, one may be poor in wing for exhibition and fine as a breeder. Yet I am sure that at least ninety per cent of the best bred Bronze turkeys can be put on exhibition when fully up in weight, and whether they win a prize or not they do credit to the owner. The main thing in breeding is to select healthy, vigorous breeding stock of good size and shape, with the very best markings possible. Don't expect perfection, but try to attain as near it as possible. Patience, perseverance and knowledge will bring success.

\section{CARE OF BREEDING STOCK-EGGS.}

When once you have your stock, be sure that you get your turkey eggs. To do this I keep my turkeys penned. I would prefer letting turkeys run at large if I could do so with much convenience to myself. But to follow from twenty-five to thirty turkeys to their nests is too great an undertaking for $m e$, and $I$ keep them in a large pen until after they have laid. Each afternoon about 4 o'clock I turn them out in an orchard of blue grass. After a few days they will come to the gate and call to get out. If I forget, they do not; but they always go back to the pen to roost. I find grass very essential both to the ferility of the eggs and to increase the number, and also to keep the turkeys healthy. If I were so situated that I could not let them out to eat grass, I would feed wheat bran with flowers of sulphur in it every other day in small quantities. There must be sulphur to insure fertility, but the grass supplies it. Plenty of lime, gravel and grass, with wheat twice a day, is all turkeys need. If too closely confined turkeys will not thrive and I believe that the freer the range the more eggs the turkey will lay, but when they lay where you cannot find the nest and you lose both hen and eggs, as I have often done, you will prefer to get the eggs they do lay in the pen.

My turkey house is sixteen feet long, eight feet wide and has two partitions, making three rooms in it. It is made of barn boarding sixteen inches wide. Two of these boards are put together at the bottom, but as they go up cracks are left so that the air can pass through; however, they are too close for animals to get through. It is one-half foot high in front and three feet in the back and is set out in the orchard where the poults will have a seven acre range of their own. This turkey shed has proved a success, and my young turkeys have seldom failed to come up at night. I think the large, airy roosting place provided has had something to do with their coming up, for in small roosting places I was always compelled to drive them in, while all $I$ do now is to turn them into the pen and they go to rcost themselves.

The fence is the best I have ever used. It is made of straight farm fence wils, with stays and locks. The wires are only three inches apart at bottom, and the distance apart is increased as they get higher.

I do not like to cut the wings of large turkeys for they often get up in trees and when they fly down they hurt themselves. My show birds are often spoiled by cutting the wings. They do not always grow out in time for the show. I do not cut the wings of the toms because they will stay with the hens.

The natural instinct of the turkey is to roost high and in ordinaly weather I think it is best for them to be out of doors. My experience is that the first turkey to get iroopy is one roosting low in the same place night after night, unless the droppings are either removed frequently or the impurities counteracted by frequent applications of either air slaked or quick lime.

I am ofren asked if one living on a small place can be suceessful with turkeys. If by small place is meant a town lot, certainly not. If an eight, ten or twenty acre place is meant, you may be successful with a limited number; and if you trespass on your neighbors and they allow it, you may be successful with a larger number.

It is no longer a question whether turkeys can be kept on small space successfully, for so many overworked women are penning the birds and so getting eggs with much less labor, proving that with proper care the stock will be just as vigorous. We do not claim they lay quite as many eggs, but we get more of them.

My experience has been equally divided between a farm and a small place for raising turkeys. I have lived seven years where my turkeys had unlimited range and seven years on an eight-acre place. I give the farm the preference after the turkeys are grown. Until they are six or seven weeks old they do as well on a small place, but from that time until they are grown the larger the range the better for the growth of the young turkeys, and yet the finest turkeys I have ever raised were raised on the small place; but this is not an argument, in 'Favor of it, for they could have been raised with ruuch less labor and expense on a larger one.

\section{HOW MANY HENS TO A TOM?}

I make twelve hens the number for one tom, as a rule, but once I kept twenty hens with a tom that was two years old in May or June, ancl never had eggs hatch better. The question of how to manage when more than one tom is de- 
sired in the same yard, is a troublesome one. The most satisfactory way in which $I$ have managed it is to let only one tom in the yard at a time. Let one stay in the yard several days, keeping the other where he cannot be seen or see the turkeys in the yard. Then change, putting the one in the yard in confinement and letting the other out. Some advocate changing toms every day where changing is practiced at all, but I prefer letting each tom stay in the yard several days at a tine. Where more than twenty hens are kept, two toms should be used as above directed if all the hens are kept in the same pen. After the hens begin laying one tom may be disposed of if so desired. After the first clutch of $\mathrm{cggs}$ is laid I find that all the heins never lay at the same time during the season. Some are sitting, some stop laying and begin again, and some carry turkeys, so that one tom is sufficient after the first fertilization. But it is always safe to have the second one at command if one should die.

How long can a tom be used, or when is he too old for service? I do not know. I use them two years and have sold yearlings that were kept three years. I never go to extremes in mating, that is, do not keep too old or too young breeding stock.

\section{FEEDING THE BREEDING STOCK.}

'The breeding stock should never be excessively fat. All stock raisers will agree with this assertion. There is nothing more productive of soft shelled and infertile eggs than over-fat hens and toms.

What to feed for the production of eggs has been a question. I confess that I have lost faith in hot mashes for either chickens or turkeys, and I never feed hot food to either young or old. Neither do I give hot drinking water. I was first forced to adopt the cold feed from sickness. I could not get anyone to prepare a mash that did not make it sloppy and I soon learned whole grain was far more healthful than sloppy food. If turkeys have free range during laying season they eat very little that you feed them. Keep grit and lime on hand in abundance and sow wheat for them. If it is laid in a pile they often leave it, but if scattered broadcast they will pick all day. "Turkeys in their normal condition do not sit around during laying season; they are active and want to roam and pick as they go. I often scatter the food after they go to roost, as they are early risers and begin picking before I have time to give them their breakfast. One thing you may depend upon and that is, to have turkeys lay well, and lay fertile eggs, they must have an egg producing diet in some way. If they run at large they will get this without any trouble to the owner, but if they are confined it must be given them. One year I fed soaked oats with excellent results, but I would not give oats without soaking them. I mix shipstuff with them so they are not so wet. Wet food sours in the crop.

When should turkeys begin to lay? The rule in my yards is, about the middle to the last of March. I have once had turkeys lay the last of February. My mother told me the "old-fashioned turkeys"--by that she meant the common ones-laid earlier than the Bronze. I think the climate may influence the habit of earlier or later laying. In a southern climate they lay earlier than in the northern.

If you want many eggs, you must breed from yearling hens and pullets. Old hens do not lay as many eggs, and extra large ones do not lay as many eggs as smaller ones. A tall turkey will lay more eggs than a short one. Why? I do not know. I think the last eggs laid by the hen before sitting sometimes produce poults with less vitality than the others.

Will the eggs from yearling turkey hens hatch as well as those from pullets? I think they will, the greatest danger of infertility lying in getting them over-fat. They must be kept vigorous and healthy, but do not overfeed in order to get weight.

I am often asked how many eggs a turkey hen will lay. One of mine last year laid eighty, which is the largest number I ever could vouch for. Of course she was not allowed to sit.

One asks, "Do you think July too late to hatch turkeys?"

We have two toms which weighed in March twenty-eight pounds without having been fattened; they were hatched July 3.

July and August hatched turkeys of large vigorous stock make good breeding bircls the first year, and excellent ones the second year, but unless scarce of breeding stock we usually farm out the late hatches the first year, and put them in our breeding yards the second. From these late hatches we give our turkey dinners during the winter.

I dispensed with the barrels this year, having only one. I put straw in the hollows and covered them over with brush, allowing the turkeys to think they were stealing their nestr. From twenty-six hens I got seventeen eggs per day, showing that confining the hens as I do does not materially lessen the egg yield. When the eggs are removed as they are laid, and I think it should be done every day, either nest egg gourds, china nest eggs or real eggs should be put in the nest. Few turkeys will continue to lay in a nest after all the eggs are removed from it. I usually put three or four infertile eggs in the nest as soon as I find a a turkey has laid in 1t. This often saves much trouble, and yet with all $\mathrm{my}$ care every year I lose both hens and eggs, for either a rain washes out a hole, a wind blows down the fence or they fly out after their wings grow out and steal nests.

\section{CARE OF SITTING HENS-EGGS-NESTS.}

How many eggs will a turkey hen lay before she sits? Some lay more than others, but I never had a hen that laid more than fifteen or sixteen eggs before she wanted to sit and I have many more that lay only twelve than I have that lay fifteen. A turkey hen may easily be broken from sitting il she is taken in time, and by this means I often get twenty to thirty eggs before I allow a hen to sit. A hen will lay in ten days after she is stopped from sitting and sometimes in shorter lime.

If you do not wish to make the nest as suggested above, then use not a flour nor lime barrel, but a salt barrel. I turn the barrel down on the side, putting it under a tree or in a shady place. The turkey will scratch the nest up for the first few days, but the barrel is a temptation she cannot resist and she will lay in it. I always put down several barrels, though I find the turkeys all like to lay in the same one.

If the hen is thorouglily dusted with a good insect powder when set, and the top outside of the barrel lightly painted with a good lice killer, she will be free from lice when the hatch comes off. Be sure in using this that you do not put it where it will touch the eggs or feathers of sitting hens. If you do you will in all probability fail to get a good hatch.

I set from seventeen to nineteen-never more. If the hen is large and the nest well made, nineteen eggs may be put under her safely.

Usually I have a turkey and domestic hen hatch the same time and give all the turkeys to the turkey hen. I have not been as successful with domestic as with turkey hens until this season. I know two other breeders who raise turkeys altogether with domestic hens, and they are very successful indced. As a rule, however, the turkey hen is the better mother, especially after the poults are seven weeks old, for other hens wean them too early. I think a very good plan is to let both chicken and turkey hens have young turkeys the same age, and when the chicken 
hens wean those under their charge the turkeys will let them follow them and care for them all.

Do not set your turkeys where there will be anything to disturb them. When they hatch to be careful to handle them very gently. If I ind I have one cross turkey about to hatch, and 1 have a gentle, kind one not due to hatch, I exchange the eggs and let the gentle turkey hatch the brood. I find to prolong the period of incubation tones the refractory disposition and often a turkey that will be fussy at the end of four weeks, will be gentle at the expiration of five.

Few people, comparatively speaking, know how to set a turkey or domestic hen, or how to catch either a turkey or chicken. When you find your turkey broody, let her alone until night. Have your nest prepared in some quiet place where she will be undisturbed by other fowls. Make the nest with care. I like the grass nest better than anything else, but as I do not have a bountiful supply of this I use wheat straw. I do not like hay nests at all. Make them very much the shape, but not so deep, as a wash bowl. If too deep the eggs will roll over each other and either be broken or they will not be kepl of an even tempurature during inculation. Make a full, thick nest, for four weeks' sitting will mash the straw down very much. Put two or three hen eggs, as they are not so valuable as turkey eggs, in the nest. At night go to the hen very quietly and put both hands unuer her, taking her firmly by the leg, close to the body and lift her straight up. Don't drag her out of the ucst. Put her head under your arm gently, talking to her all the time. Place her on the new nest very gently and set a blind firmly in front of it. The next morning you may peep in. It will be an exceptional cașe if she is not sitting as well as she did on her old nest. I look at her again about roosting time. If I find her restless I let her off. If she is kept on the nest in this restless, nervous state, she will break thc eggs and likely will not sit at all. She will probably try to get to her former nest, but as dark approaches she will go to the new one; or if she does not allow her to go to the old one and remove her as before. I have often had to do this several times with one hen. As a rule, however, the second time is enough. You may say that it is a great deal of trouble. I cio not call it trouble. It is work, and I learned very early in life that to be successful in anything required patience and work.

After the hen has fully decided to accept the nest given her then put the turkey eggs under her. So many people waste by haste. What difference will two, three or four days make in the age of the poults: But what a calamity to have a sitting of turkey eggs spoiled by a restless hen.

I usually give my turkeys the opportunity of getting off the nest every day. I find this much more satisfactory than keeping thern so long without allowing them the chance to get off. Often they do not come off for several days, and $I$ had one hen that never came off in four weeks except as I took her off the nest. I then had to put the blind up in front of the nest and force her to stay off long enough to eat. I thought that I certainly would have a. good hatch from this hen, but I had only ten poults from seventeen fertile oggs. She had smothered the turkeys by sitting so closs. Turkey eggs hatch better than chicken eggs, but they require more moisture.

If the weather is wet $I$ do not moisten the eggs, but if dry I sprinkle them the last week. When the eggs have been setting until within three or four days of the time to hatch, put them in clean, warm water-100 degrees is about right, or if it goes to 104 it will not hurt. All the eggs which bave live poults in them will move very per- ceptibly. Those which sink to the bottom have dead poults, and those which float without any jerky motion are spolled or infertile. However, the infertile eggs usually sink.

\section{TURKEY EGGS IN INCUBATORS.}

Will turkey eggs hatch in an incubator? They certainly will. I once told, a lady that from fourteen turkey eggs in an incubator I got fourteell turkeys. She in all seriousness replied that "a hen would do as well as that." If you expect more than one turkey from an egg an incubator will likcly disappoint you. I do not hatch turkey eggs in an incubator becalise $I$ do not wish to raise the young in brooders; but if an egg gets broken $I$ put it in an incubator. Last season the filest young turkey I had hatched was from an egg with quite a large piece of shell broken off of the large end and I cut a piece of cotton cloth just a little larger than the hole and made a flour paste, just touched the edges of the cotton wih it and placing it over the cavity, put the,egg in an inculator and it hatched in due time. The reason I used cloth was-it is nearer the texture of the shell. Paper is not porous enough. Flour paste is better than glue: use anly just enough to make the cloth adhere to the egg. With a clean, damp cloth I wiped off all surplus paste after the cloth was put on the egg. "This wonld not have hatched under a hen, as she would have broken the egg.

Usually I do not care to have turkeys hatch until after the cold spell in May. But it is all right earlier if the weather is warm. Yet if they come out any time in May they will get the weight for the December and January shows. This is one advantage southern breeders have over western. We ship turkey eggs south as soon as the turkeys begin to lay. When one has a large number of early hatched turkeys I would not advise the raising of late ones unless they can be entirely separated from other fowls of every kind. But if for any reason you have failed to have early hatched ones, hatch them late. They make fine table fowls.

Years ago I bought a sitting of eggs from a prominent turkey fancier. I was sorely disappointed when I opened them as I had never seen such small turkey eggs. I made another order to another fancier and never saw larger eggs than I received. The turkeys hatched from the small eggs grew to be larger at maturity, though of course they were not so large when hatched.

One tom from the small eggs weighed forty-four pounds at two years old and one hen twenty-four. Those from the large eggs never got so large, though they were fine turkeys. In speaking of this to an old lady and my surprise at results, she replied: "I don't see why you should be surprised. Nature does not vary much, whether in lower animals, the feathered tribe or the human family. All depends on the blood." I believe the old lady was right. I prefer medium sized eggs, both in turkeys and chickens. I find the very large eggs hatch large young, but they are not generally as well formed and often are weak legged and while medium sized ones hatch smaller young they seem more vigorous and grow much faster. Of course there are eggs that are small to deformity-so are there those that are large to deformity. Often the last egg laid before a hen goes to sitting will be so small it will have no yolk at all. It is also true that the largest eggs are not always laid by the largest hens, though as a rule puliets lay smaller eggs than hens.

Many do not know the difference between an infertile and a rotten egg. A rotten egg is never clear and an infertile egg is always clear at hatching time and does not have an offensive odol. Eggs may rot from age or because they are not sufficiently fertilized and the germ dies be- 
fore maturing, and they may rot under hens which sit well, but do not have sufficient body heat to hatch them. Again they may be set where there is too much dampness, which causes them to rot.

We are often asked if fanciers do not sell eggs too high. We think not, for several reasons. First, customers often write that from five dollars' worth of eggs they sell ten dollars' worth ol turkeys and have a good breeding pen left. Second, fanciers are at great expense to hold stock enough to supply egg orders, and run much risk in holding over so many turkeys which could be sold in the spring. Third, the customers build their reputations on the fancier's work, and certainly this is worth something. You are not simply buying eggs from the fancier, but you are buying the experience of years.

\section{CARE OF POULTS-FEEDING-LICE.}

I wcuid by all means prefer a . turkey hen to carry the turkeys. The natural mother is the turkey hen. She scems to understand turkey nature better than the domestic hen. Ther'e is only one advantage gained by letting the domestic len carry the poults; they do not wander so far from home, though I think this is counteracted by the disposition of the domestic hen to wean them when they need a mother's care as much as when first hatched. And the turkey hen never begins to wander so far until the poults are as old as they are when domestic hens wean them. I find that it is the poults which lead the mothers away; they go and the mother follows.

It is a mistake to give a turkey so many poults; of course she may raise them all, but the chances are much better for her to raise all of twenty than they are for her to raise thirty to thirty-five.

When the poults hatch be careful in your management of both the young and the hen. I try to have the nest. fastened very securely so that the little ones cannot get out, for they will get out of the nest and get chilled. Sometimes they hatch a day ahead of time. I look in the nest the night of the twenty-seventh day and if there are any poults I take out the shells and if there are only three or four pouits I leave them in the nest; if theres are six or eight I take then ouc and keep them in a flannel ('Ioth in a basket in the house, as so many left in the nest will cause the hen to sit off the eggs in a hovering position. If you take out only a very few they may get chilled. In the morning $I$ go again and remove the dry poults and egg shells. By night she will be done hatching, but as some of the poults are weak I just put a few of them in the nest with her so she will not refuse to take them in the morning. In the morning I have a quiet place ready for her and I give thein to her.

I think I have at last gotten the ideal turkey coop. I found that the large coops with divisions in them were all right when the poults were very small, but when from five weeks old to the time of going on roosts, they were too crowded in the division coops. I now have coops four feet square, with height of back four feet and height of front five feet. The sides are of screen wire, the back and front of plank, with a light board roof. These are set in the orchard and are moved to a fresh grass plot every week when the poults are very small, and every two or three days as they grow older. I have board roosts put in them as the poults want to go on roosts, and let them roost in these coops until all danger of drowning from heavy rains is past. Turkeys must have plenty of. air. They cannot stand confinement in close coops. These I now have are, so far as air is concerned, as good as if they sat out, and they are safe from "varmints."
FEEO FOR POULTS.

I have tried almost every plan I ever heard of and have finally settled dowu into one way of feeding. I believe the nearer we imilate nature the more successful we will be in poultry culture. I feed very little of anything to poults, especially very little bread.

I never feed my poults until they are from twentyfour to thirty-six hours old. Then I put them out in a grass pasture in a large, roomy coop, with grass runs attached. The first feed I give is milk curd with onion tops and tongue or pepper grass cut very fine, seasoned with black pepper. I give this morning, noon and night. As they grow older I add other things to the food. Table scraps are splendid for them. If I have infertile incubator eggs later experience teaches me the raw egg broken in the food from the first is good food, better than hard boiled eggs. I never use a fresh egg, simply because I do not consider it at all necessary. I give milk instead of dninking water when it is plejıtiful. Milk has all the elements of fool for the huma, or poultry race, hence I feed all I can spare to my poultry. Heat the milk, but do not boil.

I keep grit corstantly before them. Wheat is one of the finest of foods for young turkeys, but it must be pure wheat, not cheat. Cracked corn is splendid when they are older. My rule has been to mix grains of wheat in the food from the first, so that when they are old enough to change from curd to grain it will not be hard to change foods.

I have used corn chops and ship stuff, equal parts, put in the stove and made very hot, then pour cold water over it and have found it very good. Still I believe I must have some wheat mixed in. Lime should be kept where they can get it at will, hut it should be lime that has been slaked a long time. I believe fresh lime will kill old and young turkeys.

As soon as they are old enough to eat whole corn give it to them, for nothing makes them grow faster and geis them ready for this show room quicker.

It is very hard to get a young turkey to change its habits of eating. If you commence feeding them in a plate it is hard to change to a pan or on the ground. The same holds true of the diet. Whatever they learn to eat at first is what they want until they are grown. If the food could be scattered.and the urkevs allowed to hunt for it, it would be much better for them.

The groat trouble is not so nuch what to feed as what not to feed. Turkeys should not be overfed; this is the mistake made by so many amateurs. They think the more they feed the faster the little ones will grow. If it were possible to raise tine turkeys and keep them from the clutches of "varmints" (there is nothing more expensive), the very best way to raise them would be to give them to the hen and let her take care of them during the day and feed them just a lithie in the evening to keep them gentle and make them come home.

Do not allow your poults to become wild. If when you go to fced them you will call them and talk to them, tincy will learn to come to you anywhere. My turkeys and my leeghorns are gentle, and will come to me whenever they hear my voice. If possible, let none but a gentle hen carry young turkeys. A wild mother makes mild turkeys. "Like mother, like duughter" is certainly true of turkeys.

I find that cracked wheat put into the stove and browned as we used to brown our coffee, with just enough cold water or swecl milk poured over it when taken out of the oven to dampen it thoroughly, makes a very fine food for poults. I grind the wheat in a coffee mill. This I. mix with milk curd and fine chopped onions. 
Until I have fully tested it I will not give my cpinion in favor of doubtful foods, and I confess I was afraid to give the corn chops used as chicken food, though I believed it would be good if fed judiciously. One season I began when the poults were four weeks old giving corn chops at night. I just dampened with cold water and I never saw turkeys thrive better in my life. Be sure you do no: get that ground with the cob. It is not fit to feed either to chickens or poults.

I used blood meal one seasen and liked it very much. I think in order to give it I shall feed soft food at least once per week during the year. I am sure that for growing poults and chicks it is very fine. It seems to be of great benefit to them while feathering.

After turkeys are ten weeks old all that is necessary on a large grain farm is to see that they are protected at night. They will glean their own living from the fields, and while the "gude man" may complain, yet if ne will only watch them closely he will be convinced they are a benefit to his crop instead of an injury. Last year the turkeys saved the corin, but the chinch-bug killed the turkeys in many locailies. Turn a flock of young turkeys when from two or three months old or even five or six weeks old in your potatoes and cabbage; they will rot hurt them, but will keep them free from bugs. Yet there is one kind of potaio buir they selciom pick; if they do it kills them. But the capbage worm does them no harm and they do not when young hurt the calbage. They clean the corn of grasshoppers and glean after luarvest in the wheat fieids what everything clse has overlooked.

Poults will not bear handling. Mine are very gentle and eat out of my hands, still I never handle them in my hands if I can avoid it. It will not do to try to raise young turkeys in the same yard with other fowls. They are so tender that chickens run cver them. One snap from the bill of a domestic hen will kill a very young turkey.

What do you do with your little turkeys during a cold or wet spell?

We shut them up in the house they roost in and let them stay there if it is very wet or cold, but if not very coll we let them out on our front lawn. The grass is never very high, and as a rule the hen will hover them and keep them better than in a crowded spot. Keep little turkeys dry and warm, for if they once get wet or chilled they seldom recover. Some hens are more restless than others. If possible to avoid it never let a restless hen foster turk'ys; however, one good feature about them is that they are generally of that spiteful class that will protert their little ones.

It does not hurt them to turn them out soon after a hard rain if the sun comes out warm and bright, but if it is cold and cloudy they wili die from exposure and being chilled.

But if at any time they should be caught out and some seem dead when found, make a fire and warm and rub them well. Often I have brought both chicks and poults to life that seemed perfectly dead. Kørp them near the fire, but do not let them get too hot, until they are entirely dry. Give ear h of them a cracked grain of black, or a seed of red pepper. This warmis them and stimulates them.

Do not put the young turkeys out near ant holes, as the ants if swallowed sting the crop and kill the fowl, and often the ants sting the poults on the body and kill them.

Poults are greatly benefited by having their wings and tails cut. I find they get about so much better, and if a rain comes $11 \mathrm{p}$ they do not seem to get as wet, or if they do they dry so much faster. It takes so much strength to sulu- port the lons wing and tail feathers that if they are kept short until the turkeys are two months old they will be nuch stronger than if the wings and tail are left to grow witheut cutting. I cut the filght feathers about half, and the tail about the same.

There is very jictle expense attached to rearing turknys, but as a rule there is a great deal of work until they aie ten weeks old.

Summing up the requisites for success in raising poults nay be doue in the following simple words:

First, have vigorous parent stock, not over fat. Take care that the ponlts are not chilled the first two or three weeks of their iives. Be careful not to overfeed the poults. They 'require very little food for three weeks; aiter that time feeci all they will eat three times a day until they are ready for market. If, however, you have grain fields for range they will eat very little of your food after they are six weeks old unilil late in the season. Be sure to keep them free from vermin. It is almost impossible to cure a droupy poult. If une is droopy, try to find the cause and remove it befure the entire flock becomes alflicted. Young turkeys will do better with no human attention than with too much.

\section{FIGHTING LICE ON POULTS AND ADULTS.}

I find that whitewashing the house in which my fowls are kept and kteping it thoroughly clean has been a sure p)'ventative of vermin on my young turkeys.

Use tobacco stems and tubaceo dust as follows: Smoke the ruosting places with the stems and sprinkle the floors with the dust. If the coop in which the hen is put with the poults is whitewashed inside and outside before she is put in, she will not become lousy.

I swept the roosting ('oop every day and dusted it once a week with air-slakel lime. Lime must be dusted sparingly, for if too much is used it will make the feet sore.

When the nest has been well prepared and dusted there are seldom any lice on the little ones when hatched. But I dust the hen with persian insert powder when I take her from the nest, being very careful to shake the dust well out so that it will not get into the eyes of the little ones, as it may make them blind.

The turkey louse is about the color of the poult and is very hard to find by one not experienced in the art of hunting them. Thes are between the quill (flight) feathers and are often in solid knots, and at first glance will not be discovered, as they do not move until disturbed. A little clear lard oil will kill them, but it must be very carefully used. I prefer using it at night. Dust the hen well with insect powder when you turn her out in the morning. I know most persons say at night, but I have found the powder gets into the eyes of the poults.

One thing is certain and that is that poults must be kept free from lice and mites. Then it is equally certain that if not careful in the use of remedies for these the poults may be lilled. A little pure lard on the head, around vent, and on the wings, where the flight feathers come out, may be used to advantage, but too much is absolutely fatal. I wculd not advise the use of sulphur in lard to grease the heads. The lard is sufficient and the sulphur takes away proper 11se of legs; it is also liable to cause blindness. Use clear lard or thick cream. Liquid lice killer is equally dangerous if not carefully used. It may be put on the outside of the coops or a little on inside after they are a few weeks old, provided it is done in the morning and the coops are aired well during the day. Niver put it on the floors, for if the hen sits over it, it will suffocale the poults. This is equally true of little "hicks. I have tried it and know from ex- 
perience. Yet there are no better insecticides than these liquid lice killers if properly used. They will kill mites and chiggers and everything in that line, even belbugs, which infest hen houses in some localitios.

Southern turkey breeder's complain that many poults aro killed by chiggers, which do more damage than any other one thing.

We presume this is the little grass chigger which buries itself in the flesh-at least it does on people-and is very hard to exterminate and very painful to endure. We had never thought of this. The only remerly known to us is grease, and too much of that is fatal to the poults.

In the late fall and winter lice are hard on turkeysthey cannot find gcod dust baths as they can in summer, hence it is necessary to use our best efforts to kill the vermin on them, for they cannot thrive with vermin sapping their strength.

\section{PREPARING TURKEYS FOR MARKET.}

Many persons wish to know when to begin to prepare turkeys for market. The best time to begin is when they are hatched and keep up the preparation until they are put on the market. If you live on a grain or stock farm let your turkeys have free access to the feeding stalls and grain shocks and they will take care of themselves. If you, like myself, are limited to a small place, the feeding must be kept up ali the year. It will not do to increase the food too rapidly at first. During the summer feed aduit turkeys only once a day, but about September I begin feeding them twice a day, morning and evening, all that they will eat, or rather, as I keep the parent stock in the pens, my plan has been to scatter the food in the morning so that they shall be kept busy all day hunting for it. At night I give a tull feed wbere they can get it without any trouble, and gradually increase the quantity of food as the cold weather approaches. I find that both old and young turkeys turive better and eat more when the food is scattered than when it is given to them in pans. I have long since ciscarded feeding troughs in my poultry yards. They were a disadvantage to both old and young. In my opinion niuch of the so-called cholera is traceable to the feeding trough. Turkeys especially are naturally inclined to take a small quantity of food at a time and when fed in troughs they will fill their crops and do not take enough exercise to cause good äigestion.

For fattening I prefer corn to anything else, uniess it be crushed corn. Feed whole corn on the ear or scatter it in straw so they must work to get it.

If you have never noticed the necessity of lime for turkeys watch them pick whitewash oft the sides of houses. Make this difference in the treatment of those intended for market and those kept to breed from: Put all the food before the market fow it will eat; make it as fat as possiblebut if you get your breeding stock too fat, infertile eggs will be the result.

Be sure you do not wait until the day before Thanksgiving to try to sell your stock. The highest prices are usually obtainable the week before the holiday feasts. As a rule there is a great rush to market with turkeys two days before Thanksgiving. The rush often causes the price to drop just when the most was expected. I have known the highest prices to be obtained between Thanksgiving and Christmas and in F'ebruary. Of course the locality has something to do with the price, and there may, in the same locality, be different influences at different seasons. We have to do as our husbands do with their stock, watch and sell at the most propitious time. If I had only a few I would sell all at once, but if I raised from seventy-îve to a hun- dred I should sell at difierent times. One can sell the oldest first, thus giving the younger ones a chance. Market birds can not bo too fat, but they may be too heavy for the highest priccs. A few falmers in our county understand this, and to not buy the largest toms to breed from; others run to the other extreme, inbreeding and buying culls until their turkeys are too small to be profitable. I should prefer large breeding stock to small, even if I solk on the market, for if I get a lower price the difference in pounds would more than make the difference in price.

How much ouglıt young toms to weigh at "Thanksgiving, is a question often asked me. That depends on when they were hatched. An early hatched, say one hatched in May, will weigh from twenty to twenty-four pounds, and some few will go higher. One market poultryman says that an average of eighteen and twenty pounds is the rule, while those going above that are the exception.

I have been asked if I think it better to äress turkeys or sell them on foot; "which is the most profitable?" The answer to this (as most answers are) is dependent. I have a friend who dresses her turkeys about the middle of February for the St. Louis market. She says she makes money by so doing. I know others who say it does not pay them at all.

The cause of the difference of opinion lies in the difference of surroundings. The lady who says it pays her to dress her turkeys for market does the work herself and says she makes fair wages at the difference in the price between dressed turkeys and turkeys on foot. My opinion is that the average fal'mer's wife had better sell her turkeys on foot, but this is a question upon which there is a difference of opinion and one which each one must decide for berself.

I never sold a dressed turkey, yet I know how farmers' wives dress them for our market, and I dress them for my own table the same way. We cut the heads off and let them bleed well and then dry pick them and remove their entrails, washing them thoroughly with cold or luke warm water. Plump the carcass by pouring boiling water over it, then salt and let it freeze before cooking, if possible. Very few salt them to put them on the market.

Talk about turkeys eating their heads off! If a man selis hogs at five cents a pound he thinks he is doing a fine business, says he is getting fifty cents a bushel for his corn, but when a woman sells her turkeys even at eight ceuts a pound she is doing far better and is doing her husband a double favor; il is a favor to him for her to pay her own and part of his bills; besides she gets eight cents a pound for grassinoppers, which but for her turkeys would destroy the coln fodder and injure the hay as well as ruin the cabbage.

\section{PREPARING TURKEYS FOR EXHIBITION.}

Chis one thing I never lose sight of or forget-the show roum. Not alone for the scores I wish to receive on my bircls, but on account of the rememurance of what I gain at the shows in point of knowledge and the pleasure I derive from association with the many noble men and women to be met there.

Many imid ones are deterred from entering the show roum because they dread coming in competition with the moguls of the poultry business. To such I say, come! You have nothing to lose by the comparison and you may be a. winner of the prizes. At any rate you will know what the judges think of your birds, and will learn how to improve your stock. The show room is an educator and we need all the education we can get if we intend to stay in the business. Nor does it follow that because they fail to 
win a prize, your stock is poor. You will learn what it takes to make a prize bird and. what constitutes a good breeding birl. Attend a ponltry show or two each year if it is possible for you to do so.

On large farms it is not necessary to begin heavy feeding until the weather begins to get cool. But where one has limited room they must be fed the year round. Do not select show birds until they are tbrough molting, if old birds are exhibited. A breeder of thoroughbred iurkeys, for sale as fancy slock, must feed his entire flock with an aim to getting them in condition for winter shows either in his own hands or in the hands of his cuseomers.

Generally cocks may be depended on molting true to the markings of the cuckerei, but heus often are not as good in markings as they were as pullets. Still, I think turkeys are more regular in their markings after molting than chickens.

If a turkey is in healthy condition the feathers will be glossy, if not, they will not be.

I think that to keep turkeys liealthy and gentle and weil fed is about all the preparation turkeys need. It will not do to put them in confinement longer than ten days, and then it will not do to have them in a strange place, as they will not eat. Give them all the corn, grit and lime they will cat, with pienty of grass and water, and they will fatten.

How do I manage to feed my turkeys to get them in weight for the shows and not get the entire flock too fat? I keep only a few turkeys on my home place at one time, not more than fifty to seventy-five in winter and only my breedins stock in sunim. As I am continually shipping them I select the best in size and that leaves the smaller ones a better chance to grow. I 'annot separate those intended for the show room from the others, so I feed all alike and take the heaviest to the show, no matter if they are not so well marker as the others, for it is the heavy turkey which wins in the show room. In lact, I have only a few times taken my best marked turkeys to a show.

I have had very few persons come to my yards who knew how. to catch a turkey or chicken. I can pick my turkeys or chickens up anywhere in the yard with the assistance of one whom I have trained. In the first place I am very gentle with my fowls. I talk to them when I feed them. You may wonder what I say. Well, I find they are like the human race, susceptible to flattery, if flattery it may be called; I do not intend it as such, for I mean every word of it. I call them pretty things-tell them they are the prettiest turkeys anywhere around-talk to them about going to the shows, and tell them how they must behave to appear well; in fact, I am never at a loss for something to say to my fowls. When I want to catch one I prefer to go out in the yard, look the flock over while they are out, select the one I want, call my assistant, and point out the turkey. Then I begin to feed, and usually I can catch the one I desire wnile they are cating. Never rush into the flock or shoo a turkey. Very quietly step up behind it and catch it by the legs. Be sure to take hold of both legs as you catch one, then you can easily pick the bird up and it will not flap its wings and hurt itself. If there are several to catch and you do not wish to put them in different coops it is better to catch all you need before cooping any. A child can hold a forty pound tom if he knows how. Just lay him flat on his side or breast and hold his legs close to the thighs and he will not attempt to get away. I have often released ona after holding it in this manner, and it would lie still for one or two minutes before getting up.

\section{PACKING EGGS FOR SHIPPING.}

It may sound egotistical, but I believe I can pack eggs that will go around the globe without breaking, that is, with reasonable handling; yet lust year the only chick eggs reported boken did not go wwo hundred miles, and had they rot been sent to a relative as a present I presume I should have heard about them with no uncertain sound. They evidently harl been pitched off the car as baggage and crushed under some heavy body.

First line the basket with paper, then put in an inch of hay chaff in bottom if it is a large basket and many eggs are to go in; if it is only a peck basket, three-fourths or a hillf of an inch will be sufficient, but it must have a soft paciling at bottom. Relive with a good heavy paper. Wrap cach egg with paper, but do not wrap too tight; use plenty cf paper ard do it nicely. I always pack with the small end lown, because the white is in the small end and the yolk will not broak if allowed to float upon it, while if the large end is down there is nothing to prevent the yolk breaking flom the jar of the iravel. Of course if the yolk is broken the egg cannot hatch.

\section{DISEASES OF TURKEYS-CANKER.}

I receive a great many questions as to what $t s$ do for sick poults. I am a poor doctor for little turkeys. I really believe that where the parent stock is not related or inbred that it is poor management where there are sick poults.

Canker is mole prevalent than many persons suppose, and while often a iuwl may die before it is discovered, the l.ule is $i \iota$ becomes droopy and refuses to eat. The discharges become yellowish green, sometimes looking like the yellow of an egg. The canker extends often to the throat and frequrntiy forms on the longue at the opening of the wind pipe and stops the air passages.

To cure canker I have found Mustang Liniment better thin anything else $I$ have ever used. If this cannot be obtained, wash in a strong copperas water and grease with carbolized vaseline, in which put a few drops of tincture of iodine. This is an effectual cure, but it takes longer treatmenc and is more trouble. But the fowl, turkey or chicken wili need a tonic to correct the digestion and tone the system. I give a liver pill, any that I would use for a person. Give this it night and a two-grain quinine capsule in the morning. A little copperas and extract of logwood in the drinking water usually cure the trouble. Use whatever poultry tonic or cholera cure you may deem best mixed in food. Make into long rolls and put down the throat, then give the water from a bottle. I also put grit in food, Feed oniy once a day while the food must be given, but when the turkey can pick food, give twice a day and separate from other fowls. If I use Mustang Liniment I put a few drops down the throat, for I think often the canker extends through the system.

If $I$ am sure there is no canker I omil the treatment for that and give the other treatment. Do not let the fowl have anything to eat or drink which is not medicated until you know it is well. The quinine capsule may be given every moruing for a week, the liver pill every other day until three are given.

I have never lost a turkey undier the loregoing treatment when I have been able to give it regularly. And several customers have reported that under my directions they have saved their turkeys.

\section{GAPES.}

To prevent the cisease I use a little turpentine in the drinking water. A dash of flowers of sulphur in the food once a week will be beneficial until they are well feathered. Copperas in the drinking water and onions in the food will gen- 
erally prevent gapes. Turkeys having vormin are more.likely to be affected. I have been advised to use sour cream instead of lard to gruase young turkeys.

If I find the poults have galus I put Dalmation or Prersian insece powier in tine food and have no further trouble. I sprinkle the powder into the food just as I would pepper. I have cured several chicks of the gapes by first puffing the powder in the wind pipe. This kills the worms, and I extract them with a gape extractor made of a piece of soft grass. If the worms are taken out the chicken will recover unless it is injured by the operation. They are easier to take out dead than alive and I find the powder good, but one has to be careful not to grt too much in the wind pipe or the poult or chick will not be able to breathe.

\section{AIR PUFF.}

One night I noticed that the neck of one of my young turkeys was so badiy swollen it could not get its mouth to the ground to eat. 1 picked it up and found its whole body in the same condition. The skin only seemed puffed. I took a pair of sharp scissors and clipped the skin in several places. The air escaped and the turkey began to chirp. I put it with the others and it ate heartily. I put a teaspoonful of coal oil in the dinking water with a few drops of carbolic acid.

The next morning I noticed its wings drooping down and it was as badly puffed as before. I repeated the (lipping and this time I elipped around the neck; I went deeper than I intended and the neck began to bleed freely. I felt that this would kill it, but I knew it would die anyway if not relieved, so I did not grieve. I took a feather and dipped it in tar alid covered the bleeding wound, then I greased it with pure lard. My husband said: "You have killed that turkey." I replied: "Yes, I think I have, but I was trying to save it." To my astonishment it came up that night as lively as any of the others. I cut both wings and in the morning I showed it to my husband. We were both surprised. Ten days after it was as strong to all appearances as any of the others and it never puffed afterward. I concluded the bleeding was good for it, yet I would not know just how to advise it to be done, as I did that by accident.

\section{BUMBLEFOOT.}

Bumblefoot is a hard place on the bottom of the foot which often becomes very sore and contains pus. It is claimed that it is usually caused by the fowls roosting high and coming down on the ground with such force as to bruise the foot. I am inclined to favor this theory, though some high in authority deny it. At any rate, turkeys and chickens are often found with feet in this condition. I wait until the sore becomes soft, open it with a sharp knife and squeeze it until all the pus and the core, if I can get it, run out. If the core does not come ont it will run ont in a few days if the foot is bound up with a good salve.

I find one of the best salves I ever used to be vaseline, turpentine, a few drops of crude carbolic acid and tincture of jodine. I cannot give the proportions because I do not measure of drop by count. I generally make about a teacup full in the fall or early winter and it lasts me all season. A friend told me that resin would add to its merits. I put:the ingredients all on the stove and mix them together and the next time I riake this salve I think I shall add the resin.

Saiva is also good for sore head, but it is better to wash the head with copperas water before using the salve. If you can affor 1 to buy Mexican Mustang Liniment it is even better thap salve, but one often does not have the liniment at hand and can make the salve.
BOWEL TROUBLE.

The coops in winich the poults roost must have plenty of fresil air an well as be rat proof. If the weather is cold and damp tirey mist be kojt in pens, so they can be hovelod by the hen. If she is at liberty she is liable to walk around in the weeds or grass and the poults will chill and become locse in the howels. And they genrrally die when this disease is caused by the above treatment. However, if they are not too much chilled, pen them up, make a very weak pepper te'a and give this for drinking water. Sweet milk is a good remedy for bowel trouble with poults.

If you do not over feed your young birds nor give them too much water while young, and do not let them get wet arif chilled, thereby contracting cold, they will not have bowel trouble. They are nut is apt to drink too much where they can run at large as they are when kept in confinement. When runuing at large I keep water where they can have access to $i t$, but when penned up I give them a chink only three times a day.

Do not let the poults get wet. I am trying to plan a way to have them roost on a dirt floor, yet not on damp earth. I think the dampness of the ground gives them rheumatism, or makes chem delicate, but the hen mashes the poults on a plank floor. I think if the dirt can be thrown up around the coop, so as to keep the ground dry; it will be better.

Where milk curd, seasoned with black pepper and salt, is fed for the fir'sc ten days, there will be no danger of loose bowels, provided other health precautions are observed. Lic will callse bowel trouble, as will too much heat. When raused by heat give a teaspoonful of carbolic acid in a gallow of water.

Keep the drinking fountains clean and fresh. This can be done by washing them out with carbolized water.

Logwood is excellent for loose bowels. I have used and recommencled $\mathrm{jt}$ for years. There is no danger of using too much and there is nothing better for ordinary bowel trouble eitber in chicks, proults or grown fowls. It comes by the pound in boxes and sells here at ten cents per pound. I put a lump of it in a glass fruit jar, using as large a lump as I can get into the jar and pour warm (not hot) water over it. Every morning I put just enough of this into the drinking water to culor it an. 1 it keeps the bowels in a healthy conditior. If fowls are sick I use it stronger.

Overfeeding produces indigestion and indigestion causes bowel trouble. Vermin and overfeeding kill more poults than all other causes. Lice will produce all the symptoms of disease. When a poult dies from overfeeding a post mortem will usually disclose the liver swollen and probably splotched. When it is in this condition there is no chance for the poult. If taken in time a radical change of diet will effect a cure.

\section{HOT MASHES.}

A lady in Marylland writes: "I can't agree with you that hot mashes cause roup, tor in my native home (Canada) I fed my turikeys hot mashes from the time they were a few wefks old until they are grown, and so did my neighbors, and we raised large flocks and were never troubled with roup. Here I have not fed the mash and have the roup." Roosting in 1rees may be the cause of roup in her flocks now, as she says they never had it when roosting under shelter. I agree with her that in extreme climates a shelter is better. She aiso gives me a preventative for fighting which I certainly shall use. I give it to the readers of this book: Tie a small bell around the neck of toms showing a disposition to fight. The noise attracts their attention so they forget to fight. 


\section{CROP BOUND.}

In the early spring the trouble most to be dreaded with turkeys is crop bound, caused from eating dry grass. No one can prevent this unlcss they have green fields or grain for them to run in, rye or wheat fields. Even thein sometrues they will fill their crops with the dry grass, which forms a hard ball in the crop and unless it can be made to pass, it will kill the fowl. Sometimes it will pass out after a while witbout any treatment. Some recommend culting the crop, taking the substance out and sewing up the crop, and they say it never fails to cure. This may be true with experts at the business, but with me it is a total failure. I tricd it and thought it was a success, but several weeks afterward I discovered that the crops had. never grown together where they were cut open and the tinread rotted out, so they died. I have lost some of the finest turkeys I ever uwned from this trouble and have cured oihers seemingly as bad off.

I have not found an infallible cure and the most effectual cure I have found is very tedious. I give the turkey a dose of castor oil or Epsom salts as soon as I find it has the troible. I hold it and pour all the water into the crop I think it safe to give and I also put a tablespoonful of mica crystal grit in some soft food, make it in long rolls and put down the throat. Turkeys are easily choked and unless the food is made in long, slender rolls they are liable to choke. The reason I put the grit in the food is that it is liable to go dow $\mathrm{n}$ the wind pipe if poured into the mouth alune. 'Then I very gently get hold of the ball in the crop from the outside and work it with both hands, having someone else holil the turkey. I can generally soften the ball very perceptibly the first time I treat the turkey. The grit in the fuod gets into the sortened parts and helps divide the ball, the oil takes ali that it is possible to get out of the crop, out of the system so that it does not clog in the gizzard, as it :s liable to do if nul worked off immediately. The worlking must be very gently done, as it bruises the crop. I repart this process every morning at first and give pleuty of soft food and grit during the day.

If I discover, as 1 of often the case, that the turkey is getting weak, I give a two-grain capsule of quinine every morning. This increases tine appetite and gives strength to the bird. I give plenty of onions in the food. The treatment must be kept up until all the ball has entirely passed out of the system. 1 do not give the oil more than once a werk after the first few days.

One of the best tom $\mathrm{I}$ ever owned, a full brother to "Champ clark," who scored from 97 to 98 by every judge who saw him, was crop bound, and as I had sold "Champ Clark" I was anxicus to save the brother, which I considered just as good. I thought he was entirely cured, and he was to all appedrances well. He had gained flesh and was as hearty as any bird on the place. I fed him at night anc? noticed how well he looked. The next morning I folnd him dead under the roost. He weighed forty pounds and of conlse looked finer after cleath than I hid considered him in life. My only consolation was that he had waited until after the breeding season was almost over before he died.

On examination I found that a ball (not a very large one. either) of dried grass had lodged in the vent, which prevented anything from passing, and this caused his death. He had heen from under treatment about two months and I believed if I had continued the oil once a week be would have lived.

Once I noticed a turkey with the same symptoms, but all my trratment availed nothing and he died. I examined him and found the gizzard packed with dry grass and so nothing could have sived him.

"My turkcys are affected with what I call pendant crop. The (rops hang down like a bag, sometimes low enough to interfere with walking and is filled with dark liquid. The turkeys eat. but are pale about the head. What shall I do foi then "?"

Give them a teaspoonful of baking powder; soda will not do. This is a dose for one old turkey. I do not find tt:e balking powder an infallible cure, but it is the best thing I have tried. Two doses usually cure. Keep the turkey inclosed and do not feed until the powder has been in the crop an hour or two; then give soft food, wheat bread made into long rolls, and put down the throat. The roll must not be very large. Do not give any water until the liquid has passed out of the crop. A little salt mixed in the food will assist in carrying the impurities out of the systcm. Expsom salts are better than oil for crop-bound fowls. You will have to be very careful to keep water from them until they have entirely recovered, or the crop will refill and the second atta:k is always worse or more stubborn than the first. It is very unusual for this trouble to arise in summer. It is prevalent during the latter part of winter and early spring.

\section{CHOLERA.}

The cry of cholera among turkeys comes to me from many persons, and these are not confined to a given locality or state. From Mississippi, Wisconsin, Pennsylvania, Iowa and many other states I have received letters reporting cholera among turkeys and often they say there are no symptoms of the trouble among the chickens. The fact that the turkeys linger for days and sometimes even weeks is one reason for believing it is not cholera. Another is that in many instances the (hickens and turkeys are in the same yard and the chickens are not affected; then again, about the only syuptom common to all inquiries is that the droppings are a yellowish green. Some describe the heads as black, saying they mope around and will not eat. Otier's say the head is red to the last and they eat up to a few minutes betore they are seized with an attack like convulsions, and still others say they have puffs under the eyes. while another fiuck has a white substance floating over the eye.

It is a fact that almost any disease of a turkey will (ause the drcpping to become yellowish green, showing that disease in turkeys, like disease in the human family, sooner or later affects the digestive organs.

Often indigestion is the cause of the trouble. I am not quite positively certain that I ever had a genuine case of cholera in my yards, though 1 well remember when I thought every chicken or turkey that died had it.

I have been informed by one of the R. P. J. correspondents that there is a much larger per cent of deaths from what is known as black head than from cholera, and that it is infectious. He says what has often been pronounced cholera is black bead. He also informs me there is absolutely no remedy for' it which can be relied upon to be even comparatively a cure, and that the cause is unknown. This he wrote me some time since. He said that Lee's Gernozcne is the best remedy known to him. I had some experience with the trouble in the flock of a neighbor, and I docided it was caused from overfeeding while young, and then turning them out without any food; at least I found when I exanined after leath that the liver was perfectly sof: and the gizzard twice the size it should have been.

I find many persons use a grtat deal of red or cayenne 
pepper and soda in turkey food. Because I had been taught to do this I did. like my neighbors when. I commenced raising turkeys, but I soon began to use my common sense and I wondered low on earth anything could live, especially a wee bic of a turkey with the crop filled with pepper, soda, sulphur, copperas, also custard, milk, curd and many other things I was told I would have to feed to be successful. I said: "I shall try a way of my own," and whenever I have had the sense to do my own way I have succeeded in keeping my flock healthy.

Red pepper is a good tonic for chickens in cold weather if given in miuute quantities.

I find carbolic acid in drinking waler, a teaspoonful to a gallon of water, is one of the best things to keep their bowels in good condition I have ever tried. Epsom salts and salt, a teaspoonful of each to a gallon of water, is also good. Tou much salt will throw a turkey into fits, so will too much tobacco, but they will recover from the tobacco dust as soon as they get the fresh air, while from salt taken into the system they do not recover.

Whenever the droppings look yellowish I use my Cholera Cure-not that I believe they have cholera, but the droppings indicate indigestion.

\section{RHEUMATISM}

Several letters have come in, asking what to do for lameness in little turkeys, describing the poults as being affected with swollen joints. I think this trouble arises from dampness. Either the poults roost in damp places or exceedingly wet weather has been conducive to the disease. The trouble is doubtless rheumatism and the best remedy $1 \mathrm{know}$ is elder bark prepared as follows: Get the bark and scrape off the outside skin, cut in small pieces and put in apple vinegar. It does not matter how much bark you put in, but the stronger it is the better. Put in a half gallon fruit jar and add a piece of alum as large as a walinut and the same amount of copperas. Put all the bark in the jar you can get in, pouring the vinegar over it. Put enough of this liquid in the drinking water to make it taste of acid, but not enough to be unpleasant to the taste. I am sure this will prevent the trouble if it does not cure it, and I think it will cure it, provided the poults are kept free from dampness. I should use Mustang also or any good liniment that I would use for myself. A little tincture of iouine in the drinking water is good as a tonic.

I should feed either a little black or red pepper in the food for several days. In that time if I found I could not cure the fowl I would kill it, but if it were gefting better I shoild continue the treatment.

Once I noticed one of my poults could not walk, one leg seemed to be perfectly straight and the poult held it so that it appeared to be behind it. I tried to bend it and it seemed stiff in the joints. But $I$ bent it several times a day for four days when it was able to walk on both feet.

ROUP-CANKER-SWELLED EYES AND HEAD.

I have cured several cases of so-calied roup in the following manner. I made a strong salt water just as hot as I could bear my hand in comfortably and dipped the turkey's head in it, completely immersing the head. I use an old tin can for this purpose. I let the head stay in the water as long as I thought it safe for the turkey. I then take it out and give it fresh air, press the nosirils between my thumb and forefinger. If there is any secretion, this will start a running at the nose. I open the moulh and insert a moj made by wrapping a soft cloth on a sraall stick, into the opening in the roof of the mouth, dipping it first into salt water; then $I$ dip in coal oil. I make a salve of carbolic acid, a few drops of lard, spirits of camphor, a teispoonful, a teaspoonful of tincture of iodine and anoint the eyes. head and fill the nostrils and opening in roof of mouth. With a slean cloth I wiped the head as dry as jossible, (I tried not wiping the head and found it made the turkey too cold) then I rubbed it hard until it was dry. Put a little salt and Epsom salts in the drinking water. This will almost invariably cure the roup in its first stages. If a turk'y has arived at an advanced stage of roup before it, is noticed I would kill it as the only sure cure.

For ratling in the throat I find nothing better than coal oil with a little molasses in it.

Sometimes cauker is caused by fighting. I had a tom, for which I paid $\$ 10$, that got to fighting and had canker on the side of his mouth, caused by the bite of the other tom. All I did for him was to paint his mouth with iodine. He was a vigorous, healthy bird and produced strong poults. I also advise the use of Mexican Mustang Liniment, used according to directions.

Sometimes turkeys have a soft, swelled place under the eyes. The first thing is to put them by themselves. With the finger press the soft swelling, letting the pressure go towards the bill. The phlegm will go out at the nose in most cases. Take a sewing machine oil can and fill with warm water, into which a few drops of tincture of iodine have been dropped; if the water is almost hot it will be all the better. After washing the head in strong salt water as ! lot as can be borne, inject the water from the can into the nostrils and the opening in the roof of the mouth. Make a salve of lard, turpentine, crude carbolic acid, copperas melted in the lard and flowers of sulphur. Anoint with this. If this is done once a. day for a week the turkey will be well un'css it is incurable. If there is pus, an incision made with a sharp knife to let the pus out will be necessary. But the bird wiil need something to cleanse the system, and Cusinman's Roup Cire will be very fine.

However, the trouble is likely to return if you turn the turkey out in the cold. If it is worth the trouble it is better to kep it in the house until cold weather is over. Feed onions, soft food, corn and plenty of grit. I find Littell's liquid sulphur will do for flowers of sulphur in almost every case where flowers of sulphur is needed. I think simple remedies will cure almost any trouble if taken in time. Do not fail to give cnions once a week during the fall and throughout the winter. They are a safeguard against roup and any diseases caused by cold.

For canker sores try putting a little alum in the drinking water one day and copperas the next. Apply Mexican Mustang Liniment to the affected parts. Conkey's Roup Cure in the drinking water will be beneficial to the general health.

\section{WORMS}

"My turkeys arc dying fast and I found worms in the droppings. What must I do for them "?"

If the entire flock is sick, give turpentine in drinking water and in the food-a tablespoonful of turpentine to a gallon of water and a teaspoonful to a quart of food; also add a tablespoonful of Epsom salts to a gallon of water. Give both the turpentine and salts at the same time. If only one turkey is thus affected I would catch it and give it a teaspoonful of castor oil, into which put five or six drops of turpentine; then feed as a tonic cholera cure.

\section{MISCELLANEOUS.}

I quote from an old number of the R. P. J. from an article on "Turkeys as Hatchers":

"When I first read in an English poultry book of the French method of using turkeys to hatch and care for chick- 
ens, I had no incubator and concluded to try the plan. Late in the fall I sent out in the country and bought a late hatched hen turkey for very little money. In Februaly w: prepared a box (with plenty of chaff over a layer of horse manure) that could be shut up to exclude the light. Did not give either wine nor whiskey, but in two or three weeks she was sitting quietly on the china eggs and when taken off the nest tu be fed would voluntarily return. I then filled the nest with hens' eggs, lemoving them as soon as they began to pin to keep the turkey from wanting to leave the nest and putting in other eggs. After sitting three months she was put in a yard with chickens for the rest of the summer. We pitt chickens of different ages with her and she received them all with equal kindness.

"This year we have two turkeys besides an inclibator, and after hatching three sittings of eggs we thought. best to take them off the nest, but one watched her chance and went back on the nest till I filled it with eggs again, so I let her stay. The other is laying and will be ready for work later if needed.

"They make careful, patient mothers, are equal in that respect to any hen, and it is a wonder that farmers do not make more use of them than they do.

C. H. A."

\section{FARMING OUT TURKEYS.}

I am often asked if I find it satisfactory to farm out my tirkeys. It is perfectly satisfactory, because I have no one to raise turkeys for me who is not in all respects reliable; besi des they hatch them earlier than I can, as the twenty-five or thiriy hens kept at home do not lay eggs any faster than I have calls for them from the time they begin laying until the first of June. I have young turkeys now out on the farms that une has to look at the second time to be sure whether they are hens or young turkeys. Farm-bred turkeys do not get very fat, consequently do not weigh as heavy when I take them as I would make them weigh in please those who'demand the pounds of flesh, but the frame is there. Be sure you know with whom you are placing ycur strek and you will have no difficulty.

Each season leaches us some lesson that is profitable to us for the next. I have learred to take only one flock of hens and pullets and aucther of toms on the place at one time. When two or more flocks are brought in at the same time they fight so they will not eat and do not fatten. I find it better to pay board for a few flocks on the farms trian to bring them together on the lome place. I could not zaise all ny stock at home and furnish pairs and trios not relaterl, nor could I ship as I now do to the same customers every year and insure a change of blood.

To those persone who have written me, asking if I think it will pay to raise turkeys, I calı only say that I have never heard any one who has given it a fair trial say that it does not pay. Still I would not advise one to undertake to raise turkeys who is not willing or physically able to expose himself to all sorts of weather, both hot and cold. Turkeys must be kept dry while young and gotten home eariy in the afternoon.

How shall you slleeed with turkeys? The best way to succeed is to keep on trying. If you fail this year, get more in warnest and try again next year.

\section{MRS. BETTIE GLOVER MACKEY.}

\title{
RAISING TURKEYS.
}

\author{
By J. C. Clipp.
}

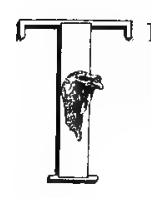

HE laying stock should be the first thought. It is best to use rather old hens mated with young Lut matured gobblers, or old gobblers mated to young hens. We prefer the first mentioner mating. As it nears the laying period more caro should be devoted to the food. We use little corn and give a soft mash with one part meat and bone to six or eight parts mixed food. Give the turkeys full iberty and give only half ritions. If the range is good feed morning and night. Give soft food in the morning, wheat and uats at night. Care should be used not to have the young turkeys too fat, and keep a constant lookout for lice. Be sure to have a tight board bottom to the coop. This lottom should be cleaned and then dusted with dust or sand, or sprinkled with bright wheat straw every day.

Cut the grass short where the coops are located, and for some distance around. Always place the coops on ground that fowls never run over; keep everything very rlean. Always feed on a clean board, and never feed more that the turkeys will eat up chan. Keep a supply of good drinking water ancl wash out the drinking vessel every day. It is best to keep sharp grit and roarse ground lwne in rishes close to the feeding boards.

Keep the young turkeys confiner close to the coop the first week, then lec them run at will, but never les them get caught in a shower or run in the dew. If a young turkey once gets wet and chilled it is hard to restore it again.

The first week we foed hard boiled eggs, into which is mixed a little ground black pepper. As soon as we remove the young from the nest we give each a grain of black pepper. When they are one week old we remove the board pen and let them run at will, but always train them to come up morning, noon and night for meals. We prepare soaked bread in a rittle sweet milk, with onion tops cut fine and mixed with their food, just enough to flavor nicely, and we enjoy that noon feed as much as the turkeys, to see them coming through the wood pasture meeting us, and we notice that they always clean up the onion tops first.

When lice make their appearance dust the turkeys with insect powder and grcase their heads with lard, using grease carefully. We have been told not to give the young turkeys any drinking water, but this is all nonsense. We give our turkeys all the fresh water they will drink, but care is used that the vessels are clean and a few drops of carbolic acid is used to each gallon of water.

In the spring we purchase a few sittings of eggs from the best heavy weight and laying strains of Mammoth Bronze turkeys that we can get, in order to build up our stok and keep them hardy and never inbred. We prefer the Manmolh Bronze turkeys her:ause they grow larger and are very hardy.

Wo always raise will lomestic hens, as they do not walder far from home and always bring their flocks up at night.

The secret in raising turkeys successfully is in having strong, healthy fowls, using clean food and fresh water and keeping th" young free from lin and out of storms.

J. C. CLIPP. 


\title{
ADVICE ON RAISING TURKEYS.
}

\author{
Descrlption of the Mammoth Bronze-Turkeys Need Room-Care and Managenent of Young Turkeys.
}

By Mrs. S. A. McClellan.

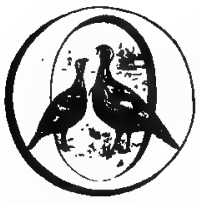

F ALL branches of poultry keeping, raising turkeys is perhaps the most intriesting, as well as the most profitalule. We feel that we have accomplished something when we take a downy little poult weighjus cnly a few onnces, and by care and attention raise him up to be a strong bird that will tip the scries at thirty pounds or more at less than a year old. I have heard of young males weighing much more thain this, but if mine reach thirty pounds without extra pushing or fattening I think I am doing pretty well.

of the several varieties the Bronze is at present the favorite, and justly so, it would seem, when we consider their many excellent qualities. The Bronze possess the handsomest plumage, attain the largest size, take on fat ieadily, and being gentle and docile in disposition, are easily controiled; while the young poults are healthy, hardy, grow rapidly and are easily raised.

Pure-breri stock I would have by all means to begin with as they mature early, which is desirable for home use, as well as for market purposes, and if the strain be ironght to anything like perfection, there is always a demand for young stock for breeding as well as for hatching. A fine specimen of Bronze scmetimes scores as higll as $981 / 2$ points out of a possible 100 .

Although a grat deal has becn said about the weight of Bronze turkeys, yet when selecting the stock one should be guided nearly as much by the symmetry of the bird and the beauty of its plumage as by its weight or size. The body should be long and deepest at the center, with a full breast, broad back. stout thighs and shanks of moierate length. In young birds, the shanks are a dead black, but they grow lighter with age until they finally become a sort of pink or flesh color.

\section{TURKEYS NEED ROOM.}

No one should attempt to raise turkeys who has not sufficient space for them; for it is useless to attempt to raise turkeys in limited runs. This is where many poultry breeders make their mistake, and when failure meets them they put it down to every cause except the right one. It must be remembered that the turkey is really the last of our domestic fowis that has been brought from its wild state and placed under domestication.

You must not be afraid of work when you go into the poultry business, either with turkeys or chickens. It takes all the patience and perseverance possible. But turkeys will pay you well for your trouble, and when six weeks old the most of the work and danger are over and you will be proud of them, for after that they will be things of beauty and joy while they last. It is pleasanter to feed turkeys than chickens. They know when they have enough and can be satisfied with a reascnable amount; that is, all except the gobbler-he never stops eating as long as there is any food in sight.
A great deal has been saiũ and written about turkeys still, to the uninitiated, raising turkeys is a great mysteryso murh so in facr that after one or two futile attempts, many give up in sespair. The scientific poultry raiser of course knows exactly how it is done, bint the wife or daughter of the farmer in moderate circumstances can afford few of the conveniences which tend to lessen the labor and which are considererl absolute necessities by the professional poultry raiser. To he sure it requires a considerable amount of exercise to keep up wih a large flock of turkeys whin they have the whole surface of the broad earth to range over, but then it is heaithful exercise; it takes us out of doors into the wholesome fresh air, and sends us back to the house with glowing cheeks and a hearty appetite.

The exact degree of lestraint to be placed upon turkeys at laying cime requires for its solution the nicest sort of. judgment. If entirely left to themselves, the most secluded spot at the farthest limit of their range will probably be selected as a nesting place. Then sometimes they will conceal their nests scarcely a hundred yards away, and be so cunning ahout i.t, with their sudden appearances and dis. alppearances, as to keep us in the dark for some time as to it whereahouts.

If we knew that a hen would keep the same nest during ihe laying of one clutch of eggs, and that the crows or varmints would not find the eggs and destroy them, we might be more willing to humor her in regard to its location, cveu though it should cost us quite a lengthy walk in visiting them. (Sisters, did you ever think how near, in sweet communion you could come to God during those long walks in the early twilight, wher all nature is bowing to the $\mathrm{Ll}$ vine will:) But the greater number of people err at the cther extreme, and confine their turkeys to a close pen from sun up to sun down.

of the two methods the latter is to be avoided more than the former, as the hens thus kept in confinement not only produce a fewer number of eggs, but a larger per cent prove infertile. But there is in this as everything else a happy medium. Have a good-sized inclosure in a rather secluded place: make partly concealed nests of old boxes and barrels turned down, with a nice nest in them made of straw and leaves: shut the turkeys in every morning for two or three weeks before they commence laying, and most of the hens will willingly accept ihese nests.

\section{TURKEYS NOT HARD TO RAISE.}

While the turkeys are laying gather in the eggs every evening, leaving two or three hen eggs in the nest. There is little more time or labor expended in rearing a flock of seventy-five turkeys than so many chickens, and the result is much more satisfactory-turkeys being subject to fewer diseases and, barring accidents, one can usually succeed in raising nearly every one hatched.

If the hen lays in a suitable place for sitting do not remove her; but should you desire to set her somewhere else 
you can easily move her by letting her stay on the nest two or three days or until she becomes real broody; then after dark sprinkle her with a good insect powder and gently move her to the new nest previously prepared for her and fasten her in. 'Then do not let her out for two or three days. Feerl, water and watch her to see she goes back on the nest. It is best to keep her shut up for several days for fear she will come off and go to her old nest. After you take her off several times and she goes back willingly you can leave the nest open, providing there is nothing to disturb her. Some hens stay so close to the nest as to scarcely come off at all during the twenty-eight days. Hens that are not inclined to come off or are shut up should be gently and quietly lifted off every third day and given a good feed of shelled corn and fresh water to drink.

In setting turkcys do not give them too many eggs. If they are of good size fifteen is plenty. At the same time give nine to a domestic hen, and when hatched give all poults to the turkey hen. Turkey eggs usually hatch well and you will probably get twenty poults, which is enough for one turkey.

Two days beforo time for them to hatch sprinkle the her again with insect powder, working it well into her feathers. When she begins to hatch it is best to remove the little poults and all shells. Take the little downy things to the house and wrap them in warm flannel. After dark take thein back and quietly slip them under the hen for the night. Should she be restless it would be best to remove most of them the second day.

When she is ready to leave the nest I move them to what I call the turkey pen, which is made of boards twelve inches or more high. In size eight by twelve to sixteen feet is a good size for one hen. For the pen select a sunny spot with short green grass, and on high ground that naturally drains itself. In one end have a large box or coop made of boards with a door that will fasten up close at the bottom so as not to leave a holo large enough for a little poult to get out, but give plenty of ventilation at top of coop. in the bottom of coop place a little straw, which can be removed when soiled and clean straw put in.

In making the turkey pen be sure you do not leave a hole at the bottom large enough for a little turkey to crowd throigh, for the first few days it seems to be like an incubalor chick, does not know enough to stay with its mother, and if they get out of the pen they are liable to wander off and be lost. After I make my pens I take a spade and throw dirt up on the outside at every place where the boards do not fit down close to the ground.

FEEDING YOUNG TURKEYS.

Young turkeys need no food at all until the second day, or until they are from twenty-four to thirty-six hours old.
Then I feed them light bread soaked in sweet milk. Feed five times a day and give them fresh water in a fountain, for little turkeys must not get wet. Should you have no small regular fountains, make one by taking an old tin can. Drive a nail through one side, near the top. (A few trials will teach you exactly where to make the hole.) Fill a can with water and turn it upside down in a saucer. The hen can scarcely drink from the saucer, but I set in an old tin can filled with water for her.

When the poults are three or four days old, turn them out for an hour o1 two in the afternoon, providing the weather is suitable and the grass dry. Watch them to see that the hen does not rove too far with them. Should she be inclinerl to lead them off, watch them awhile and then put them back in the pen and allow the hen to go out and in as she pleases. Do not turn them out when the grass is wet, as long as the footboard will keep the little ones in.

When they are a week or two old I begin to feed them curd and corn bread softened with sweet milk; and if the weather is fine and they have good range three feeds a day will do them until they are large enough to go off aid stay all day, then a feed early in the morning and one at night to bring them home is all they need. Some let them go without any food, but I think they grow faster and get out of danger sooner to feed them.

I feed bread and curd most of the time until they are able to eat whole corn, then give part bread. My turkeys are usually spoiled children. When I give them grain they won't eat much of it, but stretch up their necks and tell me they want what's in that pan.

Never allow your turkeys to roost away from home. If they do not come, go after them, and they will generally soon come of their own accord, and when near home they will raise their little wings and fly to their feeding ground, for they are as glad to get home as children let loose from school and bring with them quite as good appetites.

After they are a few weeks old do not put them up at night but let them roost out of doors in the open air. Turkeys do not like to be housed. Just drive them near the house, and cvery night know exactly where they are roosting, so that should a hard rain or storm come up in the nighl you can go out and get them in. I have often gone out at such times with a lantern and picked them up. Nor did I always get them before the rain was on me.

Never try to raise turkeys with a domestic hen, ind endeavor to keep them away from all other fowls on the farm. And do nor reglect to watch for the lice, for they will soon kill the little poults. Dust often at night with insect powder. Kep crushed oyster shells before them, as well as other poultry.

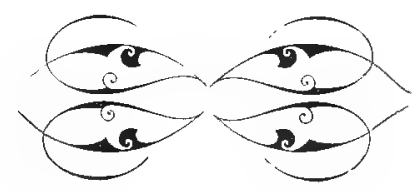




\title{
FEEDING AND CARING FOR POULTS.
}

\author{
By Mrs. Julla A. Tapscort.
}

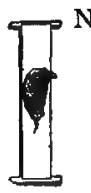

N THE early spring I watch my turkey hens and as soon as $I$ find they are wanting a nest $I$ put them up in a large house built entirely of logs, the cracks leit open so they can get pure air just the same as if they were out of coors. I put them up early of mornings and keep plenty of food, water and grit in the house for them. I keep them up until 5 o'clock in the evening and then turn them out for exercise, and after being put up a few mornings they will go to the house and wait for some one to open the door and let them in. I have nests made on the ground next to the wall and keep some chicken eggs in the nests for nesteggs. I keep from ten to sixteen hens to one tom.

I do not have any trouble in hunting turkey nests and losing the eggs by the crows. When the turkey hen goes to sitting I find the best way is to move her to some place where I can keep her shut up until she is satisfied. I set her on chicken eggs and put all the turkey eggs under gentle domestic hens, for they do not break them so badly. As soon as they begin to pip I take two or three and slip them under the turkey hen, let her hatch them out and she will then own the entire flock. As fast as they hatch out under the domestic hen I take them out of the nest and wrap them up in a flannel cloth in a basket, and keep them until they are about twenty-four hours old before I put them with the turkey hen or give them anything to eat. Then they are strong enough to keep out of the hen's way, and if she is gentle she will not mash them.

I put from twenty to twenty-five little poults with one hen in a good tight-floored house. I feed them on milk curds and a little chopped lettuce and onions, with plenty of fine grit until they are two or three weeks old. I give them water in a very shallow pan and as soon as all have drunk I take the water away from them, for they love to play in the water and will soon drabble themselves. I have a small yard fenced with plank around their houses, and I keep them in the yard until they are ten or twelve days old. I have grass in the yard and they pick the little tender shoots and seem to enjoy them greatly. When the weather is rainy and bad I keep them shut up in their houses. These houses have windows with s'reen wire and outside shutters, and If it is warm I open the shutters.

When they are ten or twelve days old I turn them out and let them go where they please over the farm, but I call them up and feed them at noon every day. They soon learn to come up just at the same time every day to be fed. After they are two weeks old I feed them corn bread made of white meal, buttermilk, soda and eggs baked in the oven until thoroughly done. I let the cake get cold before feeding. If it gets too hard and dry to crumble up for the little poults soak it in sweet milk or water and squeeze dry. I chop up green onion tops twice a week in their food, and as soon as they are large enough to eat corn I feed shelled corn and wheat. I never allow them to roost from home when they are little. I drive them to their houses every night and they soon learn to come themselves.

Just as soon as they are large enough to sit on a plank and roost at night $I$ have trestles set in their houses and lay nariow strips of plank across. I set the poults all up on the planks and the old hens up with them. These trestles are two and one-half feet high, and the little fellows will soon learn to fly up on them. I keep them in their houses at night until there is no danger of their drowning, then let them roost on the planed fence. I sweep their house floor every day, sprinkle air-slaked lime all over the floor and sides and then sweep all the lime out. Once a week I sprinkle the floor and walls with carbolic acid, and twice a week dust all the turkeys with insect powder until they are full feathered, then I dust them only once a week.

This may seem to be a great deal of work, but I think I was well paid for my labor last year, as I raised over a hundred nice turkeys. I have never kept a tom three years, but I have kept hens until they were six years old. I find the older the hens the better mothers they make, and the little poults are larger and stronger. MRS. JULIA A. TAPSCOTT.

\section{THE HAPPY MEDIUM.}

\section{By Stanley Williams.}

White Holland turkeys originated in Holland, from which they derived their name. Their plumage is snow white throughout, except the beard, which is jet black. The head and wattles are bright red, which makes the bird very attractive and much admired. They are very gentle in disposition and do not wander away from home like other breeds. Careful investigation shows that instances where a flock of this variety of turkeys failed to come home to roost are very rare. They are the most hardy turkey known, except the wild turkey, and they are equal to them. The hens are exceedingly prolific and have been known to lay as many as seventy eggs in one season when given good care and food. The little ones are the strongest and easiest to raise of all domestic turkeys. They are especially adapted to small places, or where one has near neighbors. The quality of the flesh is sweet and tender and their feathers are more valuable for commercial purposes than those of other varieties. They mature early, and while they do not attain as great weight as some of the dark colored breeds at maturity, they are as large when six months old as the majority of turkeys, and larger than many of the so-called Bronze turkeys. They are a happy medium in the turkey line, as it is the medium sized "plump" birds that sell the highest in market. Being white in plumage, they have no dark pin feathers to show and present a finer appearauce when dressed than any other breed. The chicks are very rapid growers, and if given a good range and well fed during October and November they will weigh at December 1st, toms fifteen to eighteen pounds, hens from ten to twelve pounds. The standard weights of the White Holland turkeys are: Cock, twentysix pounds; cockerel, sixteen pounds; hen, sixteen pounds; pullet, ten pounds.

STANLEY WILLIAMS. 


\title{
TURKEYS FOR PROFIT.
}

\author{
Turkeys In Demand-Varietles-Enclose the Breeders-Fencing-Mating and Houslng-Overfeeding-Late Hatched \\ Turkeys Green Food for Growth-Freeing From LIce-Results of Line Breeding Supply \\ Grit-Observation and Care Necessary to Success.
}

\author{
By Mrs. Charles Jones.
}

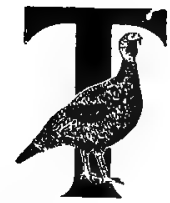

URKGYS bave been raised longer than the memory of those now living can truce and still the business is in its infancy. People a! $e^{2}$ realizing cach year that it is one of the most profitable crops of poultry that can be raised on a farm from a market standpoint. From the fanciers' outlook they are making such great sirides in size, weight and plumage, and command such high prices that they are doubly profitable.

If the exhibit of Bronze turkeys at the Chicago show was any criterion, the business of raising Bronze turkcys has reached a point that nearly eclipses all other departments of poultry raising. When one yearling tom will bring $\$ 50$ and a pair of young turkeys $\$ 75$ it proves the value of the

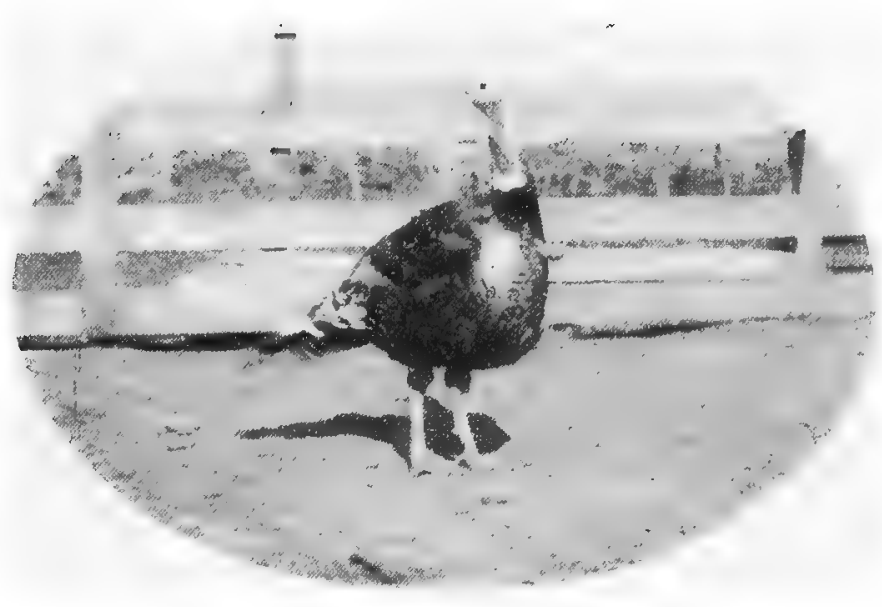

A Winner From the Yards of Mrs. Charles Jones.

gooks, and these were the prices asked and paid for some fine specinens at Chicago. Immediately lreeders put up prices on eggs from 50 cents to one dollar apiece. From these facts one can safely conclude that the Bronze turkey business is booming, especially when the last year has seen more turkeys shipped to foreign countries than were ever sent before. The turkey has been basely slandered and has been consirlered to be ahout as stupid as a mule. I have nevel had any experience in trying to teach a mule to keep his hind feet on the ground when his best friend stoud behind him, hut I have taught turkeys to respect my wishes and stay on one plantation.

Seeing a four-horse load of turkeys going to market gathered from four farms, I said, surely I must go and wake up Rip Van Winkle, so that he may see what the despised "Old Woman's hen business" is now. When he went to slcep about twelve hens and one rooster was the poultry equipment of a farm, and turkeys were wild in the forest. If per- rhance a hunter brought one down for Christmas or Thanksgiving that was all the people of those days expected.

'l'he newsiboys of Chicago were presented with over two th: lisand turkeys this season, and I really do not know which to pity most, the turkeys or the newsboys. At the mayor's barquot in Paris over 2.000 pounds of turkeys were ('cnsumerl, and still the demand increases. The poultry business as Swift's poultry packing houses in Chicago promises to equal, if not exceed, the hog packing industry.

As our population increases the great tracts of land used for grazing will be taken up into farms and the great droves of cattle now raised on them will be a thing of the past. Pork is rot good for a steady diet, and the people will dirmand an immense number of turkeys, chickens, ducks and geess to meet the deficit caused by the lack of cattle.

\section{WHITES, BLACKS, BUEFS AND REDS.}

I an frequently asked how many varieties of turkeys we have bred. I have only bred the old-fashioned scrub and the Bronze. I prefer the Bronze to any variety I have ever seen, as it grows so very much larger, is so hardy and it is such a pleasure to have a flock of these brilliant beauties around. 1 think it is easy to get a good Bronze near to standaik requirements in markings, brilliant plumage asd weight, although there has been added pound after pound to the weight clause, and one has to get them almost as large as a calf to answer the requirements in weight. I think the weight is too high, as a turkey will shrink from one to two pounds while en route to the show. I have had them wighed in the show room where they have shown a shrinkage of over three pounds. It is a settled fact that the Bronze turkey matures slower than other varieties, as til $\lrcorner y$ grow until four years old. I think the Black turkey comes next as a desirable turkey; they nearly equal the lionze in size and beanty. I breed the Bronze now for size ank beauty as well as for their popularity. There is a great demand for them. The White Holland romes next in pop11)arity. They are liked by people who have small range, as they are what one may call a domestic turkey, not given to extensive wandering, and possess very little of the wild sjipit. I am quite partial to white fowls, but on account of harriness and great weight, as well as beantiful plumage, l prefer the Bronze.

I once owned $\alpha$ trio of black turkeys for a short time In one of my orders for turkeys to go to Europe I had a (all for a trio of Black turkeys and a trio of Buffs, and as I riid not breed them I had to find some good enough to ship arcuss the ponci. I sent to a well known Ohio judge and he sent me a Black tom that had never been beaten in the show room, a pullei that took first premium at the ohio state fair, and another equally as good. Well, that trio was so dazzlingly beautiful that it almost shook my allegiance to the Bronze. If ever I should change my breed of turkeys it would be to take up the Black turkey. I also 
got a very fine trio of Buffs from a reliable breeder in our own state and those with the trio of the best of my Bronze birds made a shipment that any turkey breeder might be proud of. The honor did not all belong to me, however.

I am in receipt of a very interesting letter from a lary in Ohio in regard to the Bourbon Red turkey. She has bred them only one year. Her tom and hen were both young and to that she attributes the weakness of the poults, but as only one died a natural death it goes to show they are quite hardy. They were very large when first hatched and very pretty. They are about as hardy as the Bronze when raised under similar conditions, and make beautiful birds when grown. They are marked something like a peafowl, are very quiet and not much inclined to wander and want to be left entirely alone to attend strictly to their own business. My correspondent thinks that for a market fowl a cross of the Bronze and the Bourbon Red would give good results.

If any one knows the origin of the Bourbon Red I should be glad to obtain a knowledge of the subject.

\section{MATING AND HOUSING.}

I am often asked which is the best way to mate turkeys-young toms with hens or old toms with pullets. I like an old tom, but sometimes one suffers a serious loss among the hens, resulting from injury caused by a vigorous male. I always make cots for the spurs the same as a finger cot, and wire them on the legs with a fine copper wire. If the spur is very sharp we saw the sharp point off and cu't the toe nails very blunt. I find this an indispensable treatment if one expects to escape loss.

A correspondent asks how many turkeys she ought to keep, and how many hens and toms she should buy to begin breeding on forty acres of land. She is building a house for them. I wrote and told her not to build a house for turkeys, an open shed is all they ever need. A high shed covered with prairie hay or anything that will keep out rain and sun. I think when the ever ruling hand made turkeys He made the sky their covering. I really do like an open shed for rainy or stormy days and when the terrible blizzards sweep over the country, but you might as well try to chain the lightning or hold a cyclone in the hollow of your hand as to attempt to make turkeys break the laws of nature that made a roost on the topmost branch of the tree an ideal place for them to spend a cold night. While we cuddle down in a warm bed, they are taking a constitutional on the tree top, swaying in the blast and they come down full of vigor and with an appetite that almost equals the ostrich. I never try to control them as to their quarters for the night unless we have a severe ice storm, or one of our terrible blizzards. The rest of the time they are left to "paddle their own canoe" at night. When the Creator put into turkeys the instinct to sleep in the open air He knew more about raising turkeys than $I$ do.

As to the number of birds my correspondent should begin with, I would under no circumstances get more than ten hens and one tom. I started with three thoroughbred heris and a tom, even though $\mathrm{I}$ had raised turkeys for some years before this. I always advise inquirers to begin upon a small scale in any branch of poultry raising. One may work into the business and will not then lose the money invested, nor think the business is unprofitable. One turkey hen will lay two litters of eggs in a season, and this is all it is profitable to have her lay, for if she laid a third litter it would be too late to bother with them. She usually lays about thirty eggs in two litters, sometimes more, sometimes less. If this lady raises one hundred and fifty turkeys from ten hens she will be doing well, as the eggs will not all hatch and the poults will not all live. There are always some that are weak when first hatched. One hurdred and fifty turkeys will be as many as should be kept on forty acres, for they are not like chickens, they must have range and must hunt for the larger portion of thcir food if it is desired to raise them to perfection in size, vigor and plumage, and of course it is.

Turkeys raised on a large range are best to use as breeders, as they develop on nature's plan-bone, muscle and frame, and that is what we want instead of heavy weights and small frames. Some people think weight is the criterion of excellence in turkeys. I wish I could take them out wich me in my morning rambles and show them the points of excellence my birds are developing by roving around and picking up the food that nature contributes so lavishly for their benefit. The large, long legs and well proportioned bodies with the morning sun glancing from their brilliant plumage make a sight worth seeing. Exercise and the right kind of diet go a long way towards making a perfect turkey.

The Bronze turkey does not develop until four years old, and it stands to reason that a bird which develops slowly and healthily will make a better breeder and produce healthier and larger stock than those which are pushed to maturity, and which attain great weights simply by overfeeding and lack of exercise. First secure good health and a large frame, then let nature put on weight at maturity. If this course were followed we would not hear so much abuut diseases and non-success in raising turkeys. They were created for a special purpose and intended to be healthy, an'd when we undertake to run against nature there is war at once and we have to pay the penalty.

\section{YARDING AND TRAINING TURKEYS.}

I raise turkeys and like the business and attribute much of my success to keeping my turkeys yarded through the breeding season. People generally think it a great expense to build a fence that will keep turkeys in, though I do not find it so. A three-foot woven wire fence with barbed wire above to make the fence four or five feet high will keep them confined if the flight feathers of one wing are cut. I keep the young turkeys yarded in the same yard until they are six weeks or two months old, which makes it convenient to protect the young poults from the wet and I can look them over once a week for lice, and never have to ba hunting up my turkeys.

People ask me if they are not hard to raise. I raise a larger per cent of those hatched than I do of chickens. For the last two years I have raised over 95 per cent of all turkeys hatched.

I have found that fifty turkeys in a yard or field are enough to do well. If you keep more than that together they are apt to pile in together and smother after they are about a month old. When I get a flock of fifty I start another drove in another field. I set four or five turkey hens and at the same time give to domestic hens as many turkey eggs as I think the turkeys can take care of. If possible I sot an incubator with chicken eggs. When they all hatch I give the turkeys all the poults and the domestic hens all the incubator chicks, and that makes business lively all around, and keeps me very busy.

1 raise from three different flocks of turkeys, ten hens and one tom, in each flock. We have from one acre to three acres fenced in with a three-foot wire netting, three-inch mesh, with barbed wire at the top, making the fence five feet high. Turkeys will never try to fly over a barbed wire fence. They will crawl under if the wires are not close together, but they will never try to fly over it. If they ever at.tempt it they are almost sure to run a barb through their foot and one experience of that kind is generally enough. I have had them caught that way and hang until dead. I 
use the breeding yards for the young turkeys until they are large enough to drive out on the range, putting ifty in each yard. At six weeks or two months they are driven onto their summer range, driving them home at night until they have learned the trick of coming home to roost. There is considerable work getting them started to run out on the range and come home at night. If you allow them to run at large and stay out at night they will wander away to neigh'bors and sometimes go miles from home, but if they are driven home nightly for a week or two they will soon come home of their own accord, and then your work in the turkey yard is nearly over, as they can take care of themselves, only you must watch that they do not forget to come home.

Turkeys like a large range as they grow older, but while young, one to three acres makes plenty of range. You will soun find out when they get dissatisfied with their quarters, as they will crawl out or fly into your garden or yard, showing that they are anxions to start on their foraging expeditions. If the hay and oats are cut so 'that they can gei around without trampling things down, or finding too much to hide in, we turn them out.

Turkeys can be made to go almost anywhere their owner wants them to by driving them to the farthest fields when they are first started out, but they must be brought home nights until they learn to come home. I bought a telescope to save steps and I find it a very great help, especially as $I$ have to watch my turkeys on account of the railroad track. In the early dry part of the season I had a great deal of trouble with my turkeys wandering so far that they could rıot get back at night. We discovered thit they invariably went where they found water last year, and we concluded it was water they were after, so we took large dishes and put out where we wanted them to run, and then they only went about one-half mile away and stayed on our own place. Their going where they found water last year shows that turkeys have memories. I believe animals have much more intelligence than we give them credit for. Only their language and way of giving expression to their wants is all Greek to us.

To show how turkeys measure time our turkeys invariably start for the house in time to reach the west eage of the pasture at four o'clock, and it takes them until about sundown to reach the house near where they roost. Now, how can they tell the time of day, which they seem to do as well as we do:

I did not learn in a day nor in a year the art of raising nearly all the turkeys hatched, nor until I had lost hundreds each year, I acting as pall bearer and chief mourner, and I assure you I filled the position of mourner admirabiy, weeping copiously over buried hopes (and those hopes were of a well filled purse).

I hope I shall not have to meet those turkeys in the next world and be held accountable for my unpardonable ignolance, but perhaps by sincerely repenting my past mistakes the sin of ignorance will be forgiven me. If I can be of any help to those who raise $\$ 50$ and $\$ 75$ turkeys it may help condone the past. May our great American Thanksgiving bird soar still higher and grow bigger and reach the thousand-dollar mark. He is sure to have his praises sung in foreign tongues, and the fun of it all is, how is he ever with his stupid brain going to learn those foreign languages, and when they call him to breakfast, dinner and supper, how will he know what it all means?

\section{INDIGESTION}

A turkey grows very fast and has an appetite like an ostrich, but without an ostrich's digestive ability. As the natural way for a turkey to eat is to pick up a grain here and there in such a manner as to give the digestive organs a grain at a time to digest, then the digestive mill grinds slowly without being clogged. This method of feeding keeps up a steady circulation and the turkey keeps growing larger and stronger, the digestive organs being developed as the turkey grows, and they are therefore better able to do their work when more food is required to be digested to build up a large frame. On the other hand, when the poults are overfed, the machinery is clogged and there is a general smash-up, the effect being similar to that caused by throwing a bushel of corn into a corn sheller. The machine will do its work all right if fed slowly, so will a turkey's digestive organs. A turkey is a voracious eater and will eat as often as you feed it.

There are other causes that will bring death with very nearly the same symptoms. One is lice and one is lack of sharp grit. A turkey cannot grind its food without grit any more than a miller can grind wheat without millstones; we might as well try to chew our food without teeth.

A neighhor told me that her turkeys were dying and I sent her worl to come and get some Mica Crystal Grit and give them, as $I$ knew she was not giving them any grit. I advised her to put a little in the food every morning. Sha dit so and her turkeys are no longer dying. It was the absence of sharp grit that caused them to die.

I have adopted a treatment for turkeys and chicks that has proved a great success. If I see them act as though they were not feeling well I give a calomel pill. These I buy from the druggist, each pill to contain a tenth of a grain of cilomel. I give the pills one a day for three days, then follow with quinine pills twice a day until the birds alc well. If noticed and treated when first they show symptoms of not being well I have never failed to effect a cure. Th" calomel stirs up the liver and gets it to work, as most cases of sickness among poultry commence with $I$ disordered liver. After the system has had a thorough cleansing the quinine acts as tonic to build the birds up and gives them appetites, then nature does the rest. By this course of treatment you ward off what might terminate in srrious sickness and death. I have used similar treatment in the human family and saved a great many doctor's bills, to say nothing of long spells of sickness anc? suffering.

\section{OVERFEEDING CAUSES DEATH.}

Overfeeding is a common cause of loss in young turkeys. I feed only three times a day for the good reason that I could not possibly find time to feed oftener with the large number I raise. I find it sufficient. They take more exercise if fed less, then when they are fed they are luungry. The time between feeding, too, allows the food to digest and gives the digestive organs a little rest.

I feed more green food than most people do, as I find it has the same effect on turkeys that it has on ducks. It produces a large frame. I chop dandelion leaves for them in the morning and at night chop up onions, tops and all. I notice there is never a scrap of the green food left when they are through eating. They make rapid growth when fed this way, besides it is a cheap way to feed them.

I give a little sharp grit in their food every miorning. I use grit and oyster shell, the larger part grit, as turkeys to be healthy must have it. I have lost hundreds of turkeys I know by not having plenty of grit with which to grind their food. If they get a little sharp grit in their food every morning it keeps their grinding apparatus in perfect order. Very young turkeys do not find the grit of their own accord, and as they grow older they are liable to gorge themselves with the grit as soon as they discover its use, thereby clogging their digestive organs, while a small quantity 
in their food each morning keeps them in excellent condition.

I have my little poults so they will fly over a board a foot high when but a week old. There are more turkeys killed by overfeeding and lice and want of grit than all other things combined. If you do not keep them near the house so that you can run them under cover when a heavy storm comes up you are liable to lose a large per cent. I find a large shed with a board floor is fine to run them in in: case of sudden storms. Of course you must stay close at home to meet all these emergencies. It is not more confining than other occupations. The merchant, lawyer, dortor, mechanic and farmer have to confine themselves closely to business, and the poultry raiser, whether for the fancy or market, must make it a business and work on business principles.

\section{EVILS FROM LACK OF EXERCISE.}

I learned something about exercise for very young turkeys this year. I hatched some under hens quite early; it was wet and cold and of the two evils I decided I would not turn them out to run through the day, so I kept them cooped a week or more. When I went to feed them I found one that dicl not seem to have the use of its left side. I thought it had got hurt in some way and would soon be all right. It got no better and I still kept them cooped, as it was so cold and wet; then another got that way. They woild push themselves around with their righ't foot as they lay on their left side. When the third one was taken sick I decided it. was paralysis of the left side, brought on by lack cf exercise, and so I turned them out. Those that had beon affected died. It was still cold and wet when my other turkeys began to hatch, and I kept the first lot of chicks cooper perhaps five days, when one of them acted in the same way as the early hatched birds. I turned them out to run througin the day and that was the last of it. This convinced me that it was paralysis brought on by lack of exercise. The peculiar nalt nf it was that it was alwavs the left side affentrod. My turkeys are making rapid growth out on the range. I feed them a little grain when they come up at night, and we have such quantities of apples that I put the small ones in a box and chop them up with the spade and feed them to all the poultry, and they do enjoy the cool juice these hot, dry days, and the apples keep them in such good bealth and are so much better for them than green food or even grasshoppers exclusively.

The only road to success with turkeys is to keep them healthy. Give them plenty of exercise, commencing to let them run through the middle of the day at three or four days old; keep the lice off and give a little grit in their fond every morning, with good, clean water to drink and they will have very few diseases. Exercise they must have, but very young turkeys can have sufficient exercise on an acre or two, and a great many young turkeys can be saved by enjoying this exercise under your control. Coop at night until they begin to want to roost.

\section{PENCHING THE POULTS.}

I always mark my young poults when I put them out on the range, as otherwise they would be forgotten or neglected. With care there will be found web enough to allow a good mark and it will not grow together if, as sometimes is the case, you cut into the edge of the web. It will do no harm and will always show the mark. It is different with ducks, the mark will grow together if made in the edge of the web, but if several punch marks are made you can always see the scars, as the webs of. their feet are very transparent. Sometimes I make so large a hole in a duck's foot that it does not grow together and I often find them with a weed run through the hole. In their efforts to release themselves they get twisted and hang there until they die if not relrased.

\section{PULLING WING FEATHERS.}

I am asked if I pull the wing feathers of sick poults to improve their health, and I reply-No, not to improve their heaith, but to prevent too much strength being taken from their systems by the extreme growth of flight feathers. I ustally pull the first flight feathers on the wing when the turkeys are from three to six days old, as at that time they come out so easily that it almost seems as if nature intended those feathers to be pulled. Sometimes I cannot get the time to attend to it, and I notice the quill feathers are making such rapid growth that they hang down, almost drag, and the turkeys appear much weaker than those that have had their feathers pulled; after this period, too, they are much harder to pull and the poults have lost all the strength that it took to grow them. They should be pulled almost as soon as they start to grow, then your turkeys will put growth into the body and the other feathers. This greatly increases our chance of success.

A thought was suggested at the last Chicago Show. Does the second growth of flight feathers make as finely marked a wing as the first, or is the reverse the case? I had never thought of it in that light before and shall experiment this summer and let the readers know. This much I do know after years of experience, the little turkeys certainly are stronger and stand a better chance of living if the first flight feathers are pulled when they are from three to four days old, and they come out so easily at this time that it has no evil effect.

\section{LICE AND MITE DESTROYERS.}

Another correspondent asked about carbolineum, wishing to know if it is the same as carbolineum avenarius. It is the same article. It was originally manufactured in Germany and sent over to this country in barrels. Some claim it is still made there, but I am of the opinion that what we use is an American product. Its original use was as a wood preservative for painting fence posts where they are set in the ground. It is claimed that if posts for corn cribs are painted with it, it will keep rats out of the crib, although I have heard this contradicted. She asks if it is dangerous to use. The only danger is, it will cause the face and hands to swell if it is used in strong sunlight. She also asks if it is lasting in its effects on mites and lice. It is a wood preservative and penetrates right through an inch board in a very few minutes, and it is there to stay so long as the board tasts. For this reason it has been found to be one of the best preventives of lice and mites that is known. I gave it enough of a trial to know it will do all that is claimed for it. I painted all my turkey and chicken coops with it and never had healthier birds. I painted my coops only once. It costs ninety cents a gallon. I painted all perches and intend to spray my houses with it, as it is not expensive when used with a fine sprayer, such as can be bought for $\$ 1$.

However, I do not trust entirely to any one thing. I paint a box, which I keep for the purpose, with Lee's Lice Killer, and put turkeys and chirks in it for an hour or two, leaving sufficient provision for fresh air. I also use Lambert's Death to Lice on the little chicks and turkeys. Whether or not carbolineum avenarius or Lee's Lice Killer is dangerous to use on old fowls in the way recommended. I cannot say, but there is one thing certain, it will not poison them. Any strong insecticide will kill little turkeys or chickens if they are shut into a box which is painted with it and allowed no fresh air. This I know by sad experience. For spraying houses and painting perches I pre- 
fer the carholineum, but I like Lee's best for painting a box in which to place the birds. I use Lambert's Death to Lice for the very young birds.

\section{DIARRHOEA AND LICE.}

A lady wrote that she hatched sixty-six little turkeys and had only ten left. Her turkeys had a diarrhoea, a thin yellowish discharge. This might be from lack of grit. She said she greased them once a week for lice. Too much grease will kill turkeys. I only grease their heads a littie for the large headlice, and dust them with Lambert's Death to Lice. Most of the lice will be found between the quill feathers, below the vent, and on large turkeys on the thighs.

\section{TINCTURE OF IODINE FOR LICE.}

I have been in the habit of using tincture of iodine for lice. I take a feather (but intend getting a small brush) and brush the top of the head and across the quills of the wing feathei's, under the wings, and the fluff below the vent with the tincture of iodine. It is a fact that I have proved time and again that those treated with iodine for lice outgrew those treated with other remedies, the only objection being the expense, but if one will send and get a large bottle at wholesale price it will not be expensive.

When turkeys are making very rapid growth, I find the lice are making rapid growth also. When I take the old turkey off the nest I paint a box with lice killer, put her in and leave her for two hours. I do not shut her in an air tight compartment, only close enongh for the lice killer to thoroughly fumigate her feathers. This kills all the lice and nits. I grease the heads of the little turkeys to destroy the large head lice; I also dust them thoroughly with Lambert's Death to Lice and paint their coops with carbolineum, but with all the precautions I find I must look over them once a week for lice. One of the most essential things during July is to keep the turkeys free from lice.

The first of July generally ends the turkey egg business. Occasionally turkeys lay a third clutch of eggs after that time, but I never consider them of much value, as they do not hatch well and the young turkeys never grow very large. I remember one exception to that rule. I had a brood of young turkeys come off about the first of August, and a pullet from that flock weighed sixteen pounds on the 10 th of December. I took first premium with her at Dixon, III., before the weight was raised in the standard. That was one pound above standard weight on a pullet ten days over four months old.

The work for August in the turkey yard is very light as the turkeys are, or should be, out on the range on farms. I only feed them a little in the morning so that they may be induced to run out in search of food, and a little at night to get them to come home. After they have started out, all I have to do is to bring them home at night and keep on the watch for lice. They go through a corn field and I have noticed the old turkey and young ones stop and wallow in the loose dirt to dust themselves, so I hardly ever have much trouble with lice when they are out on the range.

In November I have watched them with a great deal of interest to see how they make up their bill of fare for breakfast. They work lively, for they have voracious appetites and have nearly cleared the place of grasshoppers. Now they make their breakfast of weeds or grass seeds with occasionally oats that have been left lying on the ground. I notice as the fall advances they spend a lot of time in the corn field, picking corn from ears that have been blown down.

The following is a good story, although I do not vouch for its truthfuluess: A farmer in Kansas has started a novel plan, based upon the prevalence of grasshoppers. He has about one thousand turkeys. After his neighbors saw the way his tields were cleared of grasshoppers they proposed hiring one hundred turkeys by the day to eat their grasshoppers, so he divided them into flocks of one hundred and hired them out at $\$ 2.50$ per one hundred for a day's work, which made $\$ 25$ income a day for the use of one thorsand turkeys, and what turkeys those turkeys will be this fall. This of course settles the grasshopper question in Kansas and Nebraska. If they can settle the rainfall question as easily, the two states will never hold the emigration that will rush there.

\section{INBREEDING AND NEED OF RANGE.}

Turkeys deterrorate quicker by inbreeding than any other animal. Inbreeding indiscriminately for a long time weakens their constitutions. Turkeys, like horses, in their wild state, elected their leaders, or rather the leaders elected themselves by their prowess. When an old leader began to show signs of feebleness a young turkey tom challenged him to mortal combat. If the old chief was equal to the combat the young aspirant was compelled to fall back to the rear or remain where he fell. When the old chief showed renewed signs of feebleness another young aspirant for royal honors stepped out of the ranks and the old tom rarely cane off conquerer. One of our hunters who goes west every year to hunt has often told me of seeing the footprints of an enormous wild turkey that he had tracked and had occasionally got a glimpse of. He described him as being as large as a calf. That old tom had evidently ruled supreme for many years and had grown too smart to be caught napping, so the hunter could never get a shot at him. Turkeys in their wild state range in large flocks, but when they are domesticated it is necessary to keep them in small flocks. I think eighty acres little enough range for 150 turkeys. They could be bred in and left to run in flocks of three hundred if they had a range of three hundred acres. The reason large flocks cannot be kept on small range is that they do not find sufficient insects and the thousan.l other things that they pick up to make their bill of fare. Fifty can be kept on from one to three acres until they are six weeks or two months old, then one just simply cannot keep them in a small enclosure, as they will crawl under or through or get out some other way, for they are growing fast and must have what nature demands. I always make a virtue of necessity and turn them out on the range.

I change males every year. I do not go out of the strain I am breeding, but take anther branch of the same line of blood, and have found that I do not impair their vigor in the least, but am building up strong, healthy birds with plumage that for years has kept my whole flock above a score of 93 , and that in a flock of one hundred and fifty birds. Last year 94 was the lowest. While I have improved them in shape and plumage I do not find one sick turkey in twenty-five throughout the season.

\section{LINE BREEDING.}

At the great Chicago show just passed two things were very strongly impressed on my mind; one was strain or linebreeding of turkeys. The two leading strains exhibited there have been line bred to my certain knowledge; one at least ten or twelve years (perhaps longer, but I am speaking of what I know), the other from information gained in different ways I am led to believe has been line bred the same length of time. They have formed two distinct types; both strains very large birds and beantifully bronzed, but with this difference in color of plumage-in one strain the bronze or gold band across tail coverts, and in fact throughout the 
whole plumage was a greenish golden color; in the other it was just the color of gold without the greenish hue. From what I know these two strains have won most of the premiums in our leading shows from Madison Square to Chicago. Upon comparing the plumage after the premiums were awarded the exhibitors were convinced that the birds represented two distinct species of the same bird. The strain that had the pure gold color had the gold band the entire length of the back. This was absent in the other strain.

The prevailing idea in looking over the Chicago show was that the old avoirdupois way of mixing blood was out of dats, and if we expect to get to the front, the blood must be weighed by apothecary weight, or better still, on the alchemist's scales, although the alchemist, I believe, has never been able to brew in his caldron ingredients that turned cut gold. One breeder proved beyond a doubt that he could put a clear, even gold band on Bronze turkeys, and the inference is that he has been for years using the alchemist scales to reach this much to be desired point of excellence.

The Brouze Turkey Club had an enthusiastic meeting; elected new officers and decided to push the Bronze turkey interest strongly to the front by every means in their power. If the exhibits of Bronze turkeys continue to grow I am afraid there will have to be erected a new Coliseum for the turkey exhiblt alone.

A member of a turkey club in Kansas thinks the Bronze Turkey Clıb a little too exclusive in not fostering all kinds of turkeys. I think it a good idea for each variety to be represented by a club, as variety is the spice of life. If we all bred Plynouth Rocks and there was only one breed and one club, the poultry business would be tame and we would lose our incentive to strive for our ideal in the variety that met our fancy. Now if the admirers and breeders of each variety of turkeys were to organize a clu'b to push the interest of their particular breed, to look up their origin and write up the good qualities that commend them to breeders the turkey business wouid be pushed to the front in a way that could not be accomplished by an indiscriminate pushing of all varieties combined.

I think there will be more turkeys raised in the future, as they are most profitable poultry and when sold on the market for Thanksgiving Day cost little to raise, besides being a benefit to the farmer in eating insects and weed seeds. I wish turkey raisers the best of success in maturing their succeeding crops of turkeys.

MRS. CHARLES JONES.

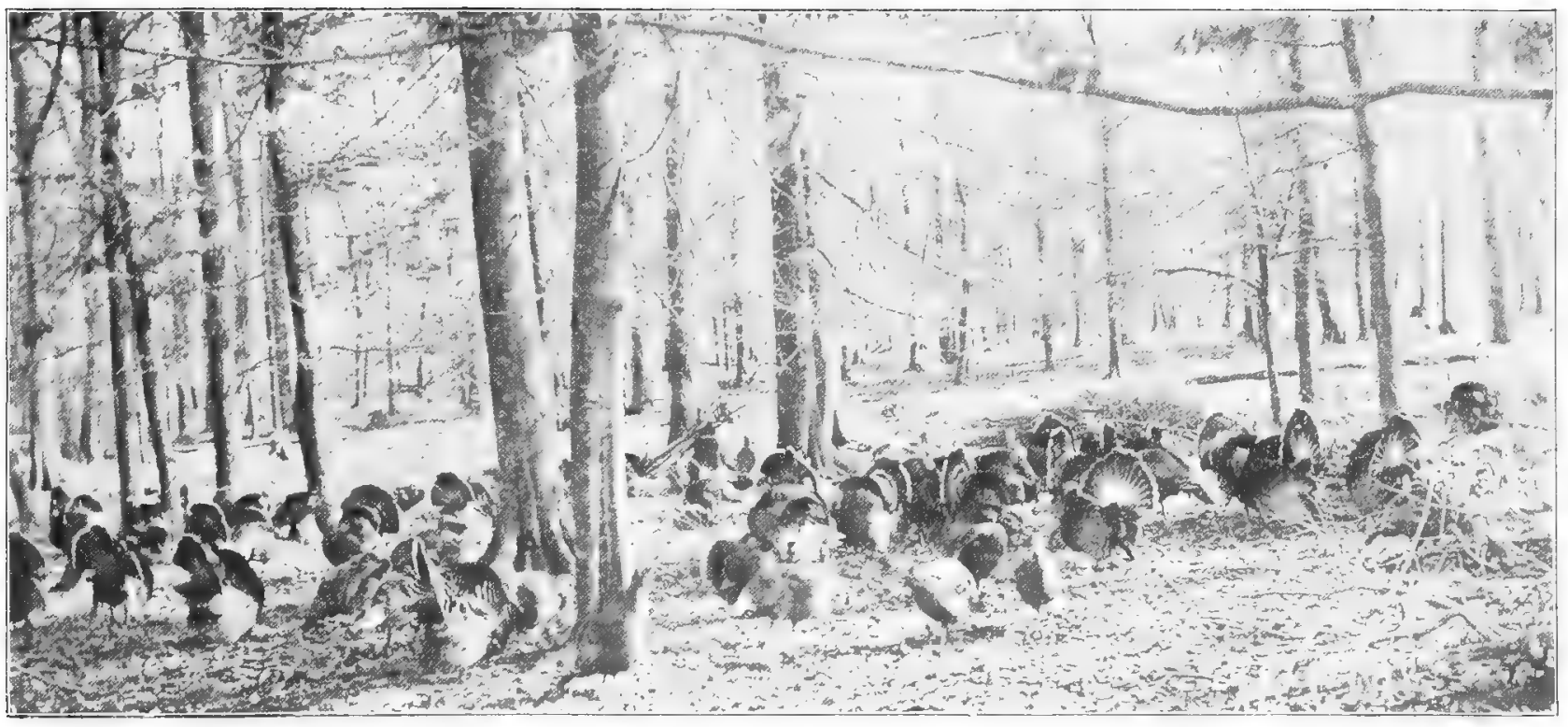

Bronze Turkeys on the Farm of Mr. Chas. McClave. 


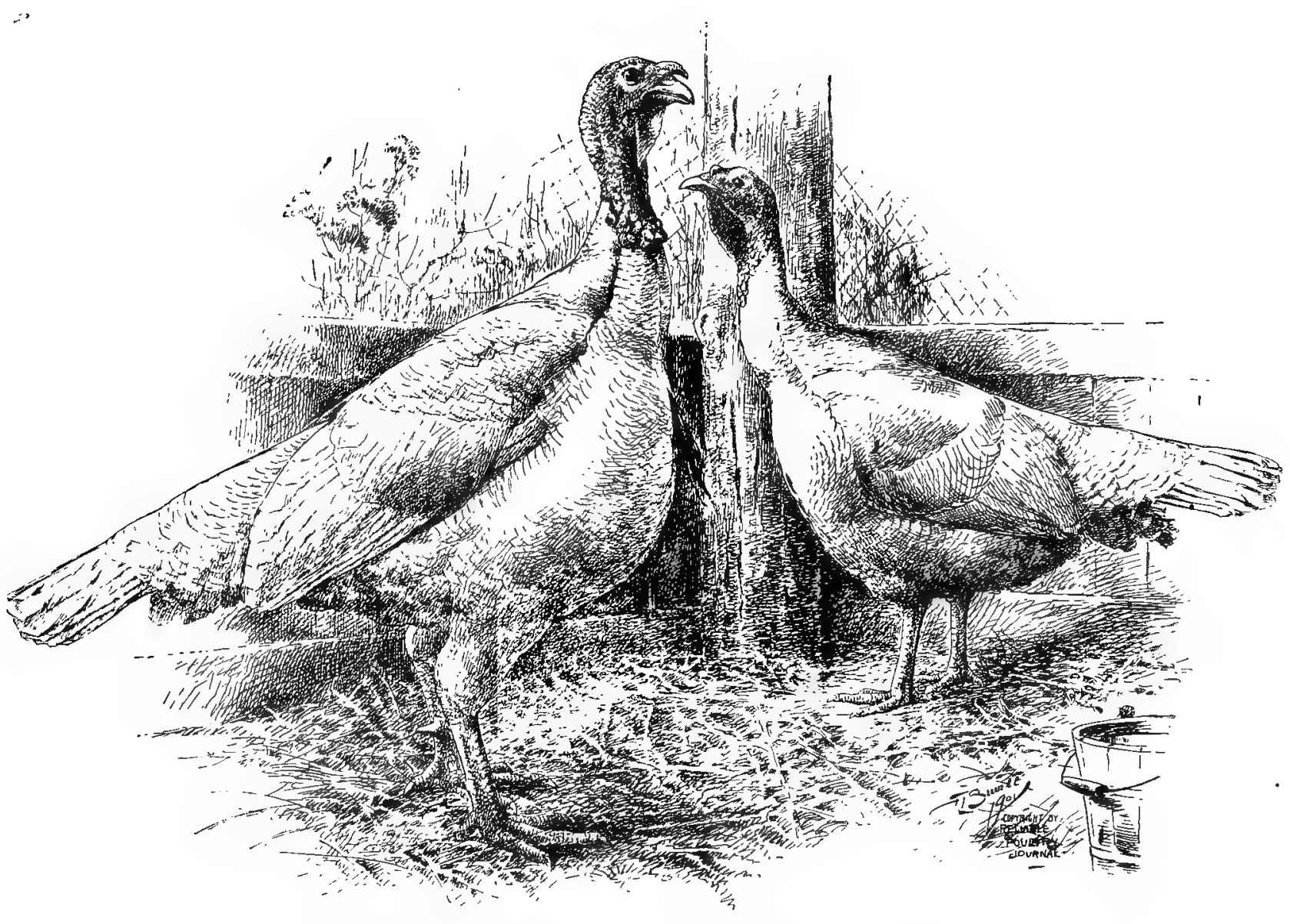

DOWN-TO-DATE WHITE HOLLAND TURKEYS-BY SEWELL. 


\title{
WHITE HOLLAND TURKEYS.
}

\author{
Beautiful In Shape and Chaste In Color, They Form an Excellent Foil for the Brillant Hues of the Bronze Varlety \\ While Their Many Excellent Qualities Make Them Worthy RIvals.
}

By Mr. John R, GarbGe.

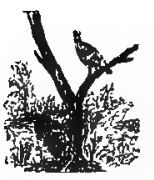

EARS ago we raised only the common turkeys and we counted ourselves among the lucky ones if we, or rather I should say the old turkey hens, raised sixteen or twenty a year. If the young turkeys weighed when dressed in November eight or ten pounds they had done well. Along about 1890 I developed a severe case of "poultry fever." I have been a reader of the Reliable Poultry Journal ever since it came into existence. I have a cornplete file of it down to date, which fact is explained when I say that I consider it the leader among poultry papers.

I also read other poultry and farm papers, and soon I was convinced that better poultry and turkeys ought to be raised on farms and that turkeys could be managed so that there should be good profit in them. Hunters were killing our common turkeys for wild ones because they wandered so far from home, thereby causing us considerable vexation and loss.

We never had seen a pure white turkey, but we read about their gentleness and that they did not roam like the other varieties. So we soid all our common ones and purchased a trio of White Holland turkeys from an R. P. J. advertiser, paying $\$ 7.50$ for them and $\$ 2$ expressage-which seemed a big price then. Since then we have paid more than that for a single bird. These first birds were rather small, though pretty. Up to this time I never had seen a standard, but I soon bought one and learned that my birds were under weight, and feed them how I would, I could not get that trio up to standard weight.

I soon learned where I could get large White Holland turkeys, and I bought some more, still keeping the little, plump hens. The next season the young poults were larger than their mothers-the result of using a large tom. The results have been about the same whether I used a large young tom or an older bird, provided the young males were big boned, biocky fellows mated to good blocky hens or pullets. Still, I prefer a tom from two to five years old. I wish to state here that when I began breeding this variety of turkeys the toms at their best weighed only sixteen pounds and the pullets and hens eight to ten pounis, but during the past three or four years, by following my own rules of mating as given here, my turkeys have doubled these weights, so that now my young toms and pullets weigh from fifteen to twenty-four pounds.

I use both pullets and hens as breeders, thougl I am careful to select the best shaped ones-those that are blocky and in first class health. The first eggs that are laid are given to domestic hens (eight or ten to each hen) or are put in an incubator. We get successful hatches either way, but we never have had success when we put the poults in a brooder. It may be the fault of this particular make of brooder, as I never have thought well of it, though it is a high priced one. So we give the poults to hens. Now, it is easy enough to hatch the poults, the main trouble is to raise them. I am free to confess $I$ do not know it all, but some things I have learned from experience. I know I have lost more poults from lice, overfeeding and chilling than from all other causes combined. Lice are the poults' worst enemies, and next they suffer from overfeeding. Our rule for feeding chicks is "any sound, wholesome food, fed a little at a lime." This rule applied to poults works equally well. We are most successful when the weather is fair and the food is given to them three times a day, and not faster than it could be digested. We find cottage cheese is good for them and they like it, but judgment must be used in feeding it. I repeat that any clean, wholesome food fed in moderation is good for them. We find a varied diet-corn bread, cracked corn, wheat, chopped vegetables, $\mathrm{t} a \mathrm{ble}$ scraps, even corn dough occasionally-works all right, while some breeders claim success on one straight diet.

After the secord and third clutches of eggs are laid we set the turkey hens. We always prefer to move them to a suitabie coop or barrel nest in the yard or near a poultry house, so they can be protected and cared for better. They can be moved with but little trouble when broody. They are corfined $i 0$ the nest for a few days by a slat coop, afiter that they get off and on at will, food and fresh water being kept near them. Remember always that lice are the great drawback to successful turkey raising, and try to have your sitting hen absolutely free from lice, mites or jiggers when the eggs hatch, and then keep her free. Watch the poults, too, and do not let them suffer from lice. A cleall coop ard purs water are essential to success.

Do not overfeed nor underfeed either. Provide a comfortable place for the hen and poults, so that the latter may not get unduly chilled, and give the hen all the food sh9 will eat, so she will not be restless, but put her food out of reach of the poults. Note how the latter will grow with this care. By the time they are feathered and large enough to roam they will be but little care and they will get a large share of their food from the fields, but if you follow the method I have outlined they will always come home for supper and will be very gentle. 


\title{
ADVOCATES WHITE HOLLAND TURKEYS.
}

\author{
Their Beauty and Market Quallflcations Make It Both Pleasant and Profltable to Ralse Them-Preferred Welght \\ of Turkeys-Inbreeding-Black Tlcking on Feathers.
}

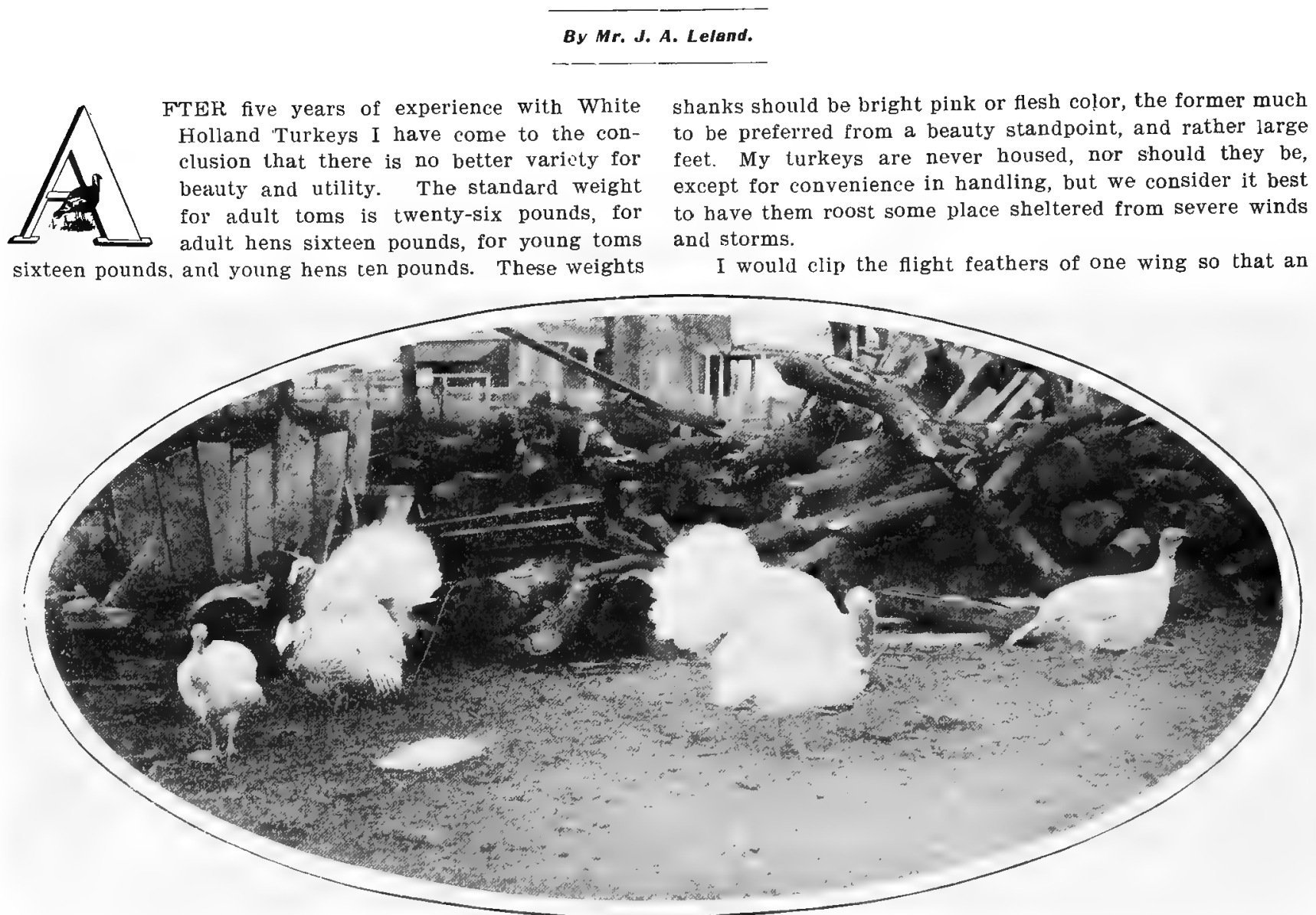

White Hollands, as Bred by Mr. J. A. Leland.

are often exceeded, but not as a rule to the advantage of the breed, although the majority of fanciers try to produce the heaviest birds possible for show purposes. In our experience young stock must reach these weights when about six months old if they ever attain standard weight when mature. Very heavy specimens are not prolific breeders and.stock weighing standard in breeding condition is generally to be preferred.

Tnbreeding is a thing that turkeys cannot stand, therefore, it is imperative that new blood be obtained each year if we wish to raise a large number of hardy, heavy boned fowls that will top either the market or show room. As to color I have never seen a White Holland turkey that did not show some black ticking in its plumage during some period of its life. However, there is a great difference in specimens in this respect and we should breed from stock as free from this fault as possible, if we ever expect to correct it. We believe an ideal White Holland should have a very full, round body (an egg with large end forward gives a good idea), neck of good length, rather long tail and pure white plumage. They should have stout legs, the ordinary five-foot fence that they could not get through nor under, would confine them.

We would not consider it profitable to raise large numbers of turkeys in small enclosures as they require a large range, where they oitain the greater part of their food at no cost. If all food were bought the cost of production would be too great and turkeys do not thrive in close confinement.

About the middle of March we place boxes and barrels for riests in out of the way places about the farm buildings. The hens find them and soon begin to lay. If turkeys are not furnished suitable nests they are apt to choose them in places exposed to crows and vermin. A crow will watch a hen half a day to get an egg and generally finds the nest, while I have found hens dead on their nests, killed by minks or skunks. If their first clutch is taken away they will lay another and sometimes a third. The broody hens should be confined a few days if their eggs are taken, as they sometimes will sit on their nests all the rest of the summer and may die while molting in the fall. It is often a good plan to set the first clutch under domestic hens, as the conditions 
in early spring are frequently unfavorable to outdoor incubation, and these hens are more easily handled in confinement. It is best to let the turkey hatch her second laying, as the third comes too late, if at all, and early hatched turkeys are most desirable.

\section{BREEDERS AND POULTS.}

Ordinarily I mate six to twelve hens with a tom and find the eggs are very fertile, but I think that as many as twenty might safely be mated to one male. Only one tom should run with the flock during the breeding season, but it is well to keep an extra one to use in case of accident.

My breeders have the run of the farm and get only what they pick up about the buildings, which amounts to considerable in winter, but to almost none when good weather comes and then they glean the bulk of their food in the fields. Turkey eggs are very fertile and hatch in twentyeight days. At hatching time the hen should be closely watched and, if uecessary, the poults taken away when dry until all are hatched in order that she shall not leave the nest with them and so chill the other eggs.

During incubation and at hatching time the hen should be frequently dusted with some good insect powder, so you may be sure she is free from lice, which, with filth and dampness, are the worst enemies of young fowls. Should this be neglected and the poults become infested, a mixture of kerosene and lard-just a few drons of the former, as it is so strong, will usually rid them of the nuisance. Apply it around the head, under the wings and about the vent.

After the poults are hatched place a coop with a good roof and slatred end over the hen. This will allow the poults to range about, but keeps the mother from tiring them out or leading them through the wet grass. When the dew has dried the hen may be given her liberty, but should be carefully watched and driven to her coop in the evening, or in case of showers. These coops should be moved each day, so that the young will roost on clean ground. The first feed may consist of infertile eggs boiled hard and chopped fine, or a little cracked grain-oats or wheat preferred. A mixture of coarsely chopped or ground grains with a little millet should be fed until they are from four to six weeks old, when they will be able to eat whole grain. From now on, in good weather, they will need only a little grain in the evening, which will serve to bring them home at night and keep them tame. They will get their food in the fields until frost comes, after that they should be fed all the corn they will eat to prepare them for market.

\section{MARKETING TURKEYS.}

Young turkeys command good prices by the first of November or even earlier in our large cities, and all the heaviest, old and young turkeys, shonld be marketed between a few days before Thanksgiving and Christmas, because after that time heavy stock is at a discount. Through January the demand is usually only fair, but it is a good time to dispose of any heavy turkeys that were not in condition to mariket earlier. Let us add right here that marketing thin poultry is throwing money away, as we might almost say that the difference between thin and prime stock is the profit. From March on the only demand is for medium to small turkeys, and that is when spring hens can be mar-

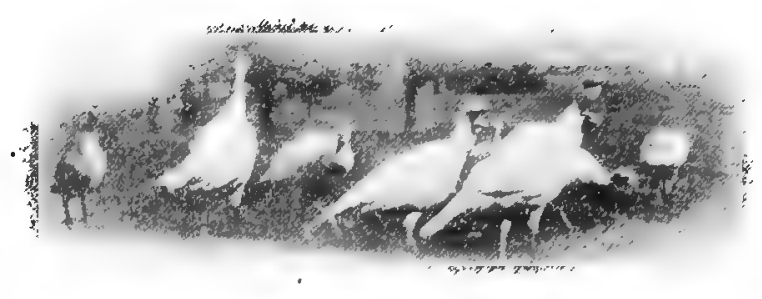

White Hollands at Woodslde Farm Mr. J. A. Leland. Proprietor.

[The two at the left are old birds, winners of 1st prize as pair at the Illinoin state show. 'The othern are young stock.J

keted best,. for they are then scarce and consequently bring a good price. It will pay well to dress them if the work is properly done.

As with other poultry, good, healthy stock must be used, it must have good care, be fed regularly and constant attention must be given to every detail of the business. Given good stock and suitable surroundings success depends largely on the owner or caretaker. Common sense must be relied on to carry us over the hard places.

In closing $I$ will say that $I$ believe there is no more hardy and profitable turkey than the White Holland. They meet all market requirements and their dressing qualities, flesh and beauty are unexcelled. $\quad$ J. A. LELAND.

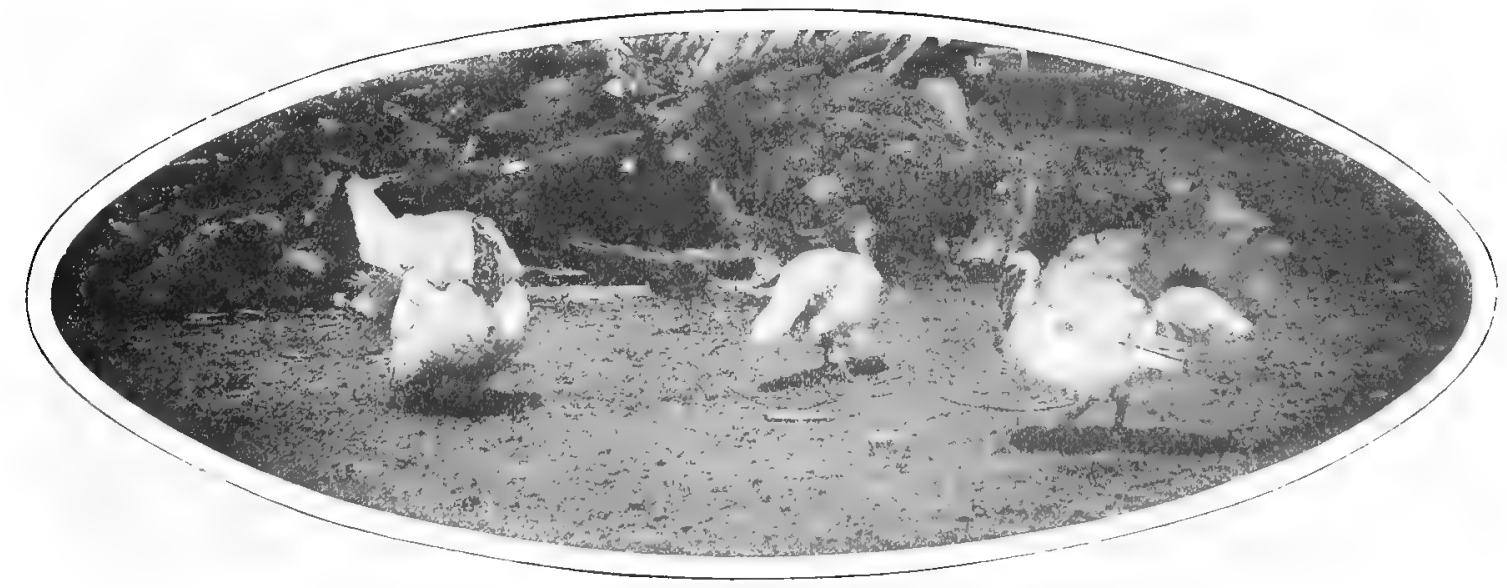




\title{
THE GREAT MARKET TURKEY.
}

\author{
The Clalms of the Narragansetts to This DIstinction-Inbreeding-Care of Poults-NIne-year-old Breeders- \\ How to Begin.
}

By Mr. S. T. Jones.

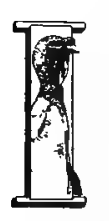

BREED all varieties of turkeys, the Bronze, Narragansett, Buff, Slate, White and Black. The Whites are the easiest to breed to standard requirements on account of their color and the Narragansetts are a close second, because they breed so true to color. I find the Bronze are the hardest to breed up to the standard, as it is very difficult to get a good color throughout and when the birds are under a year old they are not matured. They are tall, leggy and look light in the breast. If you breed what the public demands, and you must do that, you have to breed the leggy kind, because four out of five letters inquiring for young Bronze turkeys demand size. That is the cry-size, size. "We want them good in wing and tail color and great, big, heavy weight fellows." If you breed the plump, early maturing kind you cannot make forty or forty-five pound toms out of them. You must breed the big, tall, leggy kind, and when the toms are two and three years of age you will find that they will weigh forty, forty-five and even forty-eight pounds, and then, truly, you have the most magnificent bird in America. Dut the Narragansett, Buff, White and slate varieties are the best market turkeys, for they mature early. The Narragansett heads the list and is usually ready for market at five or six months of age. The Buffs and Whites are next in order. 'The standard weights for Narragansett males (thirty and twenty pounds) are too high. The cocks and cockerels should weigh the same as the Buff and slate turkeys, viz.: Twenty-seven and eighteen pounds, for they are short legged, plump and mature early.

\section{INBREEDING-RANGE.}

I introduce new blood into my flock every two or three years. I do not think it necessary to do so oftener, as I keep from two to six flocks of each variety, but I never inbreed turkeys, as I find it will not do. I breed all the varieties for exhibition, and when getting new blood I aim to improve in all sections, both in shape and color. The breast, body and back are the most important sections in shape and the wings and tail the most important in color. We do not raise turkeys in confinement. They must have a large range if we are to attain best results. I never house my turkeys, as I think they do better when raised in the open. The nearer we come to raising them in the natural way the better it is for them. I do not try to fence against them, but give them unlimited range. We keep only one variety on a farm and give that variety the run of the entire farm. 'Jurkeys that are hatched in the spring will lay the following spring, and different turkeys will lay a varying number of eggs. The Narragansetts lay more than any other variety and the Buffs are next. I have had turkeys that laid the entire season and did not offer to sit, while others will lay from ten to fifteen eggs and become broody. We keep from five to eight hens with one male, as we think that we get better results as a rule than wo do if we have a greater number of females, though we have had from twelve to fourteen hens with one male and the eggs were all fertile. Probably 90 per cent of all turkey eggs are fertile unless the turkeys are overfed, and consequently are ton fat. Let them get their own food by roaming over the pasture and stubble lands.

\section{CARE OF POULTS.}

It takes from twenty-seven to twenty-nine days to hatch turkey eggs. We have not tried hatching them under hens. For the first twenty-four to thirty-six hours after they are hatched we feed very small grit or gravel, and then we feed clabber cheese dry and some corn meal, a little millet seed or small cracked wheat. We keep the hen and poults in a small pen for eight or ten days and then put them out on pasture land. They need very little food from this on, and should not be fed more than once or twice a day for the best results. Turkeys get nearly all their food from the fields in summer and fall. Pasture and stubble land are the best places for them to run. In the fall begin feeding corn, or, if you are feeding cattle or hogs, the turkeys will get all the food they need, for they always manage to find the feed lots: The main secret in successfully feeding turkeys is to give them their food regularly, but be careful not to give too much. More turkeys are fed to death when they are young than die from any other cause. Nine out of ten breeders feed their poults until they kili them. I have had persons tell me what they feed young turkeys and then say: "My turkeys do not seem to grow well, and I know I feed them well." I do not see how they manage to raise any at all. I ain sure I could not if I fed as they do. Remember to feed lightly, always using the best of food and never feeding any damaged grain at all. A bushel of corn will feed a turkey from sixty to seventy days if it has the range of the farm. Turkeys sell here on the market at from 8 to $121 / 2$ cents per pound live weight at Thanksgiving. The dealers want turkeys weighing from ten to sixteen pounds and not over twenty pounds.

\section{A PREMIUM ON NARRAGANSETIS.}

There is a difference in the quality of turkeys and $I$ claim that the Narragansett is king. There are turkeys that can beat them on weight, but when it comes to quality, no other breed can be compared to them. I sell most of my market turkeys here at home, and sell them alive if I can. One firm here buys most of my turkeys and they always engage all the Narragansetts I have to spare and ask me why I do not breed them exclusively. I get a premium of 2 to $2 \frac{1}{2}$ cents per pound on Narragansetts. The Buffs are my next choice.

Any turkeys that are off in color or the least bit out of shape and all of the late hatched and under weight turkeys are classed with our market turkeys. Before marketing I feed all that they will eat in order to have them fat, and market all that are ready at Thanksgiving time and the 
balance of them at Christmas. As a rule, yearlings make the best breeders, but I have kept some breeders until they were eight or nine years old.

A turkey is most delicate from the time it is hatched until it is six or seven months old. If I were to name the two principal causes of the mortality among turkeys I should say overfeeding and lice. They should never be allowed to live on low, swampy ground. It is not fit for turkeys or any other kind of poultry. We raise from three hundred to a thousand.

If I were about to embark in the business of raising turkeys and had the benefit of my present experience, I should buy from some reliable breeder a tom and four to six hens and should insist upon getting good ones. I should not begin by buying eggs. I should also insist that the tom and hens be not related, and I should never inbreed.

Writing for the Reliable Poultry Journal on the subject of turkeys, a prominent eastern poultryman said the following about our favorites:

"We have always had a particular liking for the Narragansett turkey. It is nearly as large as the Bronze and equally as good for the table. Its plumage is very striking, giving one the effect of a black and white barred plumage; and as a resident of Rhode Island, the writer feels that the state which has the beautiful Narragansett Bay ought also to breed quite largely the beautiful Narragansett turkey. But it does not. Patriotic as Rhode Island is in other respects it does not let its patriotism extend to any great extent to its selection of turkeys.

"The Narragansett took its name from the Indians who once dwelt here, and was at one time more extensively bred in Rhode Island than now. We are reactionary to the extent of wishing for a return of the good old times in turkey raising, when the Narragansett turkey was the favorite breed, although, gentle reader, we will confess that any Rhode Island turkey, once bred and fattened here, if stuffed with Providence River oysters and nicely roasted, has a very satisfactory effect upon our palate. It may not equal a genuine Rhode Island clam-bake, but it comes when clam-bakes cannot be had, and it is so good that one can say, after eating of such a dish:

" 'Let the world do its worst, I have dined to-day." "

S. T. JONES.

\section{BLACK TURKEYS.}

\section{An Experlenced Breeder and Judge Writes on Their Present Standling, WIth Reference to Slze and Color.}

By Mr. Charles McClave.

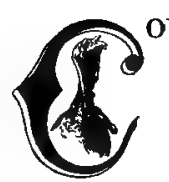

OULD the writer impress upon the minds of farmers in general the importance of this branch of farm life there would be more homes made beautiful and tasty where now the means to do this are lacking. There is no branch of poultry raising in which. one can realize more from the capital invested. To raise turkeys successfully and for profic they must be hatched early. It is best to use turkey hens, as they invariably make better mothers, caring for the young poults much more carefully than domestic hens.

One of the most promising varieties, the Blacks, are being bred in large numbers in some sections at the present time. The modern Black turkey is nearly equal to the Bronze in size. The old style Blacks were not only inferior in size, but poor in quality; however, by careful breeding and handling and with an infusion of new blood, they have been greatly improved in size and general make up. To attain their present weights and general characteristics there is no question whatever but more or less Bronze blood has been judiciously used.

From a market standpoint there is no question but the Blacks will dress yellower and even plumper than any other standard variety. The standard weights of Black turkeys are: Cocks, twenty-seven pounds; hens, eighteen pounds; cockerels, eighteen pounds, and pullets, twelve pounds. At the present time these weights are entirely too low except on hens. We have no trouble at Christmas time in having pullets from fourteen to fifteen pounds, cockerels twenty to twenty-four pounds and cock birds thirty or over. The standard requires males and females to be lustrous black throughout, but it is a difficult matter to secure young birds with solid colored plumage, as more or less feathers in wings will invariably be tipped with white. This will usually disappear at maturity. Good strains of Blacks are strictly hardy, their eggs hatch well, and they are fully as good layers as the Bronze or White. They are very docile in their habits and are not inclined to ramble as much as other varieties. The young grow rapidly from the start, and at selling time always command the top of the market.

The head and beak should be long and broad and of good shape; eyes bright hazel; neck of medium length and well curver; back broad, of good length and highest in the center and curved the shape of an egg. The breast should be hroad, deep and full; body of good length and round in outline; wings of good length and snugly folded against the sides; tail of medium length and when folded comparatively small. "Thighs, shanks and toes should be of good length with strong bone and perfectly straight. When the good qualities of the Black turkey become better known we predict that they will rival their Bronze and White cousins in popularity.

CHARLES McCLAVE. 


\title{
CATCHING, HANDLING AND SHIPPING TURKEYS.
}

\author{
Bullding a Trapplng Pen for Separation of the Flock-Using the Catchlng Net-Training for Exhibition-Coops for \\ Local and Forelgn Shipments.
}

By H. A. Nourse, Assoclate Editor Rellable Poultry Journal.

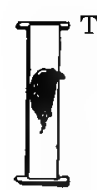

$T$ IS wise to separate from the flock in the fail the birds intended for sale, as constant raiding of the flock for bircis to ship not only keeps the breeders wild and suspicious, but makes it extremely difficult to make an intelligent selection.

The best device for "rounding up" that I have seen is a covered yard or trap about thirty feet long and twenty wide. Sometimes this may be built between two of the farm buildings, using the buildings for the two sides, thus avoiding the necessity of setting posts and erecting sides of the enclosure. The poultry netting which forms the top and one end of the trap may be stretched between the buildings and fastened to them, supported by several pieces of heavy single wire drawn tightly from one building to the other. The other end, which is the entrance to the trap, is left open and provided with a drop which will be described later. The turkeys will not distrust the farm buildings and will more readily enter a trap between them than one separaie from them. A wing should be constructed of poultry netting five feet high to extend from one corner of the entrance to a distance of fifty feet outward or away from the trap, to form an extension of the side, unless one of the buildings nappens to be so extended. The turkeys may be ariven gently along the side of the building towards the entrance and wing, and an occasional handful of corn may be thrown down to occupy their attention until they are at the entrance to the trap. Hers the wing on 1 he fal side of the entrance prevents them going beyond and they may be quickly turned into the enclosure.

Constructing a trap in an open lot with no building is quite different. Four strong posts should be set up to form the corners of a space say thirty feet long and twenty wide and no other wood should be used. The posts may well be old ones, or those not carefully trimmed, and with the bark left on, so that there will be little about them to attract attention and arouse the turkeys' suspicions. It is not best to use bright wire or to turn up much earth for the same reason. The posts should stand five feet above ground and have a heavy single wire like stock fence wire stretched around their tops and also diagonally across the tops from corner to corner to support the wire netting which is stretched over it in forming the top of the trap. More netting is stretched around the sides and one end. This is tiglitly wired to the top and its lower edge is firmly pegged to the groumd. One end is left open to serve as an entrance and is rigged with a drop. A piece of netting large enough to cover the open end is loosely wired to the strand of heavy stock fence at the top of the entrance. At the opposite side of this netting, which reaches to the ground, a heavy cord is attached, put through pulleys at the base of the entrance posts and carried to a distance of sixty or seventy-five feet directly in front of the entrance. By pulling these cords the drop will be hauled from a position on top of the trap down over the front, closing the entrance. Two wings will be required for this trap, for there is no building to assist in guiding the turkeys in. These wings, or leaders, as fishermen would call then, should extend one from each side of the entrance, spreading laterally to form a sort of funnel into the large end of which the turkeys may be toled and then driven into the trap.

The posts supporting the structure must be set deeply in the ground and all the wire stretched very tightly or it will be pressed out of shape by the flock running against it when trying to get ont. Sometimes the trap may be built in a grove of trees and the trunks of trees used in place of posts, at the same time securing the benefit of the branches and possible low brush as a screen to partially hide the trap. If it is convenient the turkeys should be given their daily allowance of grain in this pen and when it is necessary to handle them the drop can be closed and the flock confined, thus avoiding the necessity of driving them in; but if they aie trapped too often they will not go in, and cannot be driven or coaxed. Three times in a season should be enough to do all the selecting necessary.

\section{CATCHING THE BIRDS.}

For the actual capture a net of heavy twine eighteen iuches deep hung on a stout iron ring eighteen inches in diameter, which is attached to a handle seven or eight feet long, is the best contrivance I know of. This if put suddenly over the head of the bird and quickly drawn back will hold it so securely that it cannot struggle and damage its feathers. Always grasp the turkey by the shanks. If by mistake you take hold of the thigh almost every feather will be stripped oif. After obtaining a firm hold, quickly remove the net and swing the bird clear of all objects until it stops struggling; then, retaining the hold on the shanks, take the turkey under one arm in such a way that its wings will be held tightly against its sides. This has no application when the bird is tame enough to be easily handled, which, however, is not often the case with turkeys on wide range.

\section{PREPARING FOR EXHIBITION.}

The preparation of the turkey for the show room consists principally in taming and training the subject to appear to the best advantage in the coop. If the birds are wild it requires some diays to teach them to pose. For this purpose large coops covered with canvas, or in some manner constructed so that the bird cannot cut or bruise its head trying to get out, should be provided in a light, well ventilated room, without drafts, where the temperature ranges but few degrees higher than outside.

Fronts of strong slats or rods having no sharp edges or rough surfaces, with doors of generous size, are better than those of wirs because they offer more chance to make iriends of the birds confined and less opportunity for the occupants to injure themselves by dashing against it, as they frequent$1 \mathrm{y}$ do when introduced. A little patient work with the birds will win their confidence, but the attendant should be careful not to frighten them when feeding or when cleaning the 
coops or the good work will be undone. If the specimen will allow the handler to turn it around in the coop with the hand or judging stick, without becoming nervous and retreating to the far corner of the cage, it is fairly well trained and will show for what it is worth under the judge. Too long confinement lires the bird and detracts from its appearance, if it does not make it actually sick. The wisdom of this coop training is evident to any one who has studied the turkey exhibit at the large shows. Frequently a bird is so frightened at any person approaching the coop that it will crouch in a corner or dash against the top of the cage, making it practically impossible to fairly estimate its quality. Young toms are more prone to nervousness than females or old toms.

\section{COOPING FOR TRANSPORTATION.}

Coops for shipping to exhibitions should be large enough to allow the bird to stand upright, without rubbing its head against the top, and either so narrow that the occupant cannot turn around or wide enough so that it can turn without breaking its tail. I believe in the wider coop, for it is less likely to damage the plumage by constant friction. Coops for this purpose can be used season after season and should be solidly constructed of three-eighths inch lumber over frames of inch square stuff; it need noit be heavy, but it must be strong. The top may be hinged and provided with hasp and staple to be hooked or locked. Ventilation may be provided in the back of the cover by an open space one inch wide and as long as the coop, and another space of equal size along the front of the coop two or three inches below the top. These will admit plenty of air for birds shipped in cool weather, will not make a draft and the turkey cannot get its inead ont and get hurt. Handles conveniently placed should be on all large coops of this kind to facilitate handling by the expressmen and in a measure pro- tect the birds from the rough handling to which large coops not so equipped are sometimes subjected.

For shipping breeding stock to points within a few days journey a wood coop, with solid sides and slat top for cold weather and slat sides and top for warm weather, three feet long, three feet high and fifteen inches wide, is right for toms and large hens, and one six inches less in height and length will suffice for small hens and pullets. Coops of this size allow the birds to stretch to their full height and they arrive in much better condition than when closely hemmed in. Shipment to long distance points and to foreign countries should be in more roomy quarters. Foreign consignments should be forwarded in coops three feet long, three feet high and three feet wide for each bird, with a little extra length added when large toms are to go in them. These coops should be made with solid sides if they are to go on deck when crossing the water, with a space an inch wide left for ventilation near the top of the front, but may have slatted sides if to go below decks. The only door should be at the bottom of the front, just wide enough to admit the turkey turned down on its side, and should extend the length of the side and bo hinged at the top to open outward. Cleaning and feeding may be done through this door with but slight chance for the turkey to escape. The water dish should be placed well up in the coop with provision made for flling it through the sides.

Unless special arrangement is made, a bag of grain and a fow heads of cabbage should be forwarded, marked the same as the coops. Very good care is accorded consignments on board vessels and if the shipper supplies food and utensiis he may rest assured that the care taker will do his part. These instructions apply to consignments forwarded in cold or cool weather; it is not safe to attempt long distance shipments in the hot weather of midsummer.

H. A. NOURSE.

\title{
KILLING, PLUCKING AND MARKETING TURKEYS.
}

\author{
The Money Value of Attractive Appearance In Market-The Manner of KIIIng and Plucklng-Savlng the Feathers \\ for an Added Proflt-Coollng and Cleaning the Carcass-Packlng for Shlpment to Dealers-Dresslng \\ and Packlng for the Famlly Trade-The HIgh Prlces Obtained from Prlvate Customers- \\ The Advantage of Knowing the Market.
}

By H. A. Nourse, Assoclate Editor Rellable Poultry Journal.

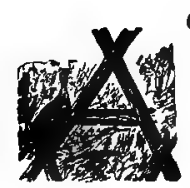

GREAT deal depends on the manner in which turkeys are killed and prepared for market. Frequently it makes the difference in price between the nighest and lowest quotations. $\mathrm{Be}$ the live specimen ever so fat and well fleshed, if it is carelessly picked and improperly packed it is often passed by for a bird not quite so well fattened, but presenting a better appearance when it reaches the market stalls. Obviously no producer can afford to send to market any bird that is not in good condition.

It is not difficult to properly flesh and fatten healthy turkeys. If they can be confined in a covered pen of good size, without becoming worried and losing their appetites, they will take on the most Hesh, for the grain fed, in the shortest time. But young ones that have been accustomed to a wild life upon a large range do not take kindly to confinement and can seldom be improved if enclosed.
As the supply of bugs and other food gets short in the fields the old hens will lead the young birds to the feeder and a good ration of. whole corn each day for two or three wecks will put them in good flesh, with sufficient fat to give the meat and skin a bright, attractive appearance.

There is a flavor belonging to the meat of a range fed and fattened turkey that cannot be found in one raised in confinement or one that has spent its days near the buildings eating with the chickens. The diet of grass, roots and berries not only produces flesh at less cost per pound, but improves the quality.

Before killing, the stock should be kept for eighteen hours in a clean, airy place where no food can be obtained. They may have water up to within eight hours of the time of killing, for water gives a healthy look to the skin and assists in cleansing the digestive organs of matter which would become sour and taint the flesh. A short, stout club, 
a long, sharp steel blade, a strong arm and a quick hand are required for the operation of killing.

\section{THE MANNER OF KILLING AND PLUCKING.}

The bird should be suspended head downward with its feet in a noose of strong cord, far enough from the walls of the house and other objects so that it cannot injure its wings when it struggles-as most of them do at some time. After stunning by dealing a sharp blow at the base of the skull with the club, pass the left arm around the body of the fowl under the wings, which usually drop down when the bird is stunned and the muscles relax, holding the side of the

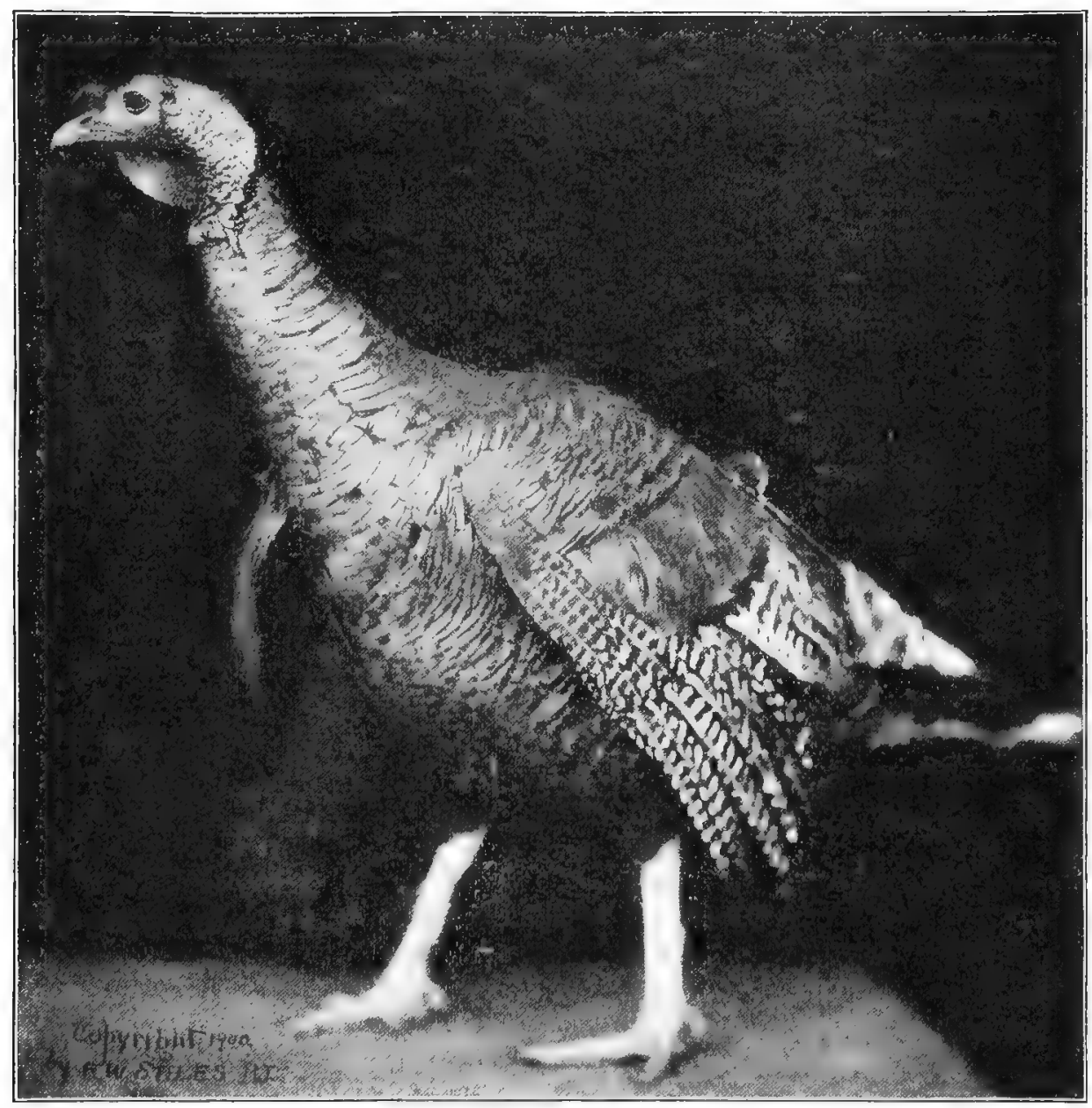

"McKinley," a Superb Bronze Turkey, that was sent to Presldent Mckinley by Horace Vose, who for thirty-five years has each season presented the President of the United States with a Thanksgivlng Turkey. purchaser of the bird to use about the kitchen in place of brushes. The long feathers of the tail are removed or not as the market for which they are intended requires.

While the skin of a turkey is less likely to be torn when removing the feathers than that of a chicken or duck, it is neerlful to be careful and none but experienced pickers can safely attempt to hurry the work. The thumb and forefinger do most of tine work by firmly grasping a few feathers and removing them by a quick jerk which begins upward toward the tail and terminates outward, which movement is accomplished by a quick twist of the wrist. This motion first loosens the feathers in their sockets by starting them the way they grow and then removes them at an angle which is least likely to tear the skin.

A well grown turkey is very powerful and requires to be held firmly yet with due care, for if the wings are grasp:d by their extremities or are held too firmly in any position the bird may struggl 2 and break or wrench them out of joint, making the carcass unfit for sale.

Careful handling after picking is very desirable, for a bruise will cause discoloration which is very detrimental 10 the appearance of the fiesh in market.

\section{SAVING THE FEATHERS.}

If many birds are killed it pays to save the feathers, especially those of the tail and wings. Those of the tail proper and the two lower joints of the wings are salable at fifteen to thirty cents per pound and can be saved by no more extra labor than is required to toss them into a clean receptacle when picking and later dry them by spreading upon the floor of a loft where there is a good circulation of air. The shorter and body feathers seldom command more than 4 to 6 cents per pound and most turkey men do not care to save them for so little remuneration. breast towards you. Grasp the head in the left hand and forcing the bill open with the thumb and fore fingers, thrust the knife blade in through the mouth to just back of the brain and make a sharp cut directly across the roof of the mouth, severing the arteries. Then holding the bird firmiy with the left arm and hand in the same position, begin at once to remove the feathers with the right hand, beginning at the juncture of neck and breast and working up over the breast and body, then giving the bird a turn which presents the back to the operator, begin at the neck or between the wings and spluck towards the tail. The short feathers of wings, tail, shanks and neck are picked next and the long feathers of the wings and tail, if removed at all, arr plucked last. As a rule the feathers of the last joint of each wing are left on and are much appreciated by the

\section{COOLING AND CLEANING THE CARCASS.}

Marketing is usually done in the cold weather of late fall and during the winter and cooling can be done by hanging the picked turkeys in the open air, out of the sun, long enougli to allow the escape of all animal heat, but not long enough to ireeze or become stiff it the temperature is low.

Most markets do not require the turkeys to be drawn, while some will pay less per pound for stock so prepared. It is always best to find what your market wants before killing, for if drawn turkeys are shipped where undrawn stock is wanted the loss on a consignment is considerable. Feet and heads should be washed clean and wiped dry and all blood lemoved from the mouth and throat. If care is used when killing and handling it will not be necessary to wash the body of the bird and the skin will retain its bright, 
yallow appearance longer than it would if dampened or if cooled in water rather than by the air.

\section{PACKING TO SHIP.}

Packing is as important an operation as picking, but not so tedious. All consignments should be packed tightly, not jammed, in clean boxes and sufficlent packing put in before the cover is nailed on to prevent shifting enroute. Birds of different sizes, but not of different qualities, may bo packed in the same box and the contents of the package sliould be correctly described on the outside of the cover. If the description says "Ten young toms and ten young hens" and the dealer, on opening the box, finds one old tom and perhaps some old hens, he of course loses confidence in the shipper and does not dare to recommend his goods. But if the contents of the package never fails to tally with the description the goods are satisfactory to handle and the returns as a rule are better. Large boxes are inconvenient to handle and less desired by small dealers than boxes weighing from one hundred and fifty to two hundred pounds and the smaller packages require to be packed less solidly and the contents show less evidence of hard pressure in the box. If the market catered to favors drawn stock it is easiest done before the bird is hung up to cool. The incision made should be as small as possible. A sharp knife should be used to cut the skin close around the vent and cut away the fat around the intestine, making an opening into the cavity. Through this the entrails must be drawn carefully, the operator reaching with his fingers into the cavity to free the upper end from its attachment. Nothing else need be removed.

\section{DRESSING AND PACKING FOR PRIVATE} TRADE.

If the stock is intended for a high price family trade, all the birds should be picked and handled with extreme care, the intestines drawn and the shanks and feet and the head removed. When cutting off the heads considerable blood will frequently be found clotted in the neck and unless removed it will turn black and show through the skin. If it happens that there is any food left in the crop it is wise to remove it before cooling. This is accomplished by pushing back the skin of the neck and working the crop out under it with the thumb and fore finger, taking care not to tear the crop in separating it from the tissues surrounding it. Removing the crop dces not leave the breast looking quite so well as when the crop is empty and left in because its absence allows the skin to sink deeper in front of the breast bone; but if the food remains it will show black through the skin and mar the appearance of the bird. The skin should be drawn well over the end of the neck and tied with a clean string. Each carcass when thoroughly cooled should be wrapped in clean wrapping paper and packed in excelsior in a clean, new wooden box to be shipped to the consumer's kitchen door. Paper without much color should be used or at the end of the journey the color will be found to have deserted the paper to cling to the skin of the turkey, which will give it more the appearance of the "tattooed man" in a circus than that of the mainstay of a family feast.

The family trade is usually very profitable, paying well for the extra labor and other expense involved. One establishment, noted for the show room quality of its turkeys, has been furnishing private customers in several states with Thanksgiving and Christmas turkeys of the finest grade for several years. These are prepared and shipped in the manner described above, the weight is taken as soon as the feathers are off and the bills for them call for thirtyfive cents a pound. No exceptional ability is needed to figure that there is money earned by properly growing and fat-

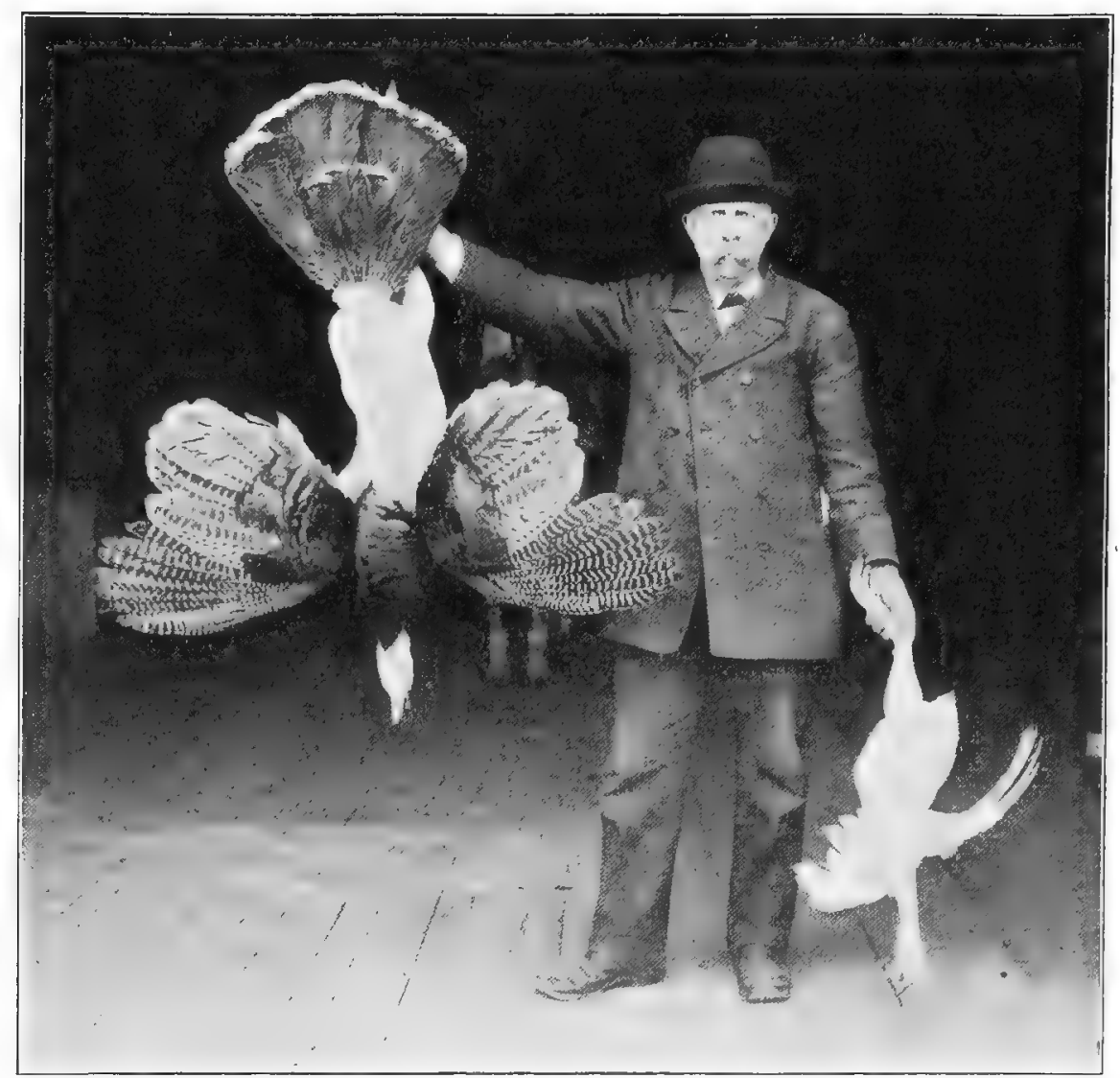

The Thanksgiving Turkey, Illustrated on the opposite page, dressed and ready for shipment to President McKinley. Mr. Vose, the donor, is holding also another choice specimen, which he has just dressed, to assist in balancing the weight of the larger one.

tenjng, arid carefully picking, packing and shipping turkeys at that price.

\section{FINISH KILLING AT NEW YEAR'S.}

It is well to kill all stock unsalable for breeding or exhibition at or before the New Year. Occasionally, however, the poultryman will be caught with a few very late hatched poults presented by some wily old hen that hid her nest so well and was so cautious in her "comings and goings" that it was not discovered until she brought off a brood contrary to her owner's wishes and intentions. Some breeders kill these late hatched ones on sight, believing that it is nothing but time wasted to look after them. Others allow them to run with the hen until cold weather and then house them with the chickens, giving them the same care. They appear to do better when confined in cold weather than in warm, but they seem to breed lice fasler than chicks and must be 
continually duster for body lice and their heads and necks greased frequently to discourage the head lice. If the youngsters take kindly to confinement they will make very good growth and sell readily in the spring to the trade calling for small sized turkeys. These birds should never be kept for breeding, for they seldom make very strong birds and do not molt in the proper season.
Every turkey raiser who markets any considerable number each year ran well afford to study his market closely; to find just what it wants and when it will pay most for it, and then bend his energies to furnishing the right stock at the right time.

Marketing often determines the profit.

\section{H. A, NOURSE.}

\section{MARKETING TURKEYS IN THE WEST.}

\section{By Mr. P. H. Sprague.}

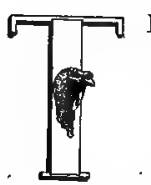

HERE is no more expense in raising good stock than poor, and for that reason we advise those who intend to raise turkeys for market to invest in good stock. Bronze turkeys sell best on this market. They dress better, make a better appearance after they are dressed and sell better than other breeds. In fattening turkeys it is not a good plan to shut them up in close quarters. It is best to let them have a small range, as they never do well when fattened in coops. We do not think the food used in fattening the turkoys has any particular effect on the flavor of the meat. The main thing is to have them fat before they are killed.

Until the weather gets cold turkeys should be shipped alive, but it is best to ship them dressed as soon as the thermometer reaches the freezing point. In dressing it is advisable to kill only the fat birds, as poor, thin stock will bring two or three cents per pound less than the price of good stock. Old turkeys and large'young gobblers should be marketed for Thanksgiving and Christmas, while small gobblers and hens scll better after New Years. The trade looks for large turkeys for holiday dinners, while later in the season small ones are in better demand.

It is impossible to tell how many turkeys are marketed in Chicago during the season, as there is no record kept, but it will run up into millions of pounds. While as far as we can learn there has not been an over supply on the market this season (1900-1901) there are more turkeys in the country than ever before. Last year the standard price on dressed turkeys was ten and a half cents per pound for number one stock, but this year we look for it to be abcul nine cents per pound.

\section{PREPARING TURKEYS FOR MARKET.}

A great deal of attention should be paid to the manntr. of dressing turkeys to command the best price in our market. Before killing and dressing them they should be kept without focd for eighteen or twenty-four hours, but during that time they should have plenty of water. as stork iresses out brighter when well watered. Full crops injure the appearance of the birds and are liable to sour. Never kill turkeys by wringing their necks or cutting off their heads. Kill by blaeding in the mouth. To properly dress turkeys they should be first liung up by the feet with a rope properly adjusted; then stick in the mouth with a sharp knife, hang a weight to the head and let the blood run into a barrel. Turkeys should always be dry picked and the feathers preserved. By allowing the blood to run into a barrel as above described it will not stain the feathers. Feathers should be removed while the turkey is bleeding and, in fact, before it is dead, as they can be removed a great deal more easily than after the bird is dead. After the body feathers are taken cff remove the tail and wing feathers and keep them separate in bunches. The body feathers can be packed in sacks. Tail feathers are worth 25 to 30 cents per pound; wing feathers from the first two joints, from 15 to 20 per pound; pointers, that is the slim feathers from the tops of the wings, are worth 5 to 7 cents per pound; body feathers, 3 to 4 cents per pound. It pays well to save the feathers.

It is sometimes advisable if poor turkeys are killed to scald them, as they look better scalded than dry picked, but dry picked turkeys always sell from one to two cents per pound more than the scalded birds. After the turkeys are picked they should hang for at least twelve hours before being packed, until they are dry and cold, but not frozen. The animal heat should be entirely out of the body, because if they are packed before it is out they will spoil very quickly. After the birds are thorqughly cool pack in boxes or barrels. Boxes that hold about two hundred pounds should be used. Pack snugly and straighten out the body and legs so they will not arrive bent and twisted out of shape. Fill the boxes as full as possible to prevent them moving about. Boxes are preferable to barrels, although barrels will do if boxes cannot be procured. Mark the contents of each shipment on the outside, giving gross weight and weight of package. If these directions are followed carefully turkeys will always bring the top price of the market. Yours truly, P. H. SPRAGUE.

\section{THE EASTERN MARKET.}

The first active lemand for turkeys is during Thanksgiving week. For chat trade small hen turkeys, ranging in weight from eight to twelve pounds, and young gobblers weighing from twelve to fifteen pounds, ale the most iesirable. After Thanksgiving small turkeys are wanted. During Christmas week any size will sell readily. That is the only time when old toms and other heavy turkeys will sell to any advantage. After the Christmas trade is over heavy turkeys are very dull and the price is low. During January, February and March small sizes are the most desirable.

Turkeys should be dry picked, as scalded stock must be sold at a concession of two to three cents a pound. The entrails should not be removed and the head and feet should be left intacl. This applies to all dressed poultry intended for this market.

Barrels or boxes may be used for packing, as the shippers prefer. Each package should be so well filled that the contents cannot be shuffect about in hauling. Care must be taken in packing, and no bird should be packed until all the animal heat has escaped. If packed while warm they are liable to turn green and so be unsalable.

PHILIP QUIGLEY. 


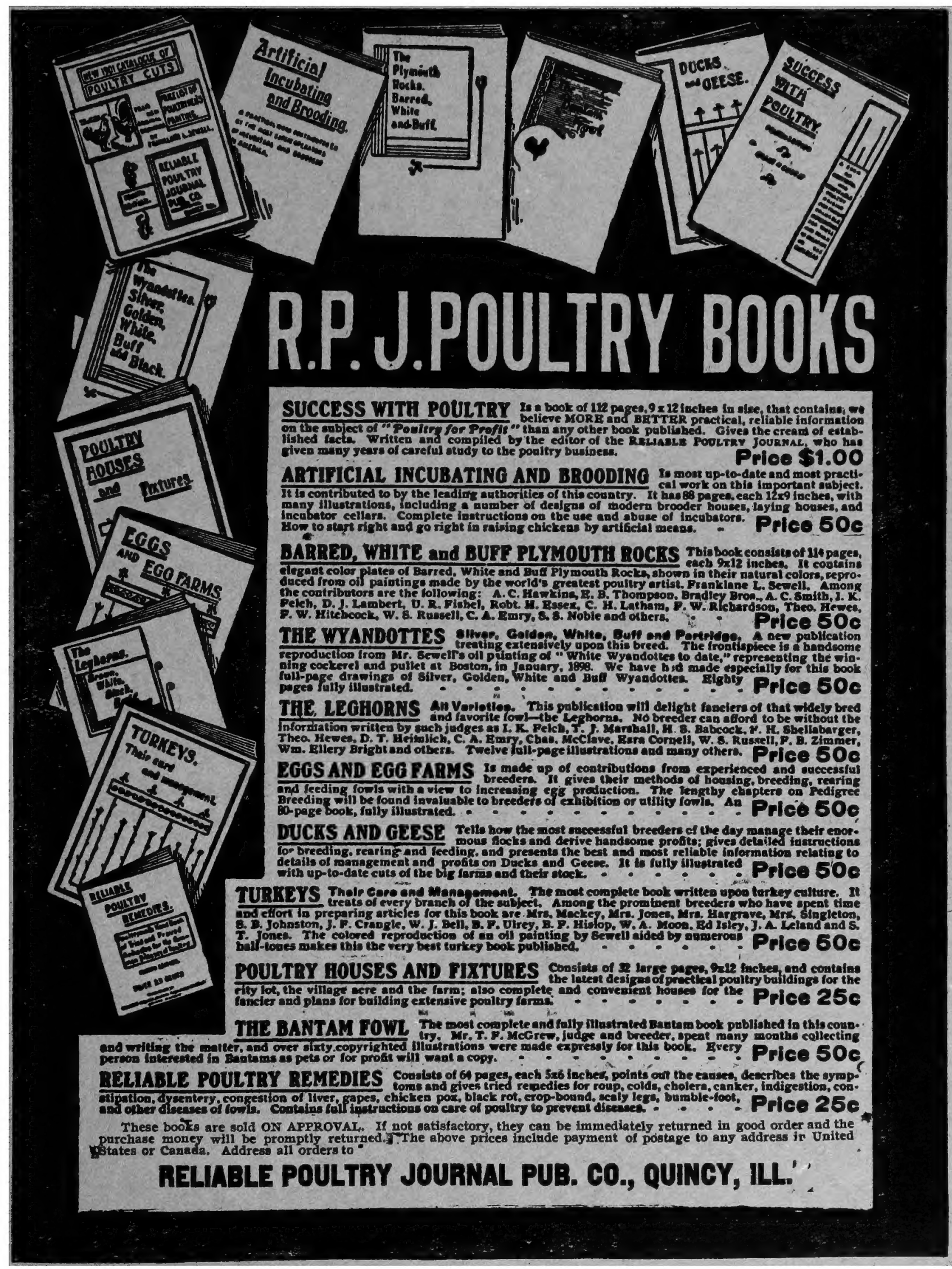




